\author{
UNIVERSIDADE DE SÃO PAULO \\ ESCOLA DE ENGENHARIA DE SÃO CARLOS
}

FRANCISCO QUIM

ANÁLISE DE ESCAVAÇÕES DE TÚNEIS COM REVESTIMENTO UTILIZANDO O MÉTODO DOS ELEMENTOS DE CONTORNO

SÃO CARLOS

- 2010 - 

FRANCISCO QUIM

\title{
ANÁLISE DE ESCAVAÇÕES DE TÚNEIS COM REVESTIMENTO UTILIZANDO O MÉTODO DOS ELEMENTOS DE CONTORNO
}

\author{
Dissertação apresentada à Escola de Engenharia \\ de São Carlos, da Universidade de São Paulo, \\ como parte dos requisitos para a obtenção do \\ Título de Mestre em Engenharia de Estruturas.
}

Orientador: Prof. Dr. Wilson Sérgio Venturini

SÃO CARLOS

-2010 - 
AUTORIZO A REPRODUÇÃO E DIVULGAÇÃO TOTAL OU PARCIAL DESTE TRABALHO, POR QUALQUER MEIO CONVENCIONAL OU ELETRÔNICO, PARA FINS DE ESTUDO E PESQUISA, DESDE QUE CITADA A FONTE.

Ficha catalográfica preparada pela Seção de Tratamento da Informação do Serviço de Biblioteca - EESC/USP

Quim, Francisco
Q6a Análise de escavações de túneis com revestimento utilizando o método dos elementos de contorno / Francisco Quim ; orientador Wilson Sérgio Venturini. -- São Carlos, 2010 .

Dissertação (Mestrado-Programa de Pós-Graduação e Área de Concentração em Engenharia de Estruturas) -- Escola de Engenharia de São Carlos da Universidade de São Paulo, 2010 .

1. Método dos elementos de contorno. 2. Túneis. 3. Enrijecedores. I. Título. 
FOLHA DE JULGAMENTO

Candidato: Engenheiro FRANCISCO QUIM.

Dissertação defendida e julgada em 26/03/2010 perante a Comissão Julgadora:

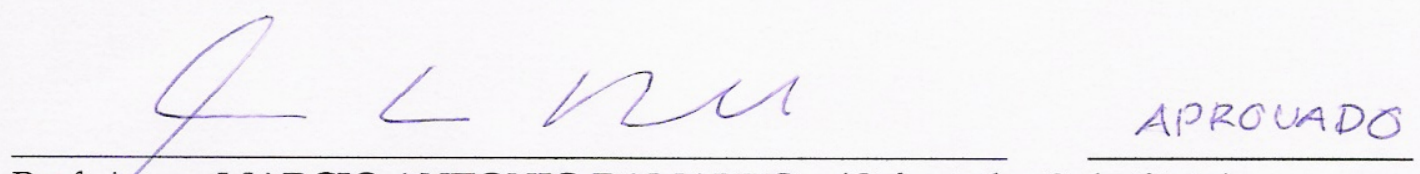

Prof. Assoc. MARCIO ANTONIO RAMALHO - (Orientador Substituto) (Eseola de Engenharia de São Carlos/USP)

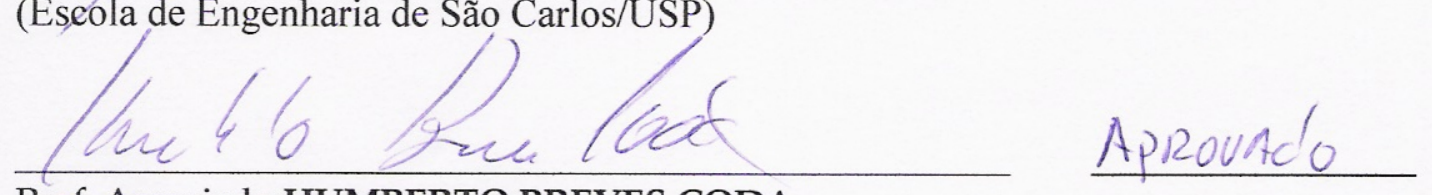

Prof. Associado HUMBERTO BREVES CODA (Escola de Engenharia de São Carlos/USP)

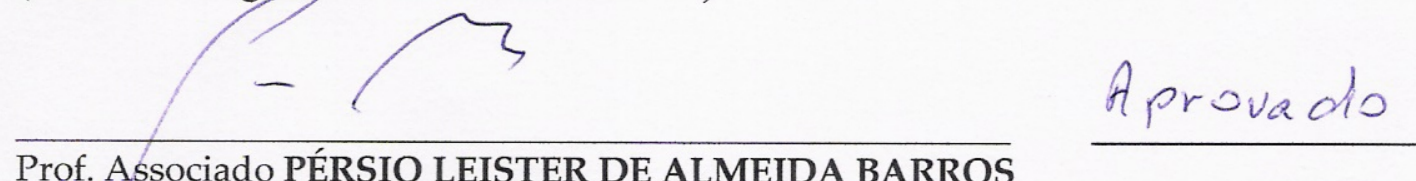

Prof. Associado PÉRSIO LEISTER DE ALMEIDA BARROS (Universidade Estadual de Campinas/UNICAMP)

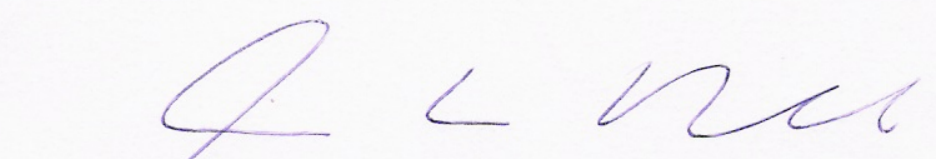

Prof. Associado MARCIO ANTONIO RAMALHO Coordenador do Programa de Pós-Graduação em Engenharia Civil (Engenharia de Estruturas)

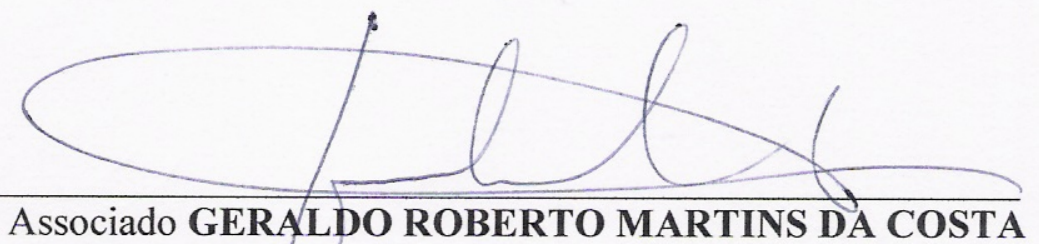

Presidente da Comissão de Pós-Graduação 

Aos meus pais Celso e Maria, meus irmãos Celso e Angela por todo carinho e afeto. 
Primeiramente agradeço a Deus.

Ao Professor Wilson Sergio Venturini, pelos ensinamentos e pela excelente orientação recebidos durante a elaboração deste trabalho, bem como pela contribuição que deu a minha formação profissional e, sobretudo, pela amizade.

Ao Professor Humberto Breves Coda pela atenção e valorosas contribuições dadas a este trabalho.

Ao professor e amigo Rogério de Oliveira Rodrigues, pela contribuição dada a minha formação profissional.

A Fundação de Amparo a Pesquisa do Estado de São Paulo - FAPESP pelo apoio financeiro.

Aos colegas do departamento de Engenharia de Estruturas da EESC que direta ou indiretamente ajudaram na realização deste trabalho.

Aos amigos de llha Solteira. 
"Nada no mundo consegue tomar o lugar da persistência. O talento não consegue; nada é mais comum que homens fracassados com talento. A genialidade não consegue; gênios não recompensados é quase um provérbio. A educação não consegue; o mundo é cheio de errantes educados. A persistência e determinação sozinhas são onipotentes" (Calvin Coolidge) 


\section{RESUMO}

QUIM, F. (2010). Análise de escavações de túneis com revestimento utilizando o método dos elementos de contorno. São Carlos. 138 p. Dissertação (Mestrado) - Escola de Engenharia de São Carlos, Universidade de São Paulo.

Neste trabalho, foi desenvolvida uma formulação do método dos elementos de contorno (MEC) isoparamétrico com aproximação de ordem qualquer para análise de domínios bidimensionais enrijecidos, particularmente túneis. Tal formulação simula os enrijecedores a partir de correções da rigidez local, que são introduzidas utilizando-se um termo adicional escrito em tensões iniciais sobre a área estreita do enrijecedor. Além das equações integrais usuais para pontos do contorno foram também necessárias as equações integrais da força normal e do momento fletor escritas para pontos do eixo do enrijecedor. Através do Polinômio de Lagrange foi feita a generalização da ordem das funções polinomiais responsáveis pela aproximação tanto das variáveis quanto da representação geométrica do problema. A partir daí, a formulação apresentada simulou com êxito a inclusão de enrijecedores em tais meios, como por exemplo, na analise de estacas, ou de enrijecedores na escavação de túneis. Foi desenvolvida também neste trabalho uma formulação para considerar o atraso na instalação do suporte de túneis. Com o desenvolvimento do elemento de contorno curvo de ordem qualquer, pôde-se obter resultados ainda melhores com discretizações reduzidas.

Palavras-chave: Método dos Elementos de Contorno. Túneis. Enrijecedores. 


\section{ABSTRACT}

QUIM, F. (2010). Excavation analysis of tunnels with lining using the boundary element method. São Carlos. 140 p. Dissertação (Mestrado) - Escola de Engenharia de São Carlos, Universidade de São Paulo.

In this work, an isoparametric boundary element method (BEM) formulation with approximation of any order was developed to the analysis of stiffened twodimensional domains, particularly tunnels. This formulation simulates the stiffeners based on local stiffness corrections, which are made using an additional integral written in terms of initial stresses, applied over the areas close to stiffeners. Besides the usual displacement integral equations the presented formulation also requires integral equations of the normal forces and the bending moments written for points defined along the stiffener axis. By using Lagrange polynomials, the generalization of the shape function order used to approximate the boundary values and the geometry was made. Excavations in infinite media or large domains are engineering applications in which the BEM is efficient due to its accuracy, reliable results and also to require coarser discretizations, always leading to smaller algebraic systems when compared to other methods. Thereafter, the presented formulation can simulate successfully the inclusion of stiffeners into two-dimensional domains, such as the analysis of piles embedded in a 2-D solids or lined tunnels. It was also developed a formulation to consider the delay to install tunnel linings.

Keywords: Boundary Element Method. Tunnels. Reinforcements. 


\section{SUMÁRIO}

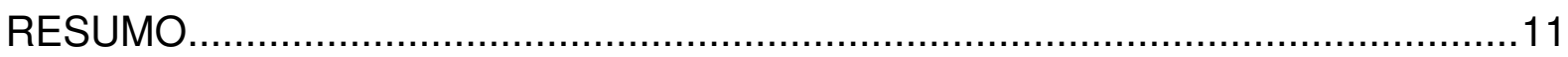

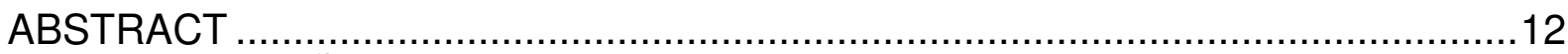

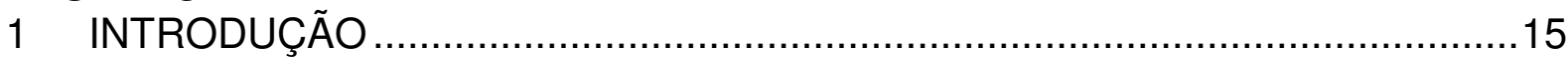

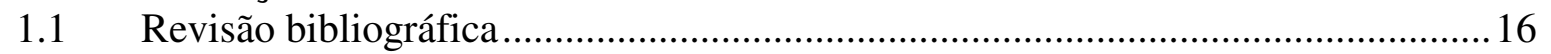

1.2 Apresentação do trabalho .....................................................................................21

2 MÉTODO DOS ELEMENTOS DE CONTORNO 2-D ......................................23

2.1 Equacionamento básico do Método dos Elementos de contorno .............................23

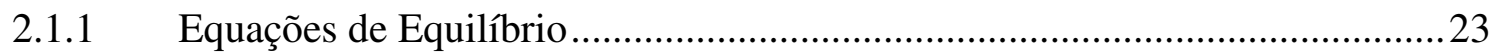

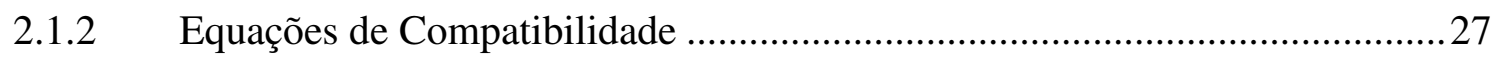

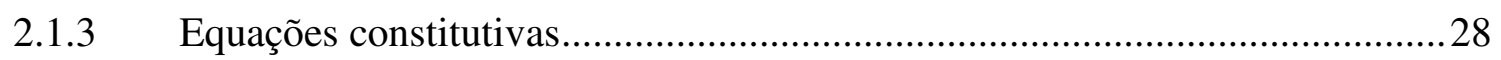

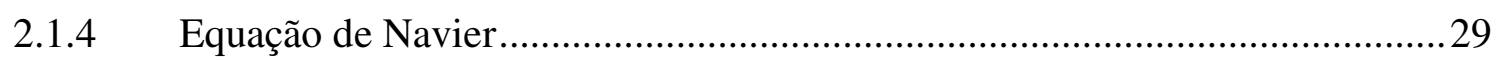

2.2 Solução Fundamental ………………………………………………………......

2.2.1 Definição ……………………………………………………………….... 30

2.2.2 Vetor de Galerkin .....................................................................................

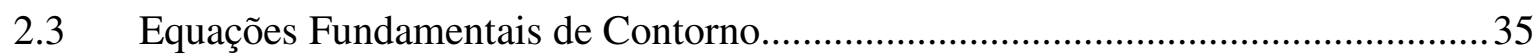

2.3.1 Formulação do Método dos Elementos de Contorno …………………………...39

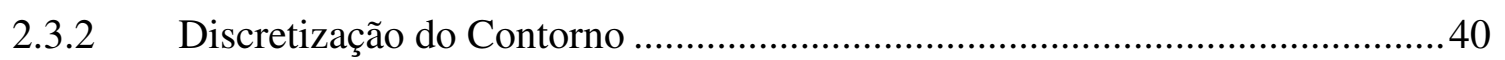

2.3.3 Equações Integrais de Contorno para Pontos no Contorno .................................45

2.3.4 Cálculo de deslocamentos e tensões nos pontos internos ...................................49

2.4 Exemplo numérico de validação ...........................................................................51

2.4.1 Análise dos deslocamentos no contorno......................................................52

2.4.2 Análise dos deslocamentos no domínio.............................................................

2.4.3 Análise das tensões para os pontos do domínio ................................................58

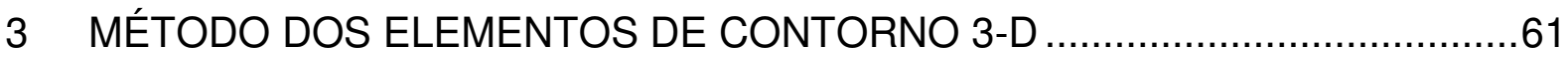

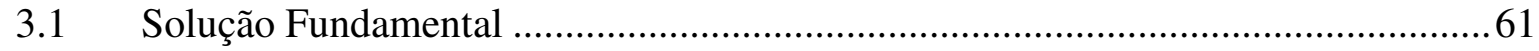

3.2 Equações integrais de Contorno ...........................................................................62

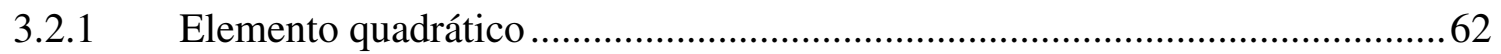

3.3 Discretização Utilizada....................................................................................66

4 FORMULAÇÃO DO MÉTODO DOS ELEMENTOS DE CONTORNO PARA DOMÍNIOS BIDIMENSIONAIS COM A PRESENÇA DE ENRIJECEDORES ............69

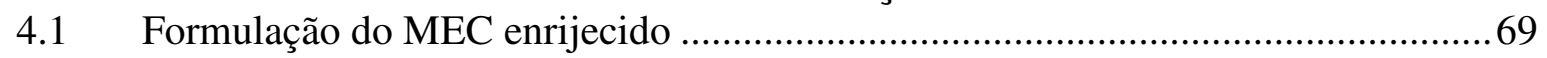

4.2 Exemplos numéricos de validação ................................................................. 78

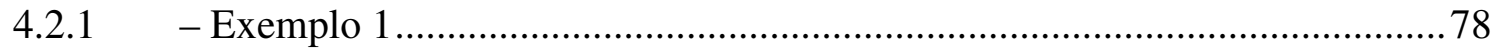

4.2.1.1 -Primeiro caso - Compressão....................................................................79 
4.2.1.2 - Segundo caso - Flexão por força aplicada .......................................... 83

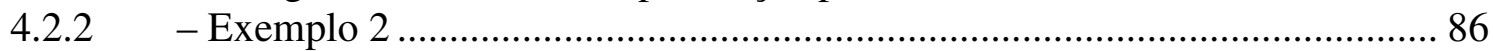

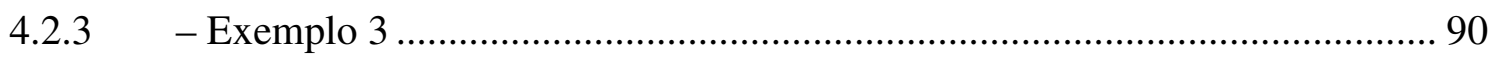

5 MÉTODOS DE ANÁLISE DA FRENTE DE ESCAVAÇÃO ...........................95

5.1 Método de Convergência-Confinamento ................................................................. 95

5.2 Método Proposto por SCHWARTZ \& EINSTEIN (1980) ..................................... 99

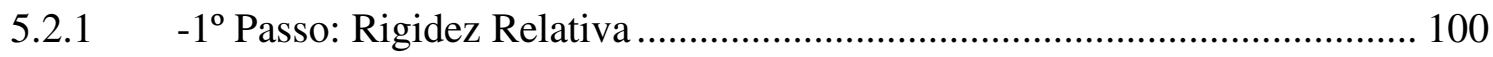

5.2.2 - - $2^{\circ}$ Passo: Atraso na Instalação do Suporte..................................................... 104

5.2.3 - - $\quad 3^{\circ}$ Passo: Plastificação do Maciço ................................................................... 106

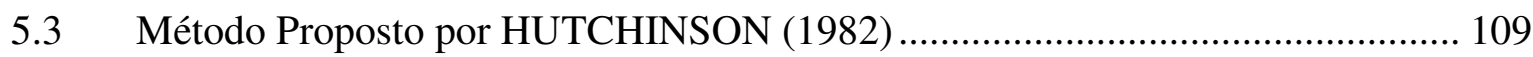

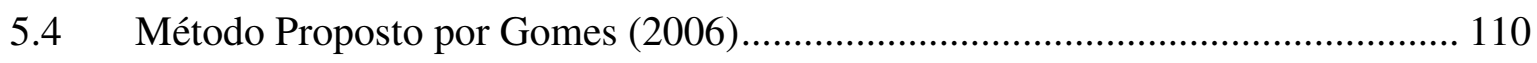

6 MODELAGEM DA FRENTE DE ESCAVAÇÃO DE TÚNEIS ......................... 115

6.1 Método Convergência-confinamento Panet e Guenot (Método de alívio de tensão)

115

6.2 Fator de redução $\lambda$ para túneis sem suporte.................................................... 117

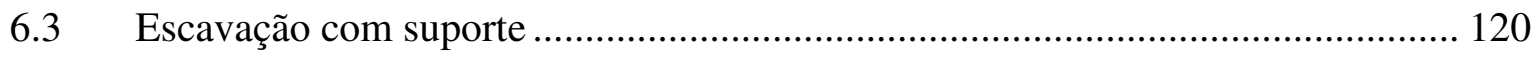

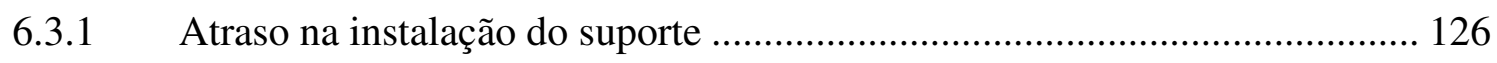

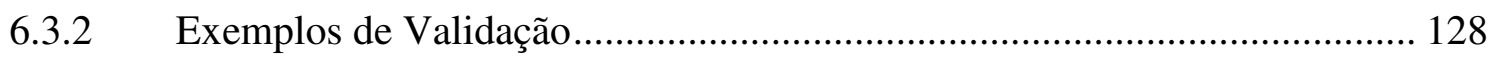

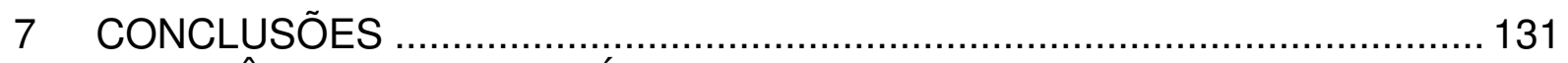

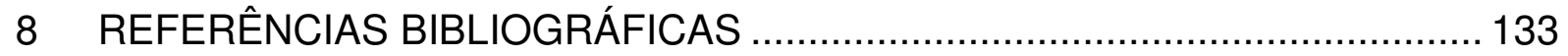




\section{INTRODUÇÃO}

Ao longo do tempo, foram desenvolvidos, métodos analíticos para a obtenção de soluções exatas de grande parte das equações diferenciais de todos os ramos da física. Porém os casos estudados são limitados por sua geometria e hipóteses bastante simplificadoras. Da necessidade de se resolver problemas mais gerais surgiram os métodos aproximados e, com eles, os métodos numéricos. Após o surgimento dos computadores e principalmente com a disseminação da informática ocorrida no final da década de oitenta, intensificaram-se as pesquisas para 0 desenvolvimento e a aplicação de tais métodos, dos quais se pode destacar o Método das Diferenças Finitas (MDF), que até hoje tem grande importância no tratamento de problemas da engenharia, e o mais utilizado que é o Método dos Elementos Finitos (MEF). Com esse desenvolvimento, o Engenheiro de Estruturas passa a ter acesso a equipamentos e programas computacionais que possibilitam uma análise estrutural baseada em modelos mais refinados, proporcionando um aumento da segurança e diminuição de custos dos projetos e das construções.

Como exposto em Leonel (2006), deve-se salientar que, com exceção a alguns métodos sem malha, os métodos numéricos descritos anteriormente aproximam a equação diferencial, que governa o problema analisado, por meio de um sistema de equações algébricas que utiliza valores de domínio e de contorno sendo por este motivo conhecidos como métodos de domínio. Assim espera-se que a resposta numérica se aproxime da resposta analítica com o aumento da discretização empregada. No entanto, este procedimento eleva consideravelmente 0 número de variáveis envolvidas na análise aumentando assim o número de operações matemáticas a serem efetuadas e conseqüentemente o sistema de equações a ser solucionado. 
Para reduzir o número de variáveis, podem-se utilizar as chamadas Técnicas (ou métodos) de Contorno, nas quais as discretizações são impostas apenas ao contorno do sistema em consideração. Estas técnicas têm como origem um dos procedimentos usados na teoria matemática para obter a solução analítica das equações diferenciais parciais, que as transformam em suas formas integrais ou, mais simplesmente, nas chamadas equações integrais.

Neste contexto, como apresentado em Coda (1993) surgiram duas formulações distintas do Método dos Elementos de Contorno, a formulação indireta, na qual as variáveis envolvidas não são as variáveis físicas do problema, introduzida por Kupradze (1965), e a direta, cujas variáveis têm significado físico, iniciada por Rizzo (1967).

O presente trabalho visa a análise de escavações enrijecidas, particularmente túneis, que têm grande importância econômica dentro da engenharia civil. A construção de túneis encurta distâncias e prejudica muito menos o meio ambiente; nas cidades permite $o$ aumento das vias de transporte. Escavações em meio infinito ou em domínios de grandes dimensões é uma das aplicações onde o MEC é eficiente pela precisão e confiança nos resultados e também por requerer pouca quantidade de dados levando sempre a sistemas computacionais de pequenas dimensões.

Com a formulação desenvolvida aqui, elimina-se a necessidade de se recorrer, pelo menos em uma fase de pré-dimensionamento, a análises tridimensionais, tão dispendiosas no que se refere principalmente a tempo de processamento e dinheiro empenhado.

\subsection{Revisão bibliográfica}

Neste item será apresentado apenas um breve histórico de trabalhos relacionados com o tema aqui abordado, tanto no âmbito do próprio Departamento de Engenharia de Estruturas da EESC - SET/EESC, quanto na literatura de uma forma geral.

Com a publicação do primeiro livro de Brebbia (1978), o MEC passou a ser mais conhecido e estudado em diversos centros importantes de pesquisa. 
Destacam-se, ainda, as publicações de Brebbia (1984), Kane (1994) e París \& Cañas (1997).

Venturini (1988) propôs uma formulação alternativa na análise de problemas de domínio não-homogêneos, tratando o domínio de forma contínua, sem a necessidade de dividi-lo em sub-regiões, apenas modificando as integrais de modo a levarem em conta as diferenças entre as constantes elásticas de cada sub-região.

Ferro (1993) aplicou a combinação MEC/MEF para analisar a interação entre as estacas e o solo. As estacas foram consideradas como elementos de barra modelados pelo método dos elementos finitos e, o solo foi considerado como um meio elástico contínuo, isotrópico, homogêneo, semi-infinito e ideal, discretizado pelo MEC através das soluções fundamentais de Mindlin. As comparações realizadas neste trabalho comprovaram sempre bons resultados tanto para deslocamentos quanto para as forças de superfície.

Leite, Coda e Venturini (2002) desenvolveram uma formulação do Método dos Elementos de Contorno para análise de domínios enrijecidos. Uma técnica particular de sub-região em que o equilíbrio é preservado ao longo das interfaces sem aproximações de esforços.

No trabalho de Wutzow (2003), a formulação linear do MEC para elasticidade bidimensional foi empregada para o estudo de domínios enrijecidos. A consideração dos enrijecedores é abordada de duas formas, a primeira delas pela técnica clássica de sub-região ou acoplamento MEC/MEC e a segunda, também pelo mesmo acoplamento, mas condensando-se as variáveis do contorno para a linha central do enrijecedor. Esta última proporcionou bons resultados eliminando perturbações em enrijecedores finos.

Fernandes, G. R. (2003) propôs uma formulação do MEC, considerando as vigas como sendo uma variação abrupta da espessura da placa e, a fim de reduzir o número de graus de liberdade do problema, apresentou um modelo alternativo onde as vigas (enrijecedor) são representadas por seus eixos médios.

Waidemam (2007) propôs uma formulação do método dos elementos de contorno para a análise de placas enrijecidas considerando-se não-lineraridades física e geométrica. Neste trabalho, entre outros, foi apresentada uma formulação com campos de tensões iniciais, consistindo assim em uma formulação alternativa à forma clássica de tratamento de problemas desse gênero, que é por sub-regiões. 
Azevedo (2007) realizou uma formulação alternativa do método dos elementos de contorno com campos de tensões iniciais, como em Waidemam (2007), porém sua formulação permite a inclusão de domínios anisotrópicos em meios isotrópicos, ou ainda, o estudo de domínios completamente anisotrópicos.

Em Leite (2007) foi desenvolvida uma formulação para análise de sólidos bidimensionais constituídos por multiregiões utilizando-se do Método dos Elementos de Contorno para análise linear e não linear. Para inclusões muito esbeltas, foi utilizada a técnica da condensação de domínios, onde o domínio 2D foi condensado inicialmente em um domínio linear de fibra e posteriormente em viga.

No trabalho de Kzam (2009) foi apresentada a formulação do método dos elementos de contorno dual aplicada à análise de problemas da Mecânica da Fratura Elástica Linear, este trabalho foi o primeiro trabalho que empregou elemento curvo de ordem qualquer no âmbito do SET/EESC, neste trabalho também foi desenvolvida a generalização do MEC através dos polinômios de Lagrange.

Sobre modelagem de estruturas com reforços ou com fibras internas, vários outros trabalhos foram desenvolvidos no âmbito do grupo de métodos numéricos do Departamento de Engenharia de Estruturas da EESC. Nesses trabalhos destacamse combinações MEC/MEF e MEC/MEC, tratamento de zonas delgadas usando o MEC por degeneração e aproximações ao longo da espessura, dentre outros procedimentos apresentados em: Coda (1993), Botta \& Venturini (2005), Leite et al (2003), Leite \& Venturini (2005), Waiderman \& Venturini (2007), Wutzow et al (2006), Coda (2001), dentre outros.

G. Beer \& Ch. Dünser (2000) analisaram através do MEC problemas em túneis, concluindo que o método estudado oferece algumas vantagens sobre o MEF na simulação numérica de tais problemas, como o tempo de processamento, devido à discretização do MEC ser feita somente no contorno, enquanto que o MEF necessita de uma discretização do solo/rocha à volta do túnel, aumentando significativamente a quantidade de elementos. Foi desenvolvida também neste trabalho uma formulação do MEC para plasticidade e para a modelagem de escavações seqüenciais com múltiplas regiões e células internas.

O Prof. Gernot Beer da Universidade de Graz (Áustria) é um dos profissionais dedicado ao tema que tem desenvolvido sistemas computacionais voltados à análise de túneis. Dos trabalhos do grupo do Prof. Beer, além de seu recente livro sobre 
elaboração de sistemas computacionais (BEER, 2001) destacam-se: Beer (1983); Beer et all (1987); dentre outros.

Em Panet (1982), utilizando análises axissimétricas com o MEF, observou que a deformação é estritamente dependente da extensão do raio de plastificação, ou seja, uma grande extensão do raio de plastificação resulta em grandes deslocamentos e em grandes distâncias da face para que estes atinjam seus valores finais. Tal fato ocorre, pois a rigidez da face se torna mais baixa quando o maciço ao seu redor se plastifica, desta forma, o efeito de suporte da face diminui.

Celestino (1992) apresentou um modelo de cálculo de tensões e deslocamentos próximo à frente de escavação, através de análises axissimétricas. Foi apresentado um procedimento para integração no tempo das equações analíticas da interação entre o maciço e o suporte. Nesse método, as propriedades dependentes do tempo do concreto projetado e do maciço foram consideradas em conjunto. Foi considerado o modelo visco-elástico de Burger para o maciço, e para o concreto projetado foi considerado um modelo reológico desenvolvido na Universidade de Leoben. O mecanismo de transferência de carga adotado, simulando o efeito tridimensional da frente de escavação, foi o de Schwartz \& Einstein (1980).

Gomes (1999) propôs um método que incorpora alguns procedimentos básicos do método proposto por Schwartz \& Einstein (1980), generalizando-o na consideração do comportamento dependente do tempo para o suporte de um túnel, simulando o enrijecimento do concreto projetado ao longo de seu eixo longitudinal. Utilizando para tal realização o Método das Diferenças Finitas para a quantificação dos esforços solicitantes.

Gomes (2006) realizou agora análises tridimensionais de túneis considerando o comportamento dependente do tempo na interação maciço-suporte. Foi realizado um estudo dos efeitos do fenômeno de transferência de carga do maciço para o suporte. Tal estudo resultou no desenvolvimento de expressões adimensionais que relacionam os esforços solicitantes encontrados no suporte com outras características geométricas e físicas do problema. Estas expressões foram obtidas através de análises estatísticas dos resultados obtidos em simulações numéricas tridimensionais utilizando MEF, com auxílio de técnicas de processamento paralelo.

Schwartz \& Einstein (1980a, b) sugeriram o uso de fatores de correção para levar em consideração os decréscimos de carregamentos no suporte devido ao 
alívio de tensões que surge com o atraso da construção do mesmo e o aumento de carregamento no suporte devido à plastificação do maciço.

Kim \& Eisenstein (2006) estudaram a previsão de carga no suporte de túneis utilizando fatores de correção, analisaram o método de Schwartz \& Einstein (1980 a, b) e a alteração sugerida por Hutchinson (1982), tal alteração se deu na forma de cálculo do fator de atraso da instalação do suporte $\left(\lambda_{d}\right)$. Esta alteração do $\left(\lambda_{d}\right)$ consiste em utilizar ao invés do comprimento de atraso $L_{d}$ (distância entre a face de escavação e o ponto médio do último segmento de suporte instalado) o comprimento $L_{D}^{\prime}$ (distância entre a face anterior de escavação e o ponto médio do último segmento de suporte instalado) em virtude da seqüência de escavação, baseado em análises axissimétricas com elementos finitos e em dados históricos, sendo que o fator de plastificação do maciço $\left(\lambda_{y}\right)$ foi calculado como em Schwartz \& Einstein. 0 método proposto por Hutchinson apresentou resultados razoáveis nas comparações realizadas, se mostrando melhores para escavações de túneis com curto comprimento de atraso da instalação do suporte. Esta alteração será mais bem explicitada posteriormente.

Gomes \& Celestino (2009) analisaram a influência dos parâmetros físicos e geométricos no mecanismo de transferência de carregamento tridimensional na frente de escavação, apresentando que opostamente à maioria dos estudos em que é concluído que as forças internas dependem somente do comprimento de atraso da instalação do suporte, a geometria e a rigidez do suporte em relação à do solo/rocha também influencia fortemente em tais forças. Em tal estudo foi apresentado uma incoerência na equação de Schawrtz and Einstein (1980) para o cálculo do fator de atraso na instalação do suporte $\left(\lambda_{d}\right)$. Foi proposta também nesse estudo uma fórmula para o cálculo da força normal baseada em parâmetros 3-D, como em Gomes (2006), para túneis circulares profundos escavados em meio elástico isotrópico, levando em conta os parâmetros físicos e geométricos relacionados.

Em Carranza-Torres \& Fairhurst (2000) é discutida a aplicação prática do método Convergência-Confinamento, em tal estudo foi apresentado um equacionamento que torna capaz a construção das curvas referente a este método e conclui que este método é uma ferramenta muito útil, não só como um método para dimensionamento da escavação de túnel com suporte em si, mas também como um 
simples modelo ilustrativo que permite um melhor entendimento do problema complexo de transferência de carregamentos junto à frente de escavação.

\subsection{Apresentação do trabalho}

Iniciando-se a parte teórica, no capítulo 2 apresenta-se o desenvolvimento da formulação do MEC bidimensional, iniciando com um pequeno resumo da teoria da elasticidade, necessário para o desenvolvimento do capítulo. Finalizando com um exemplo de validação utilizando inclusive elementos curvos.

No capítulo 3, aborda-se o MEC tridimensional de forma sucinta, apresentando o elemento utilizado, bem como um breve resumo da formulação 3-D.

No capítulo 4, trata-se do desenvolvimento de uma formulação do MEC para domínios bidimensionais com a presença de enrijecedores, finalizando com exemplos de validação.

No capítulo 5, apresenta-se uma descrição dos principais métodos utilizados na análise da interação maciço-suporte no problema de escavação de túneis.

No capítulo 6, trata-se do desenvolvimento de uma formulação para a modelagem da frente de escavação de túneis com e sem suporte, levando em conta o atraso na instalação do mesmo.

Ao final deste trabalho, no capítulo 7, faz-se a conclusão do mesmo e são descritas as propostas para desenvolvimentos futuros nesta linha de pesquisa. 


\section{MÉTODO DOS ELEMENTOS DE CONTORNO 2-D}

O Método dos Elementos de Contorno teve um desenvolvimento rápido, principalmente a partir da década de oitenta. Muitas têm sido as propostas de formulações para análise dos mais diversos problemas de engenharia, podendo-se destacar aqui problemas que exibem, por exemplo, não-linearidades físicas como: plasticidade, visco-plasticidade, visco-elasticidade, não-linearidade geométrica, iteração solo/estrutura, análises de domínios infinitos, mecânica da fratura, contato, problemas transientes, vibrações, propagação de ondas, problemas de concentração de tensão, problemas de delaminação, materiais compostos dentre outros.

A utilização do MEC para o estudo de vários problemas de engenharia tem se mostrado viável principalmente no que diz respeito à precisão dos resultados, modelagem de gradientes e outras concentrações variáveis de interesse.

Com base no exposto acima, este capítulo tem como principal objetivo discutir as particularidades do Método dos Elementos de Contorno Bidimensional.

\subsection{Equacionamento básico do Método dos Elementos de contorno}

\subsubsection{Equações de Equilíbrio}

O estado de tensão de um ponto $\mathrm{P}$ qualquer do sólido apresentado na Figura 2-1 é mostrado na Figura 2-2. 


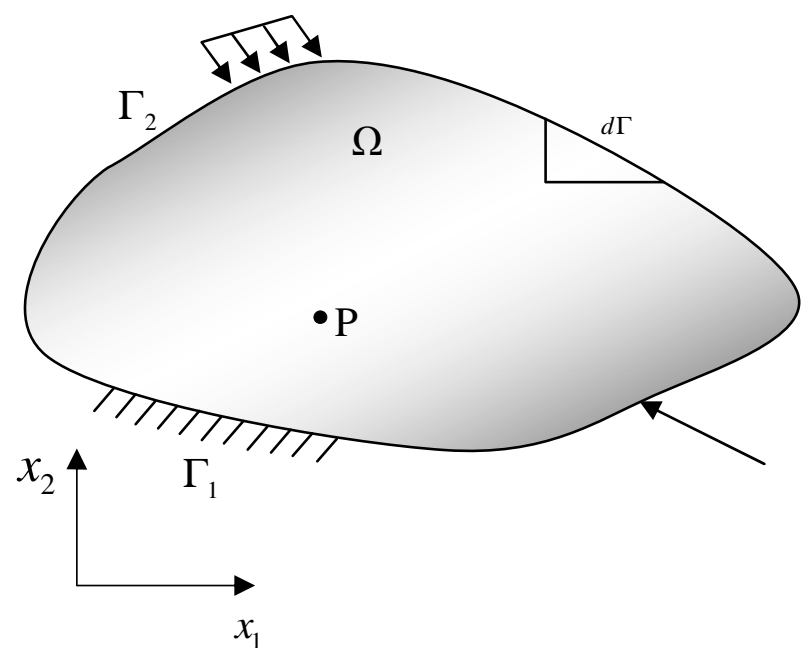

Figura 2-1 - Sólido Bidimensional.

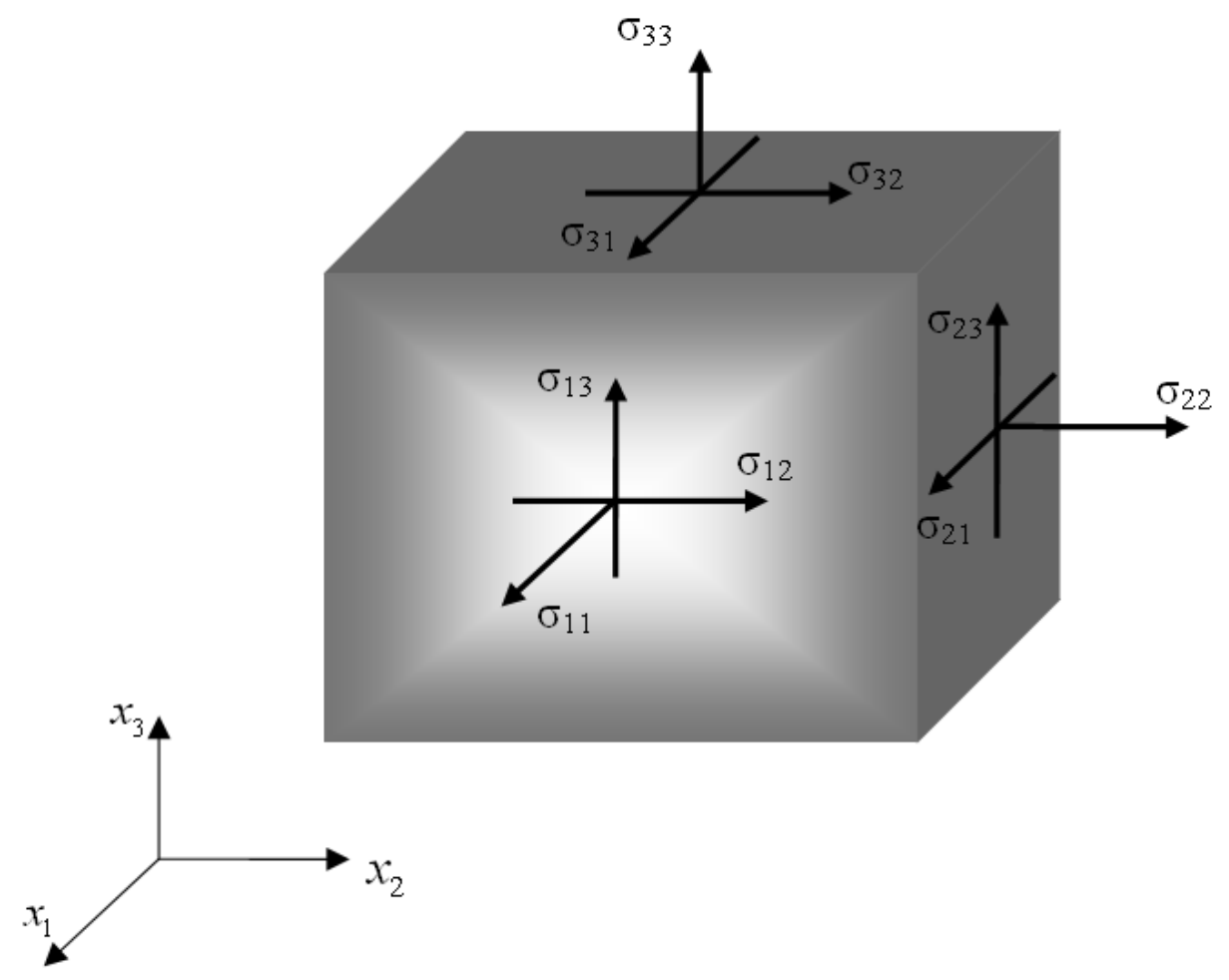

Figura 2-2 - Elemento infinitesimal Tridimensional.

Generalizando agora para o caso 2-D, considerando o Estado Plano de Deformações (EPD), como explicitado na Figura 2-3 e efetuando-se a somatória dos momentos em relação a um ponto qualquer do elemento infinitesimal, é facilmente demonstrado a relação a seguir que representa a simetria do tensor de tensões:

$$
\sigma_{j i}=\sigma_{i j} \quad, i, j=1,2
$$


A relação (2.1) reduz o número de componentes do estado de tensão bidimensional de quatro para três, como apresentado a seguir:

$$
\sigma_{j i}=\left[\begin{array}{ll}
\sigma_{11} & \sigma_{12} \\
\sigma_{12} & \sigma_{22}
\end{array}\right] .
$$

Efetuando-se agora o equilíbrio das forças no elemento infinitesimal da Figura 2-3, considerando-se a variação da tensão com apenas o primeiro termo da série de Taylor, e analisando apenas a variação das tensões na direção $x_{1}$, tem-se a equação de equilíbrio de forças expressa em (2.3).

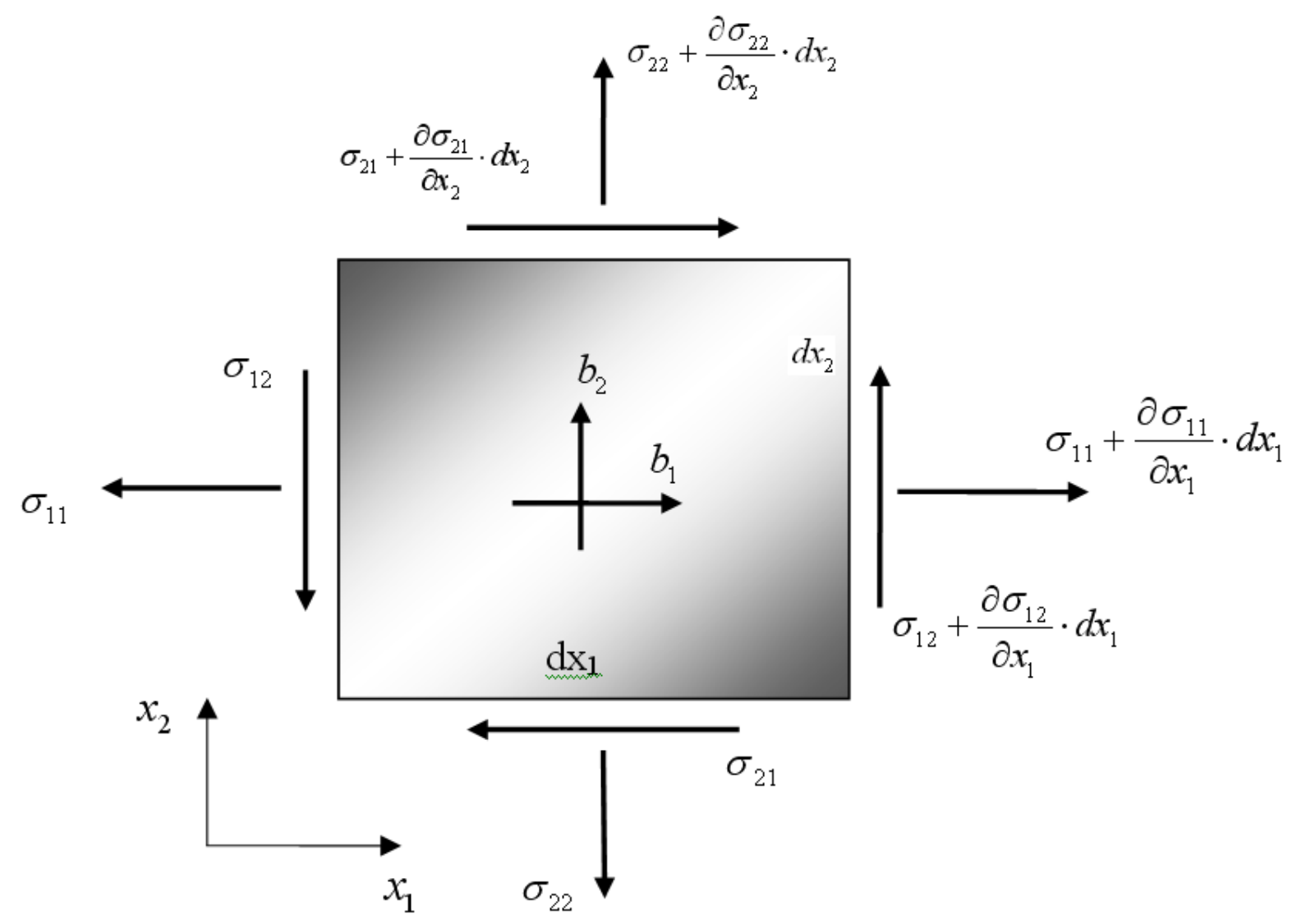

Figura 2-3 - Elemento infinitesimal Bidimensional.

$$
\begin{aligned}
& \left(\sigma_{11}+\frac{\partial \sigma_{11}}{\partial x_{1}} \cdot d x_{1}\right) \cdot d x_{2} \cdot d x_{3}-\left(\sigma_{11}\right) \cdot d x_{2} \cdot d x_{3}+ \\
& \left(\sigma_{21}+\frac{\partial \sigma_{21}}{\partial x_{2}} \cdot d x_{2}\right) \cdot d x_{1} \cdot d x_{3}-\left(\sigma_{21}\right) \cdot d x_{1} \cdot d x_{3}+b_{1} \cdot d x_{1} \cdot d x_{2} \cdot d x_{3}=0
\end{aligned}
$$


sendo $d x_{3}$ a espessura do elemento infinitesimal. A equação (2.3) resulta na seguinte expressão:

$$
\frac{\partial \sigma_{11}}{\partial x_{1}} \cdot d x_{1} \cdot d x_{2} \cdot d x_{3}+\frac{\partial \sigma_{21}}{\partial x_{2}} \cdot d x_{2} \cdot d x_{1} \cdot d x_{3}+b_{1} \cdot d x_{1} \cdot d x_{2} \cdot d x_{3}=0
$$

Efetuando-se agora a somatória dos esforços em $x_{2}$, tem-se:

$$
\begin{aligned}
& \left(\sigma_{22}+\frac{\partial \sigma_{22}}{\partial x_{2}} \cdot d x_{2}\right) \cdot d x_{1} \cdot d x_{3}-\left(\sigma_{22}\right) \cdot d x_{1} \cdot d x_{3}+ \\
& \left(\sigma_{12}+\frac{\partial \sigma_{12}}{\partial x_{2}} \cdot d x_{1}\right) \cdot d x_{2} \cdot d x_{3}-\left(\sigma_{12}\right) \cdot d x_{2} \cdot d x_{3}+b_{2} \cdot d x_{1} \cdot d x_{2} \cdot d x_{3}=0
\end{aligned}
$$

resultando em:

$$
\frac{\partial \sigma_{22}}{\partial x_{2}} \cdot d x_{1} \cdot d x_{2} \cdot d x_{3}+\frac{\partial \sigma_{12}}{\partial x_{2}} \cdot d x_{2} \cdot d x_{1} \cdot d x_{3}+b_{2} \cdot d x_{1} \cdot d x_{2} \cdot d x_{3}=0
$$

e finalmente generalizando as equações (2.4) e (2.6), em notação indicial, tem-se:

$$
\sigma_{j i, j}+b_{i}=0
$$

utilizando-se da simetria apresentada na equação (2.1) a equação (2.7) fica:

$$
\sigma_{i j, j}+b_{i}=0
$$

Na seqüência é analisado o equilíbrio de um sólido 2-D infinitesimal de espessura unitária e contorno $d \Gamma$ apresentado na Figura 2-1, definido agora, pelos planos $x_{1}=0, x_{2}=0$ e outro plano qualquer como apresentado na Figura 2-4. 


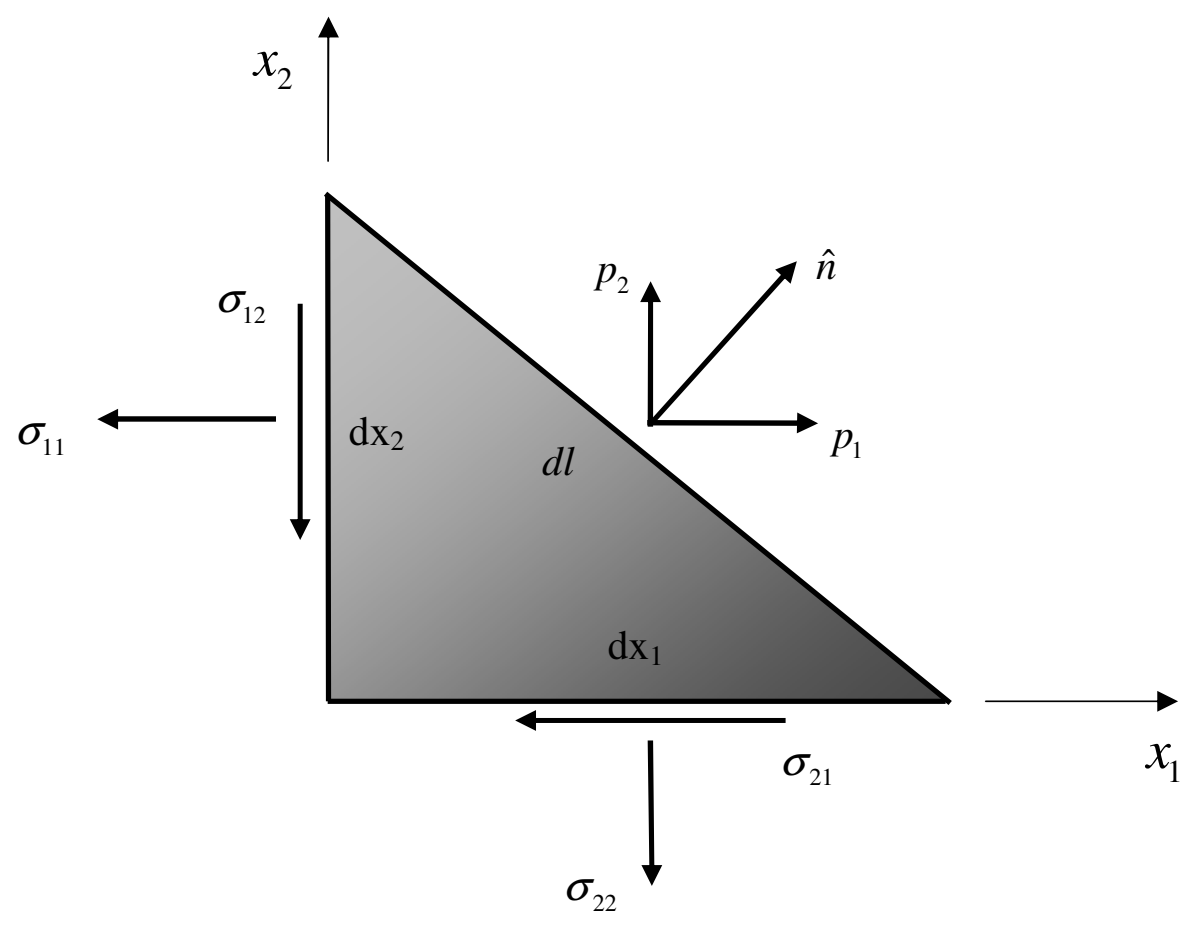

Figura 2-4 - Equilíbrio do contorno.

Na Figura 2-4 o versor $\hat{n}$ indica a orientação do plano, e suas componentes $n_{1}$ e $n_{2}$ são denominadas co-senos diretores do plano, desta forma, pode-se escrever as equações a seguir:

$$
\begin{aligned}
& p_{1}=\sigma_{11} \cdot n_{1}+\sigma_{12} \cdot n_{2} \\
& p_{2}=\sigma_{21} \cdot n_{1}+\sigma_{22} \cdot n_{2}
\end{aligned} .
$$

Definindo a equação (2.9) em notação indicial, tem-se:

$$
p_{i}=\sigma_{i j} \cdot n_{j}
$$

que é denominada de condição de contorno de Cauchy.

\subsubsection{Equações de Compatibilidade}

Pode-se relacionar o campo de deformações com o campo de deslocamentos em que está sujeito um sólido qualquer, da forma indicada a seguir: 


$$
\begin{gathered}
\varepsilon_{11}=u_{1,1} \\
\varepsilon_{12}=\varepsilon_{21}=\frac{u_{1,2}+u_{2,1}}{2} \\
\varepsilon_{22}=u_{2,2}
\end{gathered}
$$

e generalizando-se, em notação indicial, tem-se:

$$
\varepsilon_{i j}=\frac{u_{i, j}+u_{j, i}}{2}
$$

\subsubsection{Equações constitutivas}

Relaciona-se o estado de tensões em um ponto qualquer com o estado de deformações para este mesmo ponto através da lei de Hooke, apresentada a seguir:

$$
\sigma_{i j}=C_{i j k l} \varepsilon_{k l}
$$

sendo que $C_{i j k l}$ é um tensor de quarta ordem que caracteriza o material, variando de ponto a ponto dentro do corpo quando este não for homogêneo.

No caso, em que é admitida às hipóteses de meio elástico, homogêneo e isotrópico, onde não existem mudanças de temperatura, este tensor tem reduzido suas constantes elásticas à apenas dois valores, que são o módulo de elasticidade transversal do material " $\mu$ " e o coeficiente de Poisson " $v$ ", válidos para todos os pontos materiais. E o tensor, neste caso, é definido por:

$$
C_{i j k l}=\frac{2 \mu v}{1-2 v} \delta_{i j} \delta_{k l}+\mu\left(\delta_{i k} \delta_{j l}+\delta_{i l} \delta_{j k}\right)
$$

sendo $\delta$ a função delta de Kronecker.

Desta forma, a lei de Hooke pode ser reescrita apenas por: 


$$
\sigma_{i j}=\lambda \delta_{i j} \varepsilon_{k k}+2 \mu \varepsilon_{i j}
$$

sendo que, $\lambda$ e $\mu$ são também conhecidas como constantes de Lamé, definidas como segue:

$$
\lambda=\frac{2 v \mu}{(1-2 v)}
$$

e

$$
\mu=\frac{E}{2(1+v)},
$$

sendo " $E$ " o módulo de elasticidade longitudinal.

E agora, relaciona-se o estado de tensões com o de deformações pela relação inversa à apresentada em (2.15), da seguinte forma:

$$
\varepsilon_{i j}=\frac{1}{2 \mu}\left(\sigma_{i j}+\frac{\lambda}{3 \lambda+2 \mu} \delta_{i j} \sigma_{k k}\right)
$$

\subsubsection{Equação de Navier}

Através da substituição da equação (2.15) na equação (2.8) e substituindo a esta resultante a equação (2.12) tem-se uma única equação que leva em conta as relações tensão-deformação, as relações de equilíbrio e as relações deformação deslocamento, como segue:

$$
G u_{i, j j}+(G+\lambda) u_{j, j i}+b_{i}=0
$$

sendo $G$ definido como em (2.17) e também conhecido como Módulo de Elasticidade Transversal.

A expressão (2.19) é chamada de equação de Navier. 


\subsection{Solução Fundamental}

A solução fundamental de Kelvin tornou-se a mais utilizada e difundida entre os pesquisadores da área de métodos numéricos, por ser a mais abrangente e mais simples de ser implementada, Paccola (2004). Tal solução, de acordo com Love (1944) - apud Souza (2001), foi desenvolvida por Lord Kelvin e é determinada considerando-se um domínio $\Omega$, como um sólido elástico, isotrópico, homogêneo e infinito.

\subsubsection{Definição}

A solução fundamental de Kelvin é obtida a partir da equação de Navier (2.19) e é representada pelo efeito de uma força concentrada unitária aplicada em um ponto $\mathrm{s}$ (ponto fonte) de um domínio elástico infinito, em um ponto campo $f$ (ponto campo), como apresentado na Figura 2-5.

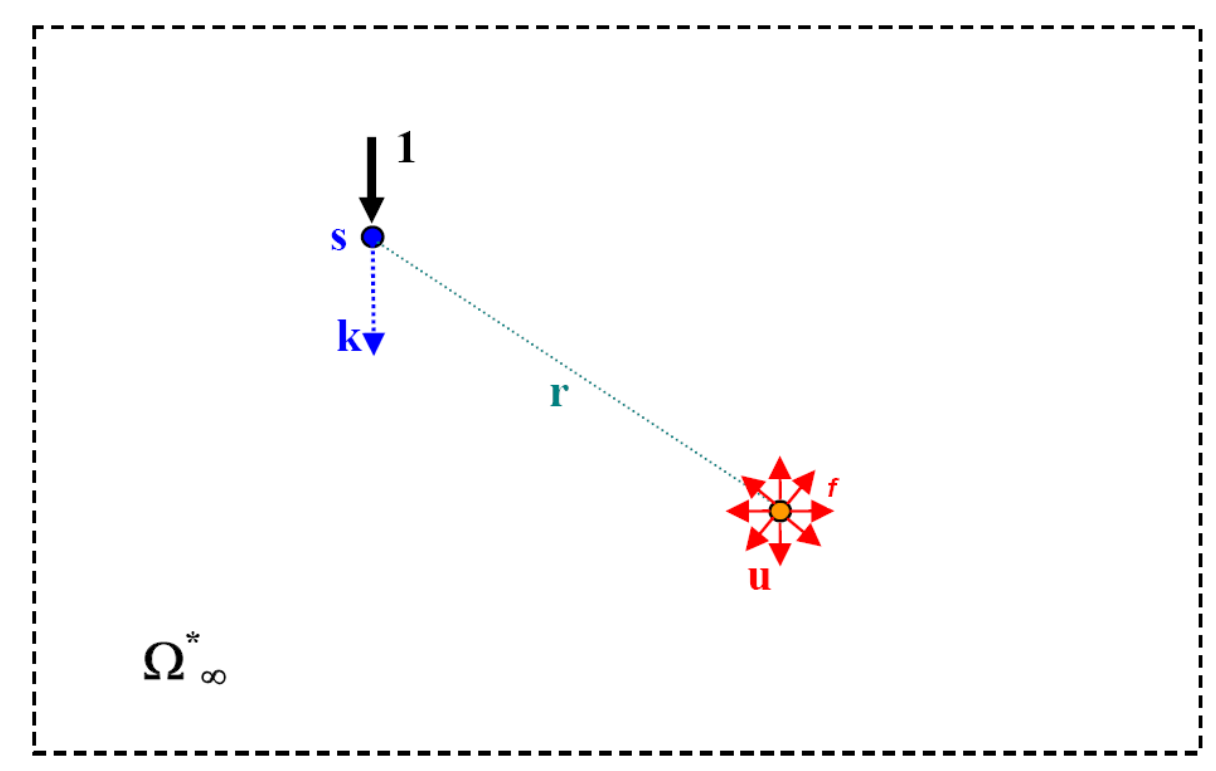

Figura 2-5 - Problema Fundamental, Ferreira (2007).

Partindo-se da equação (2.8), e abrindo-se tal equação em duas, tem-se: 


$$
\begin{aligned}
& \sigma_{k 1 j, j}^{*}+b_{k 1}^{*}=0 \\
& \sigma_{k 2 j, j}^{*}+b_{k 2}^{*}=0
\end{aligned}
$$

sendo que o índice $\mathrm{k}$ adicionado em (2.20) se refere ao número do problema fundamental em estudo e $\circ\left(^{*}\right)$ é referente ao problema fundamental, que é composto por dois casos de carregamento, são eles:

a - Força concentrada em s na direção 1.

$$
\left\{\begin{array}{l}
\sigma_{11 j, j}^{*}(s, f)+\delta_{11}^{*}(s, f)=0 \\
\sigma_{12 j, j}^{*}(s, f)+0=0
\end{array},\right.
$$

representado-se fisicamente pela Figura 2-6 a seguir.

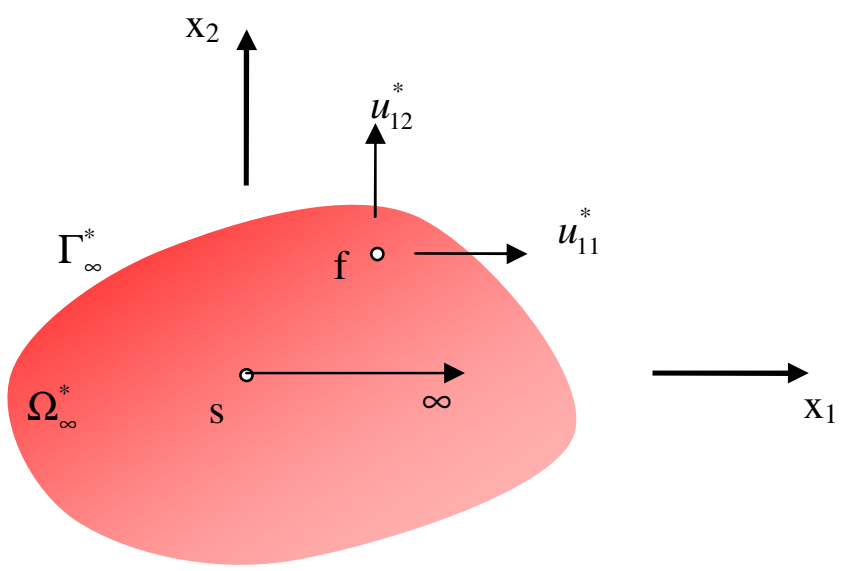

Figura 2-6 - Problema fundamental um.

b - Força concentrada em s na direção 2.

$$
\left\{\begin{array}{l}
\sigma_{21 j, j}^{*}(s, f)+0=0 \\
\sigma_{22 j, j}^{*}(s, f)+\delta_{22}^{*}(s, f)=0
\end{array},\right.
$$

apresentando-se fisicamente na Figura 2-7 a seguir. 


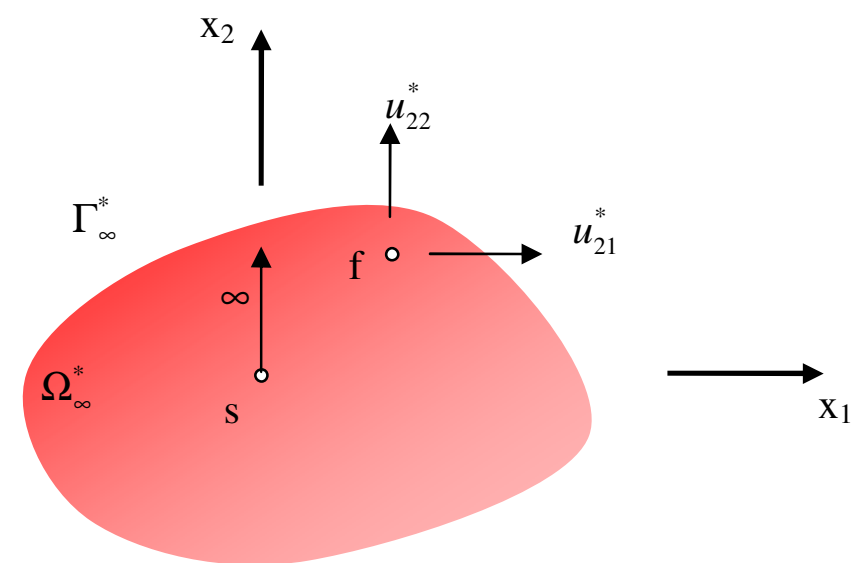

Figura 2-7 - Problema fundamental dois.

nota-se que as equações (2.21) e (2.22) estão acopladas pelo termo cruzado $\sigma_{k i j}^{*}=\sigma_{k j i}^{*}$.

Para se escrever (2.21) e (2.22) em uma só equação teremos:

$$
\sigma_{k i j, i}^{*}(s, f)+\delta_{k j} \delta(s, f)=0,
$$

sendo, $\mathrm{k}=$ problema fundamental, $\mathrm{j}=$ direção da força fundamental e $\delta(s, f)$ a função Delta de Dirac.

\subsubsection{Vetor de Galerkin}

De modo a tornar mais simples a dedução da solução fundamental, os deslocamentos podem ser representados pelo vetor de Galerkin, tal função foi introduzida por Galerkin e substitui os deslocamentos por funções derivadas de segunda ordem, Leite (2007), são elas:

$$
u_{i}=g_{i, m m}-\frac{1}{2(1-v)} g_{m, m i},
$$




$$
u_{j}=g_{j, m m}-\frac{1}{2(1-v)} g_{m, m j},
$$

sendo $g$ o vetor de Galerkin.

Substituindo-se (2.24) e (2.25) na equação de Navier (2.19), obtém-se:

$$
\frac{2(1-v)(1-2 v) g_{i, m m i j}-(1-2 v) g_{m, i m j j}+2(1-v) g_{j, m m i j}-g_{m, j m i j}}{2(1-v)(1-2 v)}+\frac{b_{i}}{\mu}=0,
$$

sabendo-se que:

$$
g_{m, j m j i}=g_{m, m j j i}=g_{m, i j j m}=g_{m, j j i m}=g_{i, m m m j},
$$

pode-se simplificar a equação (2.26) para:

$$
g_{i, m m i j}+\frac{b_{i}}{\mu}=0
$$

que é a equação de Navier em termos do vetor de Galerkin, ou, reescrevendo em notação vetorial:

$$
\nabla^{2}\left(\nabla^{2} g_{i}\right)+\frac{1}{\mu} b_{i}=0
$$

Fazendo-se:

$$
\left(g_{i, m m}\right)_{, j j}=F_{i, j j},
$$

e reescrevendo-se (2.28) nota-se que a mesma é agora desacoplada, como explicitado a seguir:

$$
F_{i, j j}+\frac{b_{i}}{\mu}=0 .
$$


Adotando-se para a equação (2.31) a solução a seguir:

$$
F_{k i}=-\frac{1}{2 \pi G} \ln (r) \delta_{k i}-\frac{1}{2 \pi G} \delta_{k i},
$$

e, substituindo-se (2.32) em (2.30), tem-se:

$$
g_{k i, m m}=-\frac{1}{2 \pi G}[\ln (r)+1] \delta_{k i} \text {. }
$$

É possível demonstrar que a equação (2.34) que é o vetor de Galerkin Fundamental, é válida, e atende à equação (2.33).

$$
g_{k i}=-\frac{1}{8 \pi G} r^{2} \ln (r) \delta_{k i}
$$

Derivando-se novamente, como segue:

$$
g_{k i, m j}=-\frac{1}{8 \pi G}\left\{2 r_{, m} r_{j}+2 \ln (r) \delta_{j m}+\delta_{j m}\right\} \delta_{k i},
$$

sendo $r_{, m}$ e $r_{, j}$ correspondentes às derivadas de $r$ em relação a $\mathrm{m}$ e j, respectivamente, e obtido da seguinte forma:

$$
r_{, m}=\frac{r_{m}}{r}
$$

sendo:

$$
r_{m}=\left|x_{m}(s)-x_{m}(f)\right|
$$

E finalmente, substituindo-se (2.35) em (2.25) com os índices devidamente alterados, tem-se: 


$$
u_{i j}=-\frac{1}{8 \pi G(1-v)}\left\{(3-4 v) \ln (r) \delta_{i j}-r_{, i} r_{, j}+\frac{7-8 v}{2} \delta_{i j}\right\}
$$

que corresponde a solução fundamental em deslocamentos de Kelvin.

Agora com o objetivo de calcular a solução fundamental de força de superfície de Kelvin. Partindo-se da solução fundamental em deslocamentos (2.38), derivandoa e substituindo-se em (2.12), tem-se:

$$
\varepsilon_{i j k}=-\frac{1}{8 \pi G r(1-v)}\left\{(1-2 v)\left[\delta_{i j} r_{, k}+\delta_{i k} r_{, j}\right]+2 r_{, i} r_{, j} r_{, k}-\delta_{k j} r_{, i}\right\},
$$

substituindo-se agora (2.39) na Lei de Hooke (2.15), encontra-se:

$$
\sigma_{i j k}=-\frac{1}{4 \pi(1-v) r}\left\{(1-2 v)\left[\delta_{i j} r_{, k}+\delta_{i k} r_{, j}-\delta_{k j} r_{, i}\right]+2 r_{, i} r_{, j} r_{, k}\right\}
$$

e, por fim, substituindo-se (2.40) em (2.10) obtém-se a solução fundamental de força de superfície de Kelvin, como segue:

$$
p_{i j}=-\frac{1}{4 \pi(1-v) r}\left\{(1-2 v)\left[r_{, j} n_{i}-r_{, i} n_{j}\right]+\left[(1-2 v) \delta_{i j}+2 r_{, i} r_{, j}\right] \frac{\partial r}{\partial n}\right\}
$$

\subsection{Equações Fundamentais de Contorno}

Considerando-se o sólido bidimensional apresentado na Figura 2-8, que possui domínio $\Omega$ e contorno $\Gamma$, e sabendo-se que a equação diferencial de equilíbrio deduzida anteriormente é:

$$
\sigma_{i j, j}+b_{i}=0
$$


utiliza-se a técnica dos resíduos ponderados para a obtenção da equação integral governante do problema elástico, a partir da multiplicação da equação (2.42) por uma função ponderadora em deslocamentos $u_{k}^{*}$ admissível para o mesmo material elástico linear, como exposto na equação (2.43).

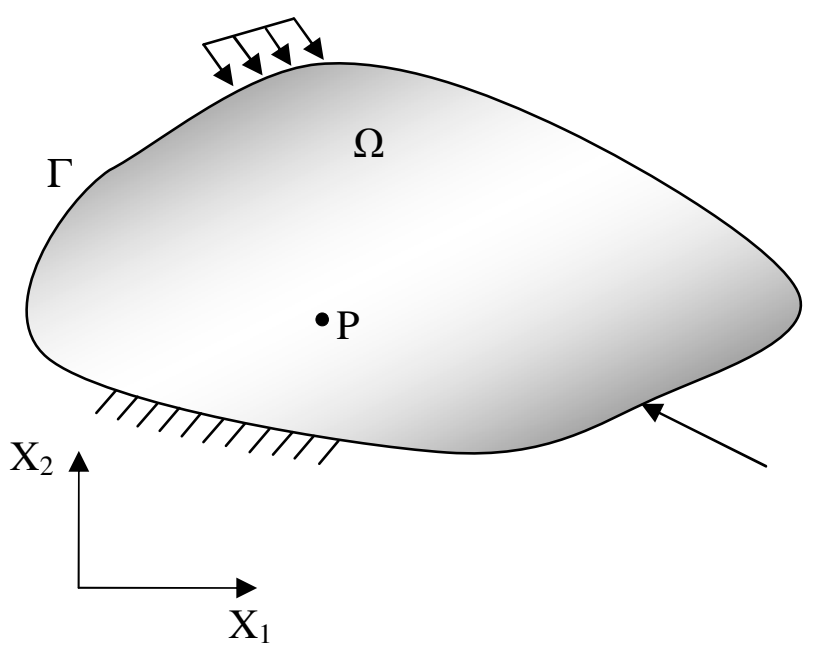

Figura 2-8 - Domínio sólido 2-D.

$$
\int_{\Omega} \sigma_{i j, j} u_{i}^{*} d \Omega+\int_{\Omega} b_{i} u_{i}^{*} d \Omega=0,
$$

aplicando-se o Teorema da Divergência ao primeiro termo, tem-se:

$$
\int_{\Gamma} \sigma_{i j} u_{i}^{*} n_{j} d \Gamma-\int_{\Omega} \sigma_{i j} u_{i, j}^{*} d \Omega+\int_{\Omega} b_{i} u_{i}^{*} d \Omega=0,
$$

tendo em mente a equação (2.13), tem-se:

$$
\begin{aligned}
& \sigma_{i j}=C_{i j k l} u_{k, l}=u_{k, l} C_{i j k l} \\
& \sigma_{i j} u_{i, j}^{*}=u_{k, l} C_{i j k l} u_{i, j}^{*}=u_{k, l} \sigma_{k l}^{*}=u_{i, j} \sigma_{i j}^{*} .
\end{aligned}
$$

Substituindo-se (2.45) em (2.44) e levando-se em consideração a condição de contorno de Cauchy (2.10), tem-se:

$$
\int_{\Gamma} p_{i} u_{i}^{*} d \Gamma-\int_{\Omega} \sigma_{i j}^{*} u_{i, j} d \Omega+\int_{\Omega} b_{i} u_{i}^{*} d \Omega=0 .
$$


Aplicando-se novamente o Teorema da Divergência ao segundo termo da equação (2.46), e passando o mesmo para a direita da igualdade, tem-se:

$$
\int_{\Gamma} p_{i} u_{i}^{*} d \Gamma+\int_{\Omega} b_{i} u_{i}^{*} d \Omega=\int_{\Gamma} \sigma_{i j}^{*} u_{i} n_{j} d \Gamma-\int_{\Omega} \sigma_{i j, j}^{*} u_{i} d \Omega
$$

Reescrevendo-se (2.47), levando-se em conta a condição de contorno de Cauchy (2.10) e que, por (2.42) $\sigma_{i j, j}^{*}=-b_{i}^{*}$, tem-se:

$$
\int_{\Gamma} p_{i} u_{i}^{*} d \Gamma+\int_{\Omega} b_{i} u_{i}^{*} d \Omega=\int_{\Gamma} p_{i}^{*} u_{i} d \Gamma+\int_{\Omega} b_{i}^{*} u_{i} d \Omega
$$

sendo $u_{i}^{*}$ e $p_{i}^{*}$ as soluções fundamentais (2.38) e (2.41) respectivamente.

A equação (2.48) é também conhecida com segundo teorema de Betti, sendo que, (2.45) é o primeiro teorema de Betti, ou seja:

$$
\sigma_{i j} \varepsilon_{i j}^{*}=\sigma_{i j}^{*} \varepsilon_{i j}
$$

reescrevendo (2.48) adicionando um índice referente aos dois problemas fundamentais apresentados anteriormente, tem-se:

$$
\int_{\Gamma} p_{i}(f) u_{k i}^{*}(s, f) d \Gamma+\int_{\Omega} b_{i}(f) u_{k i}^{*}(s, f) d \Omega=\int_{\Gamma} p_{k i}^{*}(s, f) u_{i}(f) d \Gamma+\int_{\Omega} b_{k i}^{*}(s, f) u_{i}(f) d \Omega
$$

substituindo-se agora $b_{k i}=\delta_{k j} \delta(s, f)$ como realizado em (2.23) e tratando essa integral separadamente, tem-se:

1. Ponto fonte fora do domínio real estudado:

$$
\int_{\Omega} b_{k i}^{*}(s, f) u_{i}(f) d \Omega=\int_{\Omega} \delta_{k i} \delta(s, f) u_{i}(f) d \Omega=0 ;
$$


2. Ponto fonte dentro do domínio real estudado:

$$
\int_{\Omega} b_{k i}^{*}(s, f) u_{i}(f) d \Omega=\int_{\Omega} \delta_{k i} \delta(s, f) u_{i}(f) d \Omega=\delta_{k i} u_{i}(f) ;
$$

3. Ponto fonte sobre o contorno do domínio real estudado, neste caso a equação recebe um valor intermediário entre (2.51) e (2.52), ficando da seguinte forma:

$$
\int_{\Omega} b_{k i}^{*}(s, f) u_{i}(f) d \Omega=\int_{\Omega} \delta_{k i} \delta(s, f) u_{i}(f) d \Omega=C_{k i} u_{i}(f)
$$

nesse caso a equação (2.50) fica,

$$
C_{k i} u_{i}(s)+\int_{\Gamma} p_{k i}^{*}(s, f) u_{i}(f) d \Gamma=\int_{\Gamma} p_{i} u_{k i}^{*}(s, f) d \Omega+\int_{\Omega} b_{i} u_{k i}^{*}(s, f) d \Omega,
$$

sendo que, $C_{k i}$ será definido a seguir; a integral com o traço no meio é fortemente singular e deve ser calculada de acordo com o sentido de valor principal de Cauchy.

A equação (2.54) escrita para pontos internos é também conhecida como identidade Somigliana, como segue:

$$
\delta_{k i} u_{i}(s)+\int_{\Gamma} p_{k i}^{*}(s, f) u_{i}(f) d \Gamma=\int_{\Gamma} p_{i}(f) u_{k i}^{*}(s, f) d \Omega+\int_{\Omega} b_{i}(f) u_{k i}^{*}(s, f) d \Omega,
$$

ou, na forma discreta:

$$
\begin{gathered}
\sum_{n=1}^{n e l} \int_{-1}^{1} p_{k i}^{*}(s, f) \phi_{l}(\xi) J_{n}(\xi) d \xi u_{i}(f)=\sum_{n=1}^{n e l} \int_{-1}^{1} u_{k i}^{*}(s, f) \phi_{l}(\xi) J_{n}(\xi) d \xi p_{i}(f)+ \\
\sum_{n=1}^{n e l} \int_{-1}^{1} u_{k i}^{*}(s, f) \phi_{l}(\xi) J_{n}(\xi) d \xi b_{i}(f)
\end{gathered}
$$

sendo $\phi_{l}$ as funções de forma de cada elemento, o termo $J_{n}(\xi)$ é o Jacobiano associado à transformação de coordenadas dimensionais para adimensionais e 0 
último termo, referente as forças de corpo foi obtido considerando-se tais forças constantes, portanto, o termo $\hat{u}_{k i}^{*}$ é a primitiva da solução fundamental em deslocamentos $u_{k i}^{*}$.

A equação (2.56), desprezando-se as forças de corpo, é transformada em representação algébrica utilizando-se as aproximações das variáveis de contorno e de domínio, que serão apresentadas posteriormente, chegando-se a seguinte forma:

$$
[H]\{u\}=[G]\{p\} .
$$

\subsubsection{Formulação do Método dos Elementos de Contorno}

Para a resolução da equação (2.55) pode-se dividir o contorno $\Gamma$ em elementos, como realizado em (2.56). Neste trabalho são utilizados elementos curvos, com funções aproximadoras isoparamétricas de ordem qualquer, como será apresentado a seguir.

O Método dos elementos de contorno consiste basicamente na divisão do contorno do problema em segmentos, denominados elementos de contorno, sobre os quais as variáveis são aproximadas por funções previamente escolhidas. Essas funções, ditas interpoladoras, são, em geral, polinomiais e definidas em função de pontos previamente escolhidos em cada elemento, denominados pontos nodais, Waidemam (2008).

Através dessa divisão do contorno do modelo geométrico do problema, mudase de um sistema estrutural contínuo ("infinitos graus de liberdade") para um sistema estrutural discreto, permitindo então expressar a solução exata do modelo contínuo de forma aproximada. Desta forma, as equações integrais apresentadas anteriormente são transformadas em equações algébricas que, aplicadas aos pontos nodais pré-definidos formam um sistema de equações lineares cuja resolução fornece as incógnitas do problema. 


\subsubsection{Discretização do Contorno}

Considere-se um elemento estrutural de domínio $\Omega$ e contorno $\Gamma$. Tal contorno é dividido em $\mathrm{n}$ trechos menores $\Gamma_{i}$, de forma que, a soma destes recompõe o contorno original. Até recentemente, o procedimento seguido para a divisão do contorno era a escolha do número e forma (geralmente linear ou quadrática) dos elementos de contorno a discretizar tal contorno $\Gamma_{i}$ de forma a representar da melhor maneira possível este elemento. Neste trabalho, através do Polinômio de Lagrange foi feita a generalização da ordem das funções polinomiais responsáveis pela aproximação tanto das variáveis quanto da representação geométrica do problema.

Sendo que o Polinômio de Lagrange é definido da seguinte forma:

$$
L_{i}(\xi)=\prod_{\substack{i \neq j \\ j=1}}^{n} \frac{\left(\xi-\xi_{j}\right)}{\left(\xi_{i}-\xi_{j}\right)}
$$

Tais funções assumem a forma apresentada a seguir para o caso linear:

$$
\begin{aligned}
& \phi_{1}(\xi)=\frac{\left(\xi-\xi_{2}\right)}{\left(\xi_{1}-\xi_{2}\right)}, \\
& \phi_{2}(\xi)=\frac{\left(\xi-\xi_{1}\right)}{\left(\xi_{2}-\xi_{1}\right)}
\end{aligned}
$$

sendo as funções utilizadas aqui adimensionais, ou seja, definida no espaço de $(-1 \leq \xi \leq+1)$, tem-se:

$$
\begin{aligned}
& \phi_{1}=\frac{1}{2}(1-\xi) \\
& \phi_{2}=\frac{1}{2}(1+\xi)
\end{aligned}
$$

sendo suas derivadas dadas por: 


$$
\begin{gathered}
\phi_{1, \xi}=-\frac{1}{2} \\
\phi_{2, \xi}=+\frac{1}{2},
\end{gathered}
$$

para o caso quadrático, tem-se:

$$
\begin{aligned}
\phi_{1}(\xi) & =\frac{\left(\xi-\xi_{2}\right)}{\left(\xi_{1}-\xi_{2}\right)} \frac{\left(\xi-\xi_{3}\right)}{\left(\xi_{1}-\xi_{3}\right)} \\
\phi_{2}(\xi) & =\frac{\left(\xi-\xi_{1}\right)}{\left(\xi_{2}-\xi_{1}\right)} \frac{\left(\xi-\xi_{3}\right)}{\left(\xi_{2}-\xi_{3}\right)} \\
\phi_{3}(\xi) & =\frac{\left(\xi-\xi_{1}\right)}{\left(\xi_{3}-\xi_{1}\right)} \frac{\left(\xi-\xi_{2}\right)}{\left(\xi_{3}-\xi_{2}\right)}
\end{aligned}
$$

na forma adimensional, tem-se:

$$
\begin{aligned}
\phi_{1} & =\frac{\xi}{2}(\xi-1) \\
\phi_{2} & =1-\xi^{2} \\
\phi_{3} & =\frac{\xi}{2}(\xi+1)
\end{aligned}
$$

e sendo suas derivadas dadas por:

$$
\begin{gathered}
\phi_{1, \xi}=\xi-\frac{1}{2} \\
\phi_{2, \xi}=-2 \xi \\
\phi_{3, \xi}=\xi+\frac{1}{2}
\end{gathered}
$$

Desta forma, foram desenvolvidos mais alguns graus dos Polinômios de Lagrange, com o intuito de descobrir a recorrência tanto para as funções, quanto para suas derivadas, necessárias também para a confecção de códigos computacionais relativos ao MEC. Apresenta-se a seguir nas Figura 2-9, Figura 2-10, Figura 2-11, Figura 2-12, Figura 2-13 e Figura 2-14 os gráficos do polinômio linear e sua 
derivada, do polinômio do segundo grau e sua derivada, e do polinômio do quarto grau e sua derivada, respectivamente.

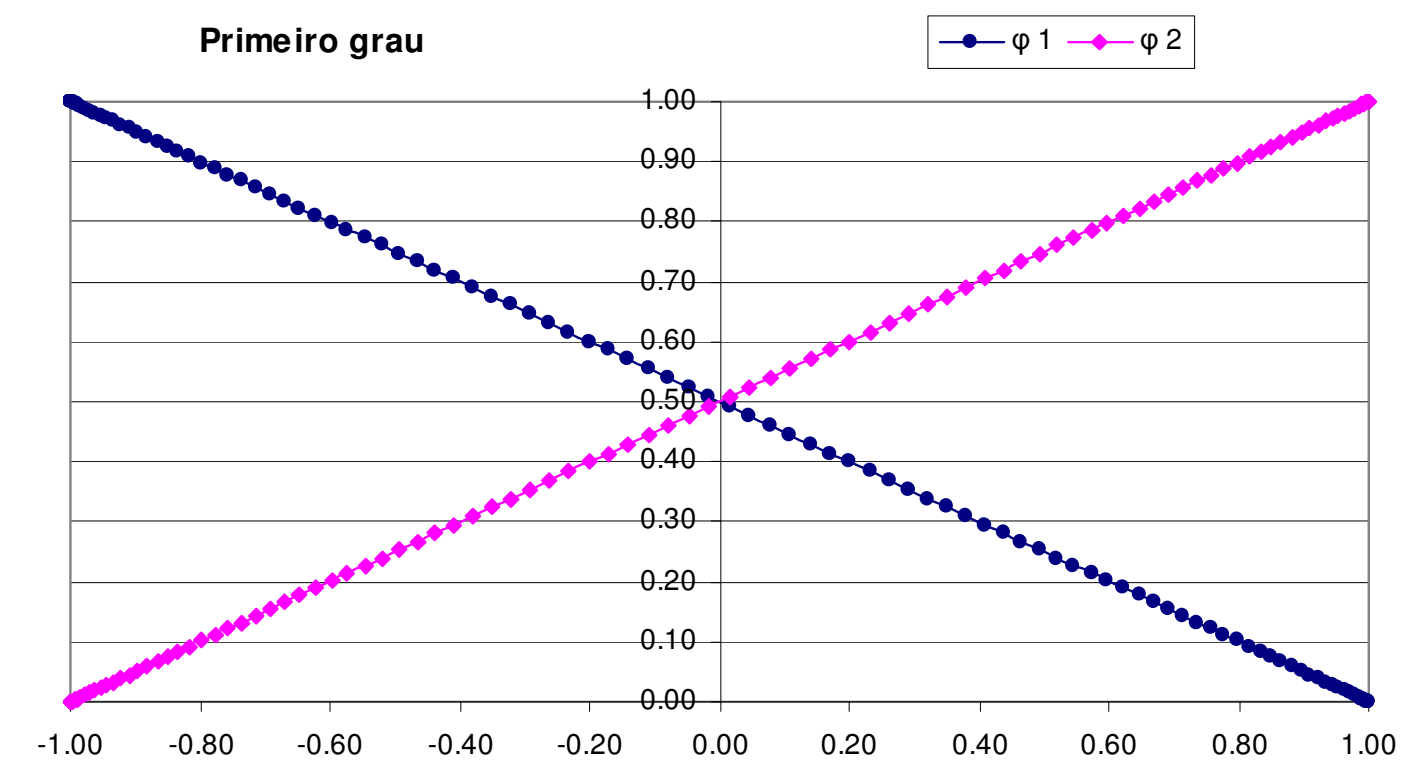

Figura 2-9 - Polinômio de Lagrange linear

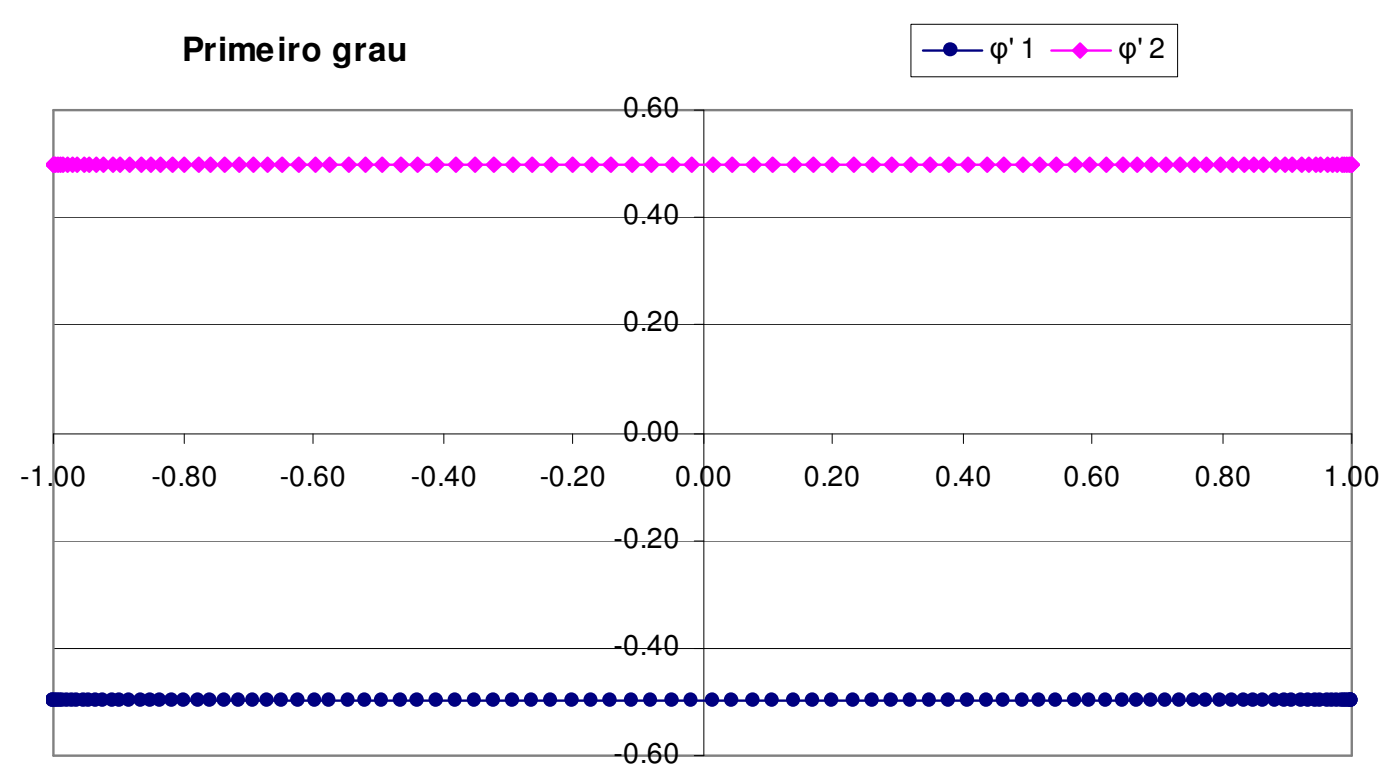

Figura 2-10 - Derivada do Polinômio de Lagrange linear 
Segundo grau

$\multimap \varphi 1 \multimap \varphi 2 \multimap \varphi 3$

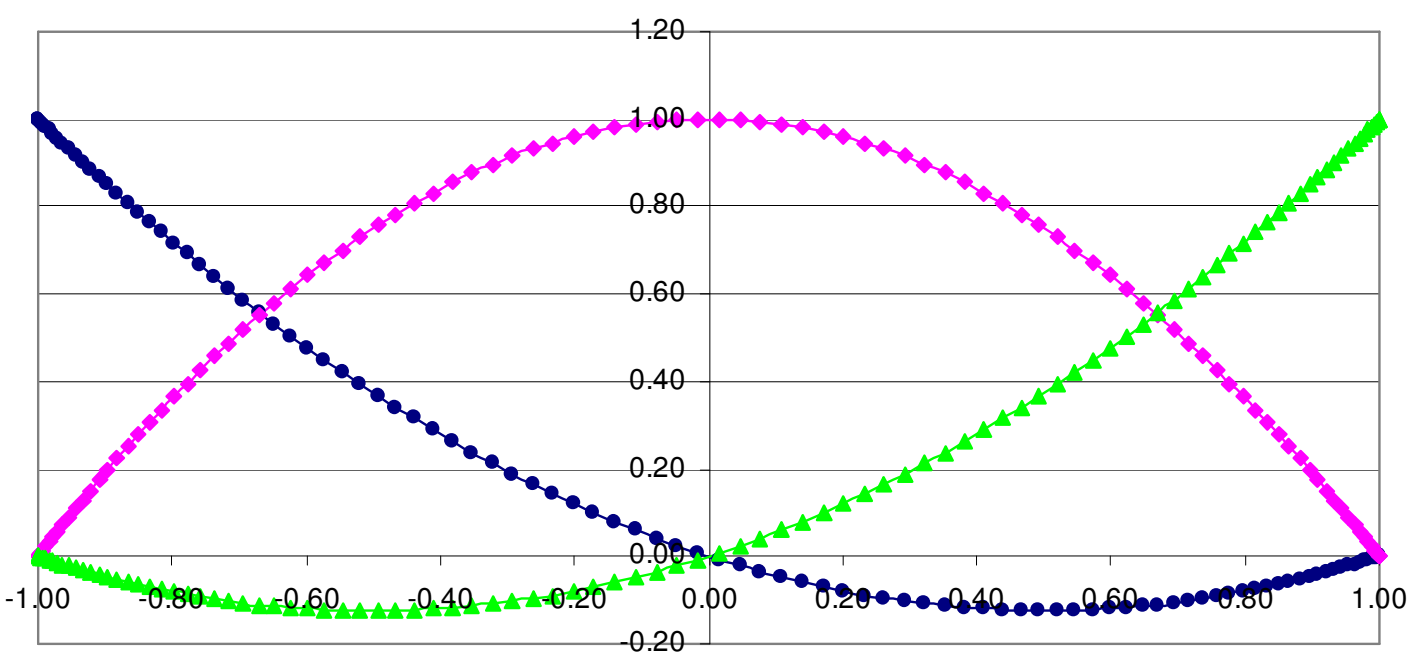

Figura 2-11 - Polinômio de Lagrange quadrático.

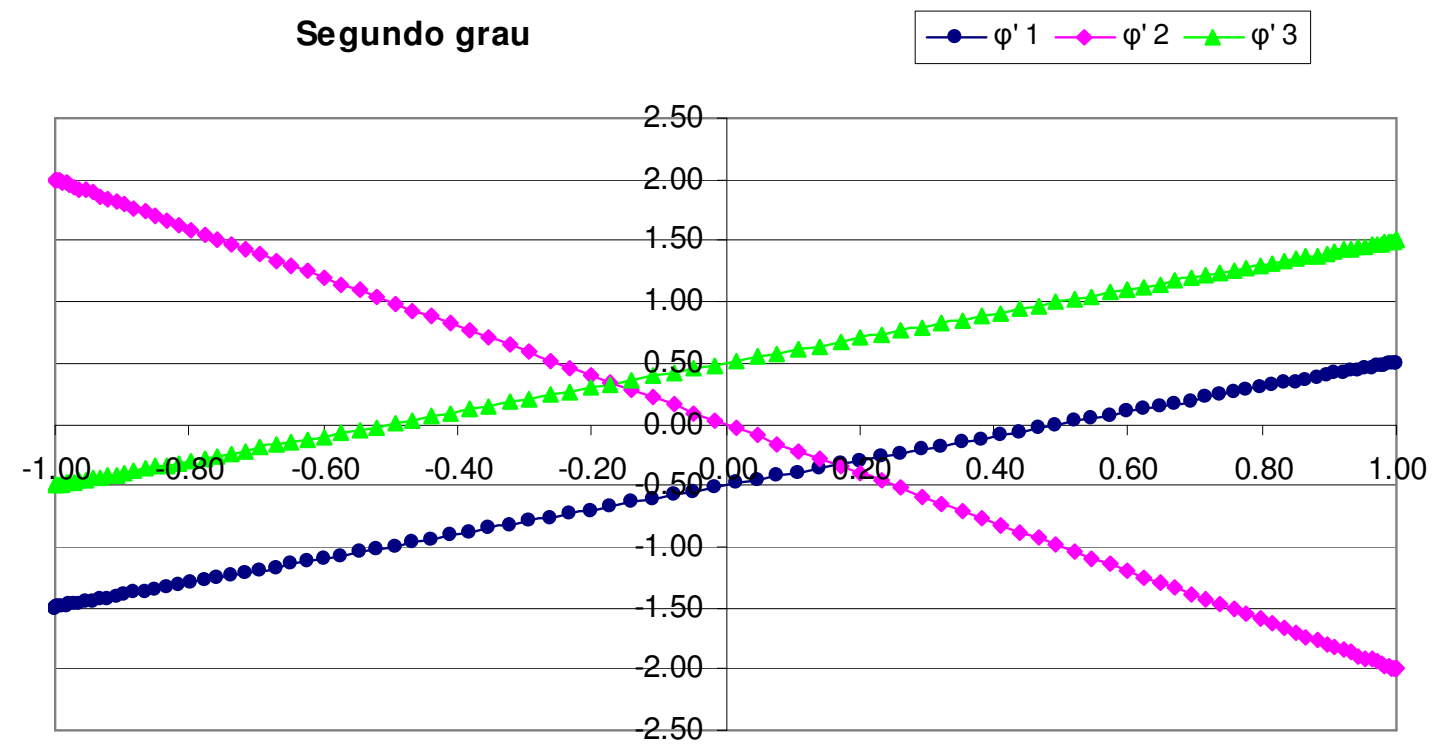

Figura 2-12 - Derivada do Polinômio de Lagrange quadrático. 


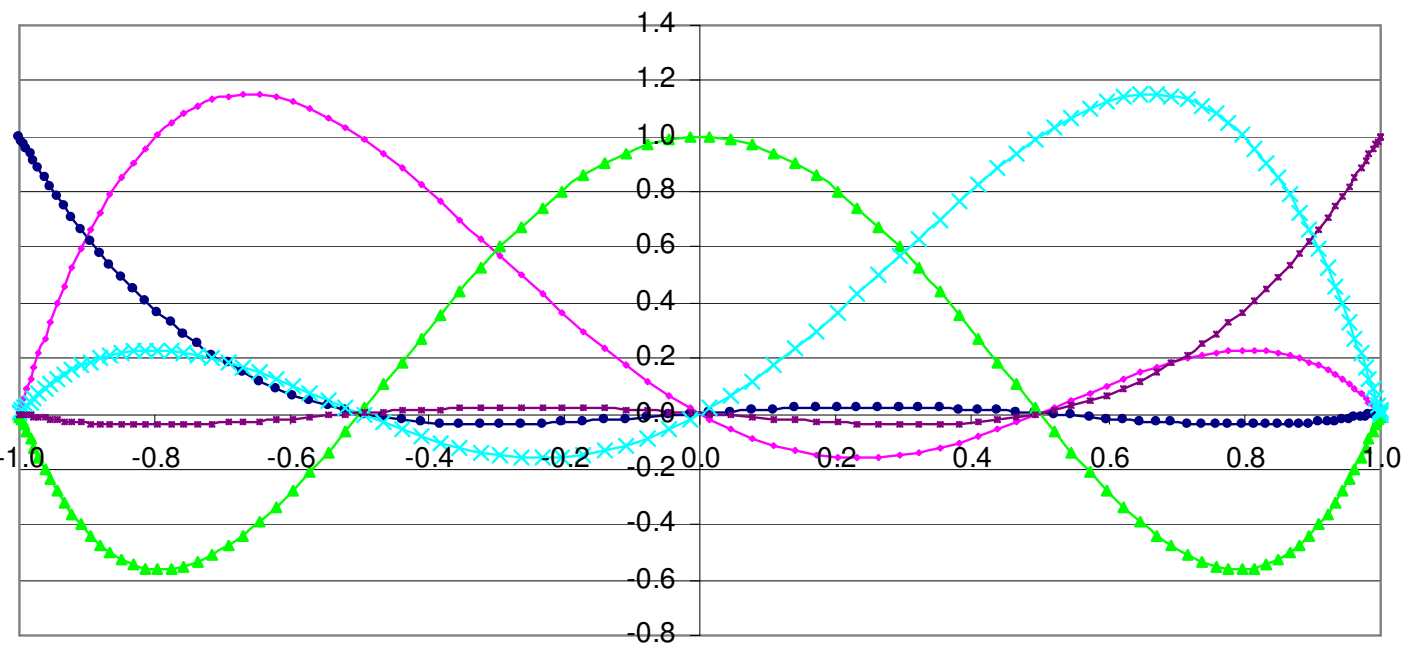

Figura 2-13 - Polinômio de Lagrange do quarto grau.

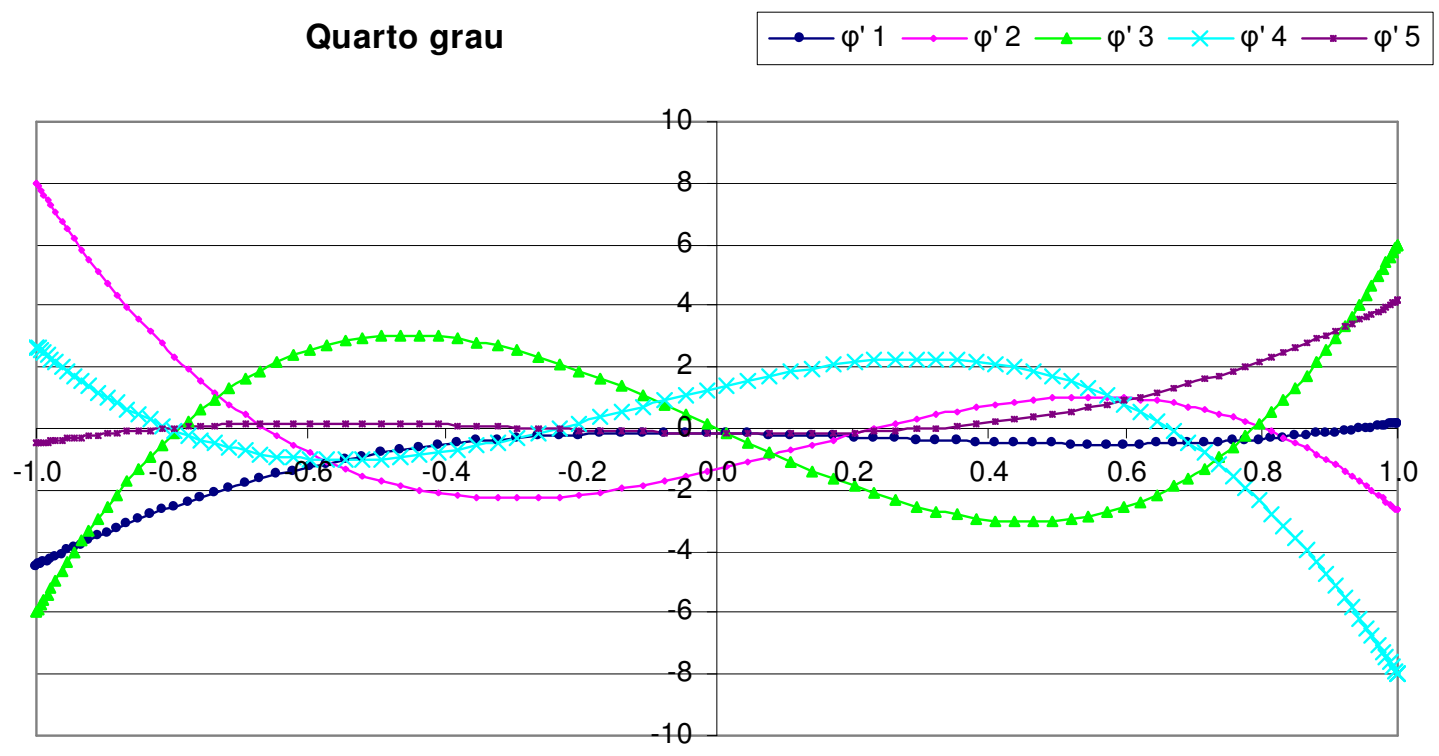

Figura 2-14 - Derivada do Polinômio de Lagrange do quarto grau.

Para os casos onde a geometria apresenta angulosidades no contorno ou diferentes condições de contorno, foi usada neste trabalho a técnica do nó duplo, como é apresentado na Figura 2-15. 


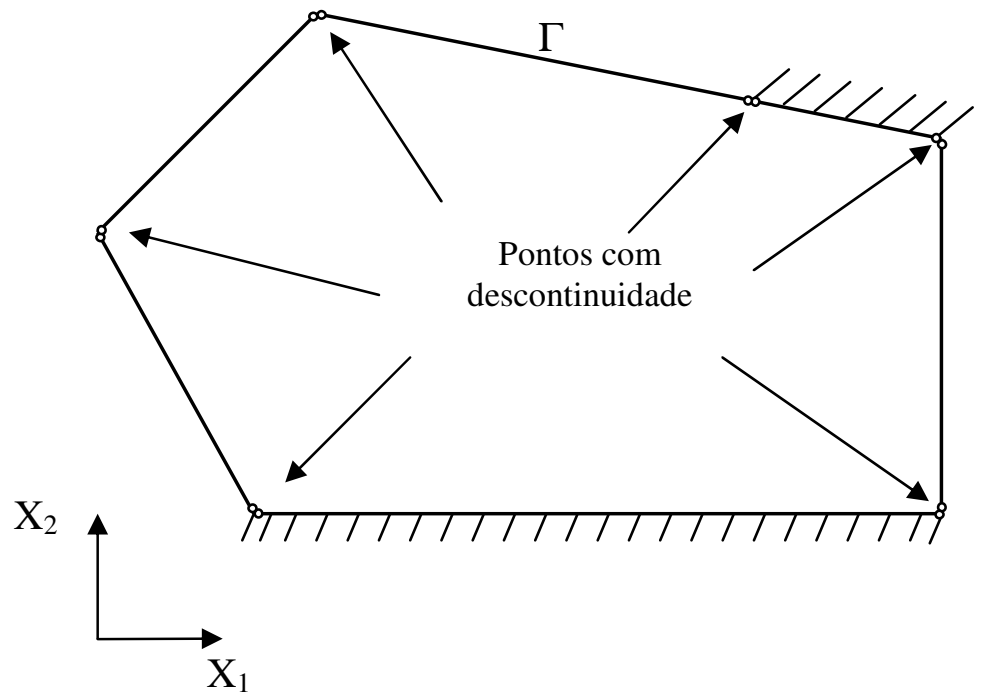

Figura 2-15 - Detalhe de utilização do nó duplo na descontinuidade.

\subsubsection{Equações Integrais de Contorno para Pontos no Contorno}

A equação (2.55) é valida para pontos fonte no domínio, portanto valida para o domínio apresentado na Figura 2-16.

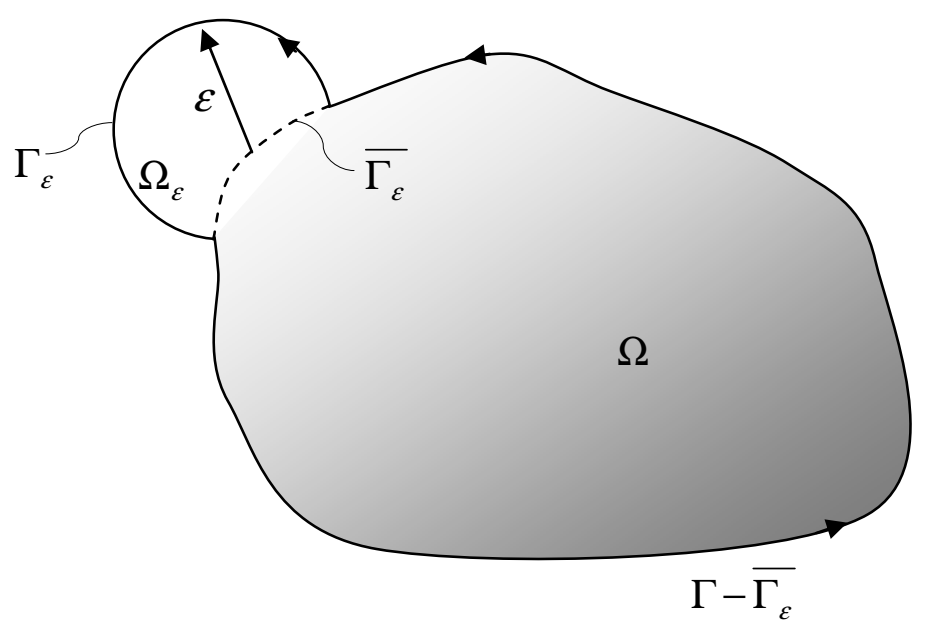

Figura 2-16 - Domínio Sólido 2-D.

Sendo $\varepsilon$ arbitrário, pode-se fazer:

$$
\Gamma=\lim _{\varepsilon \rightarrow 0}\left(\Gamma-\overline{\Gamma_{\varepsilon}}+\Gamma_{\varepsilon}\right)
$$




$$
\Omega=\lim _{\varepsilon \rightarrow 0}\left(\Omega+\Omega_{\varepsilon}\right)
$$

E, com isso, o limite da equação (2.55) fica:

$$
\lim _{\varepsilon \rightarrow 0}\left\{\delta_{k i} u_{i}(s)+\int_{\Gamma-\Gamma_{\varepsilon}+\Gamma_{\varepsilon}} p_{k i}^{*}(s, f) u_{i}(f) d \Gamma=\int_{\Gamma-\Gamma_{\varepsilon}+\Gamma_{\varepsilon}} p_{i} u_{k i}^{*}(s, f) d \Omega+\int_{\Omega+\Omega_{\varepsilon}} b_{i} u_{k i}^{*}(s, f) d \Omega\right\} .
$$

Desenvolvendo-se o limite (2.67) chega-se a seguinte equação:

$$
u_{i}(s)-\frac{\left[\theta_{2}-\theta_{1}\right]}{2 \pi} u_{i}(s)+{\underset{\Gamma}{\Gamma}}_{k i}^{*}(s, f) \cdot u_{i}(f) d \Gamma={\underset{\Gamma}{\Gamma}}_{p_{i}} \cdot u_{k i}^{*}(s, f) d \Gamma+\int_{\Omega} b_{i} \cdot u_{k i}^{*}(s, f) d \Omega, \text { (2.68) }
$$

sendo $\theta$ mostrado na Figura 2-17.

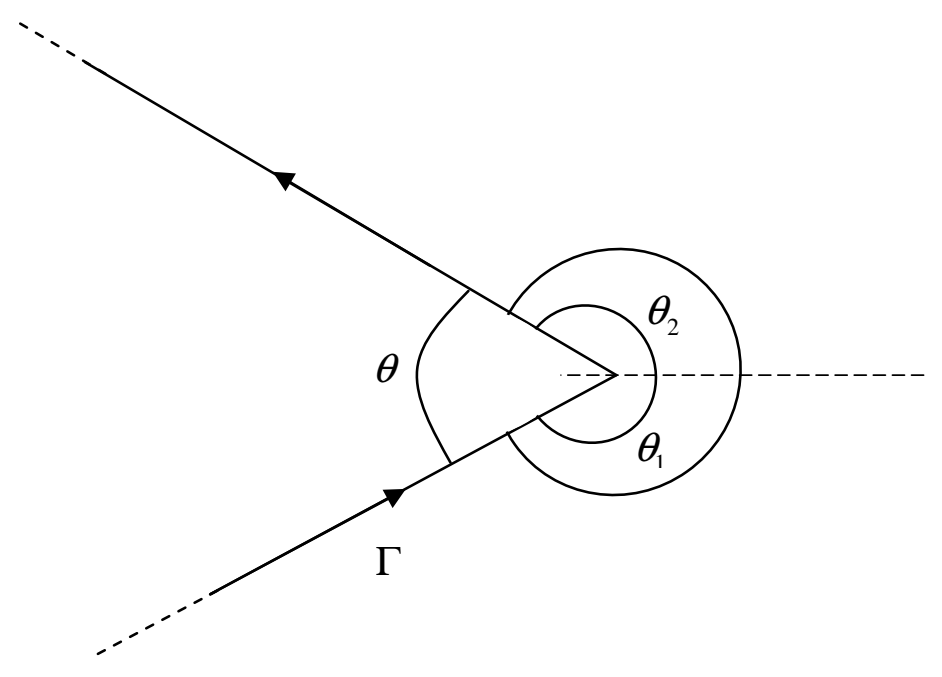

Figura 2-17 - Detalhe dos ângulos.

Desta forma, pode-se colocar em evidência os dois primeiros termos da esquerda de (2.68), resultando em:

$$
u_{i}(s)\left\{1-\frac{\left[\theta_{2}-\theta_{1}\right]}{2 \pi}\right\}=u_{i}(s)\left\{1-\frac{\theta}{2 \pi}\right\}=u_{i}(s)\left\{\frac{2 \pi-\theta}{2 \pi}\right\} \Rightarrow C=\left\{\frac{2 \pi-\theta}{2 \pi}\right\},
$$

ficando, 


$$
C(s) u_{k}(s)+f_{\Gamma} p_{k i}^{*}(s, f) \cdot u_{i}(f) d \Gamma={\underset{\Gamma}{\Gamma}}_{f} p_{i} \cdot u_{k i}^{*}(s, f) d \Gamma+\int_{\Omega} b_{i} \cdot u_{k i}^{*}(s, f) d \Omega .
$$

O lado esquerdo da equação (2.70) pode ser avaliado de duas maneiras. a) fazendo-se a integração no sentido de valor principal de Cauchy e somando-se o resultado com o termo independente; b) utilizando a propriedade de movimento de corpo rígido de qualquer sólido.

Neste trabalho optou-se por utilizar o movimento de corpo rígido para a avaliação do termo a esquerda da equação (2.70). No caso plano há três movimentos de corpo rígido: duas translações e uma rotação. Para definir os coeficientes do lado esquerdo da equação basta utilizar as duas translações. Esse procedimento evita o cálculo das integrais fortemente singulares. As demais continuam a ser calculadas por integração numérica.

Analisando-se o primeiro termo à direita da igualdade (2.70), nota-se que o termo a ser integrado é a solução fundamental em deslocamentos $u_{k i}^{*}$ que pode ser dividida em duas partes, sendo uma regular $B_{k i}$, e outra singular (singularidade considerada fraca) $A_{k i} \ln |r|$, como segue:

$$
u_{k i}^{*}=A_{k i} \ln |r|+B_{k i} .
$$

Tratando-se então do termo singular, tem-se:

$$
\begin{aligned}
& \int_{-1}^{1} A_{k i} \ln |r(\xi)| \phi_{l}(\xi) J(\xi) d \xi=\int_{-1}^{1}\left[A_{k i} \ln |r(\xi)| \bar{\phi}_{l}(\xi) J(\xi)-A_{k i} \ln |\bar{r}(\xi)| \bar{\phi}_{l}\left(\xi_{0}\right) J\left(\xi_{0}\right)\right] d \xi+ \\
& A_{k i} \bar{\phi}_{l}\left(\xi_{0}\right) \int \ln |\bar{r}(\xi)| J\left(\xi_{0}\right) d \xi
\end{aligned}
$$

sendo, $\bar{\phi}_{l}$ as funções de forma modificadas, sabendo-se que, estando o ponto fonte sobre o elemento, então haverá um ponto $\xi_{0}$ singular no elemento, dessa forma, para que esse ponto só influencie uma vez no cálculo, modifica-se a função de forma, de forma que, nesse ponto a função será igual a um, como apresentado para 
uma função linear na Figura 2-18. O termo $J(\xi)$ é o Jacobiano associado à transformação de coordenadas dimensionais para adimensionais.
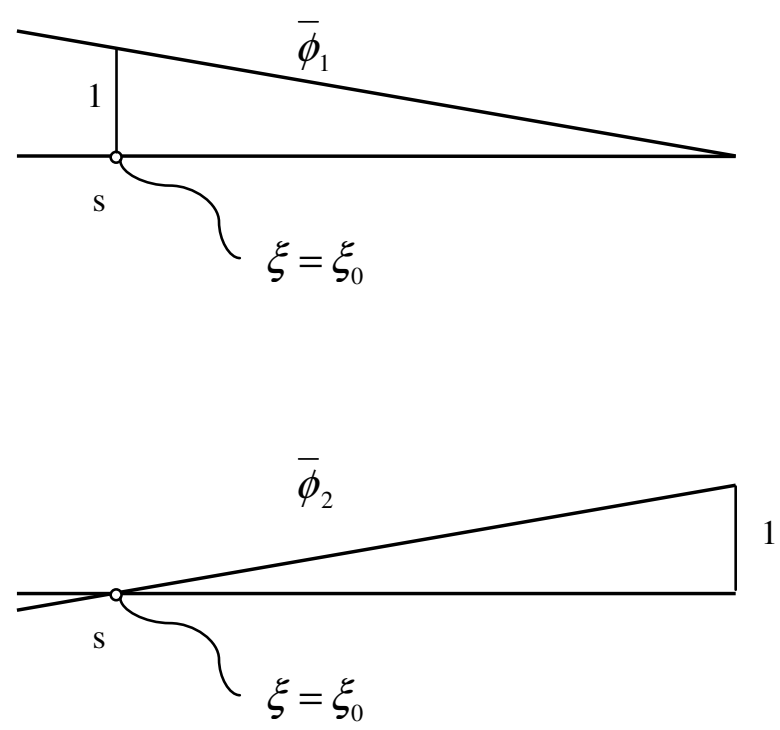

Figura 2-18 - Funções de forma modificadas.

Tratando-se agora o último termo da equação (2.72), tem-se:

$$
f \ln |\bar{r}(\xi)| J\left(\xi_{0}\right) d \xi=\int_{-1-\xi_{0}}^{-\Delta \xi} \ln || \bar{\xi}\left|\cdot J\left(\xi_{0}\right)\right| J\left(\xi_{0}\right) d \bar{\xi}+\int_{+\Delta \xi}^{1-\xi_{0}} \ln || \bar{\xi}\left|\cdot J\left(\xi_{0}\right)\right| J\left(\xi_{0}\right) d \bar{\xi},(2.73)
$$

sendo, $\bar{r}(\bar{\xi})=|\bar{\xi}| \cdot J\left(\xi_{0}\right)$, pois $\bar{\xi}=\xi-\xi_{0}$ e, com isso, os limites das integrações ficam:

$$
\begin{aligned}
& \bar{\xi}(-1)=-1-\xi_{0} \\
& \bar{\xi}(+1)=+1-\xi_{0}
\end{aligned}
$$

como apresentado na Figura 2-19.

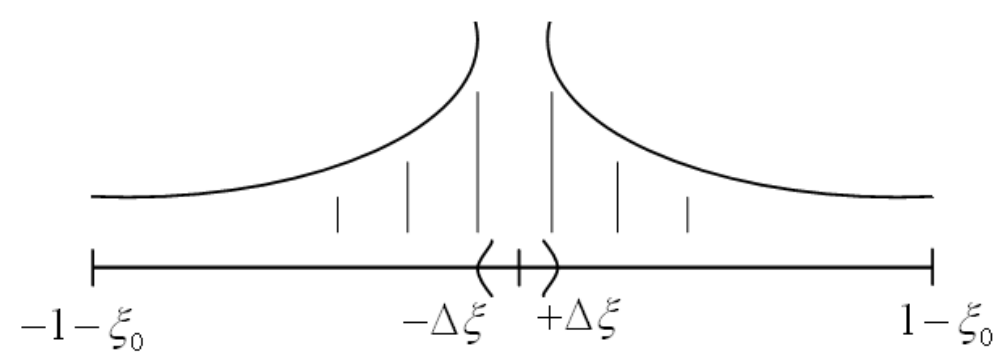

Figura 2-19 - Limites de integração 
Mudando-se os limites de integração do primeiro termo a direita da igualdade da equação (2.73), tem-se:

$$
f \ln |\bar{r}(\xi)| J\left(\xi_{0}\right) d \xi=\int_{\Delta \xi}^{1+\xi_{0}} \ln || \bar{\xi}\left|J\left(\xi_{0}\right)\right| J\left(\xi_{0}\right) d \bar{\xi}+\int_{+\Delta \xi}^{1-\xi_{0}} \ln || \bar{\xi}\left|J\left(\xi_{0}\right)\right| J\left(\xi_{0}\right) d \bar{\xi}
$$

Resolvendo agora a integral (2.75), tem-se:

$$
f \ln |\bar{r}(\xi)| J\left(\xi_{0}\right) d \xi=\left[J\left(\xi_{0}\right) \xi\left(\ln \left|J\left(\xi_{0}\right) \xi\right|-1\right)\right]_{\Delta \xi}^{1+\xi}+\left[J\left(\xi_{0}\right) \xi\left(\ln \left|J\left(\xi_{0}\right) \xi\right|-1\right)\right]_{\Delta \xi}^{1-\xi}
$$

e

$$
\begin{aligned}
& \therefore \int \ln |\bar{r}(\xi)| J\left(\xi_{0}\right) d \xi=J\left(\xi_{0}\right)\left(1+\xi_{0}\right)\left(\ln \left|J\left(\xi_{0}\right)\left(1+\xi_{0}\right)\right|\right)+ \\
& J\left(\xi_{0}\right)\left(1-\xi_{0}\right)\left(\ln \left|J\left(\xi_{0}\right)\left(1-\xi_{0}\right)\right|\right)-2 \cdot J\left(\xi_{0}\right)
\end{aligned}
$$

E finalmente, o primeiro termo a direita da igualdade da equação (2.70) fica:

$$
\begin{aligned}
& f_{\Gamma} u_{k i}^{*} p_{i} d \Gamma=\int_{-1}^{1} B_{k i} \bar{\phi}_{l}(\xi) J(\xi) d \xi p_{l i}+ \\
& \int_{-1}^{1}\left[A_{k i} \ln |r(\xi)| \bar{\phi}_{l}(\xi) J(\xi)-A_{k i} \ln |\bar{r}(\xi)| \bar{\phi}_{l}\left(\xi_{0}\right) J\left(\xi_{0}\right)\right] d \xi_{l i}+ \\
& A_{k i} \bar{\phi}_{l}\left(\xi_{0}\right)\left\{J\left(\xi_{0}\right)\left(1+\xi_{0}\right)\left(\ln \left|J\left(\xi_{0}\right)\left(1+\xi_{0}\right)\right|\right)+J\left(\xi_{0}\right)\left(1-\xi_{0}\right)\left(\ln \left|J\left(\xi_{0}\right)\left(1-\xi_{0}\right)\right|\right)-2 J\left(\xi_{0}\right)\right\} p_{l i} .
\end{aligned}
$$

\subsubsection{Cálculo de deslocamentos e tensões nos pontos internos}

Com todas as variáveis do contorno já calculadas, pode-se agora calcular os deslocamentos, as deformações e as tensões nos pontos internos ao contorno. Para isto, reescrevendo a identidade Somigliana (2.55), desprezando as forças de corpo, com a seguinte forma simplificada: 


$$
u_{k}(s)=\int_{\Gamma} p_{i} \cdot u_{k i}^{*}(s, f) d \Gamma-\int_{\Gamma} p_{k i}^{*}(s, f) \cdot u_{i}(f) d \Gamma,
$$

ou, na forma discreta:

$$
u_{k}(s)=\sum_{n=1}^{n e l}\left[\int_{-1}^{1} u_{k i}^{*}(s, f) \cdot J_{n}(\xi) \cdot \phi_{l}(\xi) d \xi \cdot p_{i l}(f)-\int_{-1}^{1} p_{k i}^{*}(s, f) \cdot J_{n}(\xi) \cdot \phi_{l}(\xi) d \xi \cdot u_{i l}(f)\right]
$$

sendo que, todas os termos à direita da equação (2.80) já foram calculados.

Para obter a representação integral das tensões parte-se da equação integral dos deslocamentos (2.79), para pontos internos, encontra-se sua derivada, (lembrando-se que para pontos internos não há singularidades), obtêm-se a equação integral das deformações a partir das equações de compatibilidade (2.12) e aplica-se a lei de Hooke (2.15) para se obter a equação integral das tensões. Com esse procedimento obtém-se a seguinte equação para pontos internos:

$$
\sigma_{k j}(s)=\int_{\Gamma} p_{i} \cdot D_{k i j}^{*}(s, f) d \Gamma-\int_{\Gamma} S_{k i j}^{*}(s, f) \cdot u_{i}(f) d \Gamma
$$

onde, os termos $D_{k i j}^{*}$ e $S_{k i j}^{*}$, são as soluções fundamentais para a equação de tensão, Dominguez \& Brebia (1992). E são apresentados a seguir:

$$
D_{k i j}^{*}=\frac{1}{4 \pi(1-v) r}\left\{(1-2 v)\left(r_{, k} \delta_{i j}+r_{, j} \delta_{k i}-r_{, i} \delta_{j k}\right)+2 r_{, i} r_{, j} r_{, k}\right\}
$$

e

$$
\begin{aligned}
& S_{k i j}^{*}=\frac{\mu}{1+v} \cdot \frac{1}{r^{2}}\left\{2 \frac{\partial r}{\partial n}\left[(1-2 v) \delta_{i j} r_{, k}+v\left(r_{, j} \delta_{i k}+r_{, i} \delta_{j k}\right)-4 r_{, i} r_{, j} r_{, k}\right]+\right. \\
& \left.2 v\left(n_{i} r_{, j} r_{, k}+n_{j} r_{, i} r_{, k}\right)+(1-2 v)\left(2 n_{k} r_{, i} r_{, j}+n_{j} \delta_{i k}+n_{i} \delta_{j k}\right)-(1-4 v) n_{k} \delta_{i j}\right\}
\end{aligned}
$$

A representação integral das tensões é também transformada em equação algébrica seguindo-se os mesmos passos utilizados para a transformação da 
equação integral de deslocamentos. Portanto, na equação (2.81) substituem-se os valores de contorno pelas suas formas discretizadas em função dos valores nodais e das funções aproximadoras adotadas anteriormente.

\subsection{Exemplo numérico de validação}

Nesta seção, é analisado um exemplo numérico de forma a validar o desempenho da formulação do MEC apresentada neste capítulo.

Será apresentada como exemplo a cavidade pressurizada em meio infinito como ilustrado na Figura 2-20, por ter resposta analítica apresentada nas equações a seguir:

$$
\begin{gathered}
\sigma_{\theta \theta}=\frac{p_{i} r_{i}^{2}}{r^{2}} \\
\sigma_{r r}=-\frac{p_{i} r_{i}^{2}}{r^{2}} \\
u_{r}=\frac{(1+v)}{E} \frac{p_{i} r_{i}^{2}}{r^{2}},
\end{gathered}
$$

como em Sadd (2005), sendo que, tal formulação é obtida a partir da solução analítica para um cilindro pressurizado, com a imposição da pressão externa igual a zero e o raio externo tendendo a infinito. Tal solução é dada em termos de deslocamentos radiais, tensões radiais e tensões circunferenciáis no ponto $A$. 


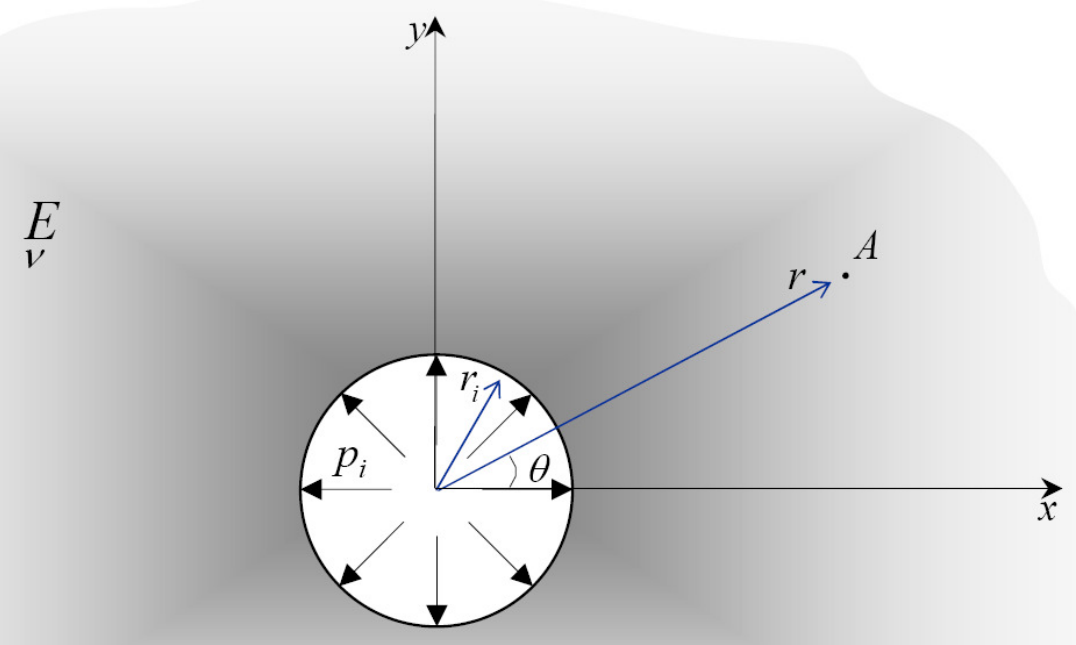

Figura 2-20 - Cavidade pressurizada em meio infinito, Kzam (2009).

Sendo que, foi feita uma análise em estado plano de deformações, com o Módulo de elasticidade do meio igual a $E=2,05 \times 10^{4} \mathrm{kN} . \mathrm{cm}^{2}$, o coeficiente de Poisson igual a $v=0.3$, a pressão interna igual a $p_{i}=100 \mathrm{kN} / \mathrm{cm}^{2}$ e o raio interno igual a $r_{i}=10 \mathrm{~m}$.

\subsubsection{Análise dos deslocamentos no contorno}

Analisando-se primeiramente os deslocamentos no contorno da cavidade, no gráfico da Figura 2-21, com uma malha de oito, dezesseis e trinta e dois elementos e variando o grau da aproximação de um até quatro, comparados com a resposta analítica. 


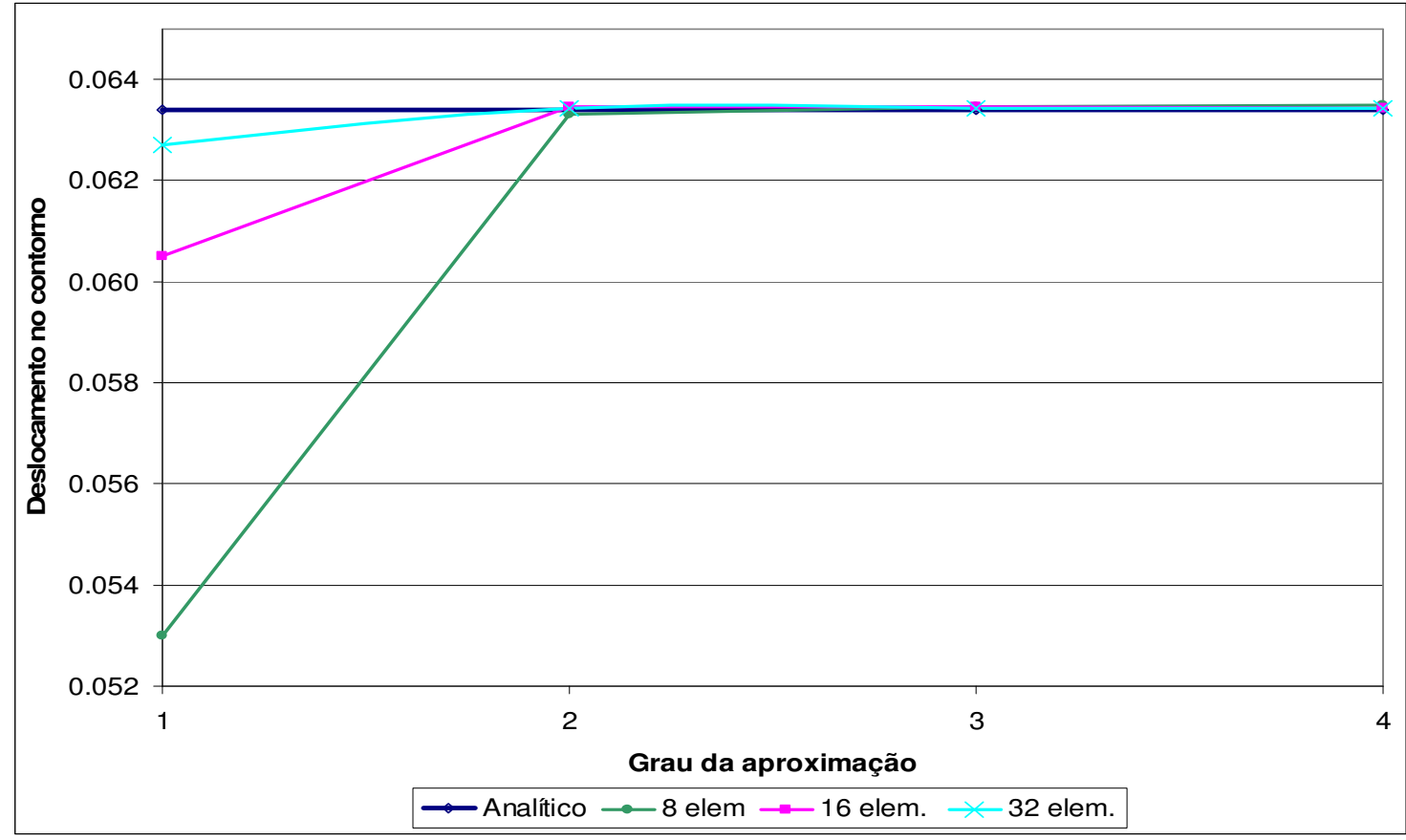

Figura 2-21 - Deslocamentos no contorno, para as malhas com 8, 16 e 32 elementos.

Considerando-se agora o erro relativo á solução analítica ocorrido nesta análise na Figura 2-22.

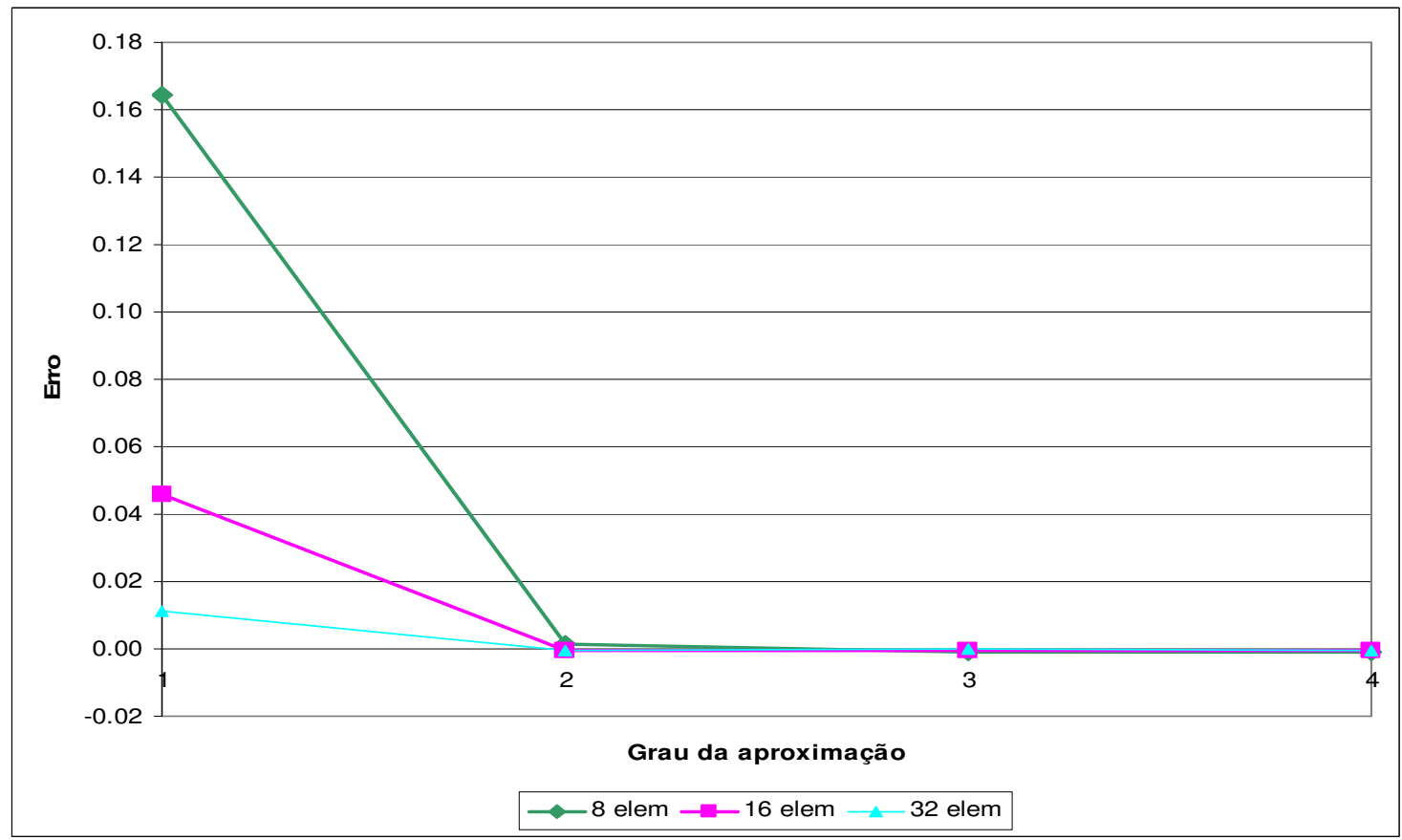

Figura 2-22 - Erro relativo no cálculo do deslocamento no contorno para as malhas com 8, 16 e 32 elementos. 


\subsubsection{Análise dos deslocamentos no domínio}

Analisando-se neste momento os deslocamentos no domínio (ou seja, no meio infinito), primeiramente um gráfico na Figura 2-23 com uma malha de oito elementos e variando o grau da aproximação de um até quatro. Sendo mostrado na Tabela 2-1 o erro relativo a esta discretização e variando o grau das aproximações de um a quatro, sendo que, na Figura 2-24 é apresentado o gráfico referente a este erro.

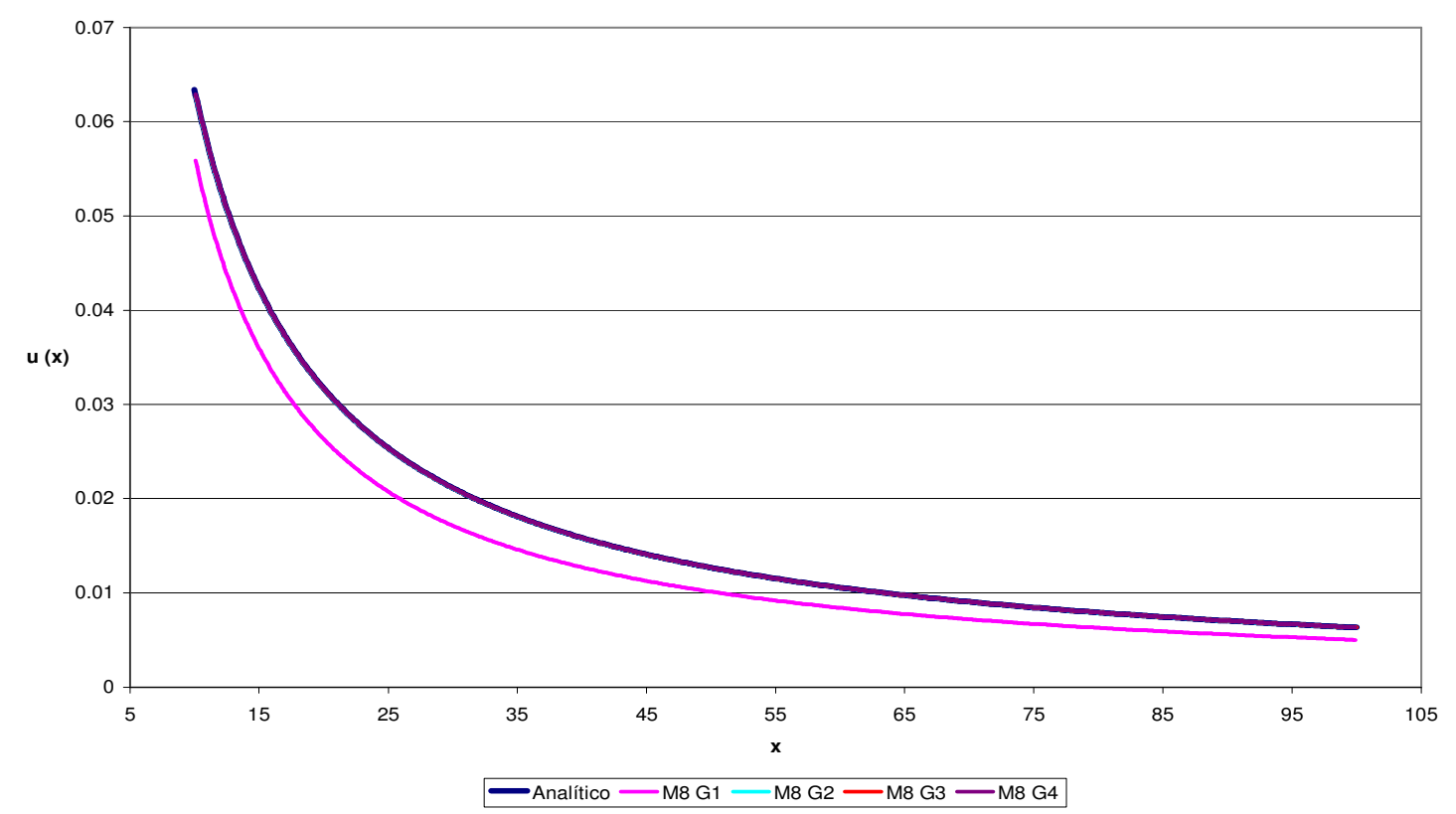

Figura 2-23 - Deslocamentos no domínio para a malha com 8 elementos.

Tabela 2-1 - Erro relativo no cálculo do deslocamento no domínio para a malha com 8 elementos.

\begin{tabular}{|c|ccccccccc|c|}
\hline Coord. & Analítico & M8 G1 & ERRO & M8 G2 & ERRO & M8 G3 & ERRO & M8 G4 & ERRO \\
\hline 10.10 & 0.062787 & 0.055920 & 0.109369 & 0.062673 & 0.001816 & & 0.062823 & -0.000571 & 0.062896 & -0.001740 \\
11.10 & 0.057130 & 0.050020 & 0.124466 & 0.057011 & 0.002093 & 0.057167 & -0.000636 & 0.057230 & -0.001753 \\
12.10 & 0.052409 & 0.045452 & 0.132742 & 0.052298 & 0.002107 & 0.052431 & -0.000422 & 0.052476 & -0.001287 \\
13.10 & 0.048408 & 0.041666 & 0.139278 & 0.048307 & 0.002095 & 0.048421 & -0.000264 & 0.048456 & -0.000979 \\
14.10 & 0.044975 & 0.038453 & 0.145017 & 0.044881 & 0.002083 & 0.044982 & -0.000159 & 0.045010 & -0.000775 \\
15.10 & 0.041996 & 0.035688 & 0.150222 & 0.041909 & 0.002075 & 0.042000 & -0.000086 & 0.042023 & -0.000634 \\
16.10 & 0.039388 & 0.033284 & 0.154973 & 0.039306 & 0.002069 & 0.039389 & -0.000032 & 0.039409 & -0.000531 \\
17.10 & 0.037085 & 0.031177 & 0.159302 & 0.037008 & 0.002067 & 0.037084 & 0.000010 & 0.037101 & -0.000453 \\
18.10 & 0.035036 & 0.029317 & 0.163233 & 0.034963 & 0.002065 & 0.035034 & 0.000045 & 0.035049 & -0.000391 \\
19.10 & 0.033201 & 0.027664 & 0.166793 & 0.033133 & 0.002065 & 0.033199 & 0.000074 & 0.033213 & -0.000342 \\
20.10 & 0.031550 & 0.026186 & 0.170010 & 0.031484 & 0.002065 & 0.031546 & 0.000099 & 0.031559 & -0.000301 \\
25.10 & 0.025265 & 0.020667 & 0.181992 & 0.025213 & 0.002069 & 0.025260 & 0.000190 & 0.025269 & -0.000172 \\
30.10 & 0.021068 & 0.017079 & 0.189357 & 0.021024 & 0.002073 & 0.021063 & 0.000245 & 0.021070 & -0.000102 \\
40.10 & 0.015814 & 0.012694 & 0.197304 & 0.015781 & 0.002078 & 0.015809 & 0.000304 & 0.015815 & -0.000032 \\
50.10 & 0.012658 & 0.010111 & 0.201196 & 0.012631 & 0.002081 & 0.012653 & 0.000333 & 0.012658 & 0.000002 \\
70.10 & 0.009046 & 0.007195 & 0.204697 & 0.009027 & 0.002084 & 0.009043 & 0.000360 & 0.009046 & 0.000033 \\
90.10 & 0.007038 & 0.005587 & 0.206168 & 0.007024 & 0.002085 & 0.007036 & 0.000371 & 0.007038 & 0.000046 \\
\hline
\end{tabular}




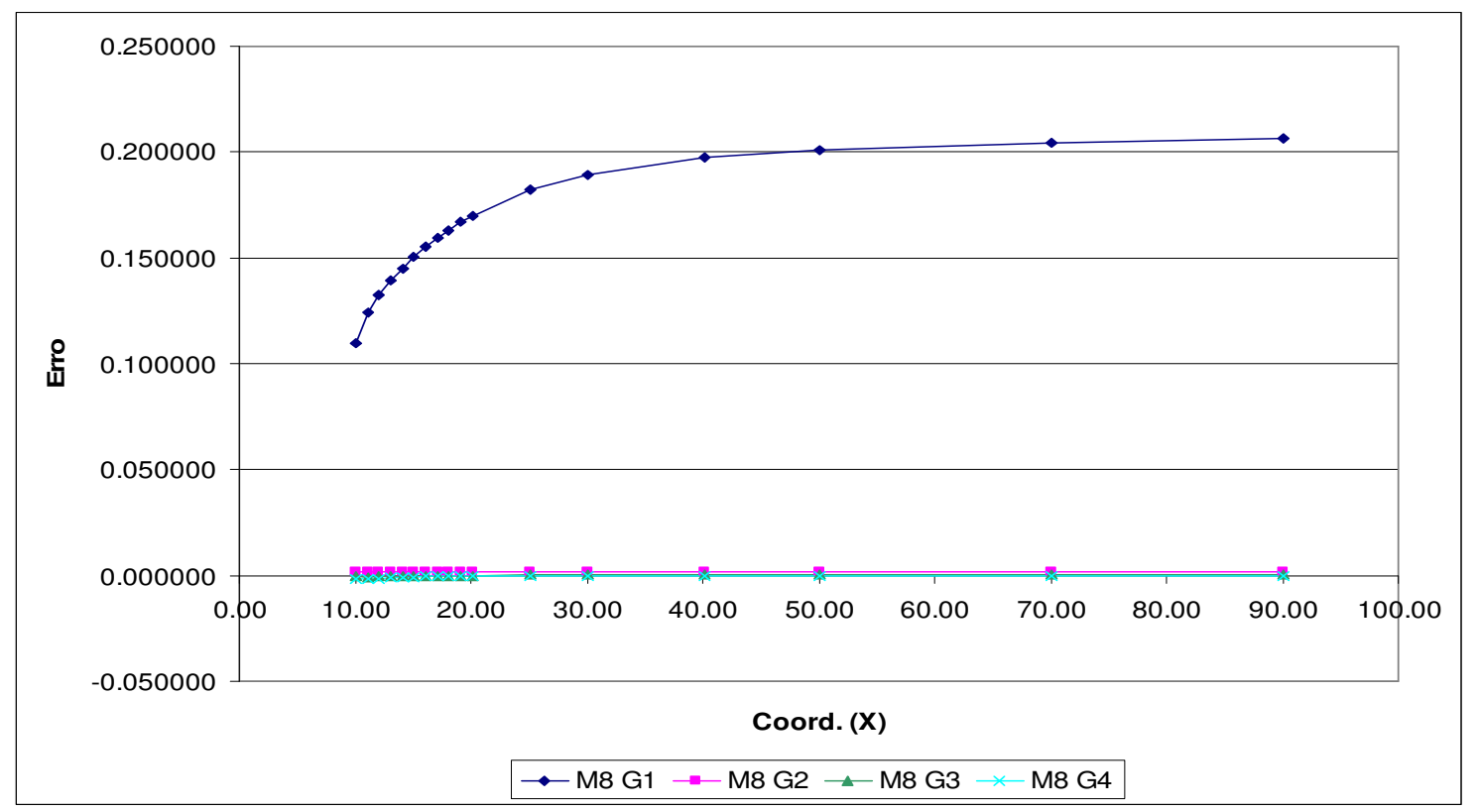

Figura 2-24 - Erro relativo no cálculo dos deslocamentos no domínio para a malha com 8 elementos.

Agora aumentando-se o número de elementos para dezesseis e variando-se o grau da aproximação de um até quatro, apresentado na Figura 2-25. E é mostrado na Tabela 2-2 o erro relativo a esta discretização e variando-se o grau das aproximações de um a quatro, sendo que, na Figura 2-26 é apresentado o gráfico relativo a este erro.

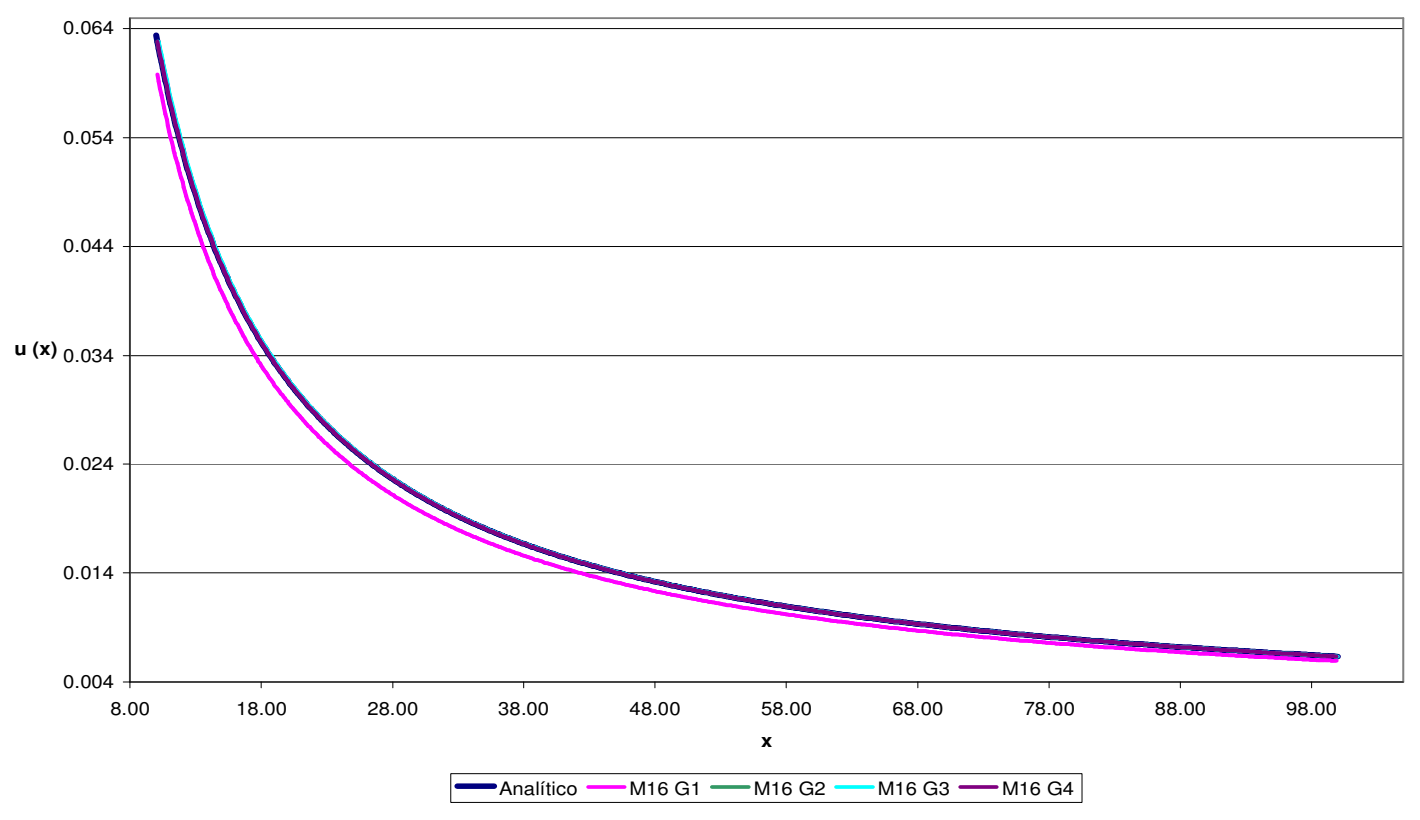

Figura 2-25 - Deslocamentos no domínio para a malha com 16 elementos. 
Tabela 2-2 - Erro relativo no cálculo do deslocamento no domínio para a malha com 16 elementos.

\begin{tabular}{|c|c|c|c|c|c|c|c|c|c|}
\hline Coord. & Analítico & M16 G1 & ERRO & M16 G2 & ERRO & M16 G3 & ERRO & M16 G4 & ERRO \\
\hline 10.10 & 0.062787 & 0.059804 & 0.047502 & 0.062862 & -0.001204 & 0.062852 & -0.001044 & 0.062841 & -0.000857 \\
\hline 11.10 & 0.057130 & 0.054072 & 0.053527 & 0.057204 & -0.001289 & 0.057185 & -0.000955 & 0.057158 & -0.000477 \\
\hline 12.10 & 0.052409 & 0.049478 & 0.055927 & 0.052453 & -0.000844 & 0.052442 & -0.000641 & 0.052417 & -0.000155 \\
\hline 13.10 & 0.048408 & 0.045631 & 0.057364 & 0.048435 & -0.000555 & 0.048429 & -0.000429 & 0.048408 & 0.000006 \\
\hline 14.10 & 0.044975 & 0.042348 & 0.058413 & 0.044992 & -0.000376 & 0.044987 & -0.000273 & 0.044971 & 0.000093 \\
\hline 15.10 & 0.041996 & 0.039508 & 0.059258 & 0.042007 & -0.000263 & 0.042003 & -0.000154 & 0.041990 & 0.000145 \\
\hline 16.10 & 0.039388 & 0.037026 & 0.059973 & 0.039395 & -0.000187 & 0.039390 & -0.000059 & 0.039381 & 0.000177 \\
\hline 17.10 & 0.037085 & 0.034838 & 0.060590 & 0.037090 & -0.000135 & 0.037084 & 0.000019 & 0.037077 & 0.000198 \\
\hline 18.10 & 0.035036 & 0.032894 & 0.061128 & 0.035039 & -0.000097 & 0.035033 & 0.000084 & 0.035028 & 0.000212 \\
\hline 19.10 & 0.033201 & 0.031156 & 0.061600 & 0.033204 & -0.000069 & 0.033197 & 0.000139 & 0.033194 & 0.000223 \\
\hline 20.10 & 0.031550 & 0.029593 & 0.062018 & 0.031551 & -0.000048 & 0.031544 & 0.000186 & 0.031542 & 0.000230 \\
\hline 25.10 & 0.025265 & 0.023660 & 0.063513 & 0.025265 & 0.000012 & 0.025256 & 0.000346 & 0.025259 & 0.000248 \\
\hline 30.10 & 0.021068 & 0.019711 & 0.064402 & 0.021067 & 0.000038 & 0.021059 & 0.000437 & 0.021063 & 0.000254 \\
\hline 40.10 & 0.015814 & 0.014781 & 0.065349 & 0.015813 & 0.000062 & 0.015806 & 0.000532 & 0.015810 & 0.000259 \\
\hline 50.10 & 0.012658 & 0.011825 & 0.065811 & 0.012657 & 0.000073 & 0.012650 & 0.000578 & 0.012654 & 0.000261 \\
\hline 70.10 & 0.009046 & 0.008447 & 0.066226 & 0.009046 & 0.000083 & 0.009041 & 0.000619 & 0.009044 & 0.000262 \\
\hline 90.10 & 0.007038 & 0.006571 & 0.066401 & 0.007038 & 0.000087 & 0.007034 & 0.000636 & 0.007036 & 0.000263 \\
\hline
\end{tabular}

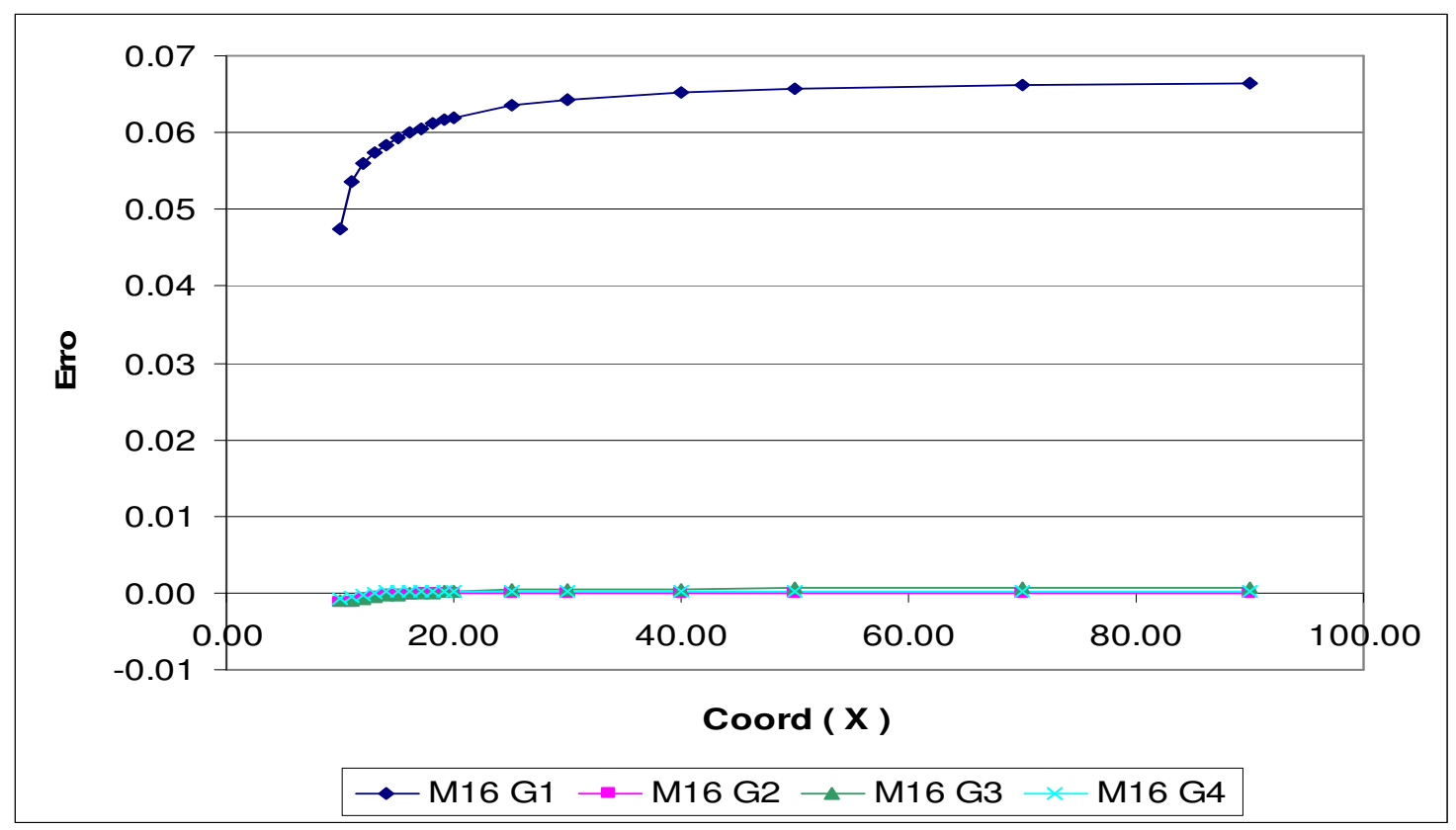

Figura 2-26 - Erro relativo no cálculo dos deslocamentos no domínio para a malha com 16 elementos.

Agora aumentando-se novamente o número de elementos para trinta e dois e variando-se o grau da aproximação de um até quatro, apresentado na Figura 2-27. E é mostrado na Tabela 2-3 o erro relativo a esta discretização e variando-se o grau das aproximações de um a quatro, sendo que, na Figura 2-28 é apresentado o gráfico relativo a este erro. 


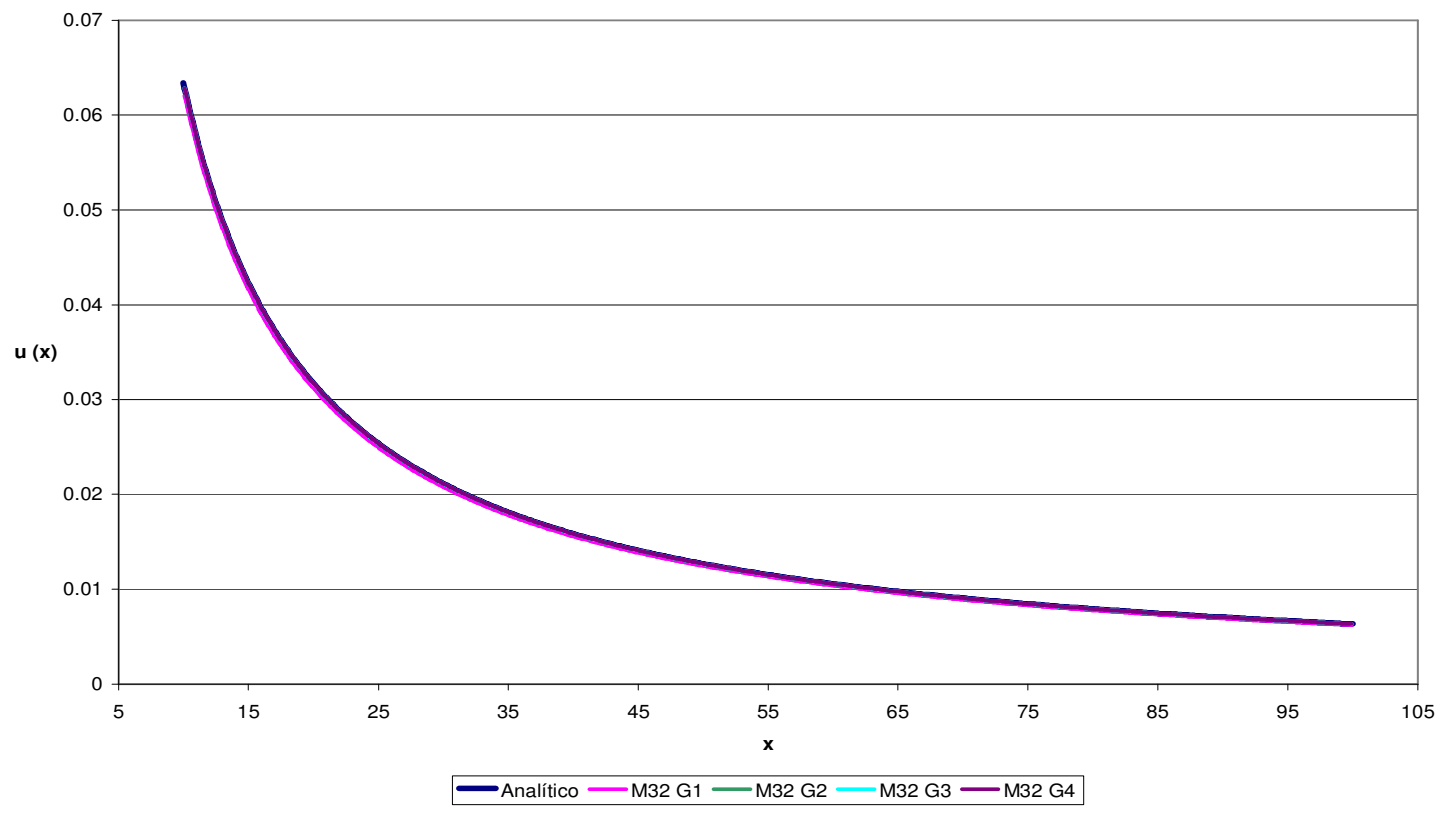

Figura 2-27 - Deslocamentos no domínio para a malha com 32 elementos.

Tabela 2-3 - Erro relativo no cálculo do deslocamento no domínio para a malha com 32 elementos.

\begin{tabular}{|c|c|cccccccc|c|}
\hline Coord. & Analítico & M32 G1 & ERRO & M32 G2 & ERRO & M32 G3 & ERRO & M32 G4 & ERRO \\
\hline 10.10 & 0.062787 & 0.062065 & 0.011498 & 0.062832 & -0.000722 & & 0.062818 & -0.000501 & 0.062831 & -0.000698 \\
11.10 & 0.057130 & 0.056382 & 0.013099 & 0.057153 & -0.000392 & 0.057143 & -0.000218 & 0.057153 & -0.000401 \\
12.10 & 0.052409 & 0.051685 & 0.013817 & 0.052418 & -0.000167 & 0.052416 & -0.000131 & 0.052429 & -0.000381 \\
13.10 & 0.048408 & 0.047715 & 0.014321 & 0.048412 & -0.000083 & 0.048412 & -0.000073 & 0.048426 & -0.000373 \\
14.10 & 0.044975 & 0.044314 & 0.014703 & 0.044977 & -0.000046 & 0.044976 & -0.000029 & 0.044991 & -0.000366 \\
15.10 & 0.041996 & 0.041366 & 0.015002 & 0.041998 & -0.000028 & 0.041996 & 0.000005 & 0.042012 & -0.000361 \\
16.10 & 0.039388 & 0.038788 & 0.015243 & 0.039389 & -0.000017 & 0.039387 & 0.000031 & 0.039402 & -0.000357 \\
17.10 & 0.037085 & 0.036512 & 0.015440 & 0.037085 & -0.000010 & 0.037083 & 0.000051 & 0.037098 & -0.000355 \\
18.10 & 0.035036 & 0.034489 & 0.015606 & 0.035036 & -0.000005 & 0.035033 & 0.000068 & 0.035048 & -0.000353 \\
19.10 & 0.033201 & 0.032679 & 0.015746 & 0.033201 & -0.000002 & 0.033199 & 0.000082 & 0.033213 & -0.000352 \\
20.10 & 0.031550 & 0.031049 & 0.015867 & 0.031550 & 0.000000 & 0.031547 & 0.000093 & 0.031561 & -0.000351 \\
25.10 & 0.025265 & 0.024853 & 0.016281 & 0.025265 & 0.000007 & 0.025261 & 0.000131 & 0.025274 & -0.000349 \\
30.10 & 0.021068 & 0.020720 & 0.016518 & 0.021068 & 0.000009 & 0.021065 & 0.000152 & 0.021075 & -0.000349 \\
40.10 & 0.015814 & 0.015549 & 0.016767 & 0.015814 & 0.000012 & 0.015811 & 0.000173 & 0.015820 & -0.000349 \\
50.10 & 0.012658 & 0.012444 & 0.016887 & 0.012657 & 0.000013 & 0.012655 & 0.000183 & 0.012662 & -0.000350 \\
70.10 & 0.009046 & 0.008893 & 0.016995 & 0.009046 & 0.000014 & 0.009045 & 0.000191 & 0.009049 & -0.000350 \\
90.10 & 0.007038 & 0.006918 & 0.017041 & 0.007038 & 0.000014 & 0.007037 & 0.000195 & 0.007041 & -0.000350 \\
\hline
\end{tabular}




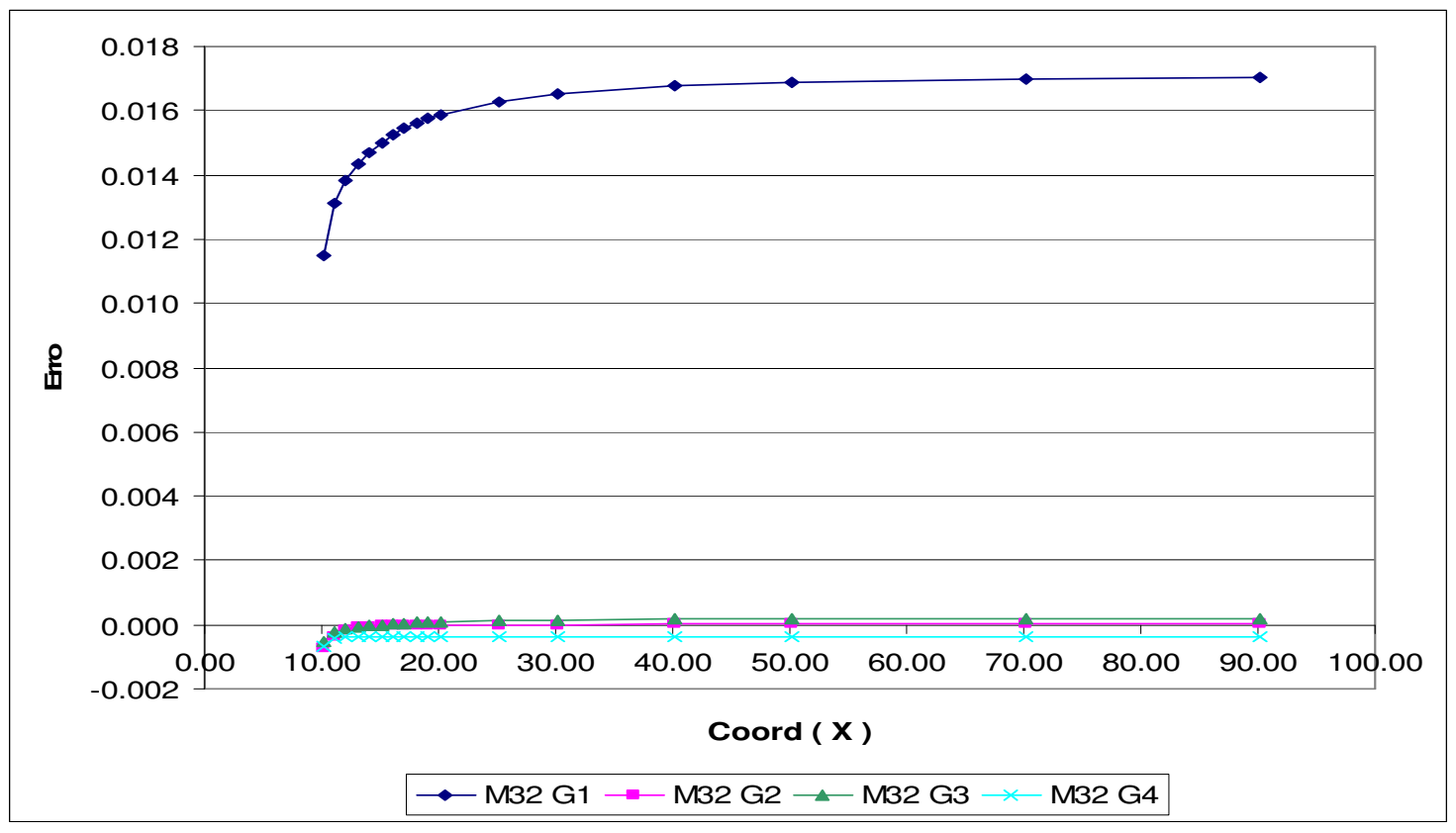

Figura 2-28 - Erro relativo no cálculo dos deslocamentos no domínio para a malha com 32 elementos.

\subsubsection{Análise das tensões para os pontos do domínio}

Analisando-se agora a tensão no domínio (ou seja, no meio infinito), primeiramente obtendo-se um gráfico na Figura 2-29 com uma malha de oito elementos e variando-se o grau da aproximação de um até quatro. 


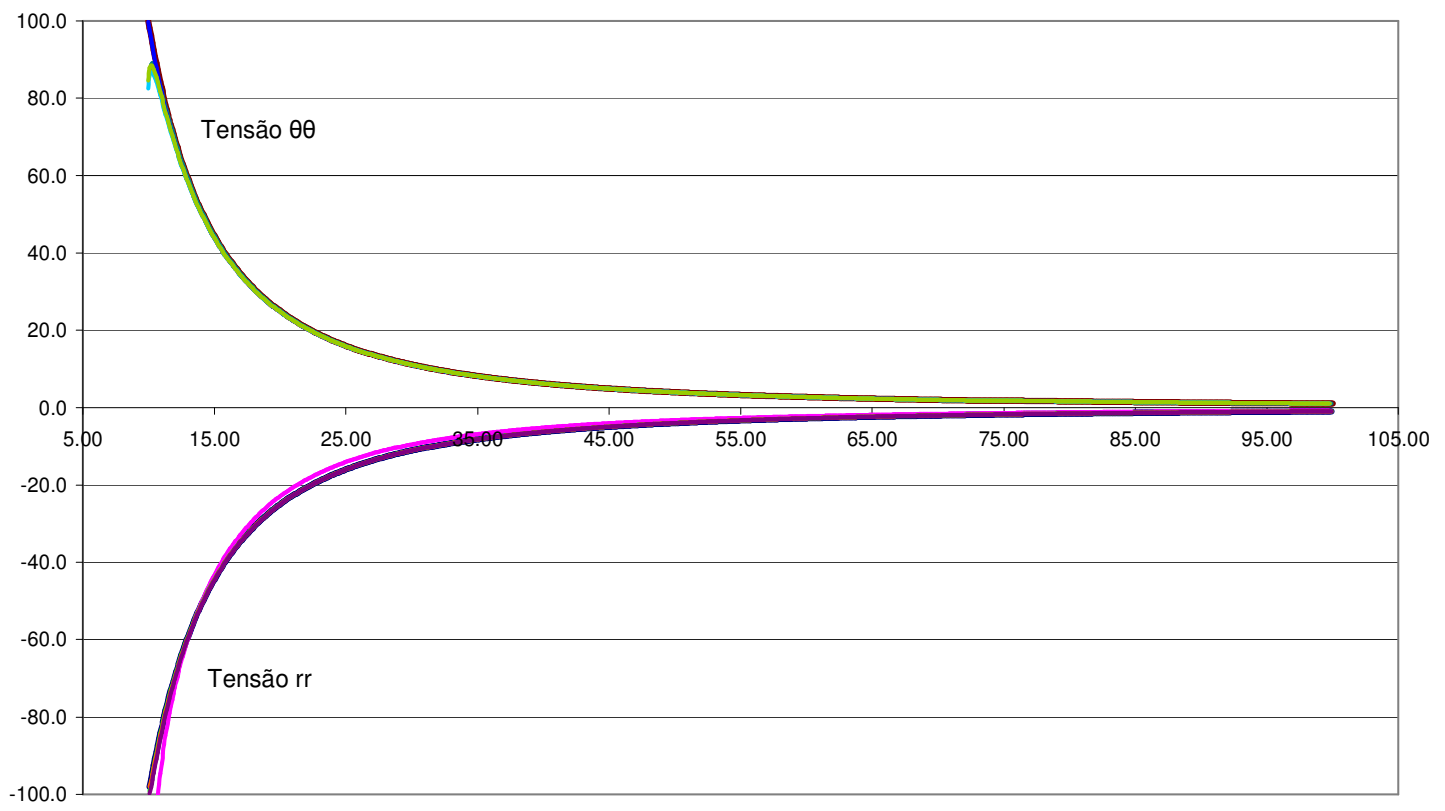

-Analítico $\mathrm{rr}-\mathrm{M} 8 \mathrm{G} 1-\mathrm{M} 8 \mathrm{G} 2-\mathrm{M} 8 \mathrm{G} 3-\mathrm{M} 8 \mathrm{G} 4-$ Analítico $\theta \theta-\mathrm{M} 8 \mathrm{G} 1 \theta \theta-\mathrm{M} 8 \mathrm{G} 2 \theta \theta-\mathrm{M} 8 \mathrm{G} 3 \theta \theta-\mathrm{M} 8 \mathrm{G} 4 \theta \theta$

Figura 2-29 - Tensões no domínio para a malha com 8 elementos.

Agora aumentando-se o número de elementos para dezesseis e variando-se o grau da aproximação de um até quatro, apresentado na Figura 2-30.

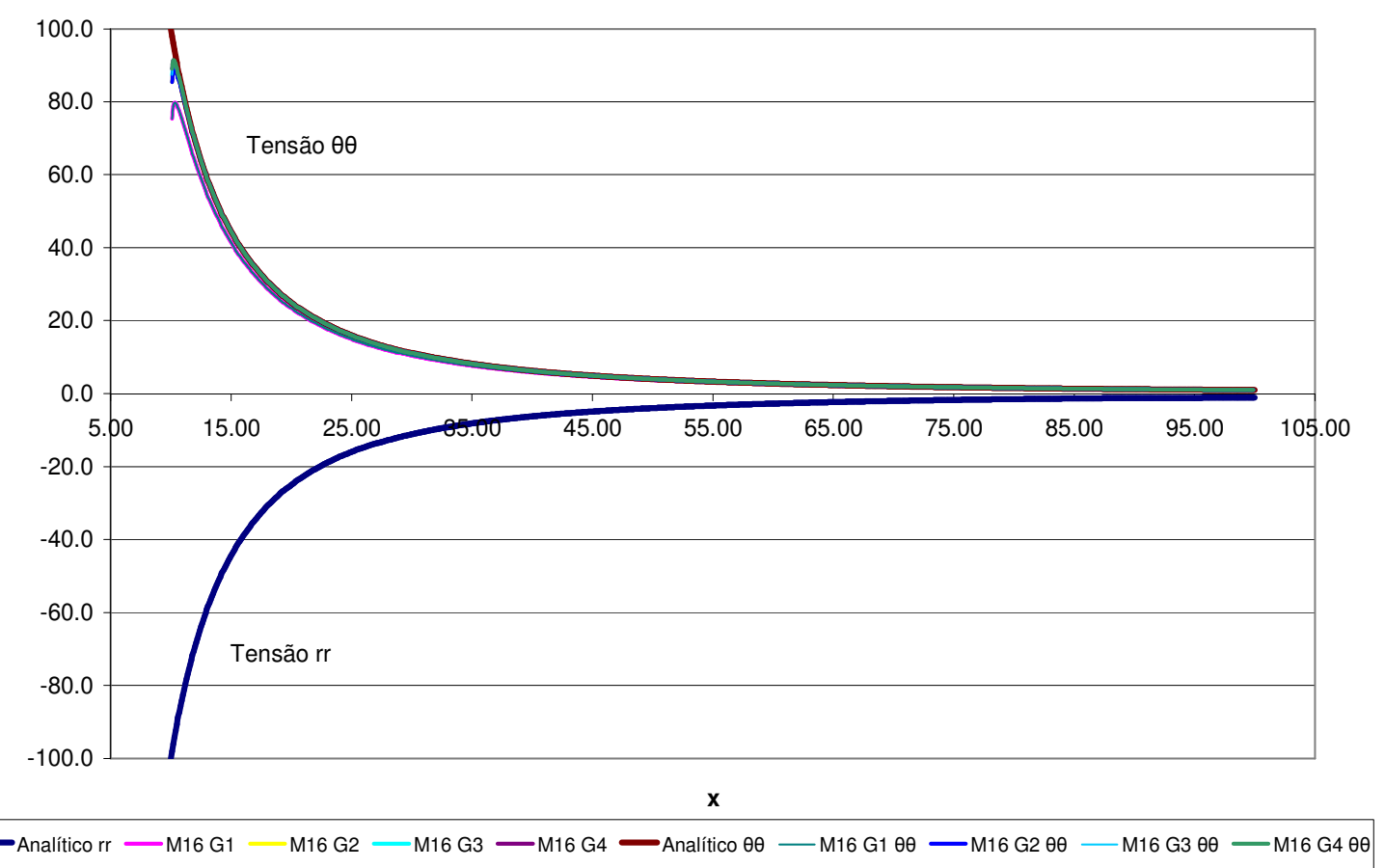

Figura 2-30 - Tensões no domínio para a malha com 16 elementos. 
Agora aumentando-se novamente o número de elementos para trinta e dois e variando-se o grau da aproximação de um até quatro, apresentado na Figura 2-31.

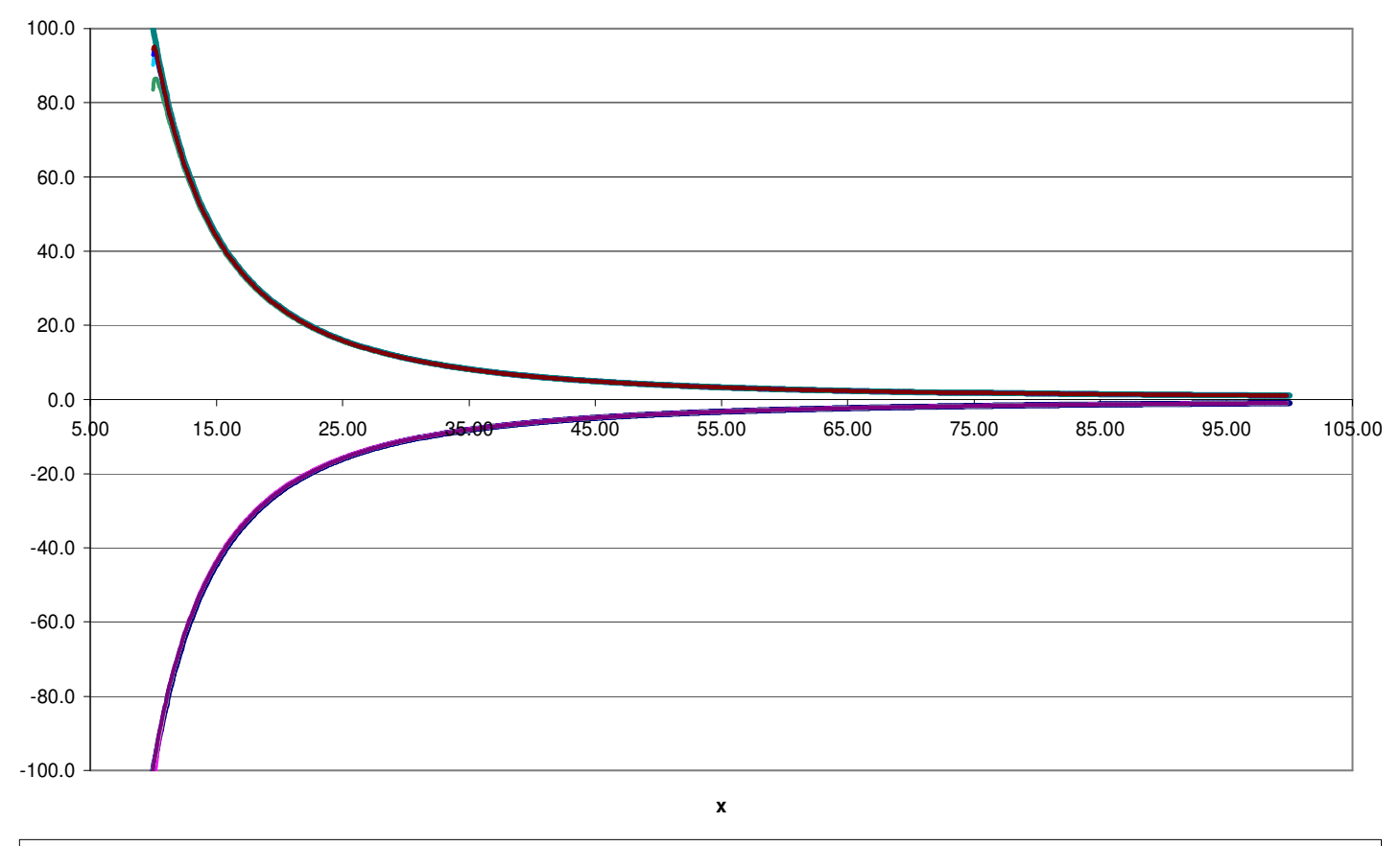

Figura 2-31 - Tensões no domínio para a malha com 32 elementos. 


\section{MÉTODO DOS ELEMENTOS DE CONTORNO 3-D}

É apresentada neste capítulo uma breve teoria a cerca da formulação do método dos elementos de contorno tridimensional e as principais mudanças com relação ao já apresentado na formulação bidimensional. Grande parte da teoria escrita neste capítulo, bem como o programa utilizado neste trabalho, foi retirada de Coda (1993).

\subsection{Solução Fundamental}

Para formular o problema 3-D muda-se inicialmente a solução fundamental de Kelvin que agora passa a ser dada por (Brebbia et al, 1984), como:

$$
u_{i j}=-\frac{1}{16 \pi G(1-v) \mu r}\left\{(3-4 v) \delta_{i j}-r_{, i} r_{j}\right\}
$$

que é o deslocamento em um ponto do domínio infinito devido à carga unitária aplicada no ponto fonte.

A solução fundamental das forças de superfície é agora dada por:

$$
p_{i j}=-\frac{1}{8 \pi(1-v) r^{2}}\left\{(1-2 v)\left[r_{, j} n_{i}-r_{, i} n_{j}\right]+\left[(1-2 v) \delta_{i j}+3 r_{, i} r_{, j}\right] \frac{\partial r}{\partial n}\right\}
$$




\subsection{Equações integrais de Contorno}

Como no caso bidimensional a equação (2.55) é transformada para sua forma algébrica dividindo-se o contorno $\Gamma$ em elementos e aproximando os valores de contorno sobre eles. Para o caso tridimensional, esse contorno é uma superfície. No caso, foram usadas funções interpoladoras do segundo grau, como será apresentado a seguir.

Como para o MEC bidimensional aqui também foi utilizada a técnica do movimento de corpo rígido para o cálculo dos termos do lado esquerdo da igualdade (2.70). Como as análises realizadas aqui se tratavam de domínios infinitos, a soma dos termos que multiplicam os deslocamentos, em cada direção é igual a zero a não ser na diagonal principal, que é igual a um.

\subsubsection{Elemento quadrático}

Nesta seção são descritas as aproximações da geometria e das variáveis físicas do problema para cada elemento utilizado.

\section{a) Aproximação da geometria}

O elemento utilizado é composto por oito nós, estes nós não precisam necessariamente pertencer a um mesmo plano, porém devem estar contidos na superfície do corpo, Figura 3-1.

Conhecidas as coordenadas destes oito nós, as coordenadas de um ponto qualquer, pertencente ao elemento, são dadas por:

$$
x_{i}=\phi_{k}(r, s) x_{i}^{k} \quad, \quad(i=1,2,3) \text { e }(k=1, \ldots, 8)
$$

com: 


$$
\begin{aligned}
& \phi_{1}=\frac{1}{4}(1-r)(1-s)(-r-s-1) \\
& \phi_{2}=\frac{1}{4}(1+r)(1-s)(r-s-1) \\
& \phi_{3}=\frac{1}{4}(1+r)(1+s)(r+s-1) \\
& \phi_{4}=\frac{1}{4}(1-r)(1+s)(-r+s-1) \\
& \phi_{5}=\frac{1}{2}\left(1-r^{2}\right)(1-s) \\
& \phi_{6}=\frac{1}{2}\left(1-s^{2}\right)(1+r) \\
& \phi_{7}=\frac{1}{2}\left(1-r^{2}\right)(1+s) \\
& \phi_{6}=\frac{1}{2}\left(1-s^{2}\right)(1-r)
\end{aligned}
$$
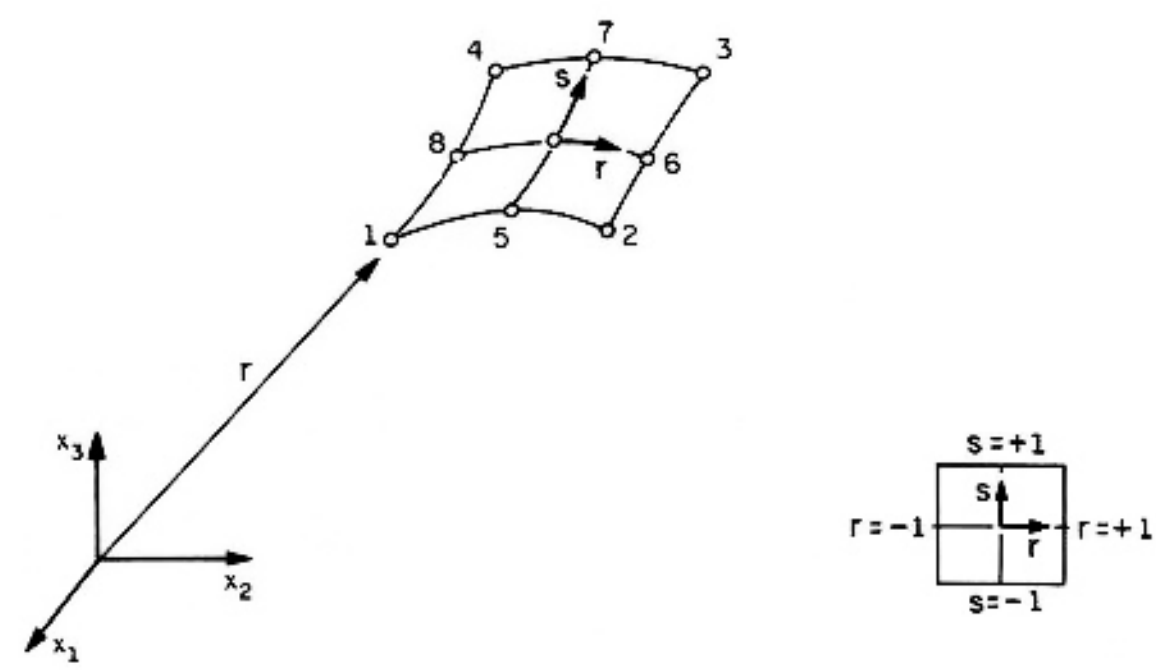

Figura 3-1 - Definição geométrica do elemento quadrático e coordenadas homogêneas.

\section{b) Aproximação das variáveis}

As variáveis físicas ( $u$ e p) são interpoladas sobre o elemento $r_{j}$ da mesma forma que a geometria. Assim, para um ponto s qualquer do elemento, tem-se: 


$$
\begin{aligned}
& u_{i}=\phi_{k}(r, s) u_{i}^{k} \\
& p_{i}=\phi_{k}(r, s) p_{i}^{k}
\end{aligned} \quad(i=1,2,3) \text { e }(k-1,2, \ldots, 8)
$$

A Figura 3-2 mostra algumas funções de forma para o elemento quadrático.
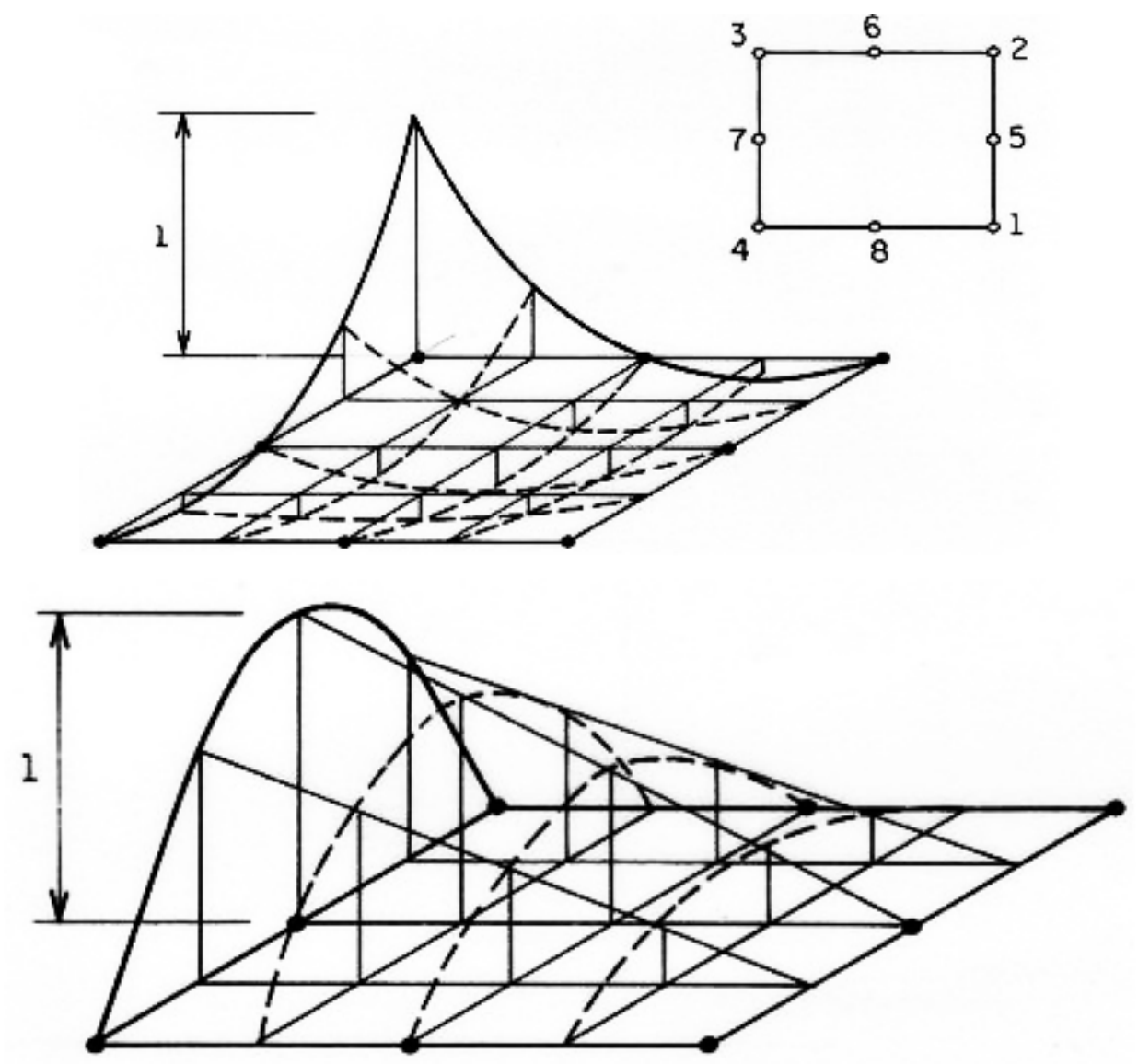

Figura 3-2 - Aproximação de variáveis sobre o elemento quadrático, Coda (1993).

Apesar de o elemento quadrático representar melhor geometrias complexas Figura 3-1, como neste trabalho a preocupação central é a discretização da superfície do solo, adota-se o elemento quadrático plano assumindo pontos nodais coplanares. Desta forma, pode-se adotar como aproximação da geometria as funções interpoladoras do elemento linear. 


\section{c) Relação entre coordenadas globais e homogêneas}

Já foram definidas as funções que levam das coordenadas adimensionais $(r, s)$ para as globais $\left(x_{1}, x_{2}, x_{3}\right)$. Porém, para que se aplique uma integração sobre um domínio transformado, precisa-se conhecer o Jacobiano de tal transformação, que irá fornecer a magnitude da alteração de área ocorrida ao se efetuar a mesma.

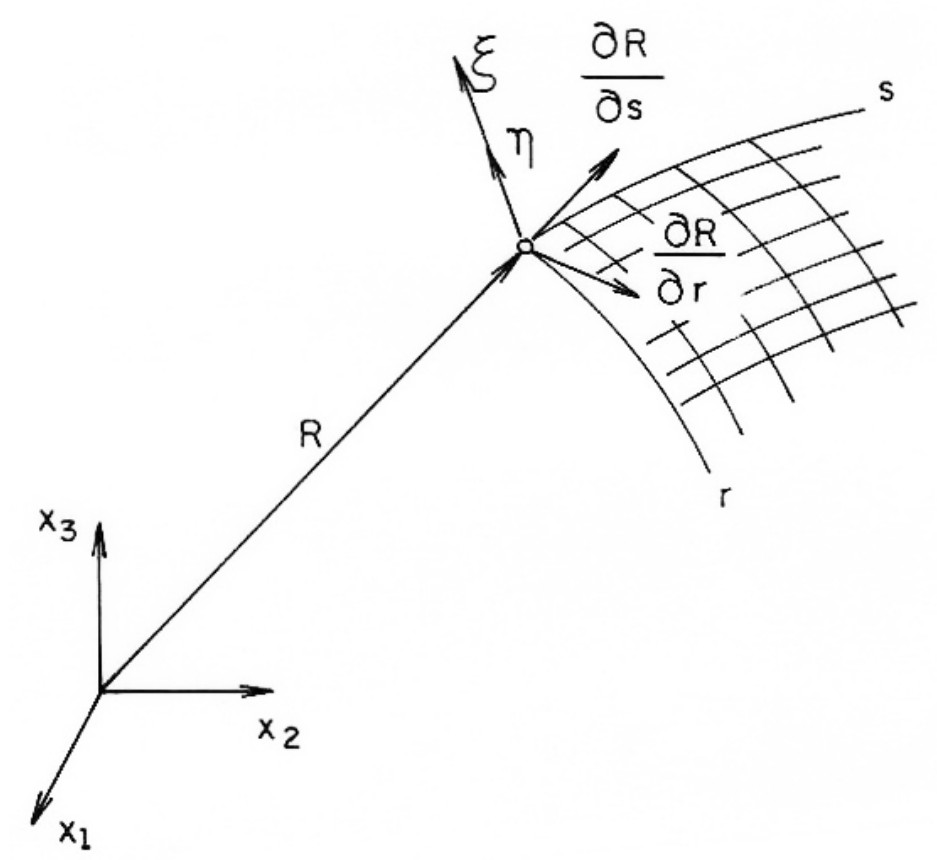

Figura 3-3 - Sistemas de coordenadas, Coda (1993).

Pela regra da cadeia, escrevem-se as derivadas de u como:

$$
\left\{\begin{array}{l}
\frac{\partial u}{\partial r} \\
\frac{\partial u}{\partial s}
\end{array}\right\}^{s}=\left[\begin{array}{lll}
\frac{\partial x_{1}}{\partial r} & \frac{\partial x_{2}}{\partial r} & \frac{\partial x_{3}}{\partial r} \\
\frac{\partial x_{1}}{\partial s} & \frac{\partial x_{2}}{\partial s} & \frac{\partial x_{3}}{\partial s}
\end{array}\right]\left\{\begin{array}{l}
\frac{\partial u}{\partial x_{1}} \\
\frac{\partial u}{\partial x_{2}} \\
\frac{\partial u}{\partial x_{3}}
\end{array}\right\}
$$

O diferencial de área sobre a superfície é igual ao módulo do vetor normal ( $\xi$ ) ao plano, que é definido pela transformação apresentada na equação (3.6), 


$$
\operatorname{det}(J(r, s))=\left|g_{1}, g_{2}, g_{3}\right|=\left(g_{1}^{2}+g_{2}^{2}+g_{3}^{2}\right)^{1 / 2}
$$

onde:

$$
\begin{aligned}
& g_{1}=\frac{\partial x_{2}}{\partial r} \frac{\partial x_{3}}{\partial s}-\frac{\partial x_{3}}{\partial r} \frac{\partial x_{2}}{\partial s} \\
& g_{2}=\frac{\partial x_{1}}{\partial s} \frac{\partial x_{3}}{\partial r}-\frac{\partial x_{3}}{\partial s} \frac{\partial x_{1}}{\partial r} \\
& g_{3}=\frac{\partial x_{1}}{\partial r} \frac{\partial x_{2}}{\partial s}-\frac{\partial x_{2}}{\partial r} \frac{\partial x_{1}}{\partial s}
\end{aligned}
$$

\subsection{Discretização Utilizada}

$\mathrm{Na}$ discretização do túnel, foi utilizada uma malha do MEC com 969 elementos e 3003 nós no contorno do túnel, como apresentada na Figura 3-4. Tal malha será usada no capítulo 6 para a obtenção das curvas de deslocamento radial do túnel na análise da frente de escavação. 


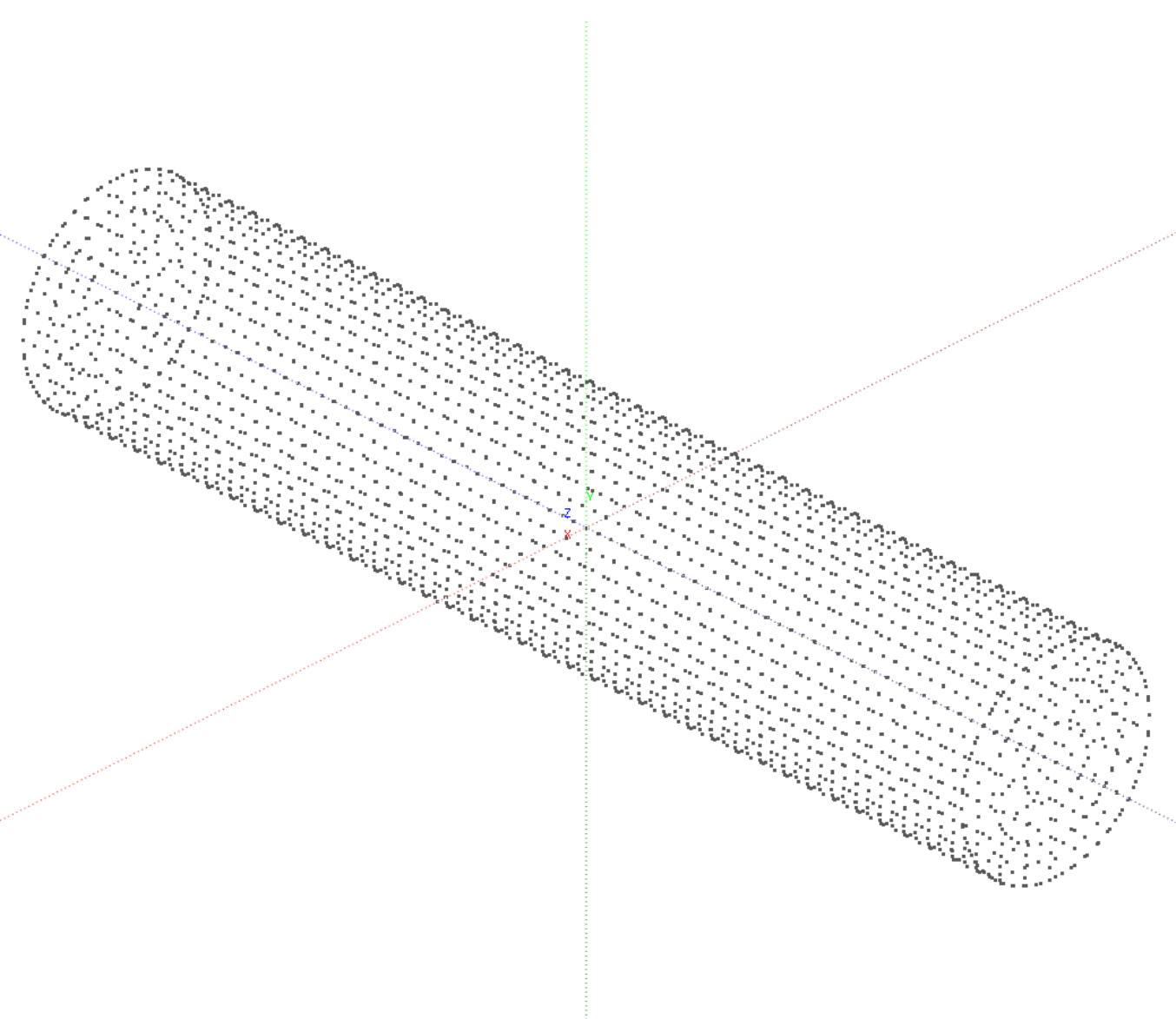

Figura 3-4 - Malha de elementos de contorno utilizada. 



\section{FORMULAÇÃO DO MÉTODO DOS ELEMENTOS DE CONTORNO PARA DOMÍNIOS BIDIMENSIONAIS COM A PRESENÇA DE ENRIJECEDORES}

Neste capítulo será apresentada a formulação integral utilizada para a resolução de domínios enrijecidos utilizando-se apenas MEC.

Tal formulação foi desenvolvida introduzindo-se um termo de domínio adicional em tensões iniciais para a correção da rigidez. A correção da rigidez foi escrita em termos de forças normais e momentos fletores corretivos a partir de uma aproximação conveniente do campo de deformações. As equações adicionais para a simulação do suporte foram escritas sobre o eixo do mesmo em termos de deslocamentos e rotações.

\subsection{Formulação do MEC enrijecido}

A maneira clássica de se tratar problemas compostos por mais de uma região, é através da técnica das sub-regiões, onde a compatibilidade dos deslocamentos e o equilíbrio de forças de superfície ao longo da interface são impostos em nível de equações algébricas. É apresentada a seguir uma forma alternativa na resolução destes problemas a partir do emprego da formulação do método dos elementos de contorno com campos de tensões iniciais.

Considere-se um domínio qualquer $\Omega$ enrijecido, finito e isotrópico como é apresentado na Figura 4-1. 


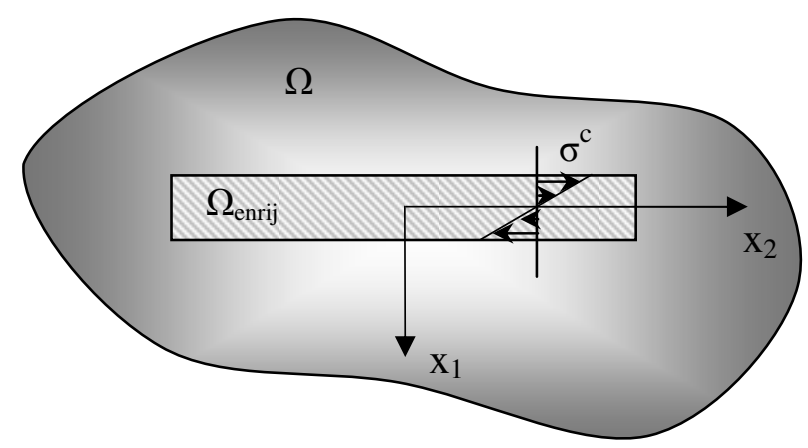

Figura 4-1 - Domínio $\Omega$ enrijecido.

Tendo como base o principio da reciprocidade de Betti apresentado na equação (4.1) a seguir:

$$
\int_{\Omega} \sigma_{j k} \varepsilon_{i j k}^{*} d \Omega=\int_{\Omega} \sigma_{i j k}^{*} \varepsilon_{j k} d \Omega
$$

assumindo-se $\Omega_{\text {enrij }}$ como um sub-domínio que tem rigidez diferente do domínio principal $\Omega$, pode-se definir uma relação entre a tensão elástica $\sigma_{j k}^{e}$, a tensão corretora $\sigma_{j k}^{c}$ e a tensão real $\sigma_{j k}$, como apresentado na equação (4.2) e ilustrado na Figura 4-2.

$$
\sigma_{j k}=\sigma_{j k}^{e}+\sigma_{j k}^{c}
$$

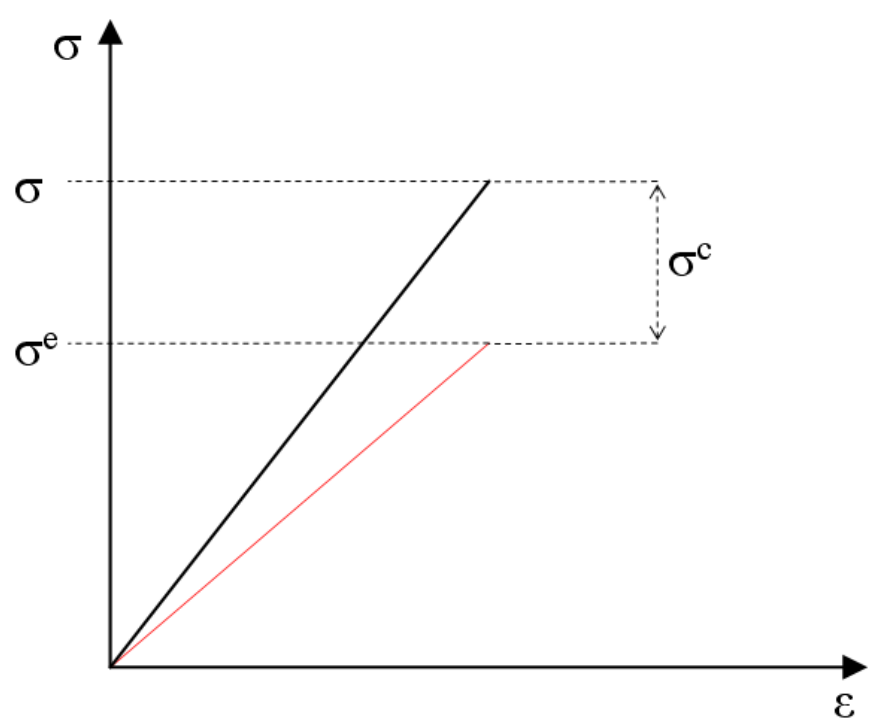

Figura 4-2 - Gráfico tensão deformação do sistema enrijecido. 
Admite-se que as componentes de tensões reais $\sigma_{j k}$ sejam vistas como uma componente de enrijecimento das tensões elásticas do material $\sigma_{j k}^{e}$, expressas sob a forma:

$$
\sigma_{j k}=\psi \sigma_{j k}^{e}
$$

onde $\psi$ para o caso de material isotrópico, é uma constante que enrijece (ou penaliza) as tensões elásticas de um material isotrópico utilizado como referência, corrigindo-as para as tensões reais no qual estaria submetido o material desejado. Substituindo-se (4.3) em (4.2), tem-se:

$$
\sigma_{j k}^{c}=(\psi-1) \sigma_{j k}^{e}
$$

Definida a relação aditiva de tensões e considerando-se o campo de tensões corretoras $\sigma_{j k}^{c}$ atuando no domínio do enrijecedor, o teorema de Betti pode ser reescrito como na equação (4.5).

$$
\int_{\Omega} \sigma_{j k} \varepsilon_{i j k}^{*} d \Omega-\int_{\Omega_{e n r i j}} \sigma_{j k}^{c} \varepsilon_{i j k}^{*} d \Omega_{e n r i j}=\int_{\Omega} \sigma_{i j k}^{*} \varepsilon_{j k} d \Omega
$$

Reescrevendo-se a equação (4.5) em função dos deslocamentos, tem-se:

$$
\int_{\Omega} \sigma_{j k} u_{i j, k}^{*} d \Omega-\int_{\Omega_{e n r i j}} \sigma_{j k}^{c} u_{i j, k}^{*} d \Omega_{e n r i j}=\int_{\Omega} \sigma_{i j k}^{*} u_{j, k} d \Omega
$$

aplicando-se o Teorema da Divergência aos termos do domínio $\Omega$,tem-se:

$$
\int_{\Gamma} \sigma_{j k} u_{i j}^{*} \eta_{\mathrm{k}} d \Gamma-\int_{\Omega} \sigma_{j k, k} u_{i j}^{*} d \Omega-\int_{\Omega_{e n r i j}} \sigma_{j k}^{c} u_{i j, k}^{*} d \Omega_{e n r i j}=\int_{\Gamma} \sigma_{i j k}^{*} u_{j} \eta_{\mathrm{k}} d \Gamma-\int_{\Omega} \sigma_{i j k, k}^{*} u_{j} \eta_{\mathrm{k}} d \Omega,(4.7
$$

Tendo-se em vista a equação de equilíbrio (2.8) e desconsiderando-se as forças de corpo, pode-se reescrever a equação (4.7) como segue: 


$$
\int_{\Gamma} \sigma_{j k} u_{i j}^{*} \eta_{\mathrm{k}} d \Gamma=\int_{\Gamma} \sigma_{i j k}^{*} u_{j} \eta_{\mathrm{k}} d \Gamma+\int_{\Omega_{e n r j}} \sigma_{j k}^{c} u_{i j, k}^{*} d \Omega_{e n r i j},
$$

levando-se em consideração a condição de contorno de Cauchy (2.10), tem-se:

$$
C_{i j} \mathrm{u}_{\mathrm{j}}+\int_{\Gamma} p_{i j}^{*} u_{j} d \Gamma=\int_{\Gamma} p_{j} u_{i j}^{*} d \Gamma+\int_{\Omega_{e n r j}} \sigma_{j k}^{c} u_{i j, k}^{*} d \Omega_{e n r i j}
$$

Aplicando-se o Teorema da Divergência agora ao termo referente ao domínio enrijecido $\Omega_{\text {enrij }}$, na equação (4.9), tem-se:

$$
C_{i j} \mathrm{u}_{\mathrm{j}}+\int_{\Gamma} p_{i j}^{*} u_{j} d \Gamma=\int_{\Gamma} p_{j} u_{i j}^{*} d \Gamma+\int_{\Gamma_{\text {enrij }}} \sigma_{j k}^{c} u_{i j}^{*} \eta_{\mathrm{k}} d \Gamma_{e n r i j}-\int_{\Omega_{e n r j}} \sigma_{j k, k}^{c} u_{i j}^{*} d \Omega_{e n r i j}
$$

sendo que, os termos $p_{i j}^{*}$ e $u_{i j}^{*}$ são as soluções fundamentais de Kelvin em força de superfície e deslocamentos, respectivamente.

Obtendo-se a primitiva do último termo da equação (4.10), tem-se:

$$
C_{i j} \mathrm{u}_{\mathrm{j}}+\int_{\Gamma} p_{i j}^{*} u_{j} d \Gamma=\int_{\Gamma} p_{j} u_{i j}^{*} d \Gamma+\int_{\Gamma_{e n r j}} \sigma_{j k}^{c} u_{i j}^{*} \eta_{\mathrm{k}} d \Gamma_{e n r i j}-\int_{\Gamma_{e n r i j}}\left(\sigma_{j k, k}^{c} \bar{u}_{i j}^{*}+\sigma_{j k, k}^{c} \hat{u}_{i j}^{*}\right) d \Gamma_{e n r i j}
$$

Procedendo a análise sobre a última parcela da equação (4.11), verifica-se que $\bar{u}_{i j}^{*}$ é a primitiva de $u_{i j}^{*}$ quando integrado no domínio do enrijecedor $\Omega_{e n r i j}$. Devido ao termo $\left(\sigma_{j k}^{c}\right)$ ser linear para o primeiro termo da integral, logo $\left(\sigma_{j k, k}^{c}\right)$ é constante, portanto:

$$
\sigma_{j k, k}^{c} \int_{\Gamma_{e n r j j}} \bar{u}_{i j}^{*} d \Gamma_{e n r i j},
$$

onde: 


$$
\bar{u}_{i j}^{*}=\frac{1}{8 \pi G(1-v)}\left[-(3-4 v) \delta_{i 1} \frac{r}{2}\left(\ln (r)-\frac{1}{2}\right)+\frac{r}{2} r_{, i} r_{, 1}\right] \frac{\partial r}{\partial n} .
$$

Já para o segundo termo dentro da última integral da equação (4.11) sua derivada é linear, pois tal termo é referente à força cortante, que por sua vez é uma curva do segundo grau, como apresentado na Figura 4-3, resultando na seguinte equação:

$$
\hat{u}_{i j}^{*}=\frac{3}{2} \frac{1}{H^{3} \pi G(1-v)}\left[(3-4 v) \frac{r^{2}}{9}(3 \ln (r)-1) \delta_{i j}-\frac{r^{2}}{3} r_{, i} r_{, j}\right] r_{, 2} \frac{\partial r}{\partial n}
$$

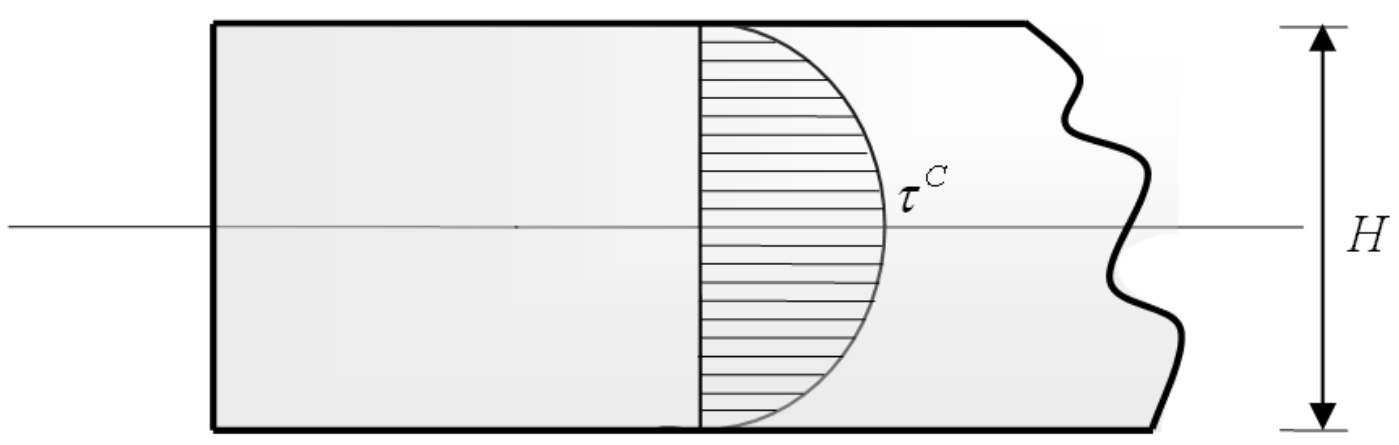

Figura 4-3 - Gráfico tensão Cisalhante no eixo do enrijecedor.

onde algebricamente pode-se escrever a equação (4.11) da seguinte forma:

$$
[H]\{u\}=[G]\{p\}+\left[G^{l}\right]\left\{\sigma^{C}\right\}
$$

A fim de obter aproximações em termos de forças normais e momentos fletores, utilizou-se a seguinte relação entre a força normal e a tensão interna:

$$
N=\sigma \cdot \text { Area }
$$

Portanto, obtêm-se as equações integrais da força normal, escritas para pontos do eixo do enrijecedor (4.17), da mesma forma que foi obtida a equação para o cálculo da tensão interna (2.81). 


$$
N_{i j}=\operatorname{Area}\left[-\int_{\Gamma} S_{i j k}^{*} u_{k} d \Gamma+\int_{\Gamma} D_{i j k}^{*} p_{k} d \Gamma+\int_{\Gamma_{e n r i j}} D_{i j k}^{*} \sigma_{j k}^{c} n_{k} d \Gamma_{e n r i j}-\int_{\Gamma_{e n r i j}}\left(\sigma_{j k, k}^{c} \bar{D}_{i j k}^{*}+\sigma_{j k, k}^{c} \widehat{D}_{i j k}^{*}\right) d \Gamma_{e n r i j}\right],
$$

sendo que, o termo $D_{k i j}^{*}$ já foi apresentado, na equação (2.82), o termo $S_{k i j}^{*}$ foi apresentado na equação (2.83), o termo $\bar{D}_{k i j}^{*}$ foi obtido derivando-se o termo $\bar{u}_{i j}^{*}$ exposto acima na equação (4.13) em relação ao ponto fonte (s), substitui-se na equação de compatibilidade (2.12) e em seguida substituindo-se na Lei de Hooke (2.15), obtendo-se então:

$$
\begin{aligned}
& \bar{D}_{i j k}^{*}=\frac{1}{8 \pi(1-v)}\left\{(1-2 v) r_{, k} \delta_{i j}+2 r_{, i} r_{, j} r_{, k}+(1-2 v) r_{, j} \delta_{i k}-\delta_{j k} r_{, i}\right\} \frac{\partial r}{\partial n}+ \\
& \frac{1}{16 \pi(1-v)}\left\{-(3-4 v)\left[\delta_{i j}\left(\ln |r|-\frac{1}{2}\right) n_{k}+\delta_{i k}\left(\ln |r|-\frac{1}{2}\right) n_{j}\right]+r_{, i} r_{, j} n_{k}+r_{, i} r_{, k} n_{j}\right\}+.(4.1 \\
& \frac{v \delta_{j k} r_{, i}(1-4 v)}{8 \pi(1-2 v)(1-v)} \frac{\partial r}{\partial n}+\frac{(3-4 v) v \delta_{j k}}{8 \pi(1-2 v)(1-v)}\left[n_{i}\left(\ln |r|-\frac{1}{2}\right)\right]
\end{aligned}
$$

e sendo o termo $\widehat{D}_{k i j}^{*}$ referente à parcela de tensão cisalhante como explicado anteriormente, fica apresentado da seguinte forma:

$$
\widehat{D}_{i j k}^{*}=\frac{-3 r}{H^{3} \pi G(1-v)}\left[\frac{(1-2 v)}{2}\left(r_{, k} \delta_{i j}+r_{, j} \delta_{k i}-r_{, i} \delta_{j k}\right)+r_{, i} r_{, j} r_{, k}\right] r_{, 2} \frac{\partial r}{\partial n}
$$

A equação (4.17) é transformada em representação algébrica utilizando-se as aproximações das variáveis de contorno e de domínio chegando-se a seguinte forma:

$$
\left\{\frac{N}{A}\right\}=-[S]\{u\}+[D]\{p\}+\left[D^{l}\right]\left\{\sigma^{C}\right\}
$$

Partindo da representação integral dos deslocamentos de pontos fontes, obtém-se a equação integral do momento fletor, como mostrado a seguir: 


$$
M_{i k l}=-E I u_{i, k l}
$$

Dessa forma, derivando-se duas vezes em relação ao ponto fonte (s) a equação de deslocamentos (4.11), encontra-se:

$$
M_{i k l}=-E I\left[-\int_{\Gamma} p_{i j, k l}^{*} u_{j} d \Gamma+\int_{\Gamma} u_{i j, k l}^{*} p_{j} d \Gamma+\int_{\Gamma_{e n r i j}} u_{i j, k l}^{*} \sigma_{j t}^{c} n_{t} d \Gamma_{e n r i j}-\int_{\Gamma_{e n r i j}}\left(u_{i j, k l}^{*} \sigma_{j t, t}^{c}+\hat{u}_{i j, k l}^{*} \sigma_{j t, t}^{c}\right) d \Gamma_{e n r i j}\right] .
$$

sendo que os núcleo novos que aparecem na equação (4.22) são dados por:

$$
\begin{aligned}
& p_{i j, m k}^{*}=\frac{1}{4 \pi(1-v) r^{3}}\left\{( 1 - 2 v ) \left[-2 \delta_{i m} r_{, k} n_{j}+2 \delta_{i j} r_{, k} n_{m}+2 \delta_{j m} r_{, k} n_{i}+2 \delta_{m k} r_{, j} n_{i}+\right.\right. \\
& \left.2 \delta_{j k} r_{, m} n_{i}-2 \delta_{m k} r_{, i} n_{j}-2 \delta_{i k} r_{, m} n_{j}+2 \delta_{i j} r_{, m} n_{k}+8 r_{, i} r_{, m} r_{, k} n_{j}-8 r_{, j} r_{, m} r_{, k} n_{i}\right]+ \\
& \left(8 r_{, i} r_{j} r_{, k} n_{m}-2 \delta_{i k} r_{, j} n_{m}-2 \delta_{j k} r_{, i} n_{m}+8 r_{, i} r_{, j} r_{, m} n_{k}-2 \delta_{i m} r_{, j} n_{k}-2 \delta_{j m} r_{i} n_{k}\right)+ \\
& \frac{\partial r}{\partial n}\left[(1-2 v)\left(2 \delta_{i j} \delta_{m k}-8 \delta_{i j} r_{, m} r_{, k}\right)-48 r_{, i} r_{, j} r_{, m} r_{, k}+8 \delta_{i m} r_{, j} r_{, k}+8 \delta_{j m} r_{i} r_{, k}+8 \delta_{i k} r_{, j} r_{, m}\right. \\
& \left.\left.+8 \delta_{j k} r_{i} r_{, m}+8 \delta_{m k} r_{i,} r_{j}-2 \delta_{i m} \delta_{j k}-2 \delta_{j m} \delta_{i k}\right]\right\}, \\
& u_{i j, m k}^{*}=\frac{1}{8 \pi G(1-v) r^{2}}\left\{(3-4 v)\left[-\delta_{i j} \delta_{m k}+2 \delta_{i j} r_{, m} r_{, k}\right]+\delta_{i m} \delta_{j k}+\delta_{j m} \delta_{i k}+8 r_{, i} r_{, m} r_{, k} r_{, j}\right. \\
& \left.-2 \delta_{i m} r_{, j} r_{, k}-2 \delta_{j m} r_{, i} r_{, k}-2 \delta_{i k} r_{, m} r_{, j}-2 \delta_{m k} r_{, i} r_{, j}-2 \delta_{j k} r_{i} r_{, m}\right\} \text {, } \\
& \bar{u}_{i j, m k}^{*}=\frac{1}{8 \pi G(1-v) r}\left\{\left[-(3-4 v) \delta_{m k} \delta_{i j}+2(3-4 v) r_{, m} r_{, k} \delta_{i j}+8 r_{, i} r_{, j} r_{, m} r_{, k}-2 r_{, m} r_{, j} \delta_{i k}-\right.\right. \\
& \left.2 r_{, m} r_{, i} \delta_{j k}-r_{, i} r_{, j} \delta_{m k}+\delta_{i m} \delta_{j k}-2 r_{, j} r_{, k} \delta_{i m}+\delta_{j m} \delta_{i k}-2 r_{, i} r_{, k} \delta_{j m}\right] \frac{\partial r}{\partial n}+\left[-(3-4 v) \delta_{i j}\left(r_{, m} n_{k}+r_{, k} n_{m}\right)\right. \\
& \left.\left.-2 r_{, i} r_{j} r_{, m} n_{k}+r_{, j}\left(\delta_{i m} n_{k}+\delta_{i k} n_{m}\right)-2 r_{, i} r_{, j} r_{, k} n_{m}+r_{, i}\left(\delta_{j m} n_{k}+\delta_{j k} n_{m}\right)\right]\right\}
\end{aligned}
$$




$$
\begin{aligned}
& \hat{u}_{i j, m k}^{*}=\frac{1}{2 H^{3} \pi G(1-v)}\left\{\left[\frac{(3-4 v)}{3}\left(3 \delta_{m k} \delta_{i j}\right)-4 r_{, i} r_{, j} r_{, m} r_{, k}+2 \delta_{i k} r_{, j} r_{, m}+2 \delta_{j k} r_{, i} r_{, m}\right.\right. \\
& \left.+2 \delta_{m k} r_{, i} r_{, j}-\delta_{i m} \delta_{j k}-\delta_{j m} \delta_{i k}\right] r_{, 2} \frac{\partial r}{\partial n}-\left[(3-4 v) 2 r_{, m} \delta_{i j}+4 r_{, i} r_{, j} r_{, m}-2 \delta_{i m} r_{, j}\right. \\
& \left.-2 \delta_{j m} r_{, i}\right] r_{, 2} \frac{\partial r}{\partial n} r_{, k}+\left[(3-4 v) 2 r_{, m} \delta_{i j}+2 r_{, i} r_{, j} r_{, m}-\delta_{i m} r_{, j}-\delta_{j m} r_{, i}\right] \delta_{2 k} \frac{\partial r}{\partial n}+ \\
& {\left[(3-4 v) 2 r_{, m} \delta_{i j}+2 r_{, i} r_{, j} r_{, m}-\delta_{i m} r_{, j}-\delta_{j m} r_{, i}\right] r_{, 2} n_{k}+\left[\frac{(3-4 v)}{3}(3 \ln |r|+2) r_{, k} \delta_{i j}+r_{, i} r_{, j} r_{, k}\right.} \\
& \left.-\delta_{, i} r_{, j}\right] \delta_{2 m} \frac{\partial r}{\partial n} r_{, k}+\left[\frac{(3-4 v)}{3}(3 \ln |r|+2) \delta_{, k} \delta_{i j}+r_{, i} r_{, j} r_{, k}-\delta_{i k} r_{, j}-\delta_{j k} r_{, i}\right] r_{, 2} n_{m}+ \\
& {\left[\frac{(3-4 v)}{3 n}+\left[\frac{(3-4 v)}{3}(3 \ln |r|-1) \delta_{i j}-r_{, i} r_{, j}\right] \delta_{2 m} n_{k}-\left[\frac{(3-4 v)}{3}(3 \ln |r|-1) \delta_{i j}\right.\right.} \\
& \left.\left.[3 \ln |r|-1) \delta_{i j}-r_{, i} r_{, j}\right]\left(\delta_{2 k}-r_{, 2} r_{, k}\right) n_{m}\right\}
\end{aligned}
$$

onde algebricamente pode-se escrever a equação (4.22) da seguinte forma:

$$
\{M\}=-E I\left\{-[S 1]\{u\}+[D 1]\{p\}+\left[D 1^{l}\right]\left\{\sigma^{C}\right\}\right\}
$$

As hipóteses de Bernoulli são consideradas para o enrijecedor, diminuindo assim os graus de liberdade do problema. São necessários apenas dois graus de liberdade (força normal e momento fletor) para aproximar o campo de tensões na superfície do enrijecedor. Momento fletor e força normal podem ser escritos em termos de tensões e vice e versa. Os termos de domínio, como apresentado acima, correspondentes ao campo de tensão inicial (ou em termos de momento fletor e força normal) foram transformados para o contorno do enrijecedor ou interface com o domínio principal. Desta forma, as singularidades são evitadas uma vez que os pontos de colocação para se escreverem as equações adicionais estão definidos no eixo do enrijecedor e as integrais são feitas na interface do mesmo.

Inicialmente, foi substituída no termo de tensão inicial uma função constante, sendo ela a Força Normal, como segue: 


$$
\sigma^{C}=\frac{N^{C}}{A}
$$

tal substituição é ideal para a análise de enrijecedores muito esbeltos, com características de fibra, e reduz ainda mais o número de graus de liberdade do sistema de equações. Essa simplificação se traduz em rigidez a flexão do enrijecedor nula. Porém não é adequado para análises onde a rigidez do enrijecedor à flexão é importante ou preponderante. Tal sistema, composto pelas equações (4.15) e (4.20), ficou disposto algebricamente como segue:

$$
\left[\begin{array}{cc}
H & \lambda \\
S & \lambda 1
\end{array}\right]\left\{\begin{array}{c}
u \\
N
\end{array}\right\}=\left[\begin{array}{c}
G \\
D
\end{array}\right]\{p\} .
$$

Para a formulação proposta posteriormente neste trabalho, o campo de tensão inicial ou campo de tensão corretora é substituído por momento fletores e forças normais dado pela seguinte relação linear:

$$
\sigma^{C}=\frac{N^{C}}{A} \pm \frac{M^{C}}{I} y
$$

dando ao enrijecedor uma característica de viga. Tais esforços podem ser verificados na Figura 4-4.

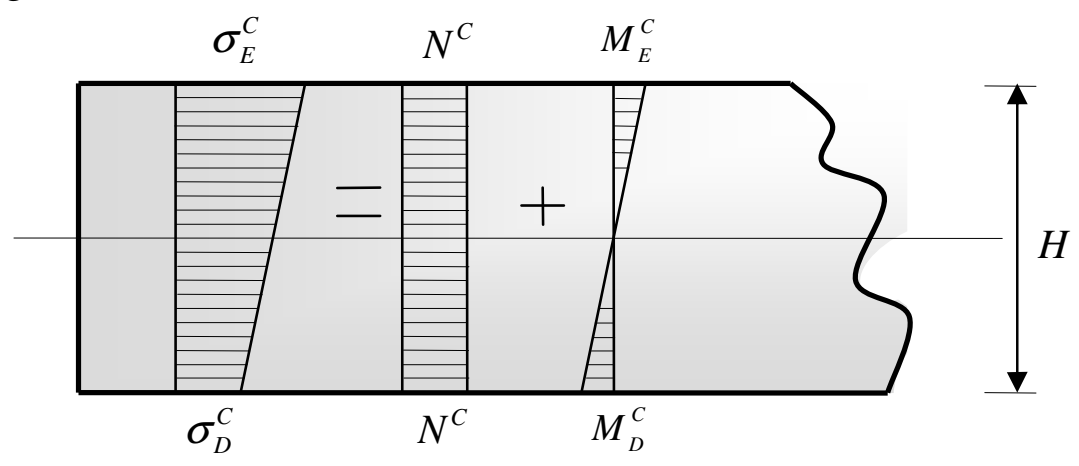

Figura 4-4 - Tensões e esforços solicitantes no enrijecedor.

E por fim, algebricamente, o sistema completo constituído pelas equações (4.15), (4.20) e (4.27) fica definido da seguinte forma: 


$$
\left[\begin{array}{ccc}
H & \lambda & \Psi \\
S & \lambda 1 & \Psi 1 \\
S 2 & \lambda 2 & \Psi 2
\end{array}\right]\left\{\begin{array}{c}
u \\
N \\
M
\end{array}\right\}=\left[\begin{array}{c}
G \\
D \\
D 2
\end{array}\right]\{p\} .
$$

Considerando-se a viga ilustrada na Figura 4-5. Na figura a linha contínua discretizada representa o eixo médio do enrijecedor e as linhas tracejadas a largura total do mesmo. É apresentado ainda na mesma figura o detalhe do elemento $\mathrm{k}$ do enrijecedor.

Outro fato importante apresentado na Figura 4-5 é o posicionamento do nó do enrijecedor quando este coincide com o contorno externo. De modo, a evitar singularidades, optou-se por deslocar o nó para o interior do elemento.

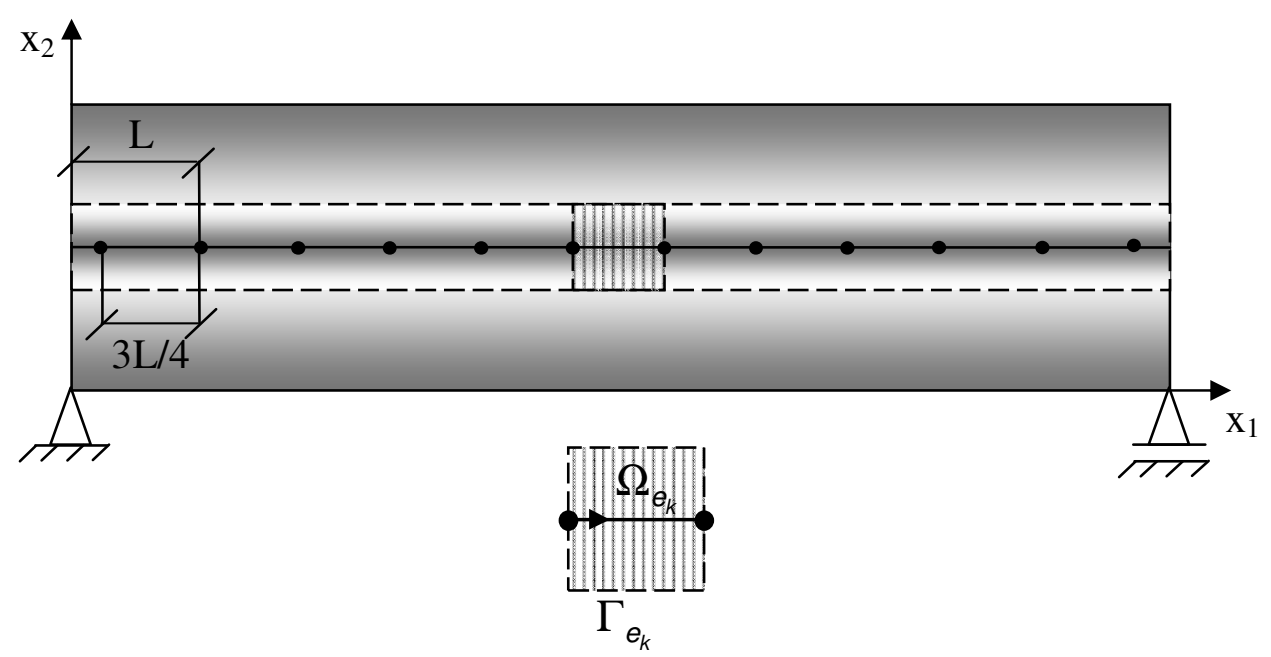

Figura 4-5 - Discretização utilizada nos enrijecedores.

\subsection{Exemplos numéricos de validação}

A seguir, serão analisados exemplos numéricos de forma a validar 0 desempenho da formulação do MEC para domínios 2-D com presença de enrijecedores.

\subsection{1 - Exemplo 1}

Os resultados estão apresentados com aproximações quadráticas (discretizada com 172 nós no contorno da viga e 204 nós no contorno do 
enrijecedor) e cúbicas (discretizada com 178 nós no contorno da viga e 204 nós no contorno do enrijecedor) e comparados com os resultados obtidos com a ferramenta computacional ANSYS. Serão apresentados também, a deformação da estrutura sem a presença do enrijecedor, a título comparativo.

A Figura 4-6 mostra o exemplo em questão, um sólido com uma inclusão de material diferente, simulando o comportamento de uma viga de concreto armado de comportamento elástico linear. A figura mostra ainda as características geométricas da estrutura, bem como o esquema de como foi discretizada, e os carregamentos que serão analisados.

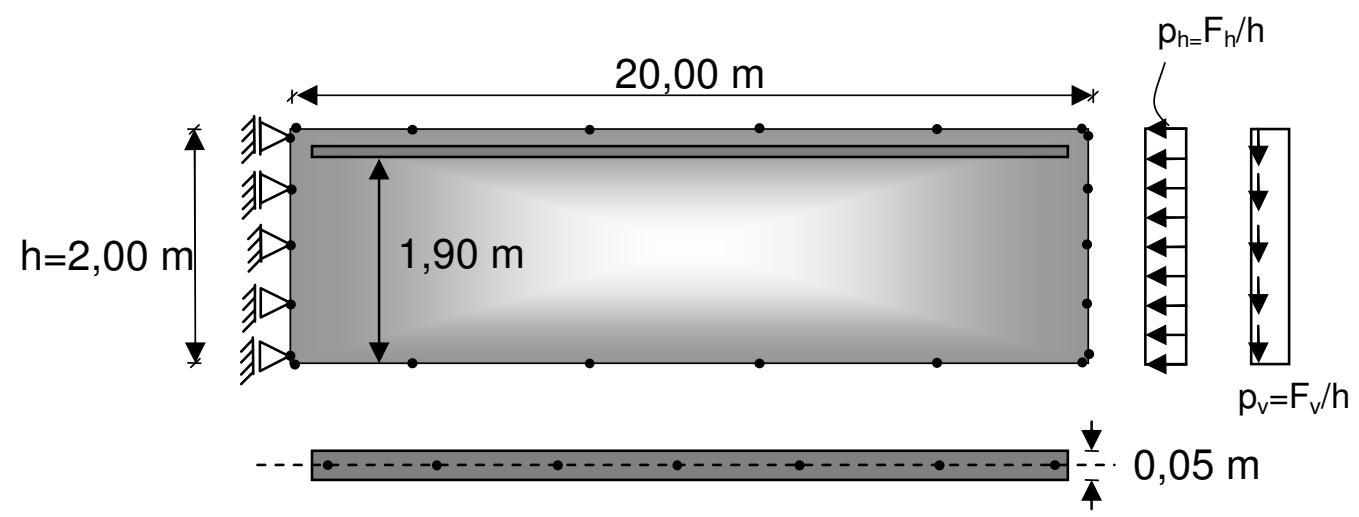

Figura 4-6 - Sólido Bidimensional com inclusão, características geométricas e carregamentos.

A relação entre os módulos de elasticidade da inclusão e do domínio principal é de $E_{i} / E_{S}=10$, sendo que ambas as regiões possuem coeficiente de Poisson $v=$ 0,25 .

\subsubsection{1 -Primeiro caso - Compressão}

Será analisada neste caso a viga em questão sujeita ao carregamento de compressão "ph", como ilustrado na Figura 4-6.

Os resultados são dados em termos de deslocamentos da face inferior nas direções x e y na Figura 4-7 e na Figura 4-8, respectivamente. 


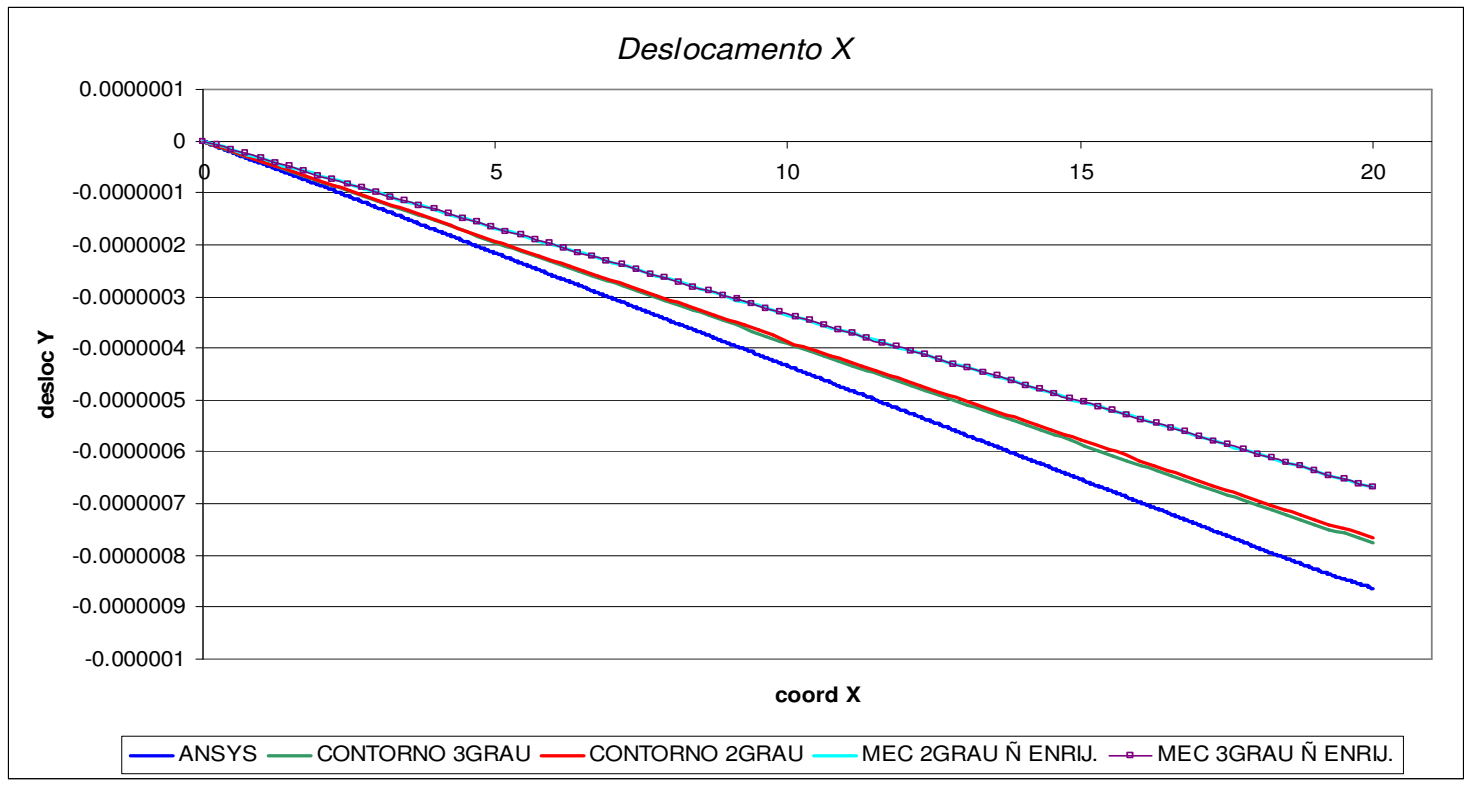

Figura 4-7 - Gráfico deslocamento X ao longo da viga sujeita a compressão.

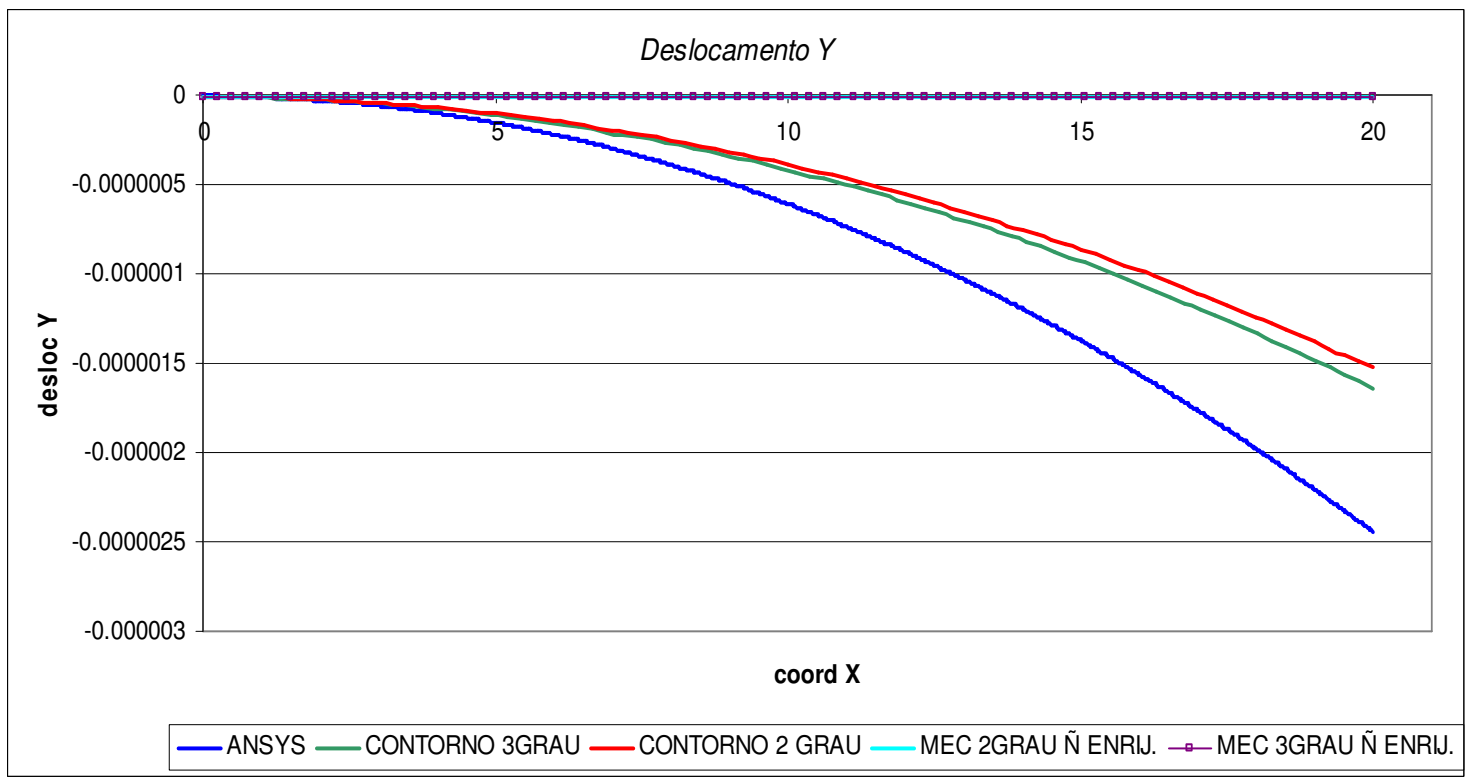

Figura 4-8 - Gráfico deslocamento Y ao longo da viga sujeita a compressão.

Considerando-se agora a diferença relativa ao resultado obtido com o ANSYS ocorrido nesta análise, na Figura 4-9. 


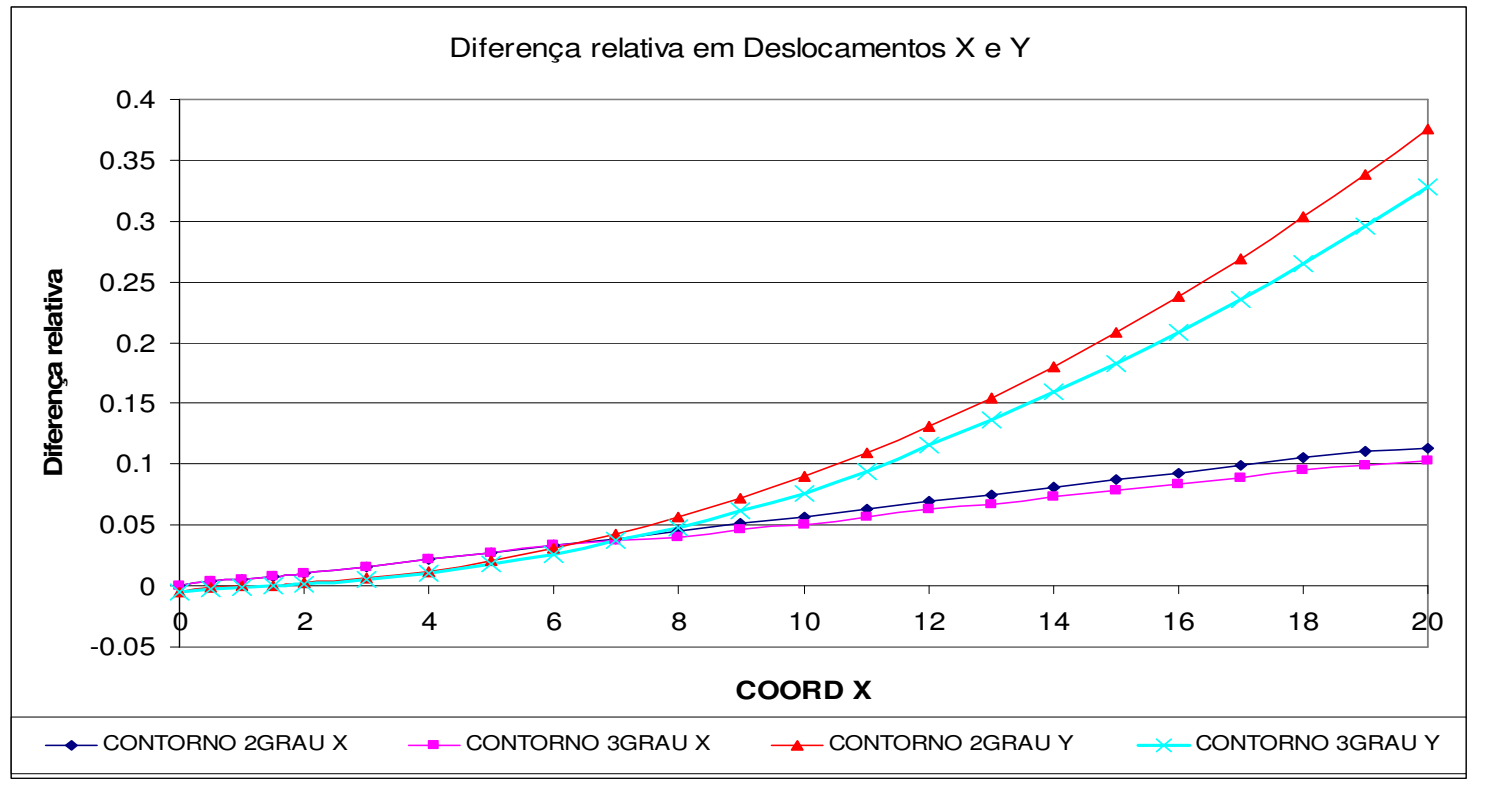

Figura 4-9 - Diferença relativa no cálculo do deslocamento no contorno.

A seguir são apresentados os resultados das forças normais (Fxx) na Figura 4-10 e cortantes (Fxy) na Figura 4-11, ambas no eixo do enrijecedor, ainda referente a viga sujeita a compressão.

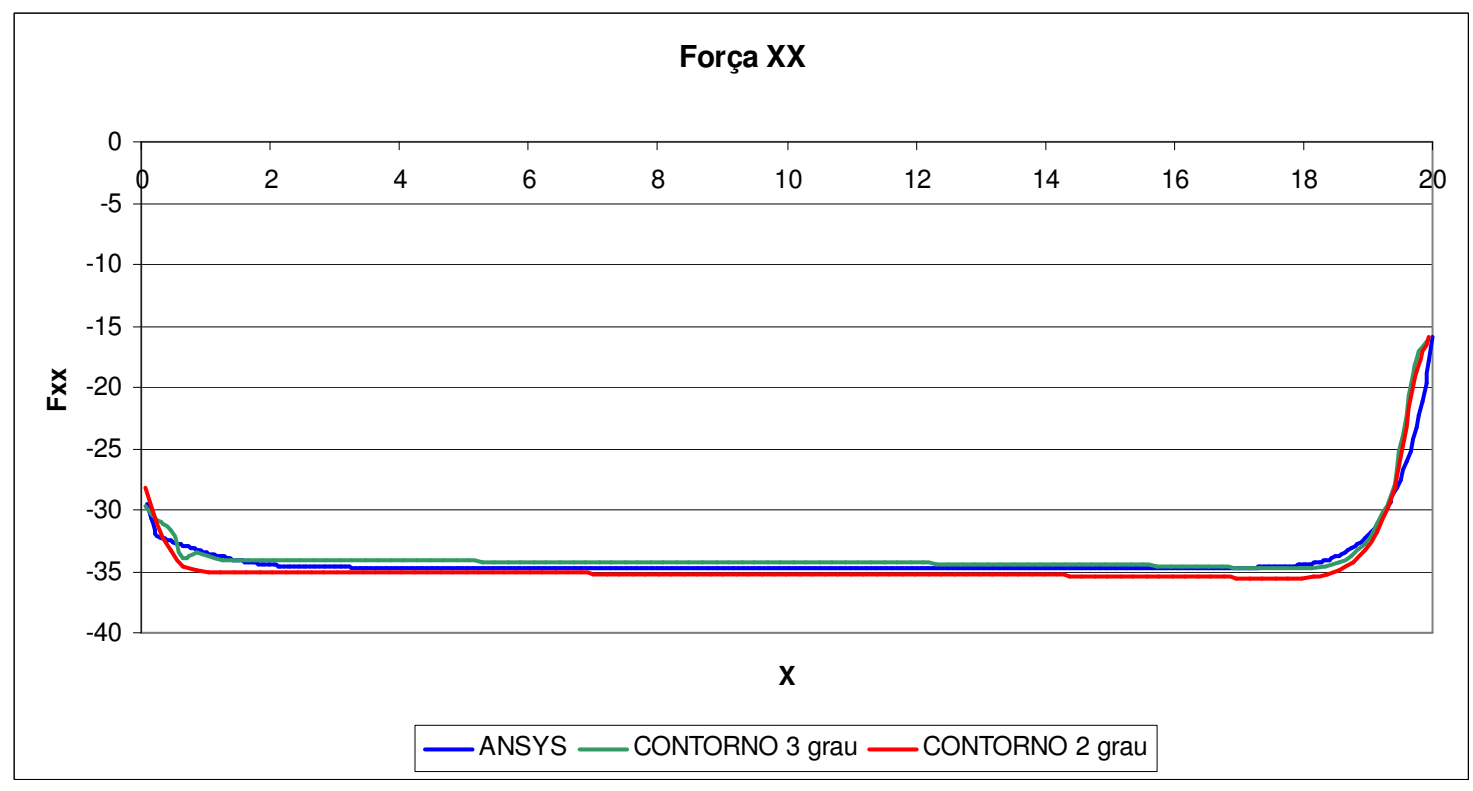

Figura 4-10 - Gráfico Força Normal ao longo do enrijecedor. 


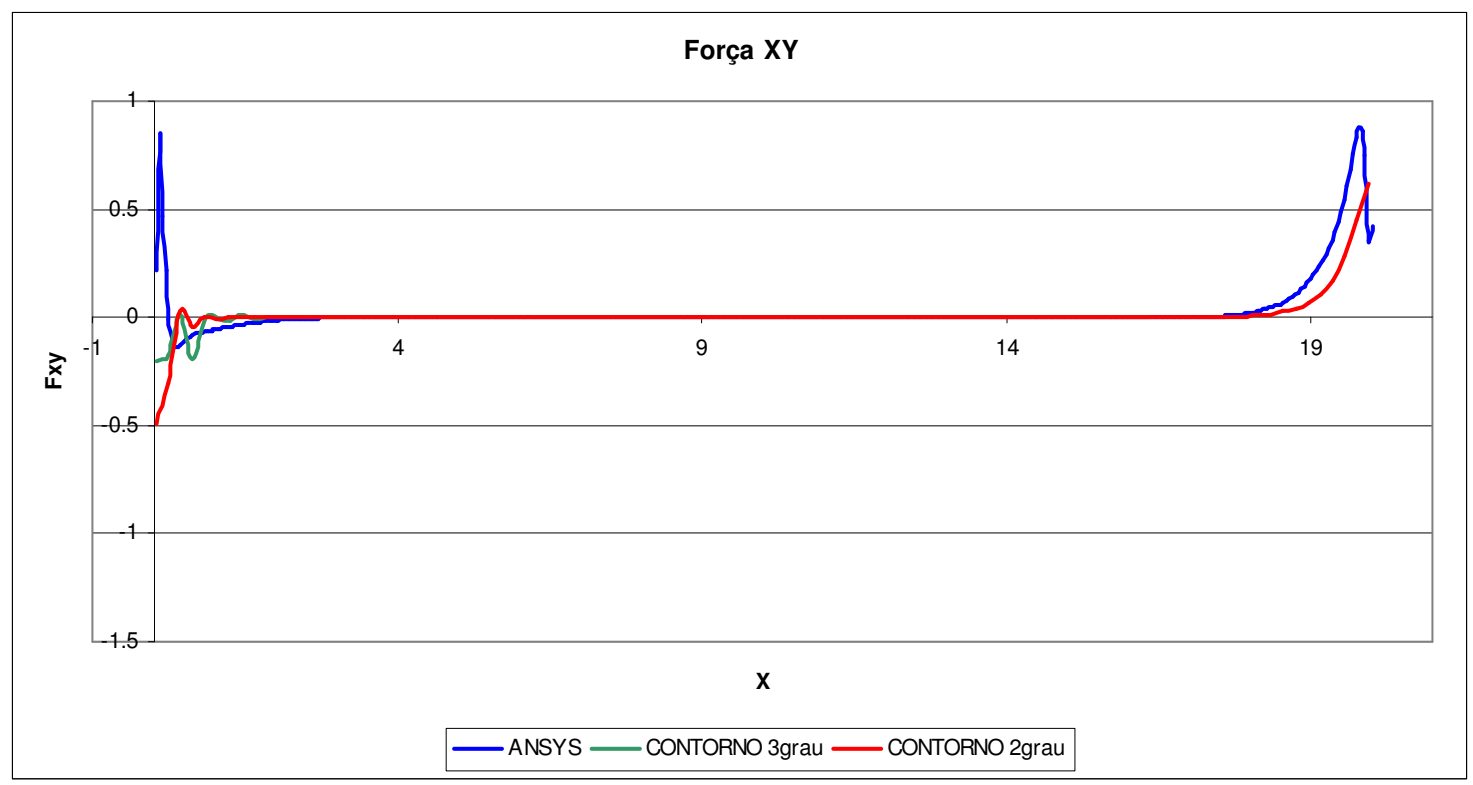

Figura 4-11 - Gráfico Força Cortante ao longo do enrijecedor.

Considerando-se agora a diferença relativa ao resultado obtido com o ANSYS ocorrido nesta análise, na Figura 4-12.

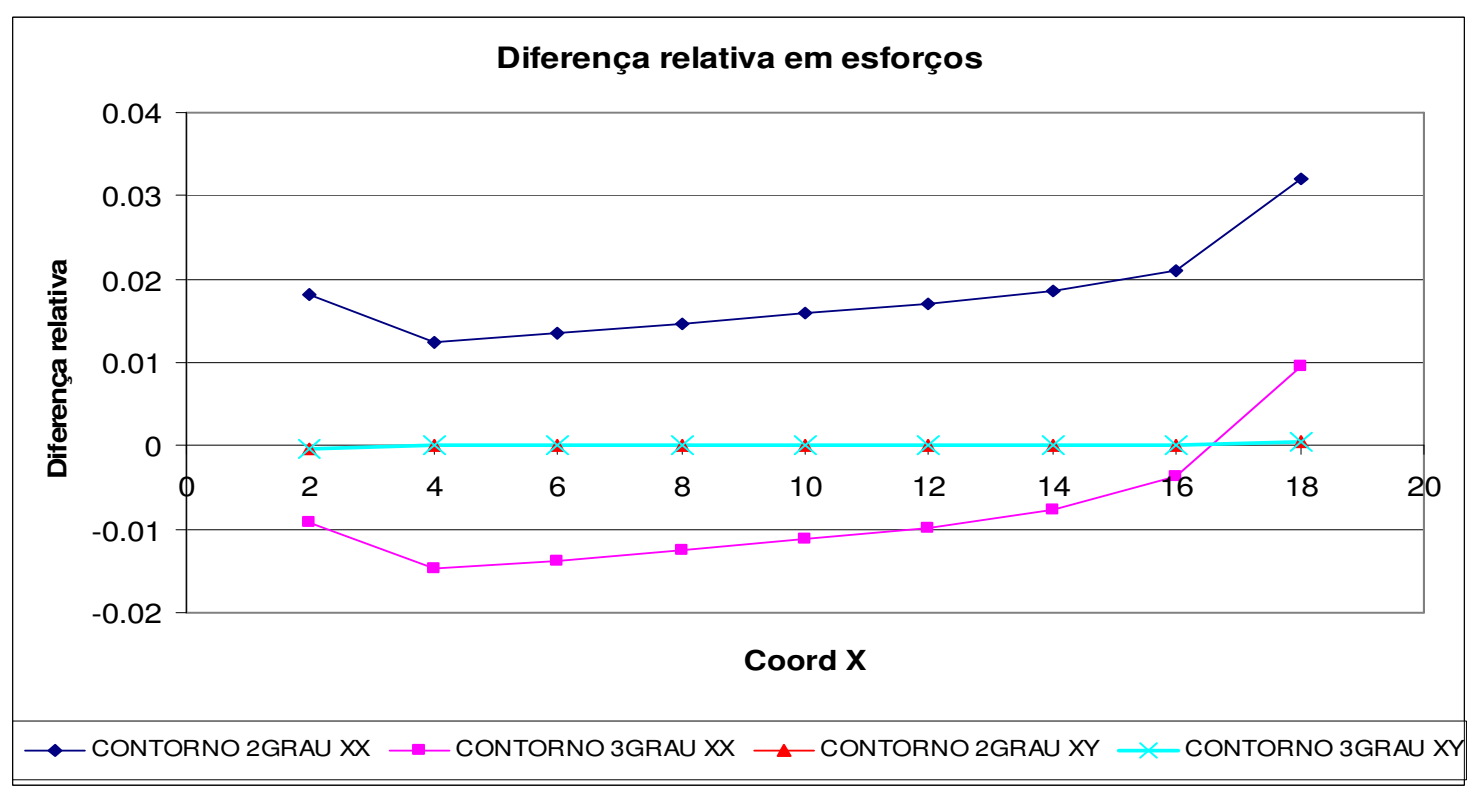

Figura 4-12 - Diferença relativa no cálculo das forças Normal e Cortante no eixo do enrijecedor. 


\subsubsection{2 - Segundo caso - Flexão por força aplicada}

Será analisada neste caso a viga em questão sujeita à flexão por uma força transversal " $p_{v}$ ", ao eixo da viga como apresentado na Figura 4-6.

Em seguida são apresentados os resultados de deslocamentos da face inferior, na Figura 4-13 e na Figura 4-14. Sendo que, é apresentada também na Figura 4-14 a linha elástica da estrutura em questão, que foi traçada primeiramente calculando-se a posição da linha neutra, posteriormente calculando-se a inércia equivalente da viga e finalmente calculando-se a curva, com a equação apresentada a seguir:

$$
v(x)=\frac{P l^{3}}{6 E I}\left[2-3 \frac{x}{l}+\left(\frac{x}{l}\right)^{3}\right],
$$

sendo $P$ a carga aplicada, $l$ o comprimento total da viga, $E$ o módulo de elasticidade do concreto, $I$ a inércia equivalente e $x$ a posição que se deseja calcular a deformada.

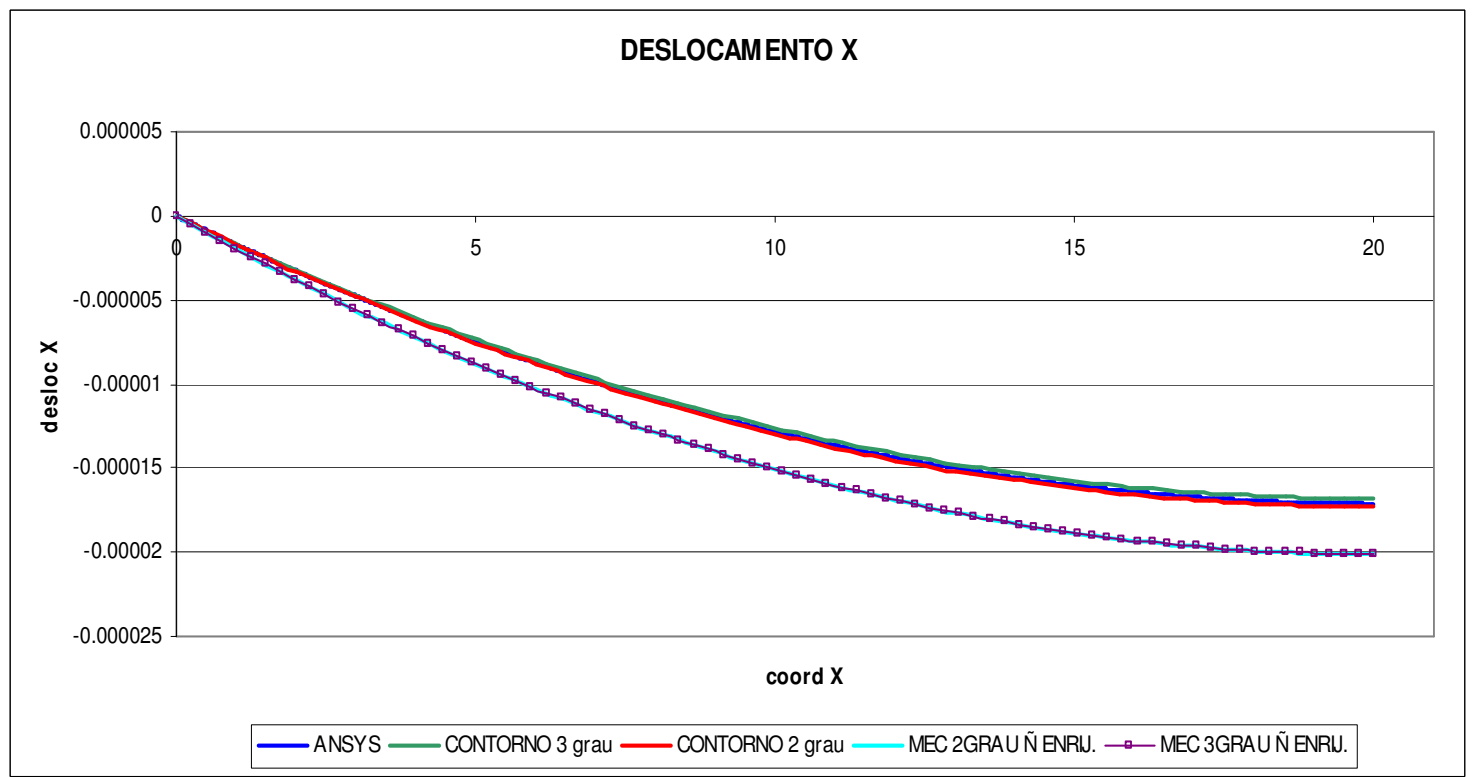

Figura 4-13 - Gráfico deslocamento X ao longo da viga sujeita a flexão. 


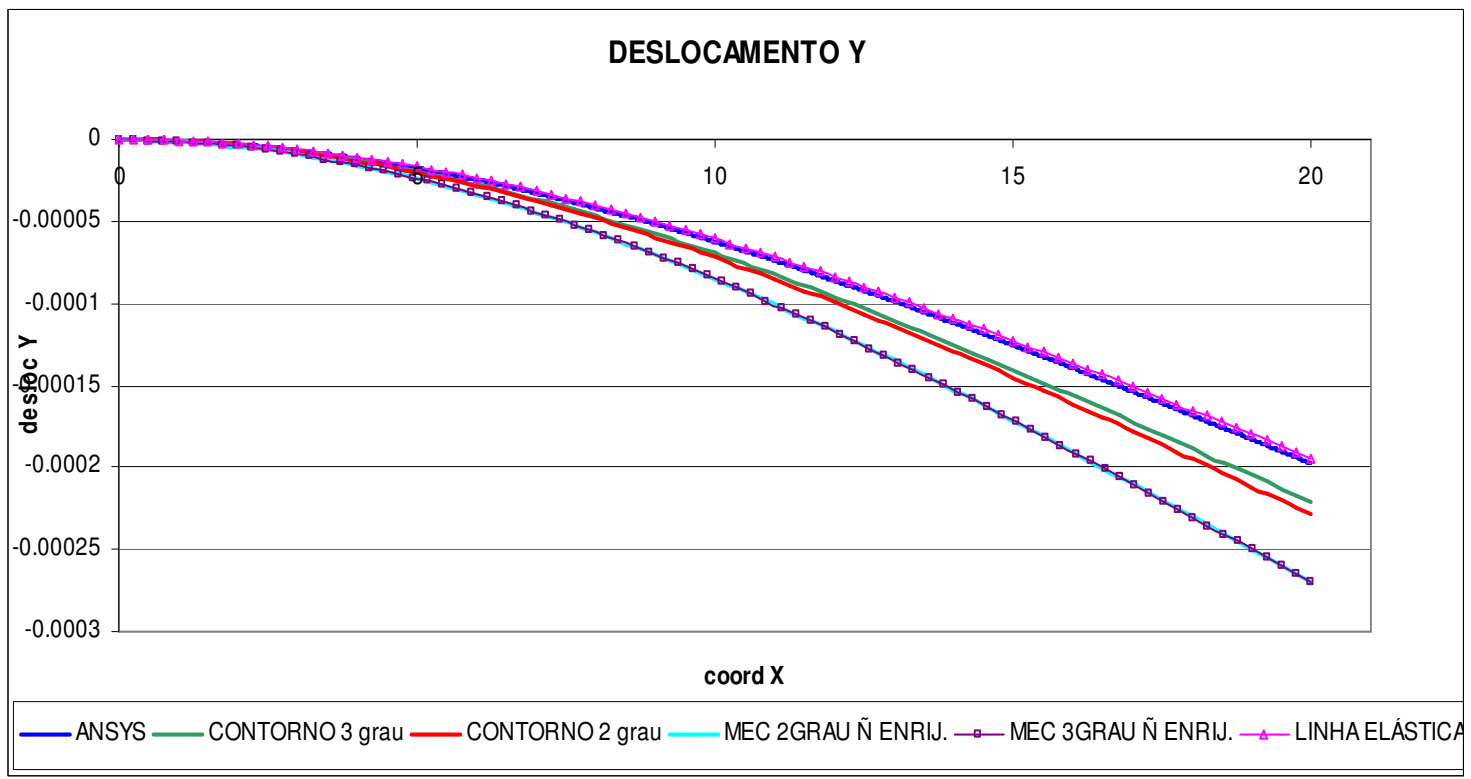

Figura 4-14 - Gráfico deslocamento Y ao longo da viga sujeita a flexão.

Considerando-se agora a diferença relativa ao resultado obtido com o ANSYS ocorrido nesta análise, na Figura 4-15.

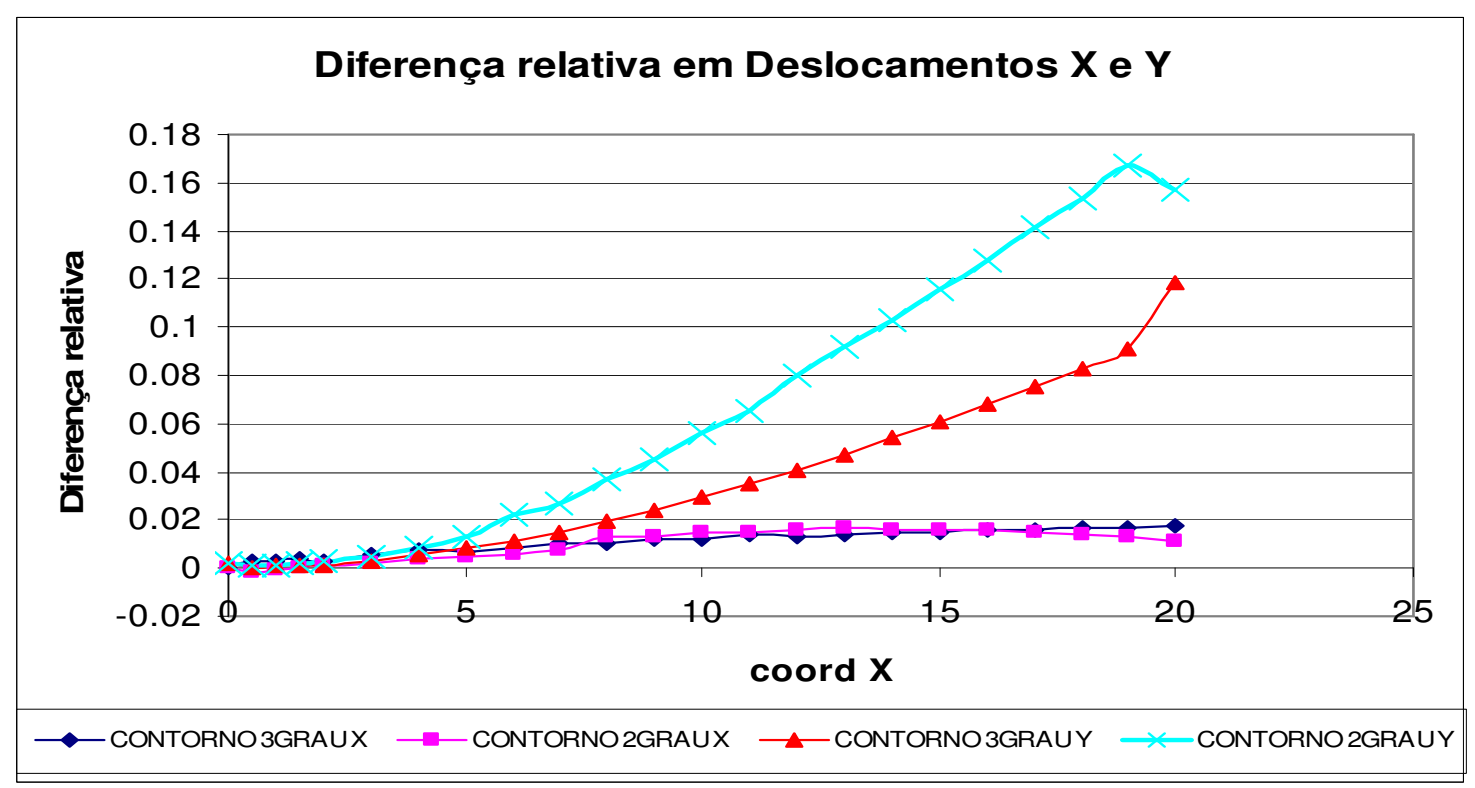

Figura 4-15 - Diferença relativa no cálculo do deslocamento no contorno.

A seguir são apresentados os resultados das forças normais (Fxx) na Figura 4-16 e cortantes (Fxy) na Figura 4-17, ambas no eixo do enrijecedor, ainda referente a viga sujeita a flexão. 


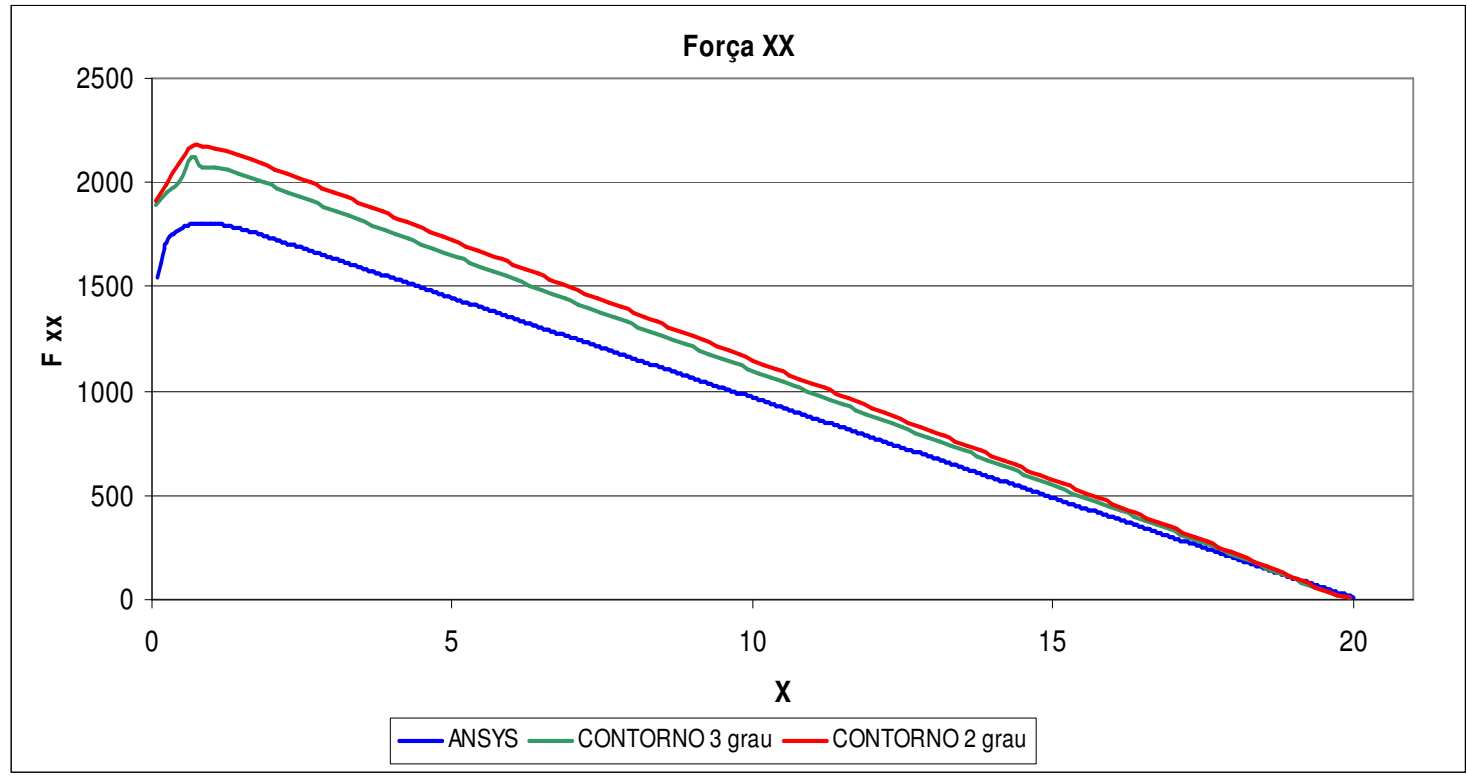

Figura 4-16 - Gráfico Força Normal ao longo do enrijecedor.

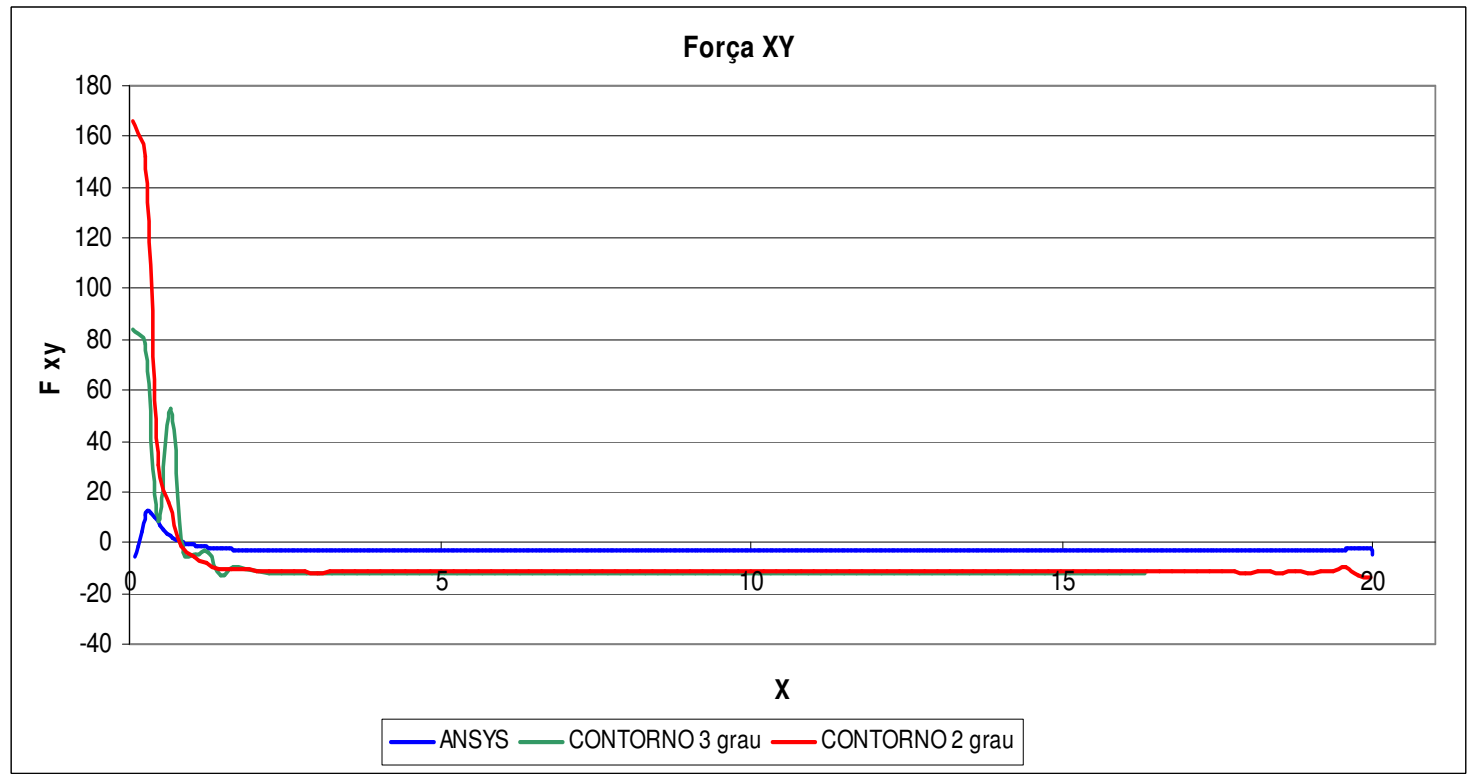

Figura 4-17 - Gráfico Força Cortante ao longo do enrijecedor.

Considerando-se agora a diferença relativa ao resultado obtido com o ANSYS ocorrido nesta análise, na Figura 4-18. 


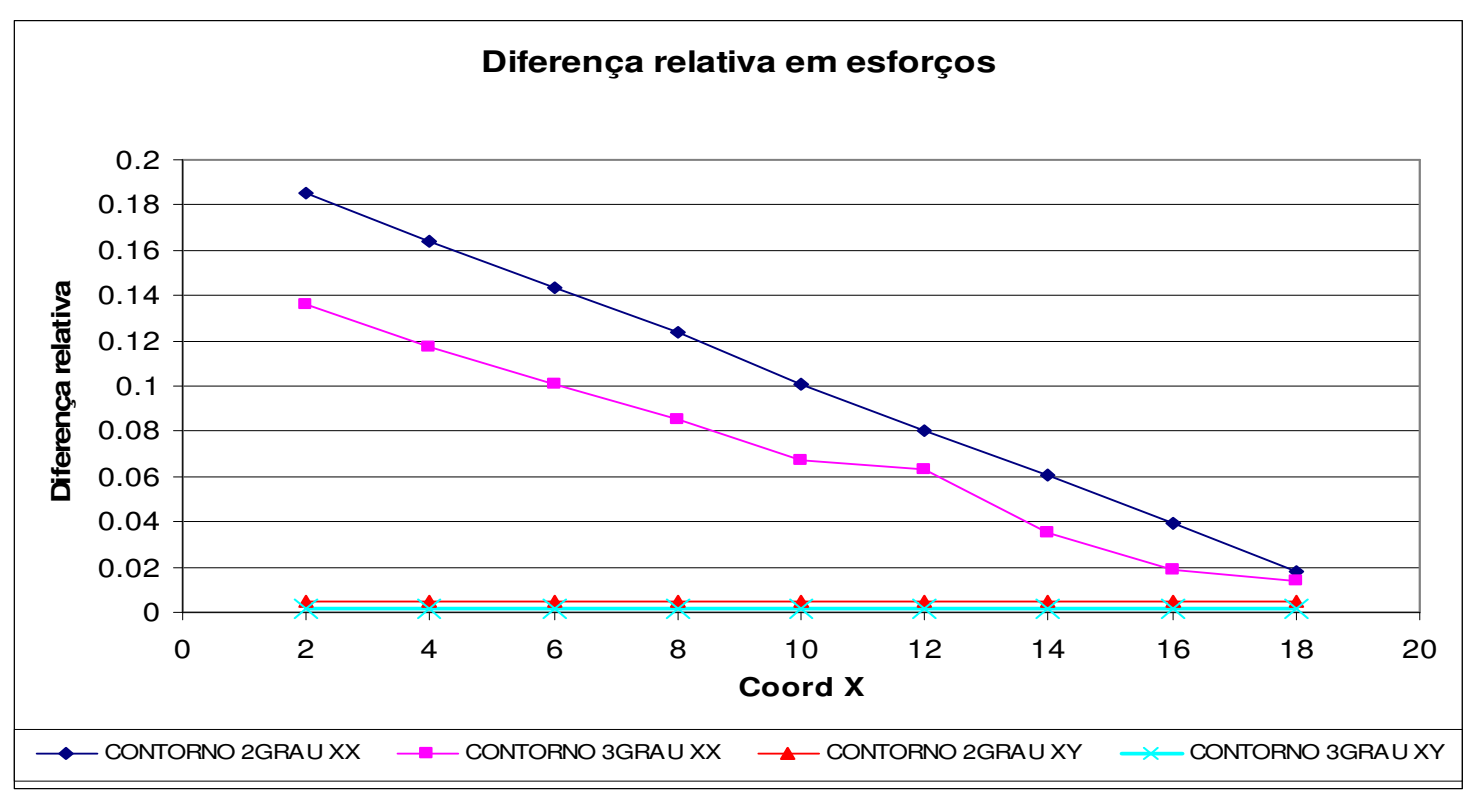

Figura 4-18 - Diferença relativa no cálculo das forças Normal e Cortante no eixo do enrijecedor.

\subsection{2 - Exemplo 2}

Os resultados estão novamente apresentados com aproximações quadráticas (discretizada com 172 nós no contorno da viga e 204 nós no contorno do enrijecedor) e cúbicas (discretizada com 178 nós no contorno da viga e 204 nós no contorno do enrijecedor) e comparados com os resultados obtidos com a ferramenta computacional ANSYS. Está apresentada também, a deformação da estrutura sem a presença do enrijecedor, a título comparativo.

A Figura 4-19 mostra o exemplo em questão, um sólido com uma inclusão de material diferente, simulando o comportamento de uma viga de concreto armado de comportamento elástico linear. A figura mostra ainda as características geométricas da estrutura, bem como o esquema de como foi discretizada, e o carregamento que foi analisado. 


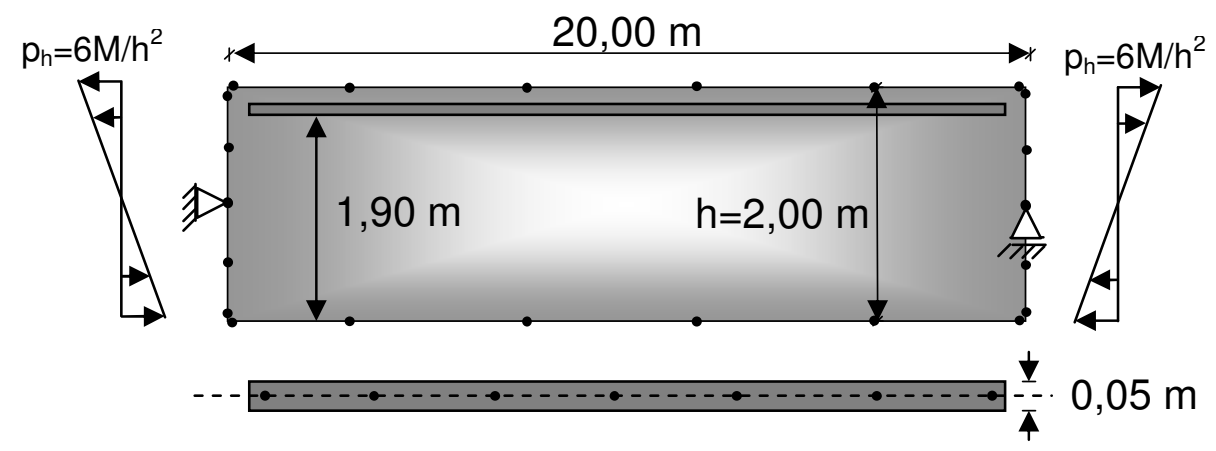

Figura 4-19 - Sólido Bidimensional com inclusão, características geométricas e carregamento.

A relação entre os módulos de elasticidade da inclusão e do domínio principal é de $E_{i} / E_{S}=10$, sendo que ambas as regiões possuem coeficiente de Poisson $v=$ 0,25 .

Primeiramente são apresentados os resultados referentes à viga sujeita à flexão na Figura 4-20 e na Figura 4-21. Tais resultados são dados em termos de deslocamentos da face inferior nas direções x e y, respectivamente.

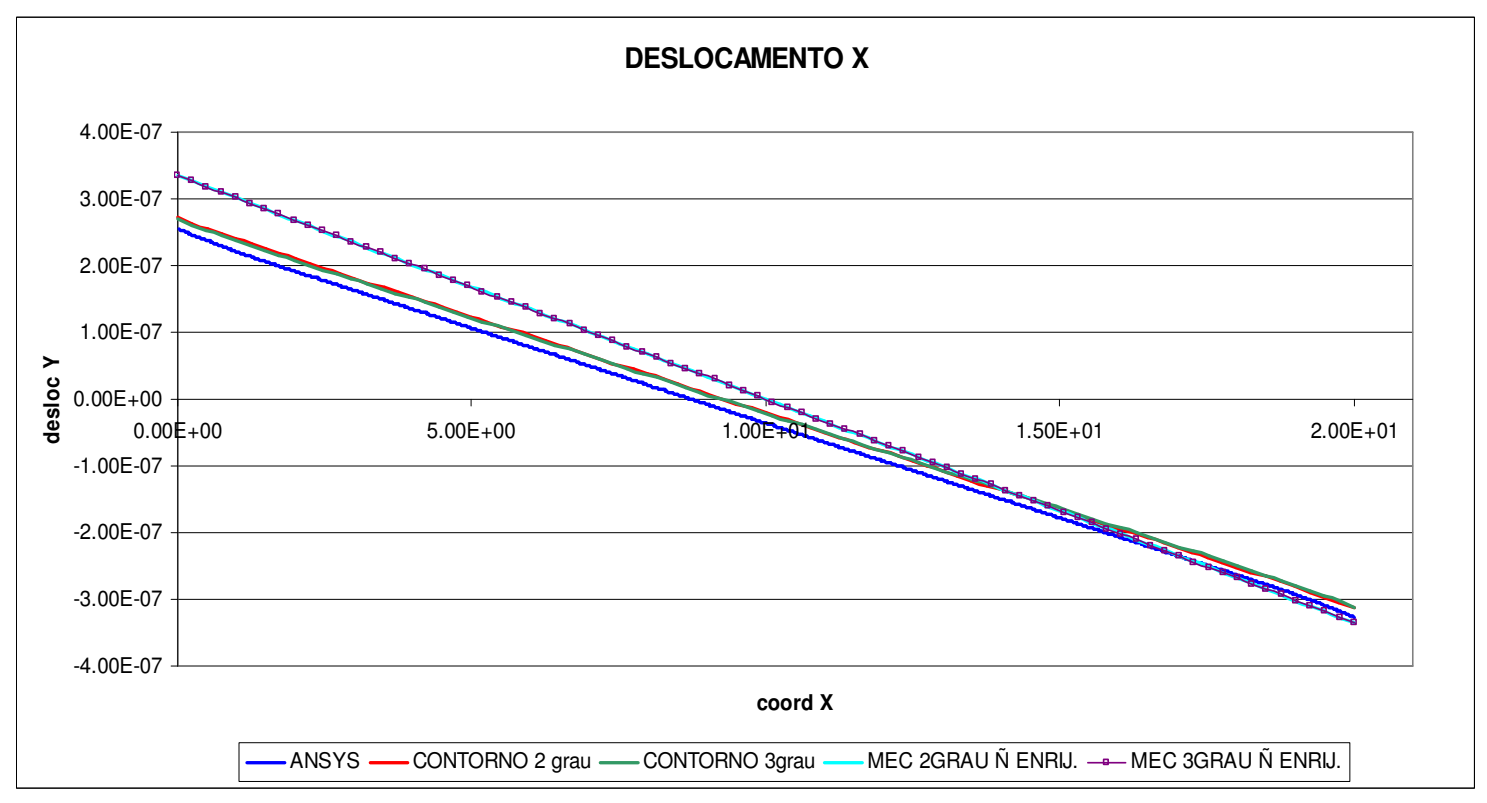

Figura 4-20 - Gráfico deslocamento $X$ ao longo da viga sujeita a flexão por momento aplicado. 


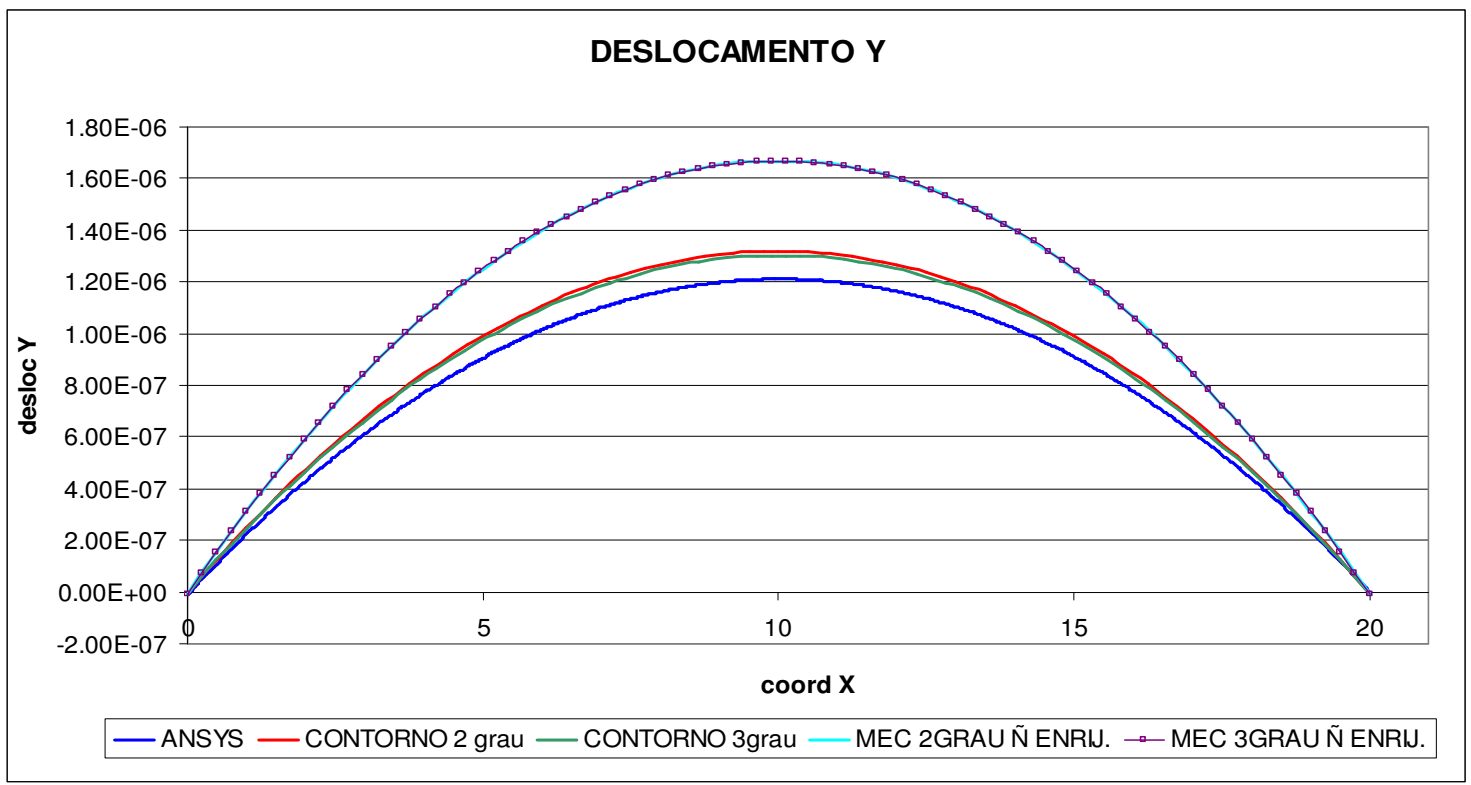

Figura 4-21 - Gráfico deslocamento Y ao longo da viga sujeita a flexão por momento aplicado.

Considerando-se agora a diferença relativa ao resultado obtido com o ANSYS ocorrido nesta análise, na Figura 4-22.

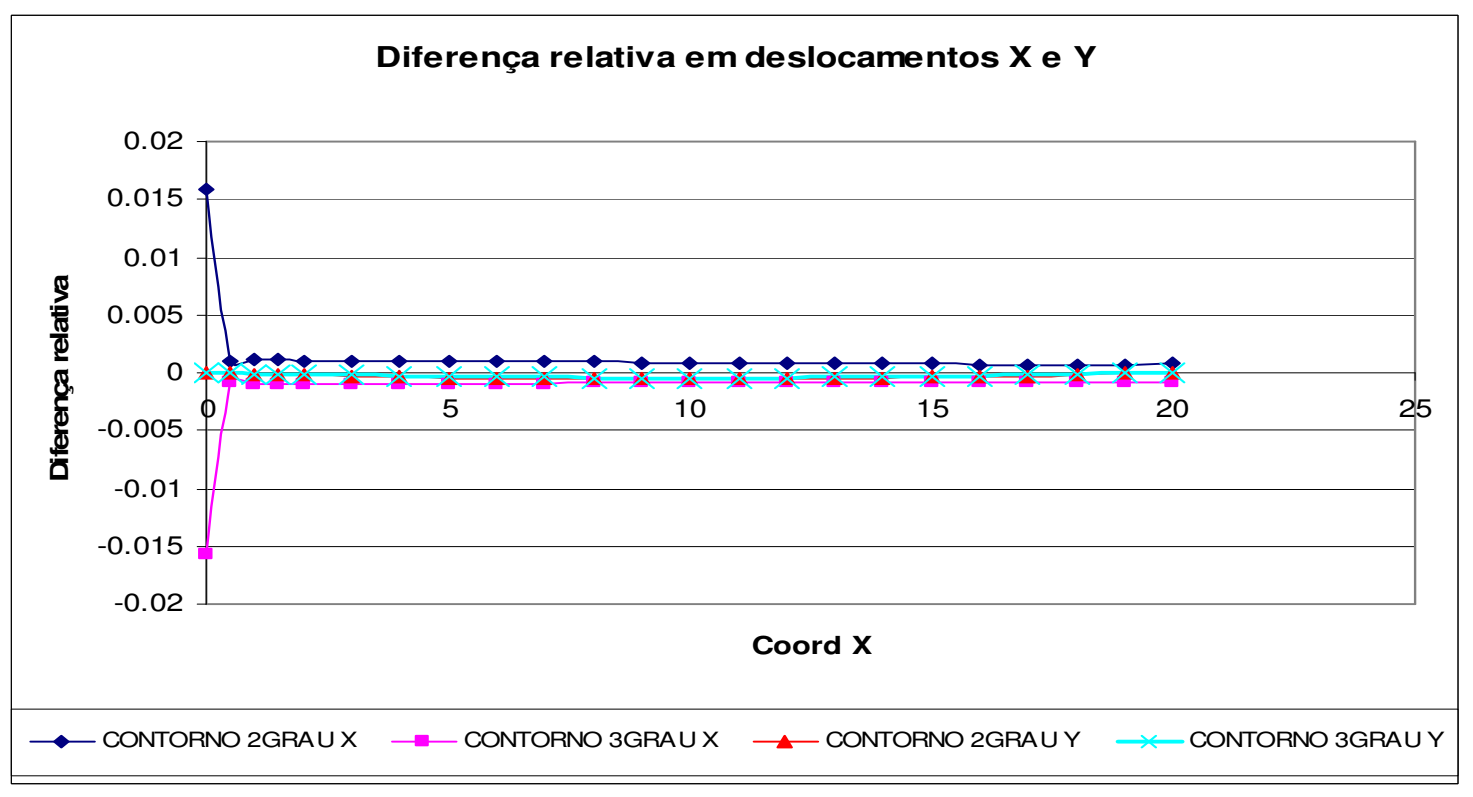

Figura 4-22 - Diferença relativa no cálculo do deslocamento no contorno.

A seguir são apresentados os resultados das forças normais (Fxx) na Figura 4-23 e cortantes (Fxy) na Figura 4-24, ambas no eixo do enrijecedor, ainda referente a viga sujeita a flexão. 


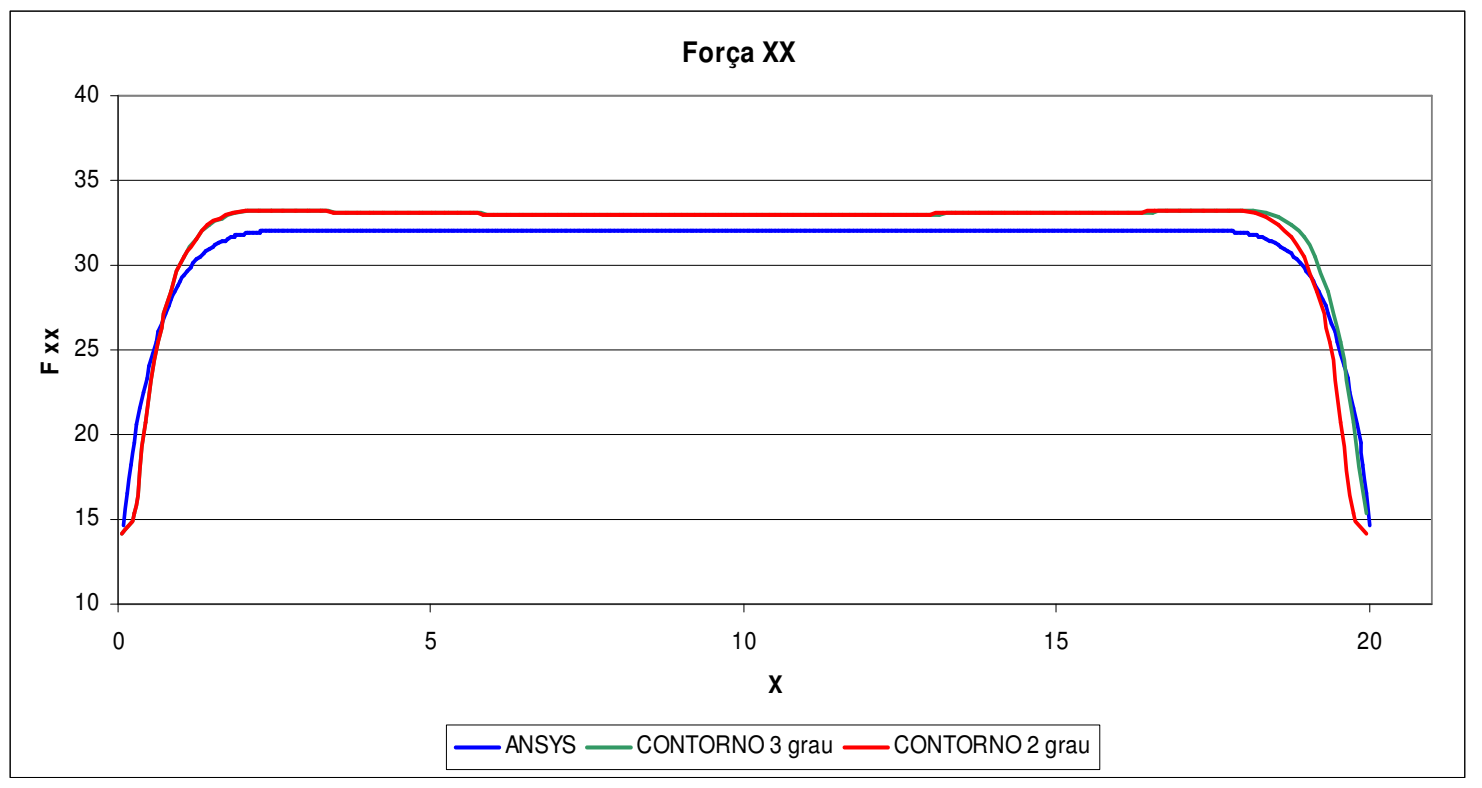

Figura 4-23 - Gráfico Força Normal ao longo do enrijecedor.

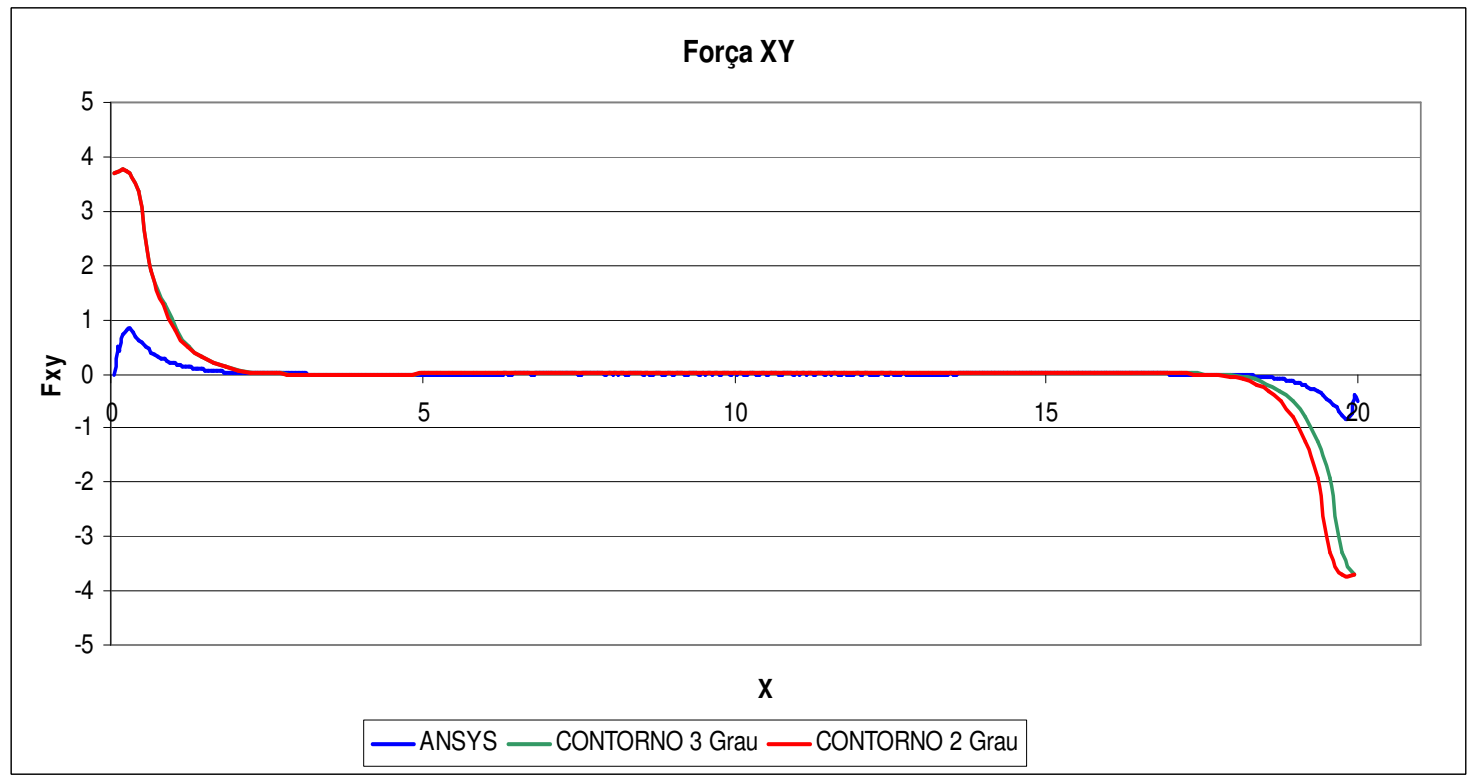

Figura 4-24 - Gráfico Força Cortante ao longo do enrijecedor.

Considerando-se agora a diferença relativa ao resultado obtido com o ANSYS ocorrido nesta análise, na Figura 4-25. 


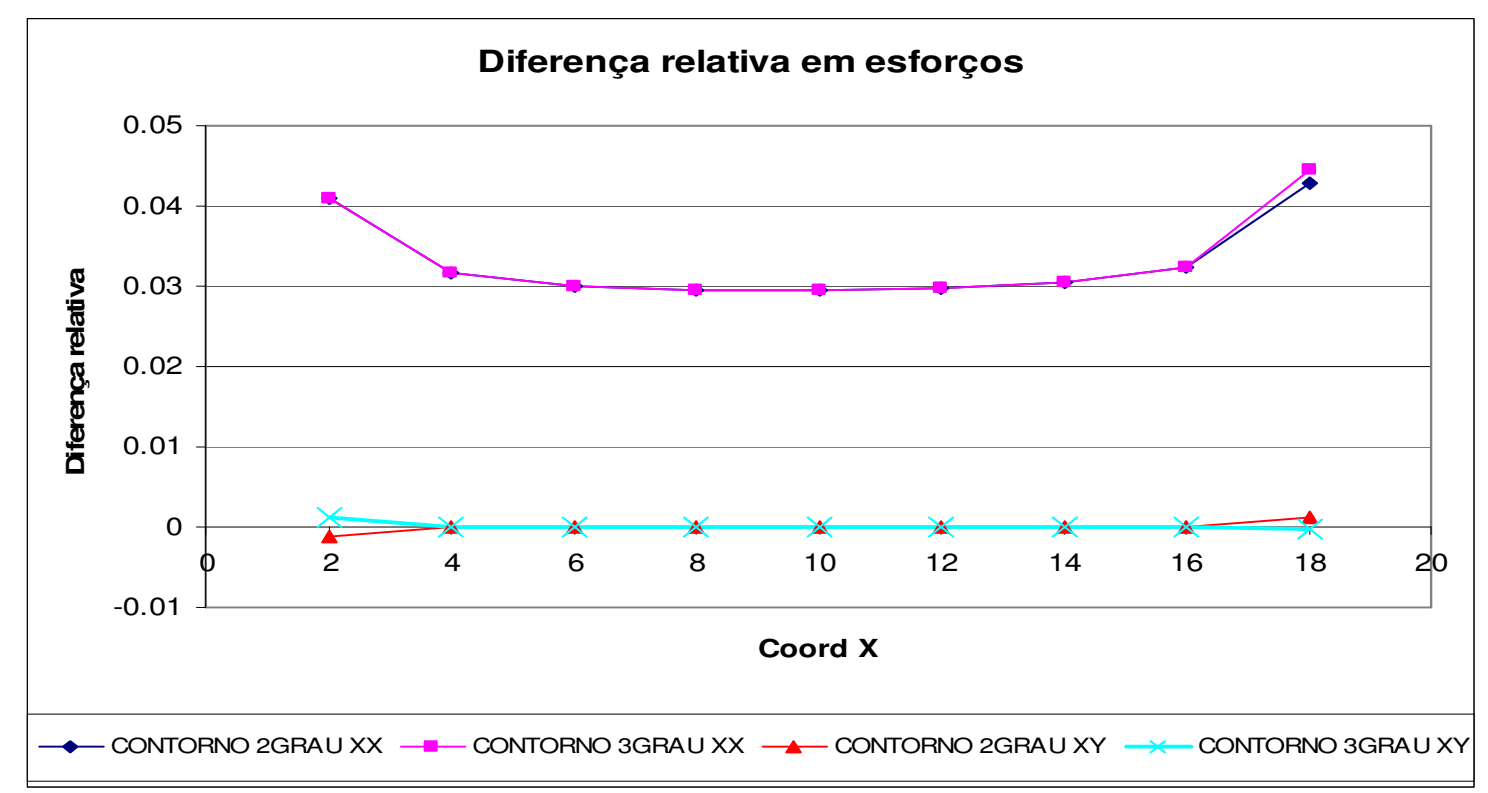

Figura 4-25 - Diferença relativa no cálculo das forças Normal e Cortante no eixo do enrijecedor.

\subsection{3 - Exemplo 3}

A Figura 4-26 mostra o exemplo em questão, um sólido com uma inclusão de material diferente, simulando o comportamento de uma estaca de concreto com comportamento elástico linear. A figura mostra ainda as características geométricas da estrutura, bem como o esquema de como foi discretizada, e o carregamento que foi analisado.

Os dados do problema são:

$H=40 \mathrm{~m} ;$

$L=20 \mathrm{~m}$;

$W_{P}=2 \mathrm{~m} ;$

$M=1000 \mathrm{Nm}$;

$E_{i} / E_{S}=10$. 


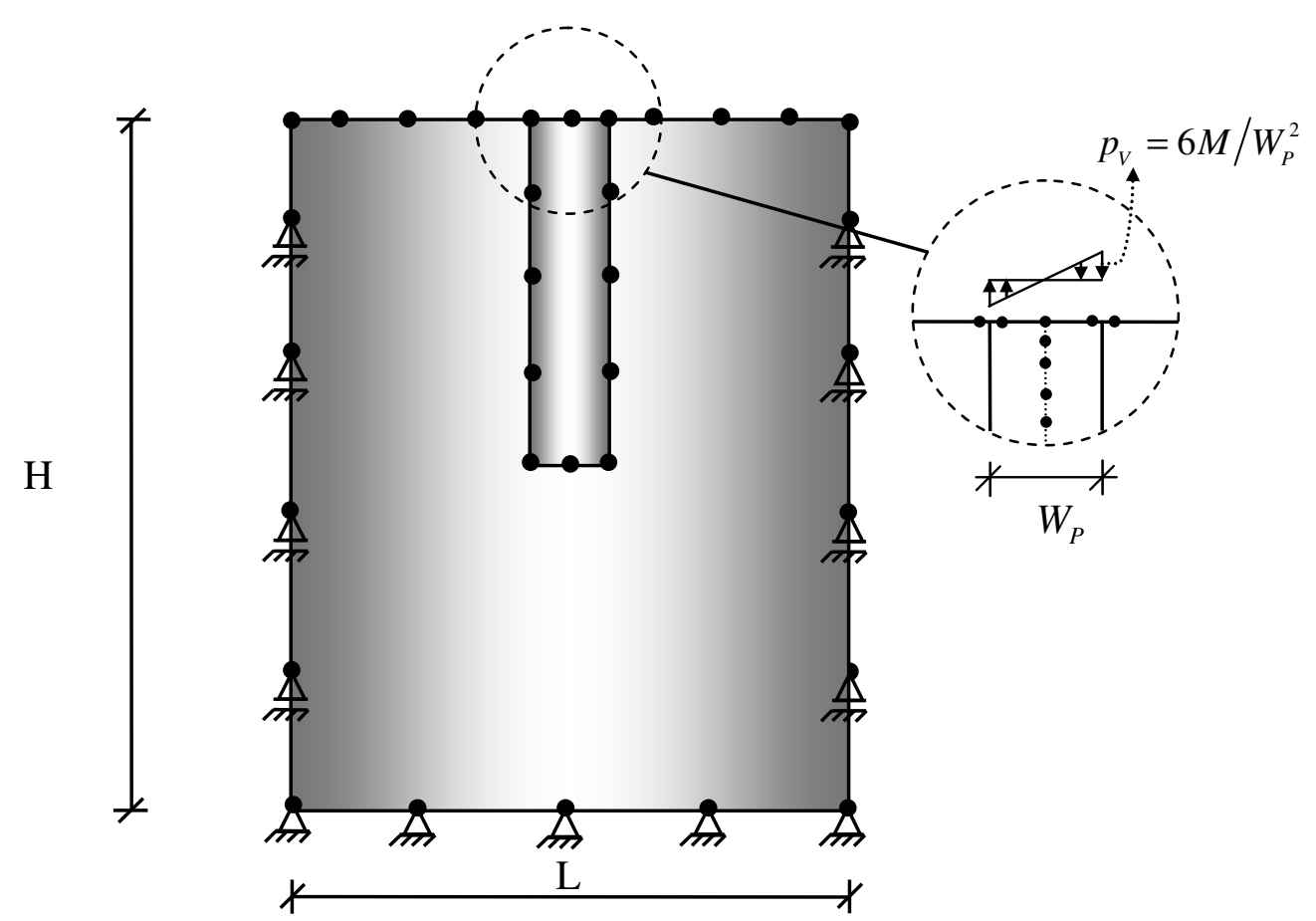

Figura 4-26 - Sólido Bidimensional com inclusão, características geométricas e carregamento.

São apresentados os resultados referentes ao momento fletor no eixo da estaca, sendo que os resultados são apresentados com aproximações quadráticas (primeiramente discretizada com 414 nós no contorno externo e 204 nós no contorno do enrijecedor e posteriormente com 564 nós no contorno externo e 504 nós no contorno do enrijecedor) e cúbicas (discretizada com 423 nós no contorno externo e 204 nós no contorno do enrijecedor) e comparados com os resultados obtidos com a ferramenta computacional ANSYS, utilizando-se modelos relativamente parecidos. Sendo que, no Ansys primeiramente foi simulada a estaca com elementos de viga (ansys1) e posteriormente com elementos de bidimensionais (ansys2), tais resultados são apresentados na Figura 4-27 e Figura 4-29, respectivamente. 


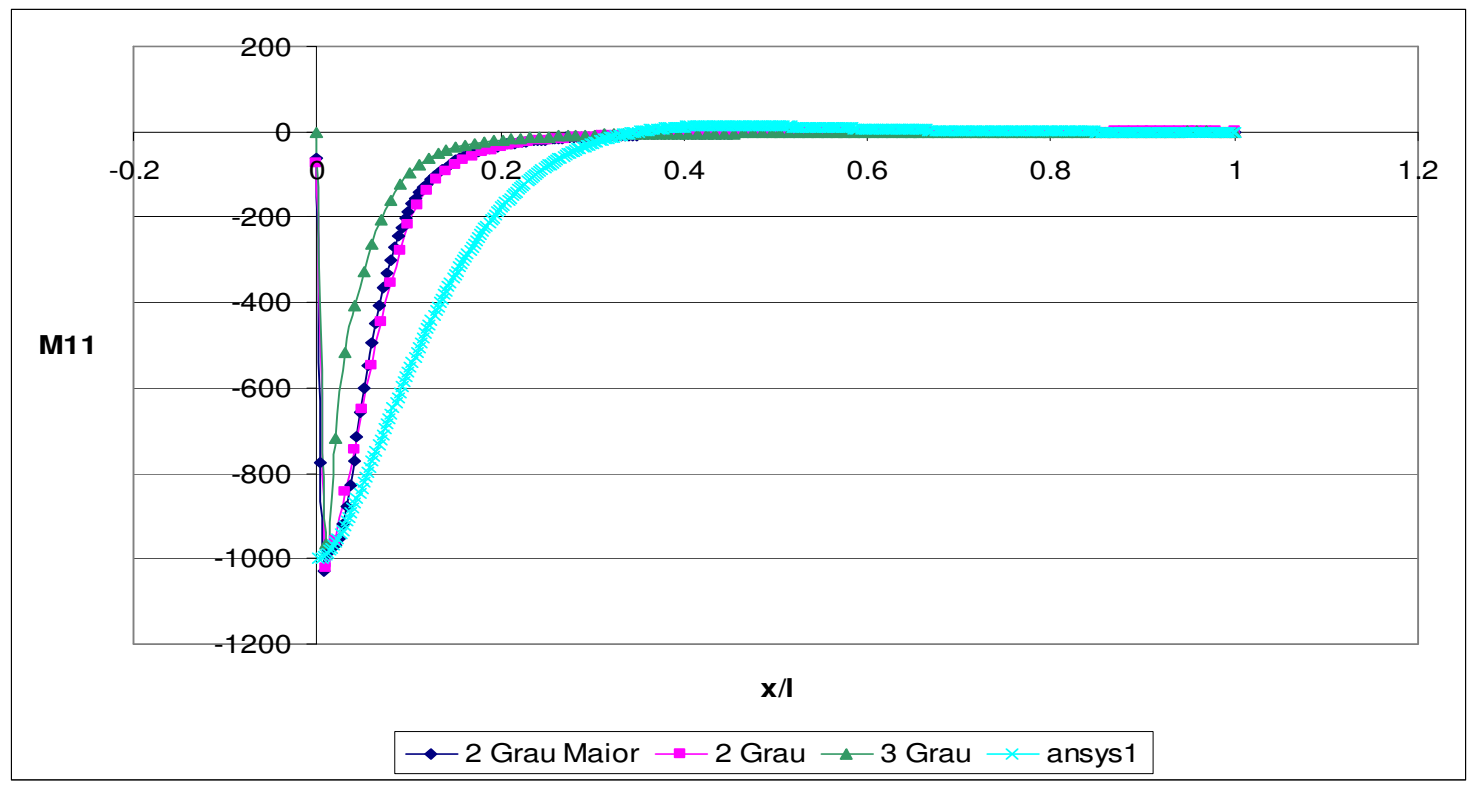

Figura 4-27 - Gráfico Momento fletor ao longo do enrijecedor comparado com (ansys1).

Considerando-se agora a diferença relativa ao resultado obtido com o ANSYS ocorrido nesta análise, na Figura 4-28.

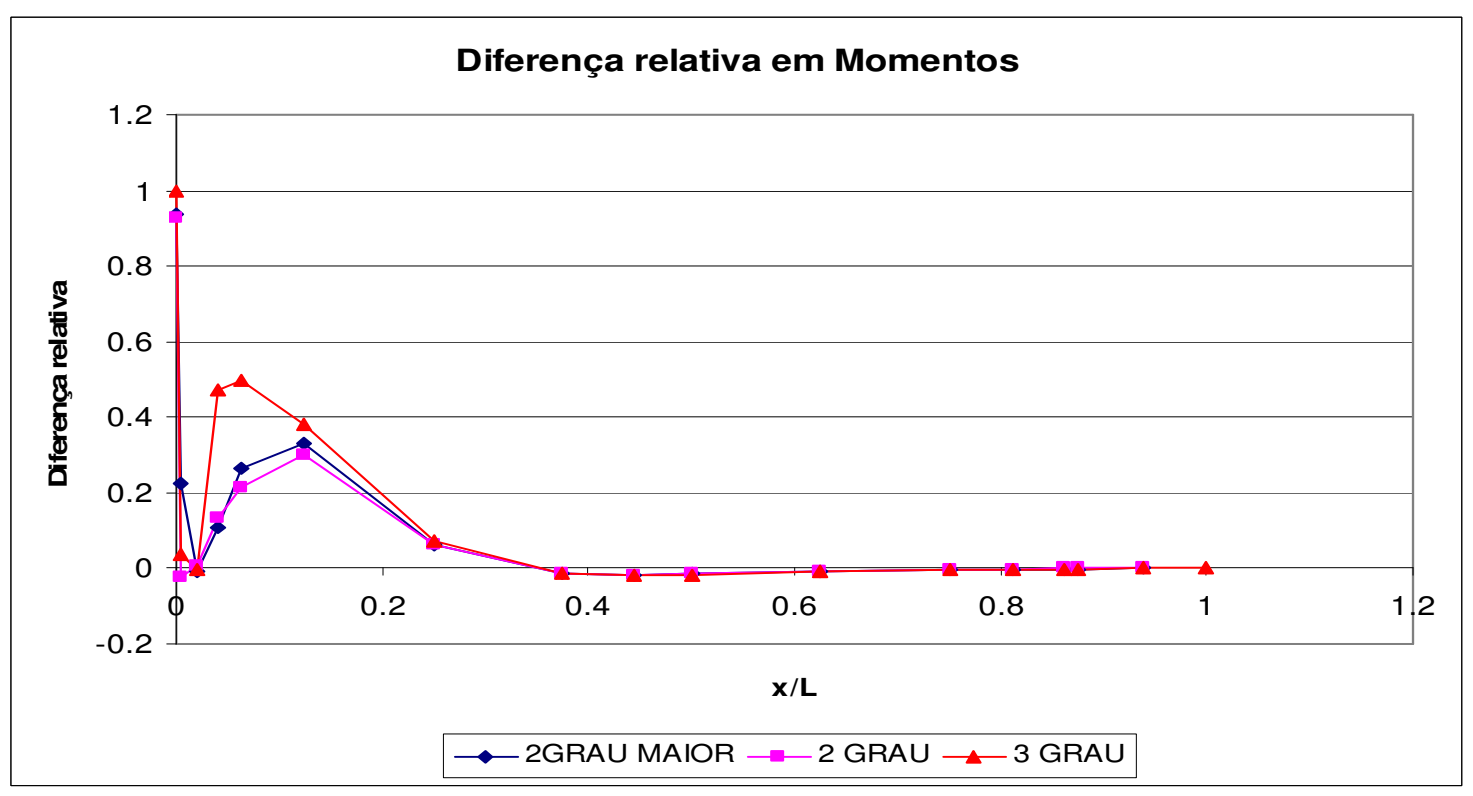

Figura 4-28 - Diferença relativa no cálculo do momento fletor no eixo do enrijecedor, (ansys1). 


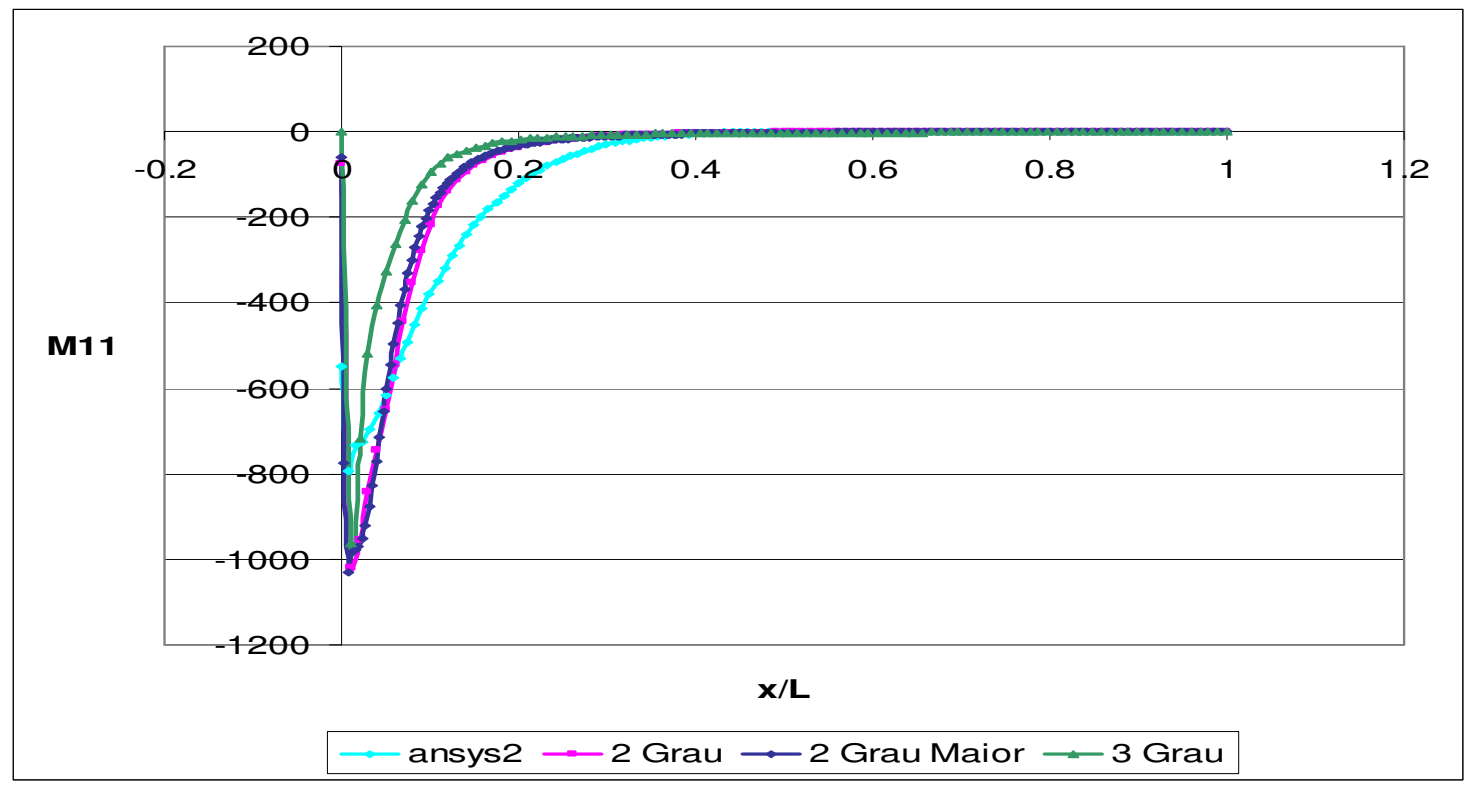

Figura 4-29 - Gráfico Momento fletor ao longo do enrijecedor comparado com (ansys2).

Considerando-se agora a diferença relativa ao resultado obtido com o ANSYS ocorrido nesta análise, na Figura 4-30.

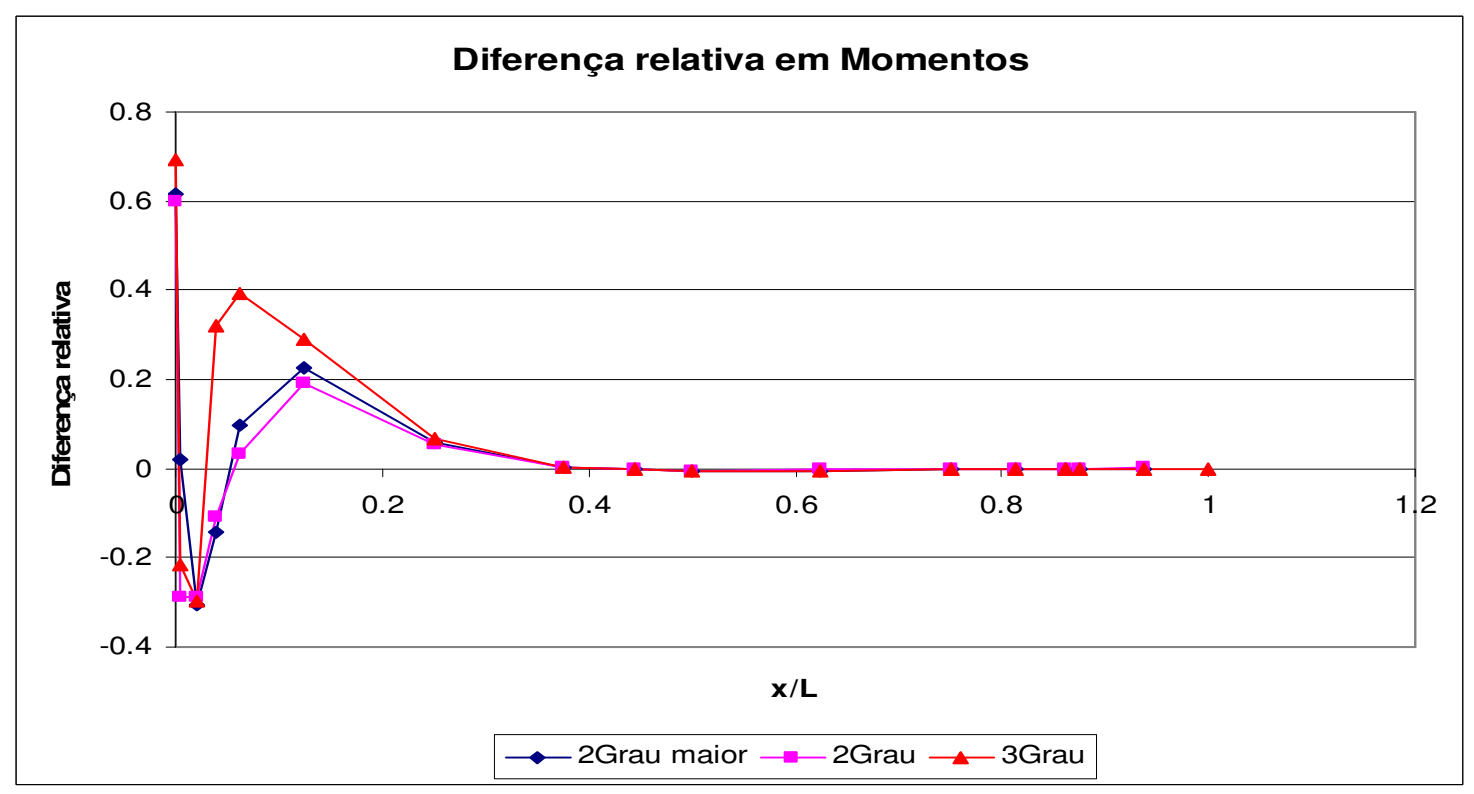

Figura 4-30 - Diferença relativa no cálculo do momento fletor no eixo do enrijecedor, (ansys2).

Como pode ser constatado pelos gráficos acima, os resultados estão coerentes, tendendo à resposta obtida com uma discretização bem refinada no 
software ANSYS, sendo que, com uma discretização relativamente pequena do MEC foram obtidas boas aproximações. 


\section{MÉTOdOS DE ANÁLISE DA FRENTE DE ESCAVAÇÃO}

É apresentada aqui uma breve revisão bibliográfica, de maneira a introduzir os conceitos referentes aos métodos de análise da interação entre o maciço e a estrutura de contenção de túneis. Iniciando pelo método ConvergênciaConfinamento, que é um dos mais simples e antigos métodos de análise da interação, e auxiliará na descrição de alguns fenômenos e na elucidação de outros métodos expostos posteriormente.

Posteriormente será apresentado o Método de Análise Simplificado da Interação Maciço-Suporte, proposto por Schwartz \& Einstein (1980), que é exposto com mais ênfase, pois devido à sua simplicidade por considerar somente suportes com propriedades constantes, tem sido largamente usado na prática de construção de túneis.

E a seguir outros métodos serão apresentados, métodos considerados mais elaborados, como o proposto por Gomes (2006) e o proposto por Hutchinson (1982).

\subsection{Método de Convergência-Confinamento}

O método de Convergência-Confinamento (ou Curvas Características) é uma ferramenta que vem sendo utilizada há muito tempo auxiliando no desenvolvimento de projeto de túneis. Segundo alguns autores, o método tem sido usado desde a publicação de Fenner (1938).

Na Figura 5-1, são apresentadas as variáveis envolvidas na análise, o maciço rochoso está sujeito a um carregamento "in situ" hidrostático $\sigma_{0}$, sendo, $\boldsymbol{u}_{\boldsymbol{r}}$ o 
deslocamento radial, $\boldsymbol{P}_{i}$ a pressão de reação do suporte nas paredes do túnel e $\boldsymbol{P}_{\boldsymbol{s}}$ representa o carregamento transmitido pelo maciço rochoso ao suporte.
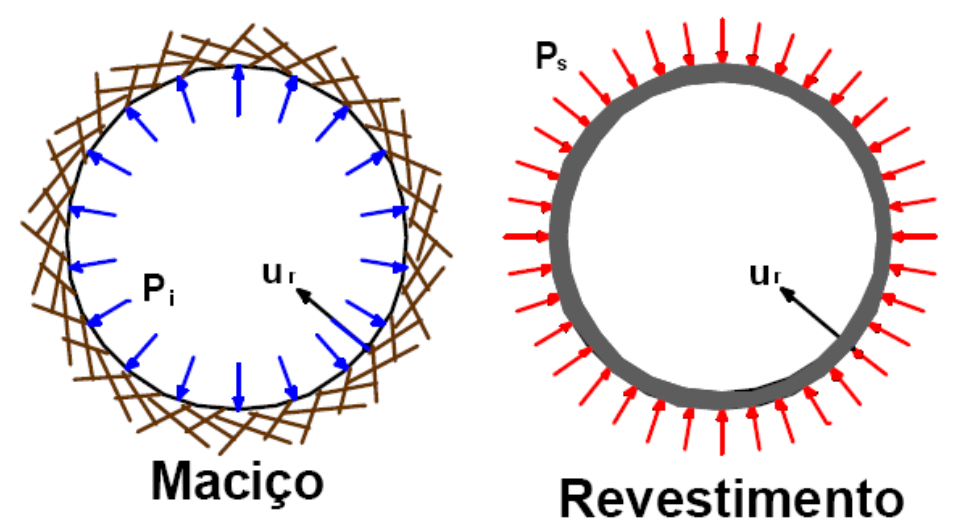

Figura 5-1 - Corte do maciço rochoso e corte do suporte na seção analisada.

Para a confecção das curvas características se procede da seguinte forma, como apresentado na Figura 5-2. No tempo inicial $t_{0}$, Figura 5-2 (a), quando é instalado o suporte na seção A-A' a uma distância $L$ da frente de escavação, ocorre um deslocamento radial $\boldsymbol{u}_{0}$, e é assumido neste instante que, até que a face avance mais além, não é transmitido carregamento ao suporte, $\boldsymbol{P}_{\boldsymbol{s}}^{0}=0$.

À medida que o túnel avança para a direita, Figura 5-2 (b), a seção A-A' analisada está agora a uma distância $L_{t}$ da face de escavação, o maciço e o suporte se deformam juntos, $\boldsymbol{u}_{r}^{t}>\boldsymbol{u}_{0}$, e o suporte passa a resistir à parte do carregamento, $\boldsymbol{P}_{s}^{t}$, anteriormente destinado à face de escavação.

Quando a frente de escavação estiver se movido suficientemente para a direita, o sistema maciço-suporte da seção A-A' estará em equilíbrio e o suporte receberá o carregamento final $\boldsymbol{P}_{\boldsymbol{s}}^{D}$, nesse instante, $t_{D}$, a influência da frente de escavação haverá desaparecido e o sistema terá desenvolvido o deslocamento final $u_{f}$. 


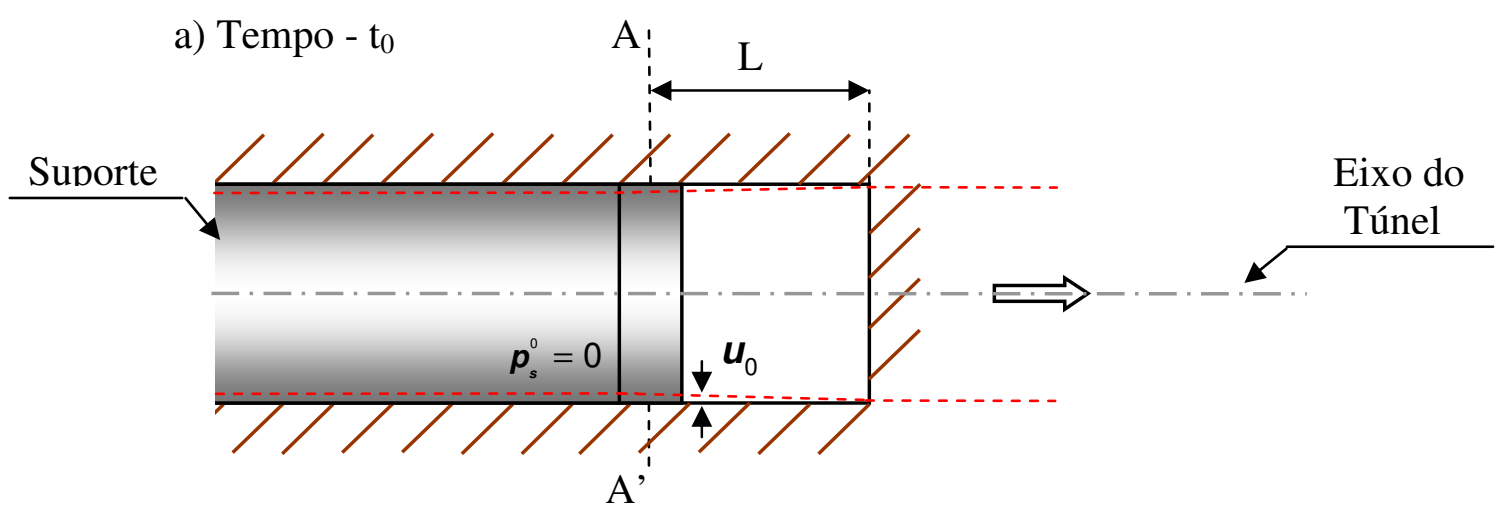

b) Tempo - $t$

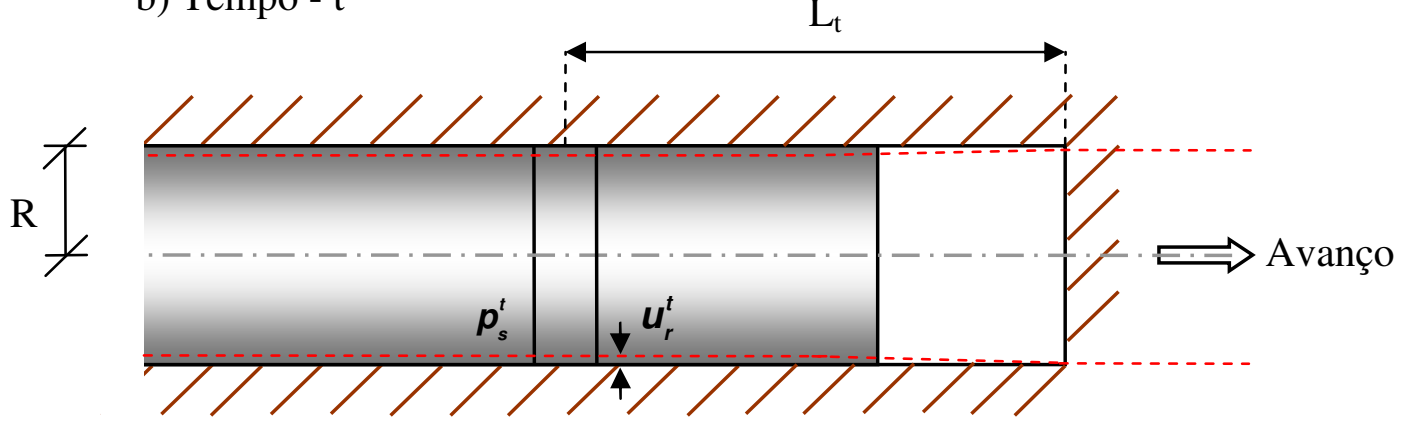

c) Tempo - $t_{D}$

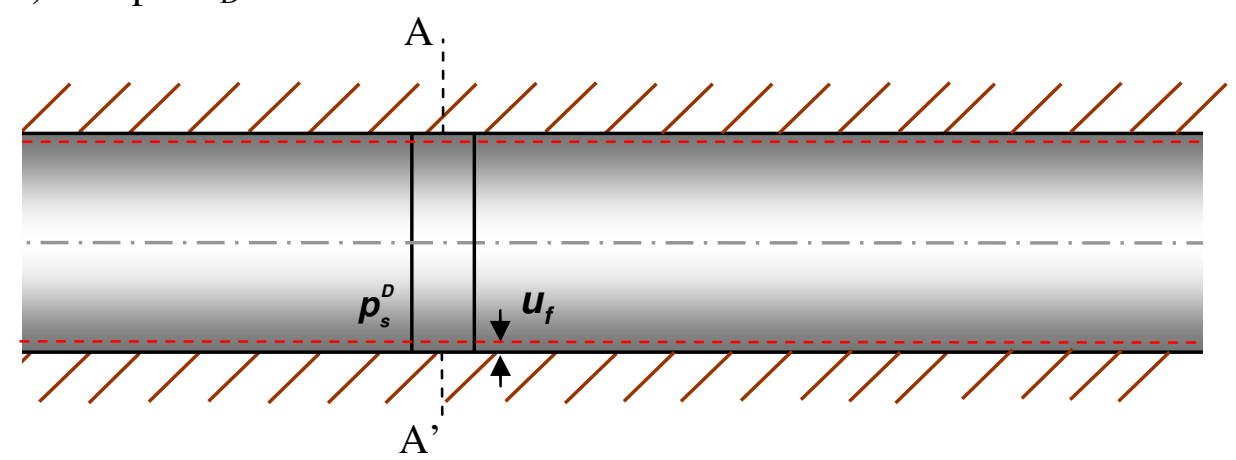

Figura 5-2 - Carregamento do suporte na seção A-A' devido ao avanço progressivo da frente de escavação.

São divididos em três os componentes básicos para o método ConvergênciaConfinamento, são eles: (i) O Perfil de Deformação Longitudinal - LDP (Longitudinal Deformation Profile); (ii) A Curva de Reação do Maciço - GRC (Ground Reaction Curve); e a Curva Característica do Suporte - SCC (Support Characteristic Curve), Carranza-Torres \& Fairhurst (2000).

O LDP é a representação gráfica do deslocamento radial que ocorre no eixo do túnel sem suporte, adiante e atrás da frente de escavação. Na Figura 5-3 é 
apresentado tal perfil na curva de cor preto, sendo que, no eixo vertical do lado direito, está representada a distância em relação à frente de escavação normalizada em relação ao diâmetro do túnel. No eixo horizontal está o deslocamento radial $\boldsymbol{u}_{\boldsymbol{r}}$, normalizado com relação ao deslocamento final da estrutura $\boldsymbol{u}_{\boldsymbol{f}}$ (correspondente ao deslocamento radial de um túnel sem suporte infinitamente longo onde não ocorre mais o "efeito face"). E no eixo vertical do lado esquerdo está representada a pressão $P_{i}$ ou $P_{s}$ agindo nas paredes do túnel e suporte, respectivamente, normalizada com relação à tensão inicial $\sigma_{0}$. O LDP é um importante componente neste método, pois indica onde o suporte começa a interagir com o maciço rochoso (define o ponto R).

Considera-se agora a curva GRC representada pela curva em azul da Figura 5-3. Tal curva é definida pela relação entre a decrescente pressão interna $\boldsymbol{P}_{\boldsymbol{i}}$ e 0 crescente deslocamento $\boldsymbol{u}_{\boldsymbol{r}}$ do maciço escavado sem inserção de suporte. É representada pela curva $\mathrm{OPQ}$, dividida em dois trechos, o primeiro trecho, $\mathrm{OP}$, em que o maciço tem o comportamento elástico e o segundo trecho, $P Q$, em que é apresentado um comportamento plástico.

E, por fim, a curva SCC que é representado pela curva em vermelho da Figura 5-3, que é formado pela crescente pressão no suporte $\boldsymbol{P}_{\boldsymbol{s}}$ e 0 crescente deslocamento $\boldsymbol{u}_{r}$ do suporte. Sendo que, o ponto $S$, é o ponto de equilíbrio do sistema. 


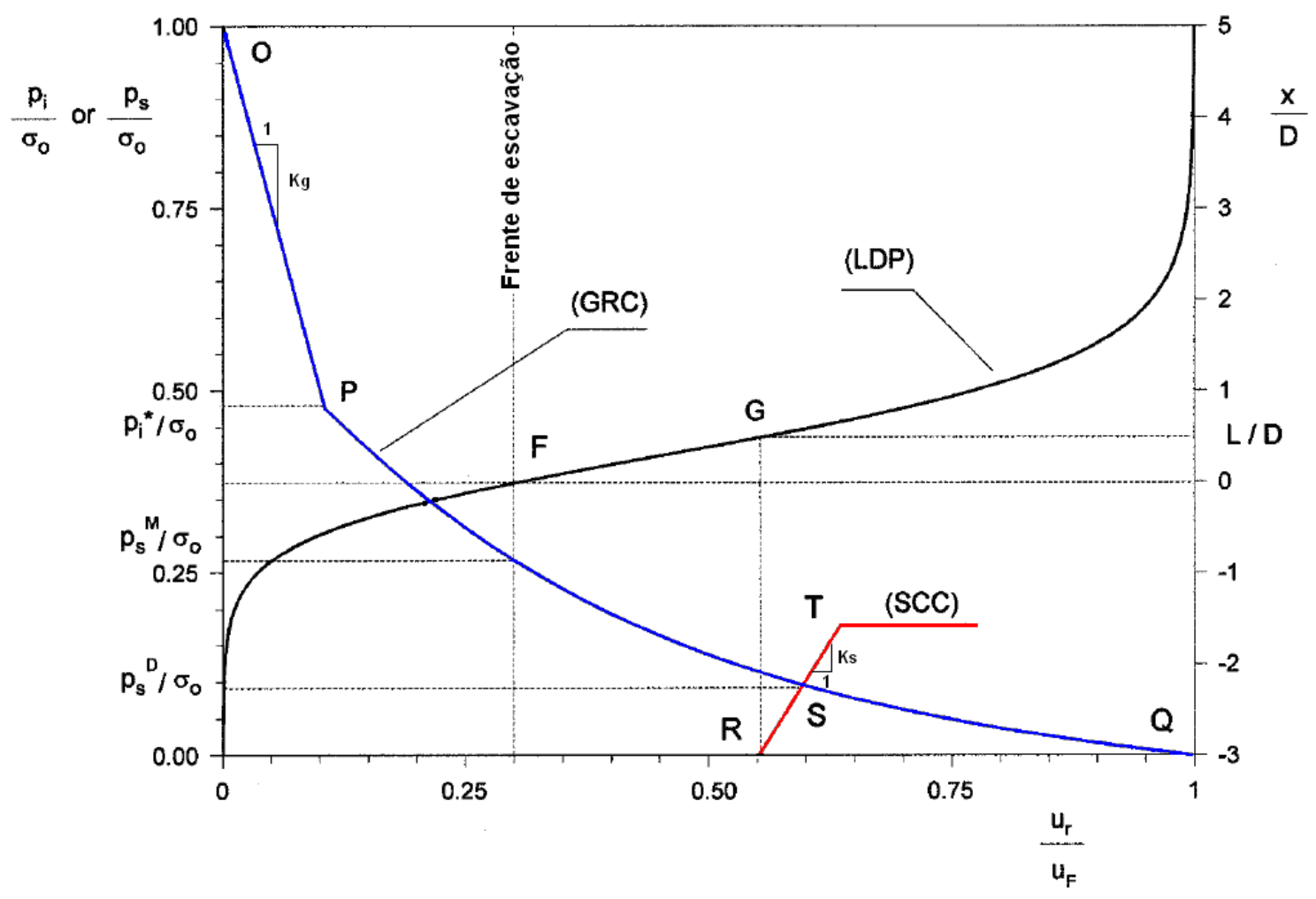

Figura 5-3 - Representação esquemática das curvas LDP, GRC e SCC.

\subsection{Método Proposto por SCHWARTZ \& EINSTEIN (1980)}

Inicialmente foi proposto em Schwartz \& Einstein (1979) uma solução analítica fechada para estimar os esforços no suporte. Tal solução é dependente principalmente da rigidez do suporte em relação ao maciço e do estado de tensão no local da escavação. Entretanto, apesar de largamente utilizado devido à sua simplicidade, o método original de Einstein e Schwartz superestima o carregamento sobre o suporte, devido a ser calculado baseado na pressão total exercida sobre o suporte, desconsiderando o alívio de tensão provocado pelo atraso na instalação do mesmo.

Posteriormente em Schwartz \& Einstein (1980) tal superestimativa foi corrigida, atribuindo agora, explicitamente, aos efeitos de três variáveis como sendo os principais responsáveis pelos esforços solicitantes encontrados em um suporte pela escavação de um túnel. São elas: a rigidez do suporte em relação ao maciço, a 
distância entre o último lance revestido e a face (atraso na instalação do suporte) e a plastificação do maciço ao redor da abertura.

Devido à complexidade do problema em questão, apesar de abranger qualquer combinação de maciço e de suporte, de levar em conta aspectos tridimensionais da escavação e o comportamento físico não-linear do maciço, neste método são levadas em consideração as seguintes hipóteses simplificadoras:

- $\quad$ O túnel é único e de seção circular;

- Apresenta profundidade o suficiente para que seja insignificante influência da superfície, e para que as variações nas tensões do maciço ao longo da altura do túnel sejam desprezíveis, quando comparadas com a magnitude total das tensões;

- $\quad$ O maciço é tratado como um meio contínuo, homogêneo e isotrópico;

- Comportamento independente do tempo nas análises tanto do maciço quanto do suporte;

- $\quad$ O suporte é considerado elástico linear;

- O suporte possui o seu "invert" completo (anel completamente fechado);

- Qualquer efeito de pressão da água nas cargas atuantes do suporte deverá ser tratado de maneira separada.

As três principais variáveis citadas anteriormente são organizadas em três passos principais para a estruturação do método, sendo eles apresentados a seguir.

\subsection{1 -1으 Passo: Rigidez Relativa}

O comportamento do suporte de um túnel é um típico problema de interação solo-estrutura. O suporte sob influência do estado de tensões do maciço contrairá e mudará de forma e com essas deformações do suporte afetarão o comportamento do maciço. Essa contração e mudança de forma do suporte dependem largamente da rigidez do suporte em relação à do maciço.

Os efeitos da rigidez relativa maciço-suporte no carregamento final são incorporados no método simplificado através das soluções analíticas fechadas já citadas anteriormente. Tais soluções assumem as condições do estado plano de 
deformações, de comportamento elástico linear do maciço e do suporte, assim como as convenções de sinais apresentadas na Figura 5-4.

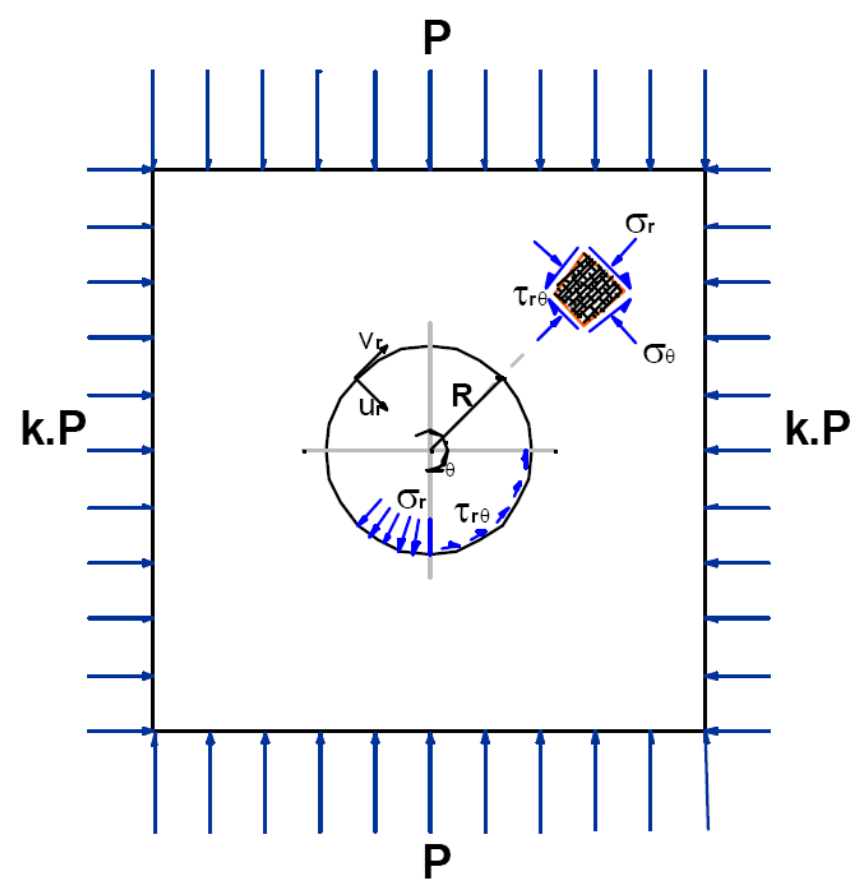

(a) Conv. sinais do maciço
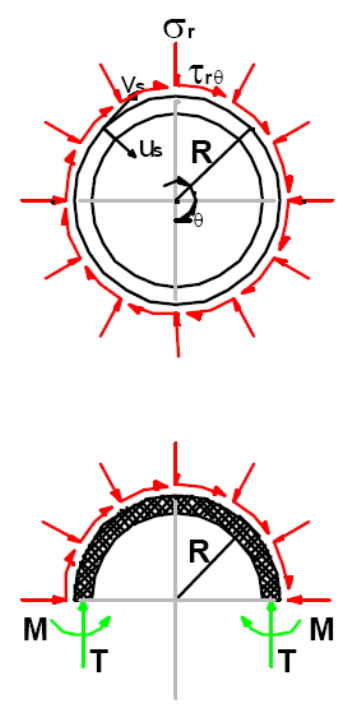

(b) Revestimento

Figura 5-4 - Convenção de sinais positivos utilizada para carregamentos e esforços solicitantes na dedução das soluções analíticas fechadas de rigidez relativa Gomes (2006).

Os esforços calculados pelas soluções analíticas fechadas podem ser pensados como esforços básicos para o desenvolvimento do método.

O coeficiente adimensional de compressibilidade, $C^{*}$, no qual se estabelece uma medida da rigidez relativa à compressão do suporte em relação ao maciço, é definido como:

$$
C^{*}=\frac{E R\left(1-v_{S}^{2}\right)}{E_{S} A_{S}\left(1-v^{2}\right)}
$$

e o coeficiente adimensional de flexibilidade, $F^{*}$, no qual se estabelece uma medida relativa à flexão do suporte e do maciço, é definido como: 


$$
F^{*}=\frac{E R^{3}\left(1-v_{S}^{2}\right)}{E_{S} I_{S}\left(1-v^{2}\right)},
$$

sendo que:

$E, v \quad$ - Módulo de elasticidade e coeficiente de Poisson do maciço;

$E_{S}, v_{S} \quad$ - Módulo de elasticidade e coeficiente de Poisson do suporte;

$A_{S} \quad$ - Área da seção transversal do suporte por unidade de comprimento longitudinal do túnel;

I $\quad$ - Momento de inércia da seção do suporte em relação a seu eixo central principal de inércia;

$R$

- Raio da escavação;

K - Coeficiente de empuxo lateral do maciço.

$\mathrm{Na}$ dedução das expressões analíticas para os esforços solicitantes de compressão, 'T', e de momento, 'M', são consideradas duas condições limites de transferência de tensões cisalhantes na interface maciço-suporte. A primeira delas permite o deslizamento total do suporte relativo ao maciço, com isso não há transferência de tensões cisalhantes, ou seja, $\tau_{r \theta}=0$. O que nos leva a:

$$
\frac{T}{P R}=\frac{1}{2}(1+K)\left(1-a_{0}^{*}\right)+\frac{1}{2}(1-K)\left(1-2 a_{2}^{*}\right) \cos (2 \theta),
$$

e

$$
\frac{M}{P R^{2}}=\frac{1}{2}(1-K)\left(1-2 a_{2}^{*}\right) \cos (2 \theta)
$$

com: 


$$
a_{0}^{*}=\frac{C^{*} F^{*}(1-v)}{C^{*}+F^{*}+C^{*} F^{*}(1-v)},
$$

e

$$
a_{2}^{*}=\frac{\left(6+F^{*}\right)(1-v)}{2 F^{*}(1-v)+6(5-6 v)} .
$$

As equações obtidas através da consideração da condição de deslizamento relativo impedido, ou de transferência total de esforços cisalhantes na interface entre o maciço e o suporte, são:

$$
\frac{T}{P R}=\frac{1}{2}(1+K)\left(1-a_{0}^{*}\right)+\frac{1}{2}(1-K)\left(1-2 a_{2}^{*}\right) \cos (2 \theta),
$$

e

$$
\frac{M}{P R^{2}}=\frac{1}{4}(1-K)\left(1-2 a_{2}^{*}+2 b_{2}^{*}\right) \cos (2 \theta),
$$

com:

$$
\beta=\frac{C^{*}\left(6+F^{*}\right)(1-v)+2 v F^{*}}{3 F^{*}+3 C^{*}+2 C^{*} F^{*}(1-v)},
$$

e

$$
b_{2}^{*}=\frac{C^{*}(1-v)}{2\left\{C^{*}(1-v)+4 v-6 \beta-3 \beta C^{*}(1-v)\right\}},
$$

sendo: 


$$
a_{2}^{*}=\beta b_{2}^{*} .
$$

A partir de análises paramétricas executadas com as expressões acima, Schwartz \& Einstein (1980) chegaram a algumas conclusões gerais acerca da sensibilidade dos esforços solicitantes às variações nos parâmetros de entrada, dentre elas, expôs, que baseado em considerações teóricas de equilíbrio limite, a maioria das situações reais analisadas pelo método são satisfeitas pela consideração de não se transferir tensões cisalhantes pela interface. Mesmo nos casos onde a total transferência de cisalhamento é encontrada, as diferenças entre os esforços calculados por ambas as formas são pequenas.

\subsection{2 -2o Passo: Atraso na Instalação do Suporte}

Os deslocamentos radiais do maciço ocorridos adiante da face, ou seja, bem antes de ser escavado, atingem uma parcela de 20 a $35 \%$ dos deslocamentos radiais totais ao redor do túnel, como é apresentado na Figura 5-5.

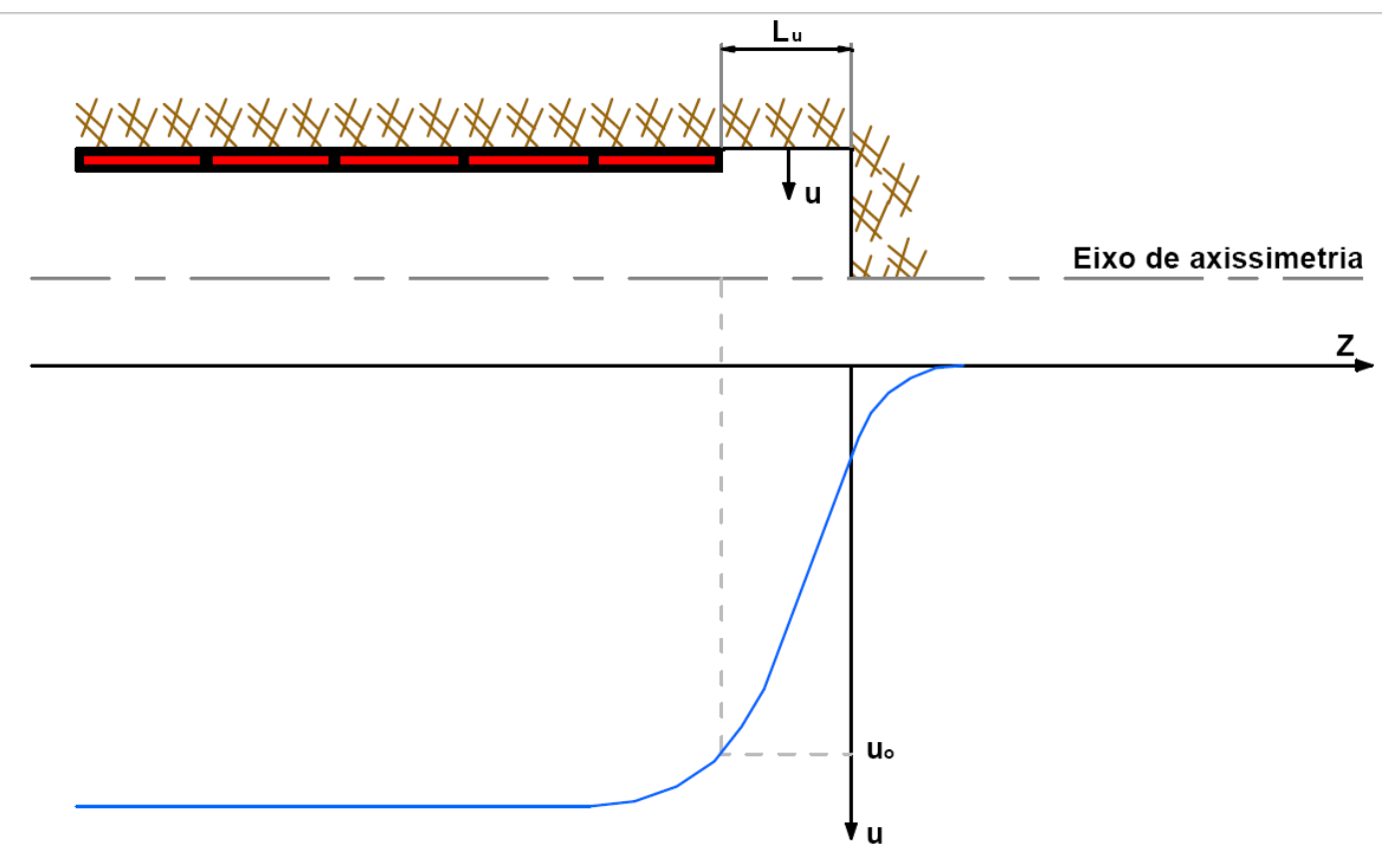

Figura 5-5 - Deslocamentos radiais ocorridos anterior e posteriormente à passagem da face, Gomes (2006). 
E, como também pode ser visto na Figura 5-5, outros deslocamentos são gerados pelo fato de que o suporte não é construído simultaneamente à retirada de material do último lance escavado, restando assim uma região não revestida de comprimento $\mathrm{L}_{u}$. Ao analisar o deslocamento radial total anterior a instalação do suporte, chega-se a conclusão de que o maciço acaba por arcar sozinho com parte do carregamento, anteriormente destinado ao suporte nas soluções de rigidez relativa.

Tal redução dos carregamentos no suporte, ocasionada pela distancia entre o último lance de suporte instalado e a frente de escavação, foi determinada por análises numéricas ( $K=1$, através do Método dos Elementos Finitos) e expressões analíticas ( $K \neq 1$, através da redução do módulo de elasticidade do núcleo do túnel). Essas análises assumiram um comportamento elástico linear para o maciço e o suporte. Os resultados dessas análises, em ambos os casos, a redução nos esforços do suporte é representada por um fator de atraso, chamado de $\lambda_{d}$, e é definido matematicamente por:

$$
\lambda_{d}=\frac{u_{f}-u_{0}}{u_{f}}=\frac{P_{s}^{\prime}}{P_{s}},
$$

sendo que $P_{S}$ representa o esforço básico de compressão do suporte calculado no primeiro passo e $P_{S}^{\prime}$ é o esforço de compressão reduzido dos efeitos de atraso do suporte.

No passo em estudo, o principal parâmetro considerado é o comprimento de atraso normalizado $L_{d} / R$. O parâmetro $L_{d}$ é entendido como a distância entre a face e o ponto médio do último segmento de suporte executado de comprimento $L_{S}$, como apresentado na Figura 5-6. 


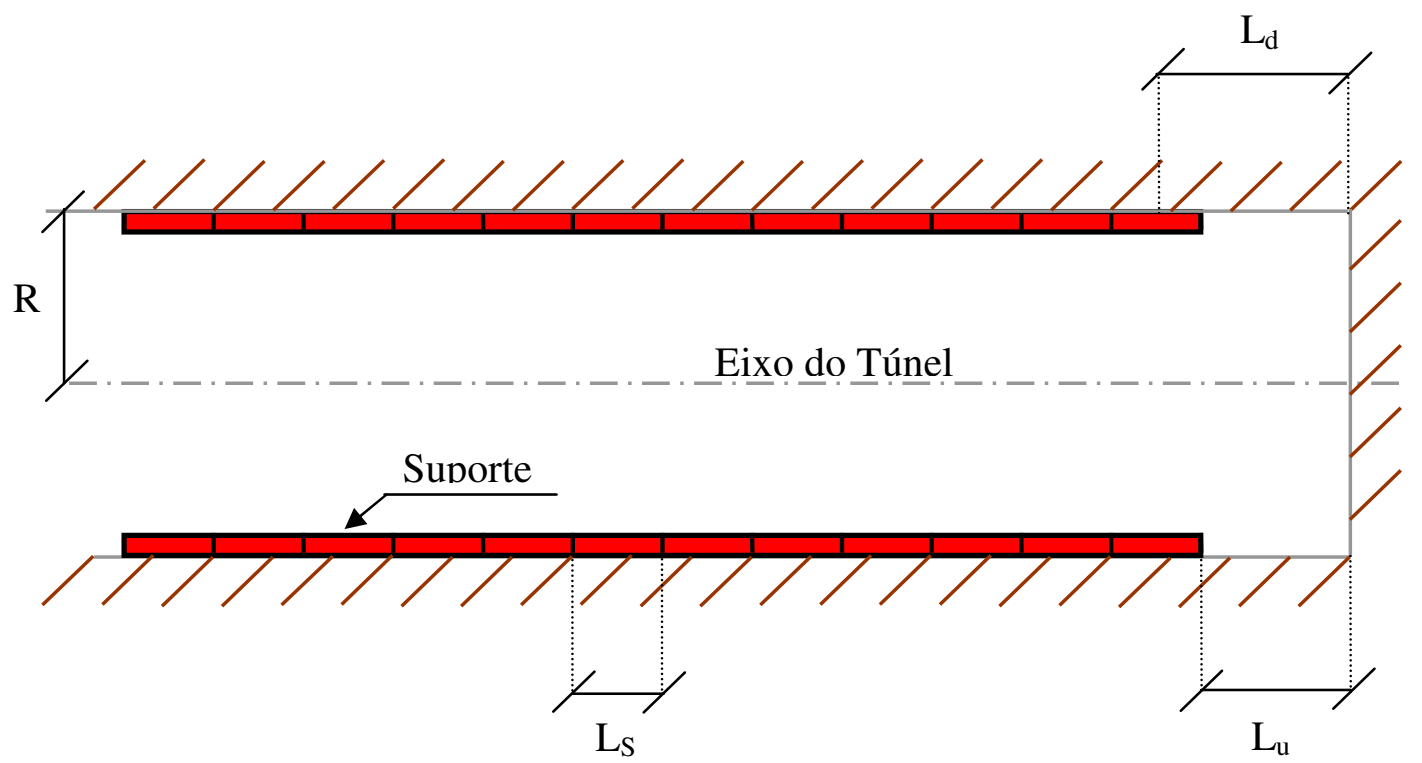

Figura 5-6 - Seção de um túnel circular (situação posterior à escavação).

A relação entre $\lambda_{d}$ e $L_{d} / R$ foi determinada pela correlação de forma adimensionalizada entre os esforços solicitantes de compressão resultantes das análises axissimétricas em elementos finitos e a distância à frente de escavação. $A$ regressão linear entre as variáveis de atraso e esforços solicitantes gerou a equação:

$$
\lambda_{d}=0.982-0.571\left(\frac{L_{d}}{R}\right) .
$$

Sendo que os limites físicos para $\lambda_{d}$, varia entre os extremos um, que indica que o processo de escavação e revestimento é simultâneo, e zero, que indica que não ocorre o revestimento da abertura ou que houve um grande atraso na instalação do suporte.

\subsection{3 -3ำ Passo: Plastificação do Maciço}

A precisa determinação dos efeitos de plastificação do maciço é algo complexo, pois os efeitos da rigidez relativa do suporte, o seu atraso de instalação e a plasticidade estão todos acoplados. 
Para os conjuntos de estudos em questão, foi indicado um fator de plasticidade $\lambda_{y}$ para representar os efeitos da plastificação do maciço, como demonstra a expressão abaixo:

$$
\lambda_{y}=\frac{P_{S}^{*}}{P_{S}^{\prime}}=\frac{P_{S}^{*}}{\lambda_{d} P_{S}},
$$

sendo que, como apresentado na Figura 5-7, o termo $P_{S}^{\prime}$ é a pressão de equilíbrio do sistema maciço-suporte no caso elástico, reduzida pelos efeitos do atraso do suporte por $\lambda_{d}$. $P_{S}^{*}$ é a pressão de equilíbrio do suporte no caso de plastificação. O fator $\lambda_{y}$ possui um limite físico inferior de um, correspondente ao comportamento completamente elástico do maciço, mas não possui limite superior.

A pressão de equilíbrio do suporte, em um maciço elástico perfeitamente plástico, deve satisfazer a equação a seguir:

$$
f_{g}(P)-f_{s}(P)-f_{d}^{\prime}\left(\lambda_{d}\right)=0
$$

onde

$f_{g}(P) \quad$ - relação funcional entre os deslocamentos radiais e as pressões internas para um maciço, ou seja, a curva característica do maciço. Schwartz \& Einstein (1980) utilizaram este valor usando o critério de plastificação de MohrCoulomb com zero de variação do volume total da zona plastificada;

$f_{s}(P) \quad$ - curva característica do suporte, expressa também por:

$$
f_{s}(P)=\frac{P_{s} R^{2}\left(1-v^{2}\right)}{E_{s} A_{s}} ;
$$

$f_{d}^{\prime}\left(\lambda_{d}\right) \quad$ - representa o translado da curva característica do suporte, correspondente ao atraso na sua instalação, também expressa por: 


$$
f_{d}^{\prime}=\frac{P R(1+v)}{E_{s}}\left(1-\lambda_{d}\right),
$$

onde, nas equações (5.16) e (5.17), $E_{s}$ é o módulo de elasticidade do suporte, $A_{s}$ é a área do suporte e $v$ é o coeficiente de Poisson do suporte.

A equação (5.15) pode ser representada também graficamente pelas curvas características da Figura 5-7.

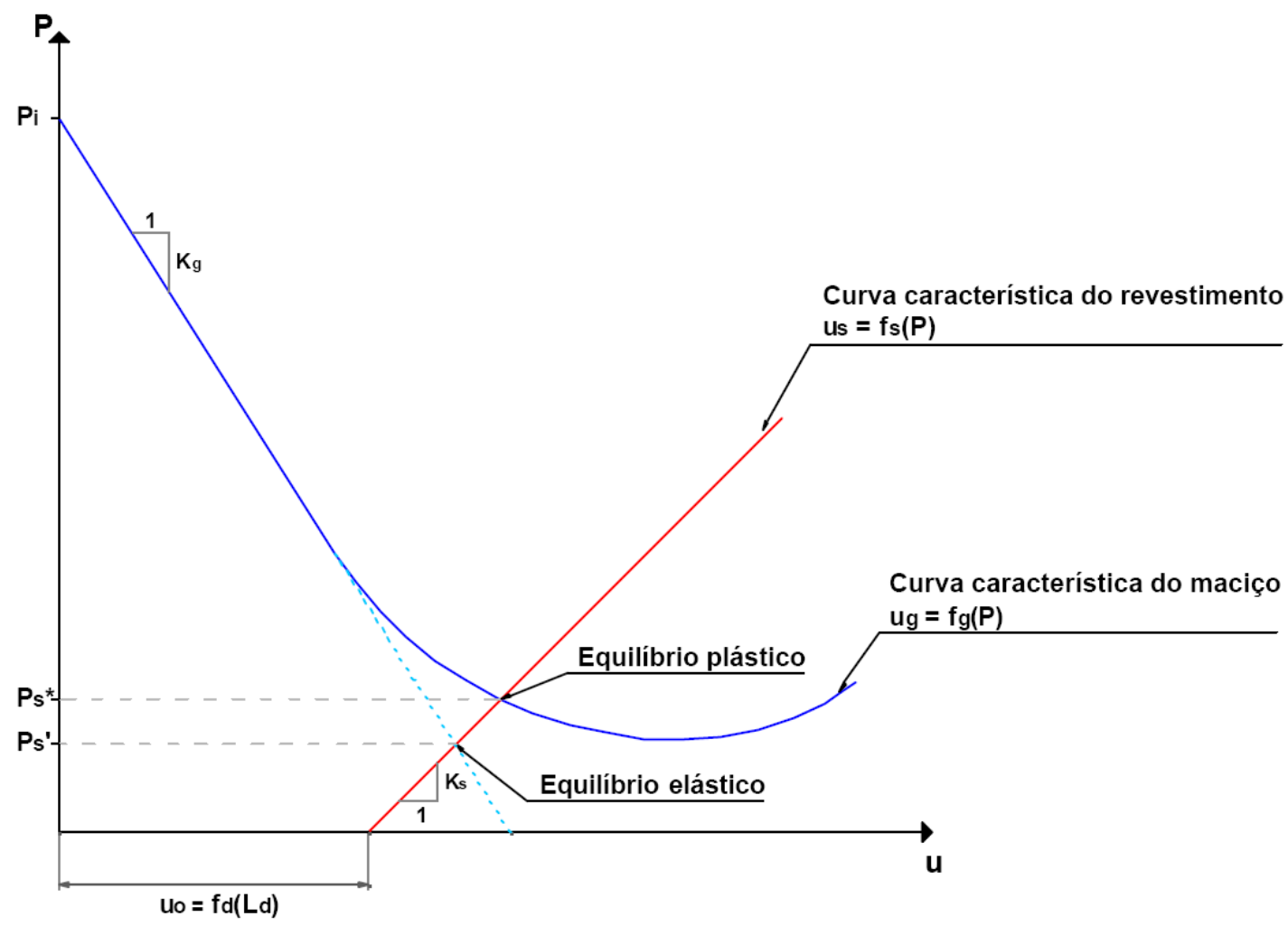

Figura 5-7 - Representação gráfica da equação (5.15), Gomes (2006).

Para se calcular o fator de plastificação, a equação (5.15) deve ser resolvida duas vezes. Primeiramente $P_{S}^{\prime}$ é calculado considerando-se o maciço com comportamento elástico. Na segunda vez, considera-se comportamento plástico e calcula-se $P_{S}^{*}$. Feito isso, o fator de plastificação é calculado como sendo a razão $P_{s}^{*} / P_{s}^{\prime}$.

O esforço do suporte, $T$, é então calculado:

$$
T^{*}=\lambda_{d} \lambda_{y} T
$$


sendo que:

$T$ - esforço solicitante de compressão do suporte, calculado pela original solução fechada de Schwartz \& Einstein (1979);

$\lambda_{d} \quad$ - fator de atraso;

$\lambda_{y} \quad$ - fator de plastificação;

$T^{*} \quad$ - esforço solicitante final de projeto.

\subsection{Método Proposto por HUTCHINSON (1982)}

Hutchinson (apud KIM; EISENSTEIN, 2006) propôs uma alteração no método de cálculo do fator de atraso de instalação do suporte, proposto por Schwartz \& Einstein (1980). Hutchinson observou que $L_{d}^{\prime}$, a distância da face anterior à escavação até ao centro do último segmento de suporte como apresentado na Figura 5-8, deveria ser considerado como o comprimento de atraso para as seqüências atuais de escavação baseadas em análises axissimétricas com elementos finitos e baseadas em casos históricos. Sugeriu que houvesse uma alteração na equação da reta, responsável pelo cálculo do fator de atraso da instalação do suporte $\lambda_{d}$ para:

$$
\lambda_{d}=0,70-0,57\left(\frac{L_{d}^{\prime}}{R}\right) .
$$

Hutchinson sugeriu tal alteração baseado na suposição de que a escavação e instalação do suporte não podem ser feito ao mesmo tempo, como exposto nas análises por elementos finitos efetuadas por Schwartz \& Einstein. Neste trabalho também foi proposta outra alteração adicionando um termo referente ao deslocamento inicial do maciço. 


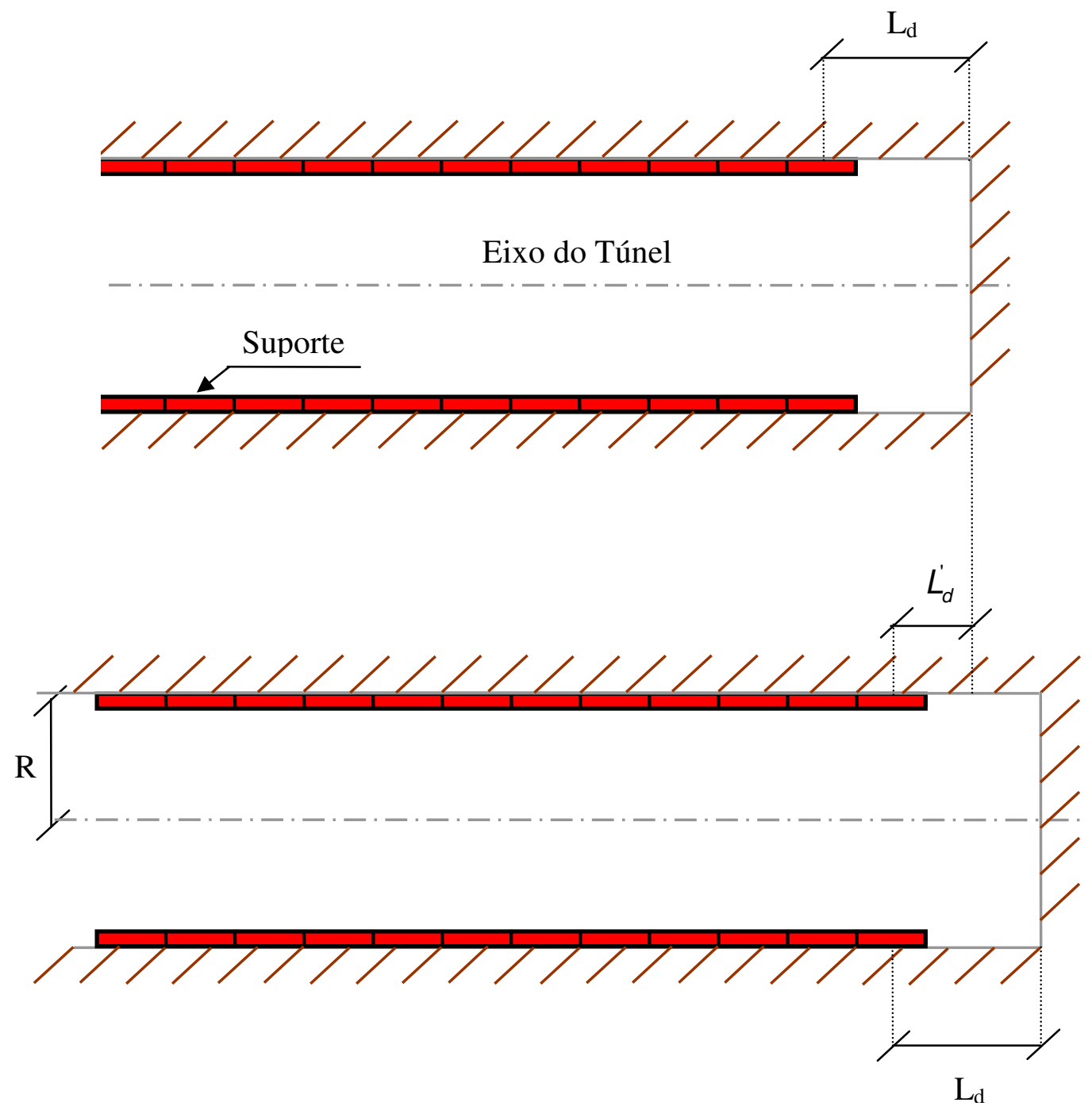

Figura 5-8 - Seqüência de escavação.

A alteração na formulação de Schwartz \& Einstein proposta por Hutchinson proporcionou melhores resultados nas comparações realizadas. E segundo Kim \& Eisenstein (2006) o método proposto traz bons resultados para túneis com pequeno comprimento de atraso, isto é, $L_{d}^{\prime} / R$ menor que um.

\subsection{Método Proposto por Gomes (2006)}

Em Gomes (2006) foi mostrado, por meio de análises numéricas tridimensionais, que a solução proposta por Schwartz \& Einstein (1980) para levar em conta o efeito do atraso de instalação do suporte no mecanismo de transferência 
de carga do maciço para a estrutura incorre em erros significativos ao não levar em conta a dimensão de escavação, e a rigidez do maciço na região da frente de escavação do túnel. Além disso, há uma incongruência naquela formulação, que será apresentada a seguir, relativa à simulação numérica do menor dos comprimentos de atraso na instalação do suporte.

Uma solução alternativa à de Schwartz \& Einstein (1980) foi apresentada, incorporando todos os parâmetros geométricos e físicos relevantes da escavação subterrânea, inclusive o endurecimento do suporte de concreto projetado ao longo do eixo do túnel e a anisotropia de tensões principais, com grande vantagem de precisão. Além disso, foi apresentado de maneira não muito conclusiva que a suposição feita por Schwartz \& Einstein (1980), de que o mesmo coeficiente de atraso determina os esforços normais de compressão seria responsável pela determinação dos esforços de flexão, pode estar correta, pois os pontos mostram dispersões muito semelhantes nos dois casos.

Foi utilizado nas simulações realizadas por Schwartz \& Einstein (1980) um modelo axissimétrico pouco refinado, como apresentado na Figura 5-9.

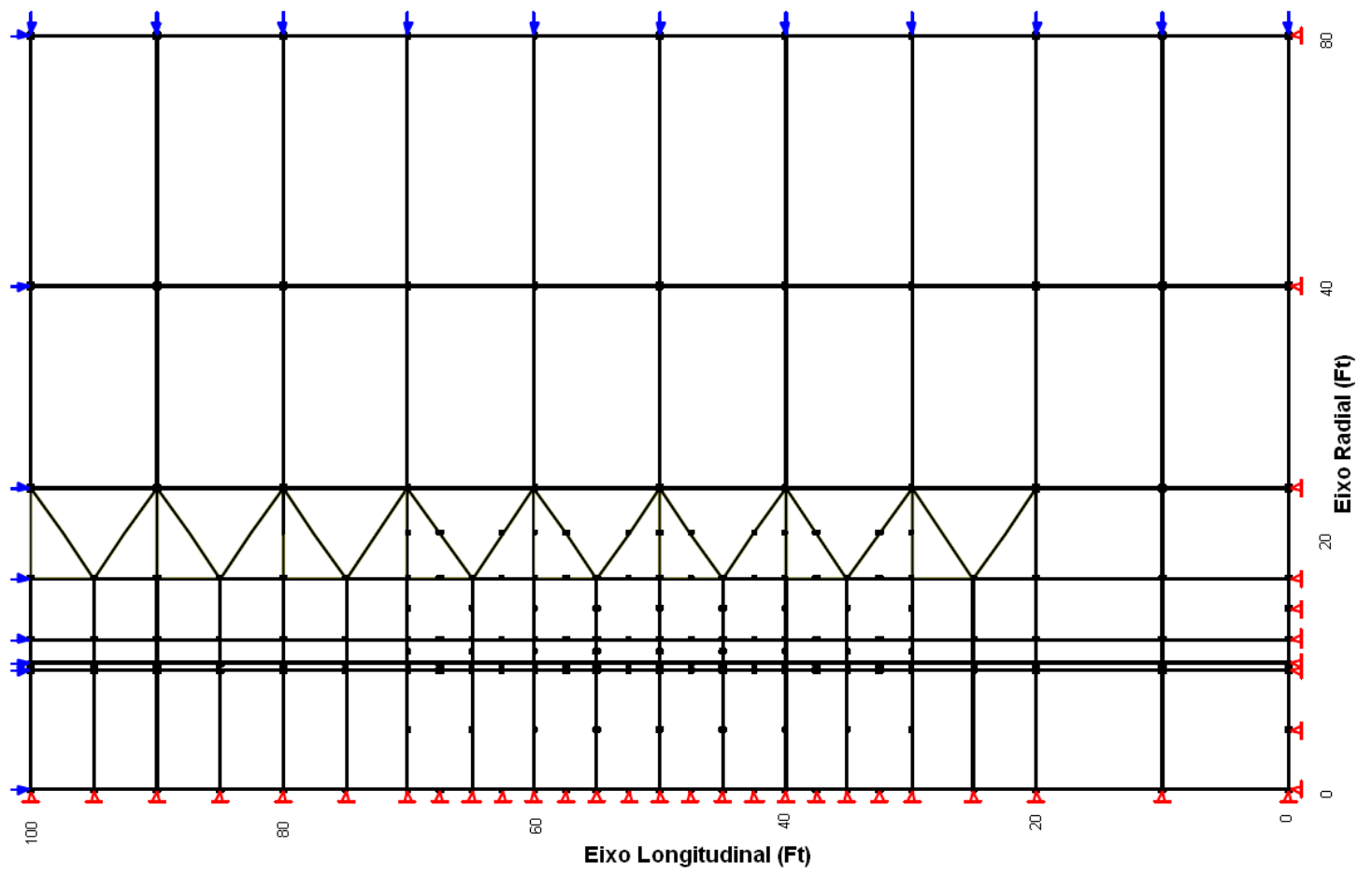

Figura 5-9 - Reprodução da malha de elementos finitos utilizada por, Schwartz \& Einstein (1980). 
Em tal discretização foram utilizados 118 elementos e 225 nós, apresentando assim um total de 402 graus de liberdade. Sendo, portanto, uma malha muito pobre para um problema com tamanha complexidade.

Outro ponto importante de se observar no trabalho de Schwartz \& Einstein (1980) é que, ao se observar a Figura 5-10, verifica-se que o comprimento de atraso $L_{d} / R=0,25$ não pode ser considerado como válido, pois esse comprimento de atraso indica que, para a convenção adotada, que o revestimento é introduzido antes de se escavar o maciço, não sendo esse o intuito deste trabalho. Visto isso, esta solução adimensional foi obtida através de uma regressão linear com base em três nuvens de pontos, tais nuvens referentes aos três atrasos na instalação do suporte, $L_{d} / R=$ 0,$25 ; 0,75 ; 1,25$. No entanto, a situação $L_{d} / R=0,25$ representa uma situação irreal de escavação e deve ser descartada. Assim, o que resta são apenas duas nuvens de pontos para o ajuste de uma reta, resultando em uma regressão linear com um grau de significância muito baixo. Somando a esta insuficiência de dados aos outros fatores já citados, o nível de precisão atingido pela solução adimensional na quantificação de esforços para qualquer atraso na instalação do suporte é altamente comprometido.

Através de análises numéricas tridimensionais mais elaboradas, Gomes (2006) realizou um estudo estatístico das variáveis relevantes no problema em questão de forma a ajustar da melhor forma a compressão adimensional $\mathrm{T}^{*}$ tanto para as propriedades do enrijecedor constantes apresentado na equação (5.20), como com a consideração do endurecimento do concreto projetado.

$$
\begin{aligned}
& T^{*}=-0.035 \ln \left(E_{m} / E_{s}\right)-0.103 \ln \left(L_{e} / R\right)-0.301 \ln \left(L_{u i} / L_{e}+1\right) \\
& +0.013 \ln \left(E_{m} / E_{s}\right) \ln \left(L_{e} / R\right)+0.034 \ln \left(E_{m} / E_{s}\right) \ln \left(L_{u i} / L_{e}+1\right) \\
& -0.086 \ln \left(L_{e} / R\right) \ln \left(L_{u i} / L_{e}+1\right)+0.304
\end{aligned}
$$



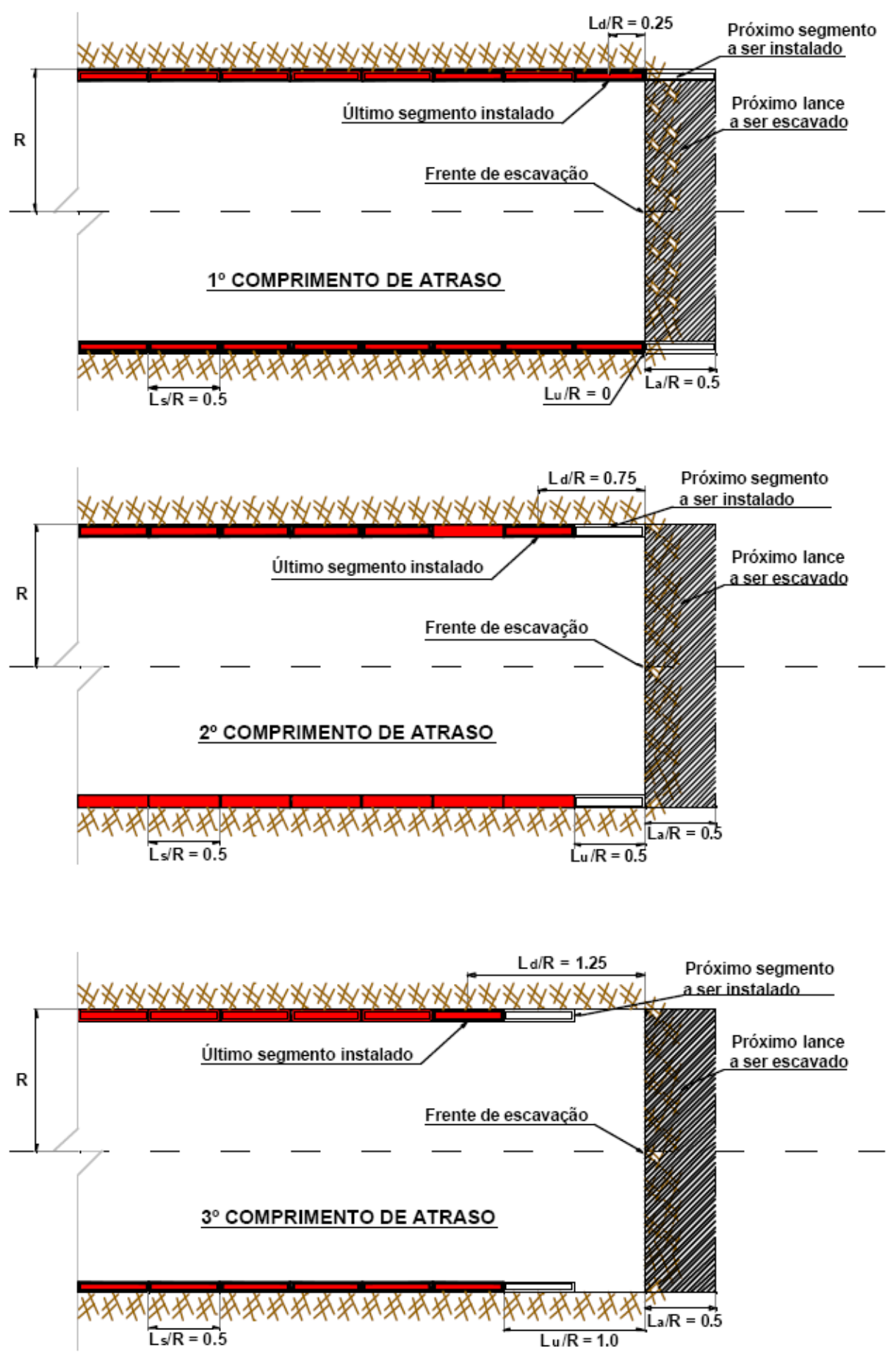

Figura 5-10 - Representação dos três comprimentos de atraso simulados por Schwartz \& Einstein (1980) (GOMES 2006).

Sendo que, $E_{m}$ e $E_{s}$ são os módulos de elasticidade do maciço e do suporte, respectivamente. $\mathrm{E}$ as variáveis responsáveis pela geometria estão descritas na Figura 5-11. 


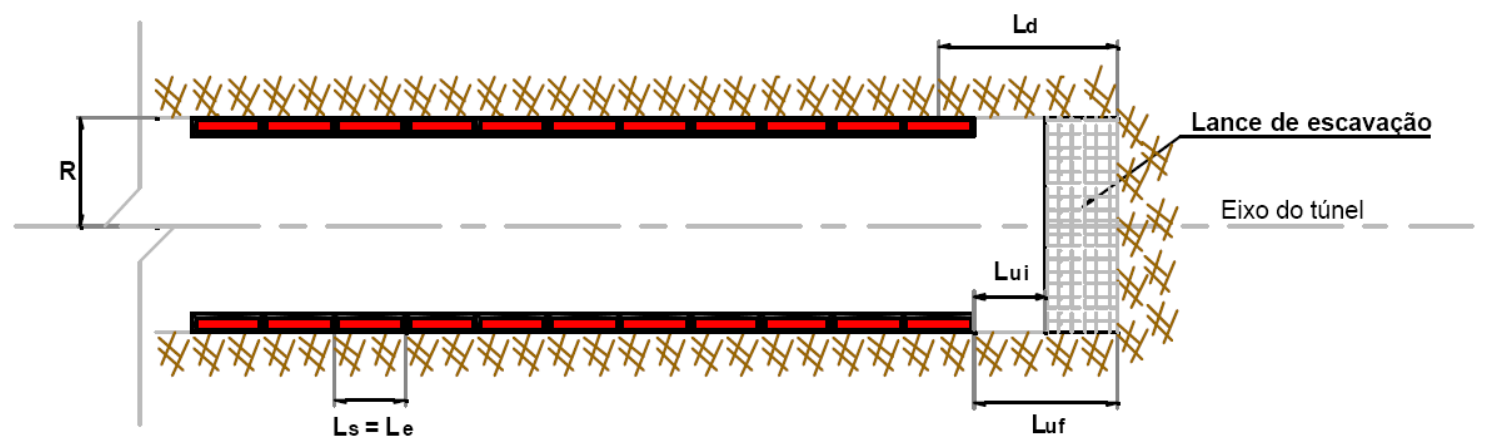

Figura 5-11 - Representação gráfica da nomenclatura geométrica adotada em (GOMES 2006), (GOMES 2006). 


\section{MOdELAGEM DA FRENTE DE escavaçÃo DE TÚNEIS}

Neste capítulo é apresentada a formulação base e o desenvolvimento dos fatores que possibilitam a utilização de um modelo bidimensional levando em consideração o efeito tridimensional da escavação de túneis com e sem suporte. Sendo que, inicialmente é apresentada a teoria básica de Panet e Guenot (1982), como uma forma introdutória ao tratamento de escavações sem suporte.

\subsection{Método Convergência-confinamento Panet e Guenot (Método de alívio de tensão)}

O método de Convergência-confinamento introduzido por Panet e Guenot (1982), é um dos métodos usados para considerar o efeito de "face" tridimensional, utilizando um estado plano de deformações, Karakus (2007). De acordo com este método, a tensão radial $\left(\sigma_{r}\right)$ na borda do túnel para simular esse efeito de face é dada por:

$$
\sigma_{r}=(1-\lambda) \sigma^{0}
$$

sendo $\lambda$ o fator de redução da tensão inicial $\sigma^{0}$, varia de 0 a 1 e é dado por:

$$
\lambda=\frac{u_{r}(x)}{u_{f}}
$$


e sendo $u_{f}$ o deslocamento radial máximo do túnel atrás da face de escavação. Dado também por:

$$
u_{f}=\frac{1+v}{E} \sigma^{0} r
$$

onde r é o raio do túnel.

Considerando um problema de túnel bidimensional, como ilustrado na Figura 6-1, no estado plano de deformações, a tensão radial $\left(\sigma_{r}\right)$ é aplicada à borda do túnel que vai sofrer um decréscimo de $\sigma^{0}$ até zero no caso sem suporte.

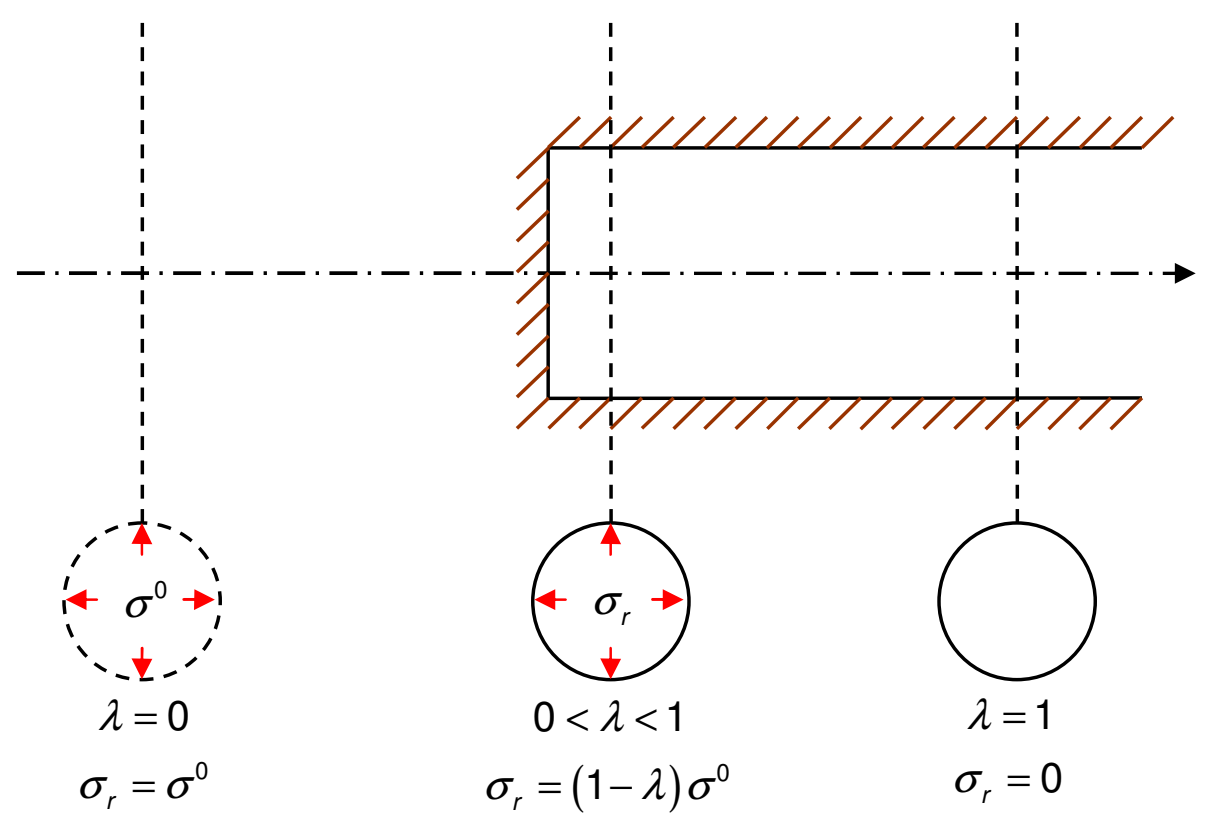

Figura 6-1 - Problema bidimensional de túnel, representação do fator de redução de deslocamento.

Ao se plotar o valor de $\lambda$ (como será feito a seguir), conforme equação (6.2), versus a distância em relação à face de escavação, parametrizado em relação ao diâmetro do túnel, o fator de redução para a tensão inicial pode ser encontrado. Aplicando este fator em uma análise bidimensional assumindo-se estado plano de deformações possibilitará o cálculo das deformações radiais. 


\subsection{Fator de redução $\lambda$ para túneis sem suporte}

Com base no exposto acima, foram analisados diversos casos de túneis, com carregamentos diferentes, propriedades físicas do maciço diferentes e propriedades geométricas do túnel diferentes, sendo que, alguns deles são apresentados na Tabela 6-1. Na Figura 3-4 foi apresentada a malha de elementos de contorno utilizada para tais analises, e agora serão apresentados os deslocamentos em algumas vistas do túnel, para o caso 5 da Tabela 6-1, nas Figura 6-2, Figura 6-3, Figura 6-4 e Figura 6-5.

Nota-se, que esta curva obtida ao se plotar de $\lambda$ versus a distância em relação à frente de escavação, parametrizado em relação ao diâmetro do túnel, é a mesma curva LDP anteriormente apresentada, no método ConvergênciaConfinamento.

Tabela 6-1 - Casos de escavações de túneis analisados.

\begin{tabular}{|cccccc|}
\hline Caso & $\mathrm{D}(\mathbf{m})$ & $\mathrm{E}\left(\mathrm{MN} / \mathbf{m}^{2}\right)$ & $\mathbf{v}$ & $\mathrm{Gm}\left(\mathrm{MN} / \mathbf{m}^{2}\right)$ & $\mathbf{P i}$ \\
1 & 10,00 & $1.00 \mathrm{E}+03$ & 0.30 & $3.85 \mathrm{E}+02$ & $1.00 \mathrm{E}+01$ \\
2 & 10,00 & $5.00 \mathrm{E}+02$ & 0.30 & $1.92 \mathrm{E}+02$ & $2.00 \mathrm{E}+01$ \\
3 & 10,00 & $5.00 \mathrm{E}+02$ & 0.15 & $2.17 \mathrm{E}+02$ & $3.00 \mathrm{E}+01$ \\
4 & 5,00 & $2.10 \mathrm{E}+09$ & 0.13 & $9.29 \mathrm{E}+08$ & $1.00 \mathrm{E}+04$ \\
5 & 10,00 & $2.10 \mathrm{E}+09$ & 0.13 & $9.29 \mathrm{E}+08$ & $1.00 \mathrm{E}+04$ \\
6 & 12,00 & $2.10 \mathrm{E}+09$ & 0.13 & $9.29 \mathrm{E}+08$ & $1.00 \mathrm{E}+04$ \\
7 & 14,00 & $2.10 \mathrm{E}+09$ & 0.13 & $9.29 \mathrm{E}+08$ & $1.00 \mathrm{E}+04$ \\
\hline
\end{tabular}



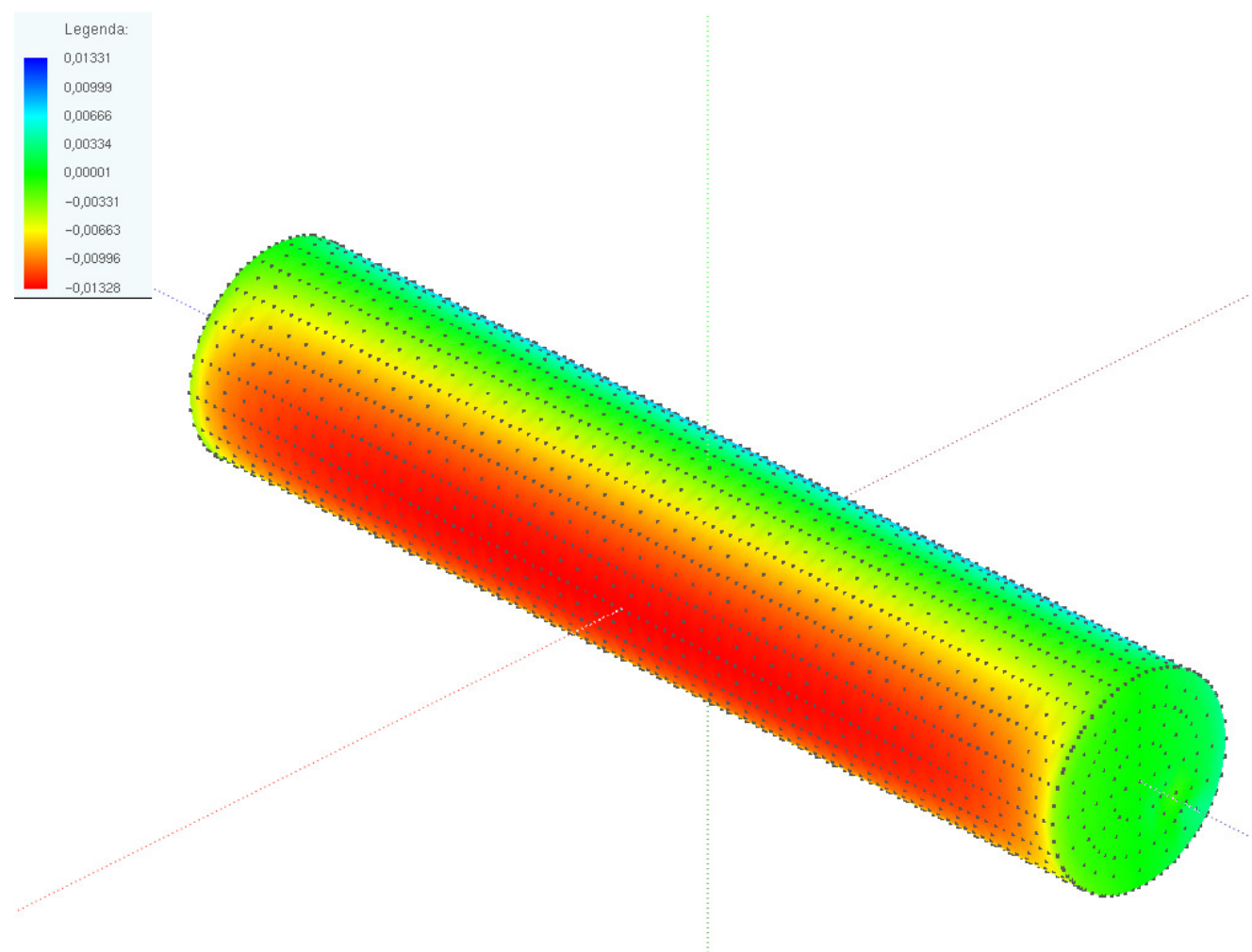

Figura 6-2 - Deslocamento X (eixo vermelho).

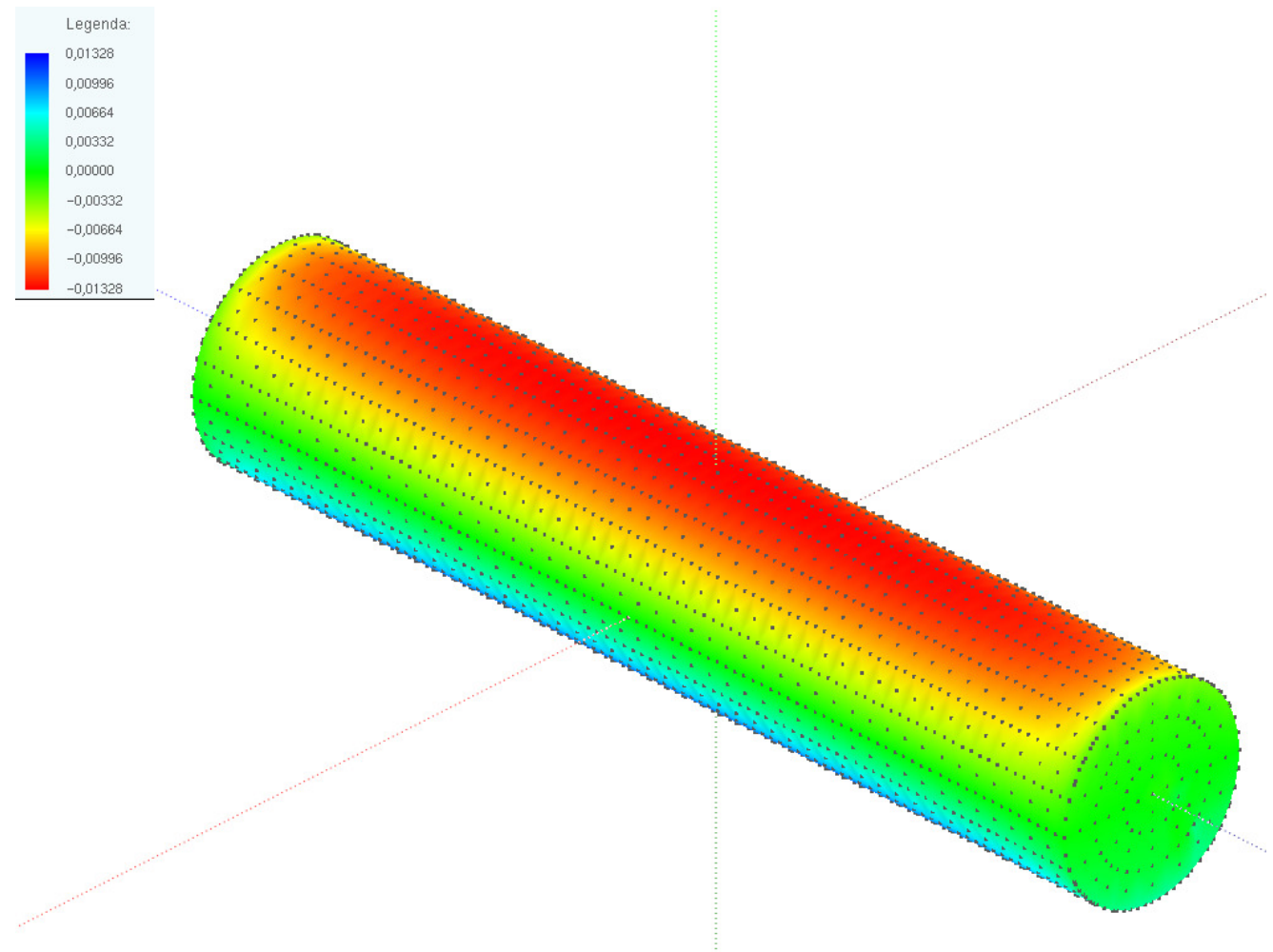

Figura 6-3 - Deslocamento Y (eixo verde). 


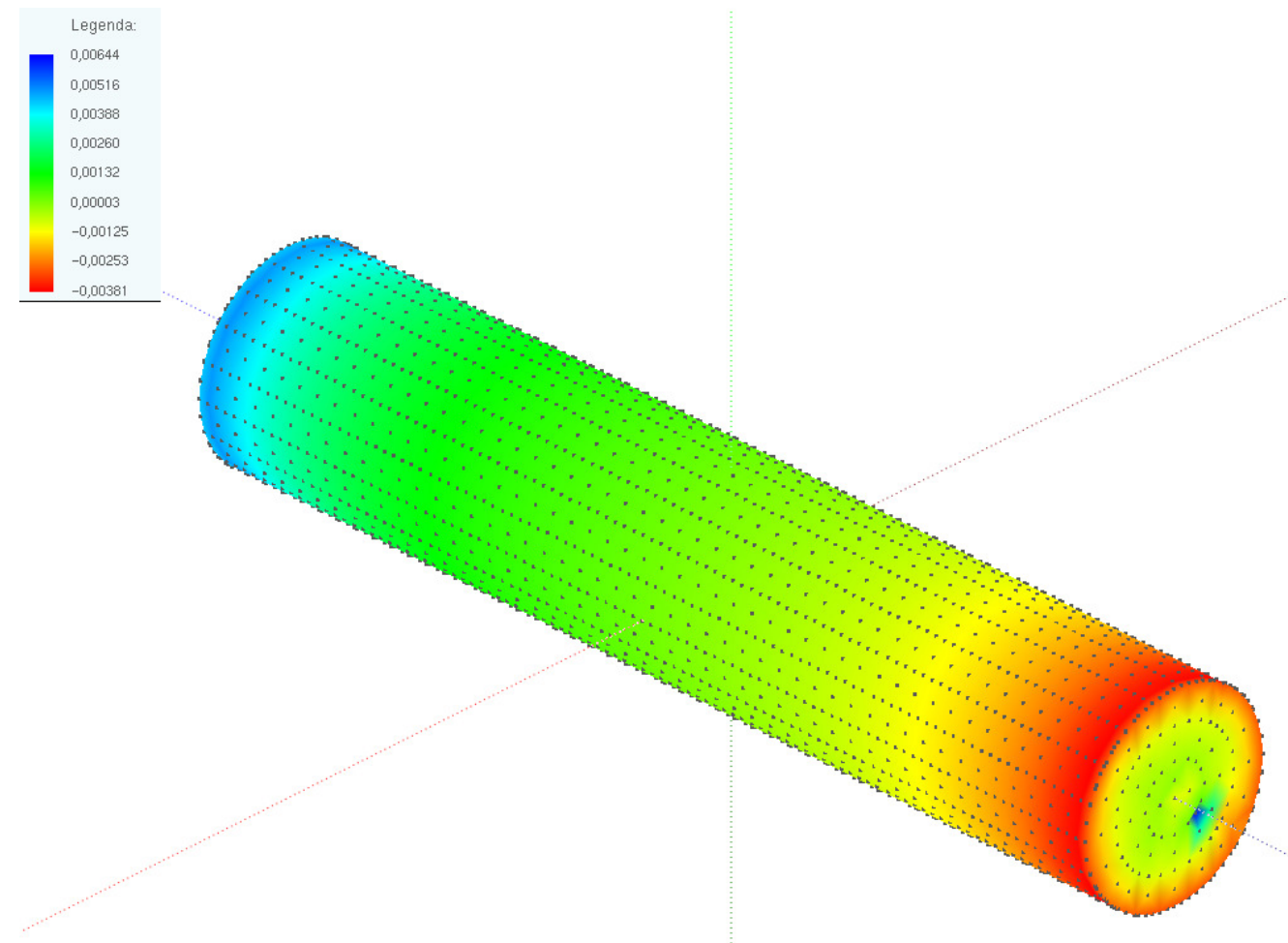

Figura 6-4 - Deslocamento Z (eixo azul).

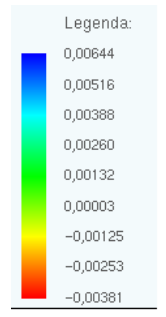

Figura 6-5 - Vista lateral do deslocamento Z.

Após tais análises, foi constatado que, para os diversos casos estudados, obteve-se a mesma curva de $\lambda$, como exemplificado com alguns desses casos, plotados na Figura 6-6. 


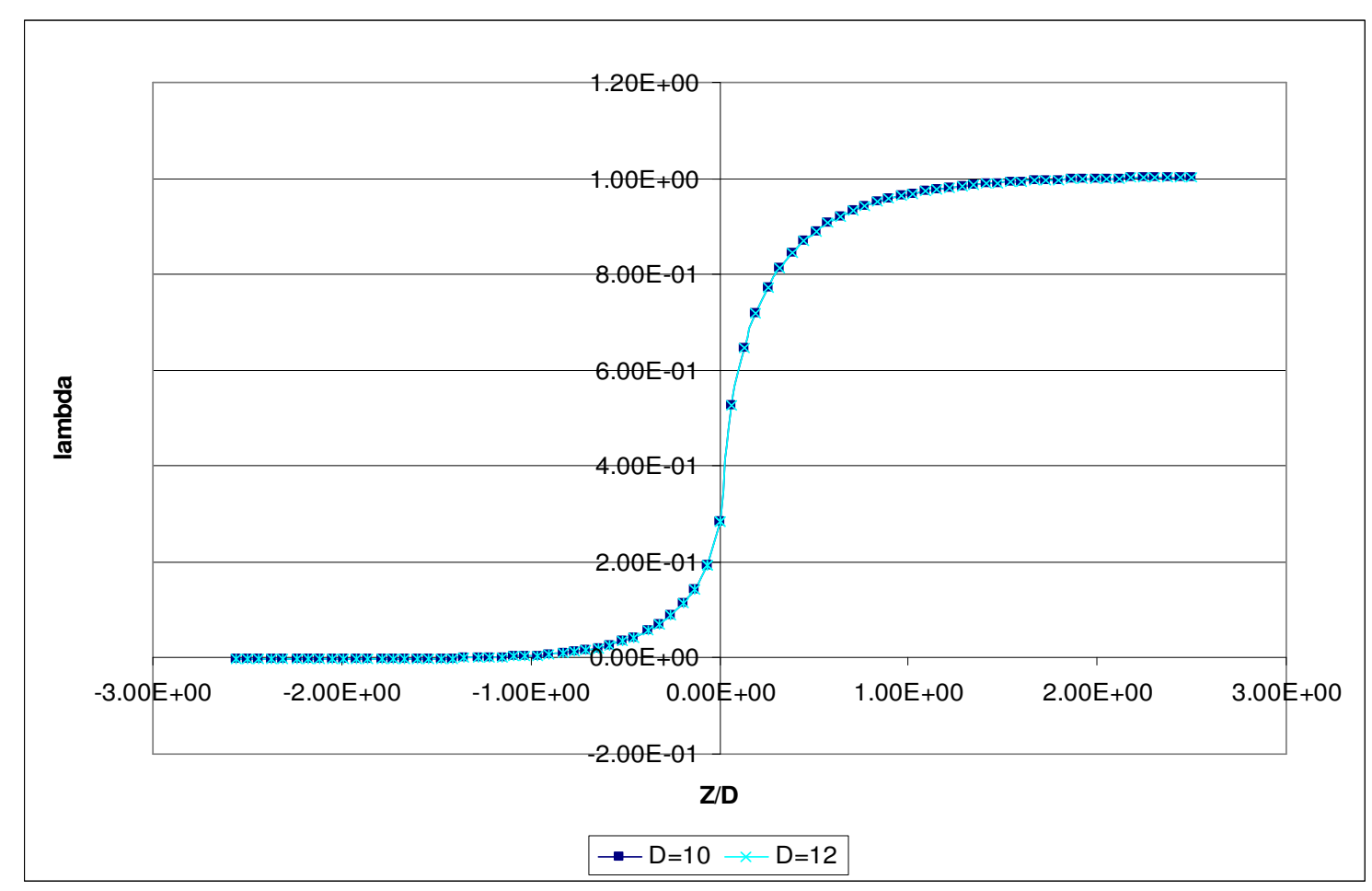

Figura 6-6 - Variação do fator de redução $\lambda$.

\subsection{Escavação com suporte}

Esta seção tem como objetivo desenvolver um método simplificado que seja capaz de reproduzir o efeito tridimensional da escavação de túneis com suporte através de uma análise bidimensional. Desta forma, este item visa determinar uma formulação que seja capaz de determinar o ponto de equilíbrio para a interação entre o suporte e o maciço escavado.

Admite-se um regime elástico linear para os dois tipos de estruturas que se interagem neste problema, como apresentado no diagrama de ConvergênciaConfinamento na Figura 6-7. A curva característica do maciço (em azul), será chamada aqui de "Cm" e a curva característica do revestimento (em vermelho), será chamada aqui de "Cs". 


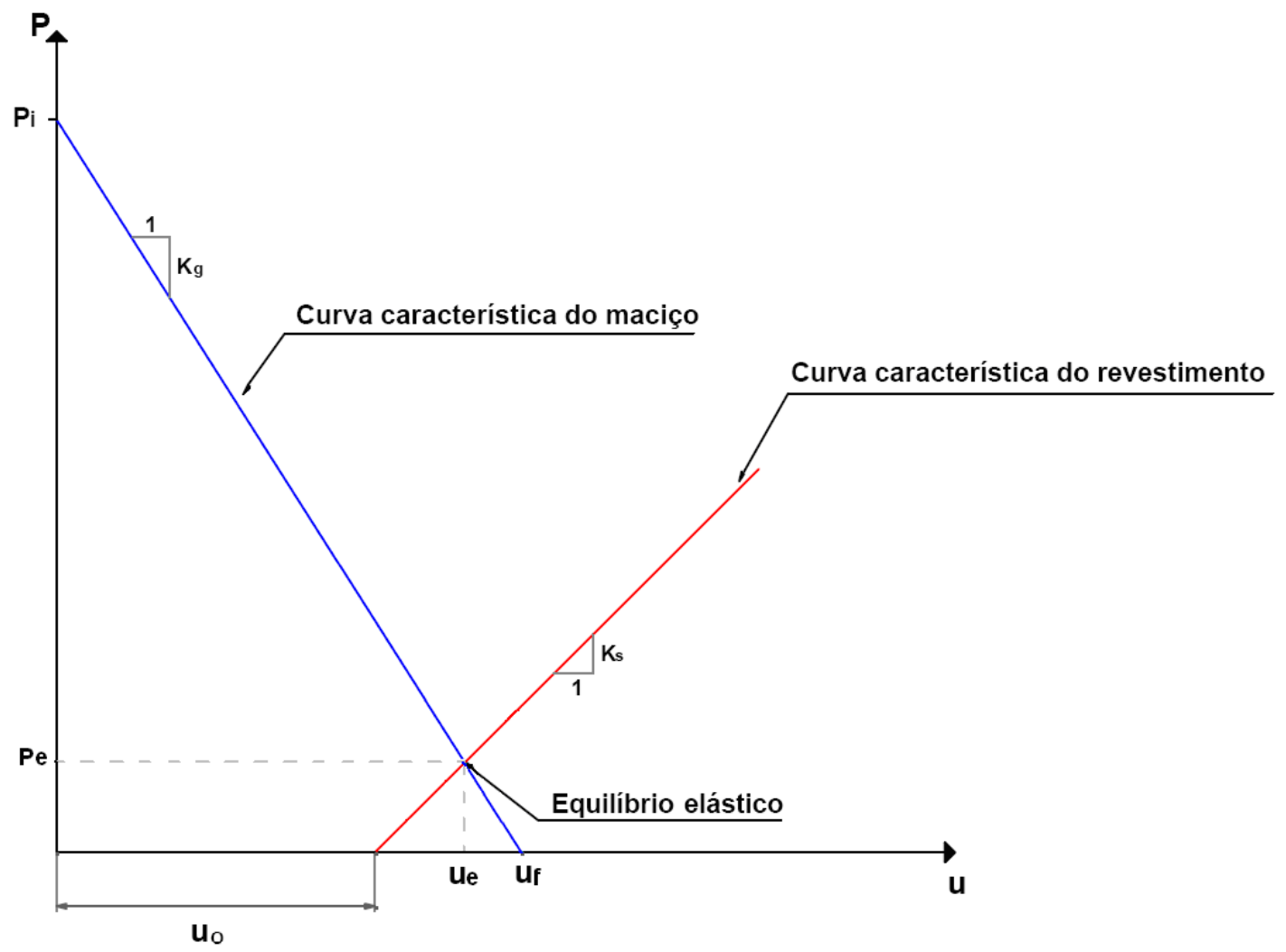

Figura 6-7 - Curvas características admitindo-se regime elástico.

Sendo que, $\mathrm{u}_{0}$ corresponde ao deslocamento inicial do suporte, e é função do comprimento de atraso na instalação do suporte $L_{D}$, apresentado na Figura 5-8. $u_{f}$ é o deslocamento final do maciço, se não houver a instalação do suporte. $\mathrm{K}_{\mathrm{g}}$ e $\mathrm{K}_{\mathrm{s}}$ são, respectivamente, a rigidez do maciço e do suporte.

Como o objetivo aqui é determinar o ponto de equilíbrio $\left(u_{e}, P_{e}\right)$ entre as duas estruturas, que é o ponto de intersecção entre as duas curvas, Cm e Cs, tais curvas serão escritas, como segue:

$$
\begin{aligned}
& C m(u)=a u+b \\
& C s(u)=c u+d
\end{aligned},
$$

sendo que, para a determinação das constantes a, b, c e d basta aplicar as condições de contorno do problema, como apresentado em Figura 6-7, da seguinte forma:

$$
C m(u)=P_{i} \quad \rightarrow \quad u=0
$$




$$
\begin{gathered}
C m(u)=0 \quad \rightarrow \quad u=u_{f}, \\
\operatorname{Cs}(u)=0 \quad \rightarrow \quad u=u_{0}, \\
\operatorname{Cs}^{\prime}(u)=\frac{E_{S} A_{s}}{r^{2}\left(1-v_{s}^{2}\right)} \quad \rightarrow \quad u \geq 0 .
\end{gathered}
$$

A última condição, referente à derivada da curva característica do suporte é a mesma obtida pela análise bidimensional de um anel solicitado por um carregamento radial, tal equação de reta é a mesma utilizada por Schwartz \& Einstein (1980) como exposto na equação (5.16).

Aplicando-se as condições de contorno acima, e sabendo-se que:

$$
u_{f}=\frac{P_{i} r}{2 G_{M}}
$$

sendo $G_{M}$ o módulo de elasticidade transversal do maciço, chega-se a:

$$
\begin{gathered}
C m(u)=\frac{-2 G_{M}}{r} u+P_{i}, \\
C s(u)=\frac{E_{S} A_{S}}{r^{2}\left(1-v_{S}^{2}\right)} u-\frac{E_{S} A_{S}}{r^{2}\left(1-v_{S}^{2}\right)} u_{0} .
\end{gathered}
$$

No ponto de equilíbrio, essas duas curvas se igualam como segue:

$$
\frac{-2 G_{M}}{r} u+P_{i}=\frac{E_{S} A_{S}}{r^{2}\left(1-v_{S}^{2}\right)} u-\frac{E_{S} A_{S}}{r^{2}\left(1-v_{S}^{2}\right)} u_{0},
$$

substituindo-se o valor de u e reorganizando-se, para a condição:

$$
C m=C s \quad \rightarrow \quad u=u_{e}
$$

tem-se: 


$$
u_{0}=\left[\frac{r}{A_{S}} \frac{G_{M}}{G_{S}}\left(1-v_{S}\right)+1\right] u_{e}-\frac{P_{i} r^{2}\left(1-v_{S}^{2}\right)}{E_{S} A_{S}}
$$

sendo que, $G_{s}$ é o módulo de elasticidade transversal do suporte e que o último termo depois da igualdade corresponde ao deslocamento final do suporte $\boldsymbol{u}_{r}^{\boldsymbol{s}}$, com isso, reescrevendo-se a equação (6.14), tem-se:

$$
u_{0}=\left[\frac{r}{A_{S}} \frac{G_{M}}{G_{S}}\left(1-v_{S}\right)+1\right] u_{e}-u_{r}^{S},
$$

sendo que, o termo dentro do colchete foi chamado de Kappa ( $\boldsymbol{\kappa}$ ) em Freitas (2008), como segue:

$$
\kappa=\left[\frac{r}{A_{S}} \frac{G_{M}}{G_{S}}\left(1-v_{S}\right)+1\right],
$$

e dessa forma:

$$
u_{0}=\kappa u_{e}-u_{r}^{S} .
$$

Ao se analisar este parâmetro $\boldsymbol{\kappa}$, nota-se, como pode ser visto na Figura 6-8, onde foi plotado na curva em azul os valores de $\boldsymbol{\kappa}$ variando-se o módulo de elasticidade do suporte " $E_{s}$ " e deixando o módulo de elasticidade do maciço " $E_{m}$ " fixo em um valor relativamente pequeno e na curva rosa foi plotado um valor para " $E_{m}$ " relativamente grande. Portanto, à medida que a relação $G_{M} / G_{S}$ varia, este parâmetro varia de $1<\boldsymbol{\kappa}<\infty$. 


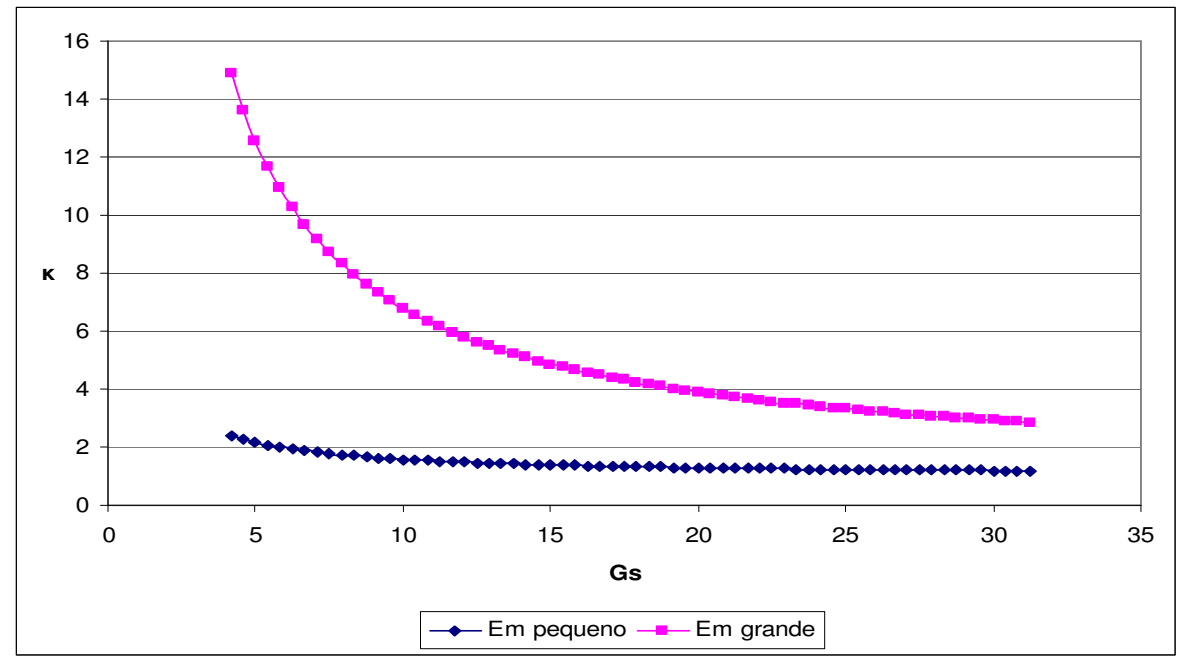

Figura 6-8 - Variação de Kappa.

Agora, isolando-se $\boldsymbol{u}_{\boldsymbol{e}}$ na equação (6.17), parametrizando esta em relação ao deslocamento final do maciço $\boldsymbol{u}_{\boldsymbol{f}}$, substituindo-se a expressão (6.9) e (5.16), tem-se:

$$
\frac{u_{e}}{u_{f}}=1+\frac{1}{\kappa}\left(\frac{u_{0}}{u_{f}}-1\right)
$$

Na Figura 6-9, foi plotada a equação (6.18) apresentando os valores possíveis de ocorrer.

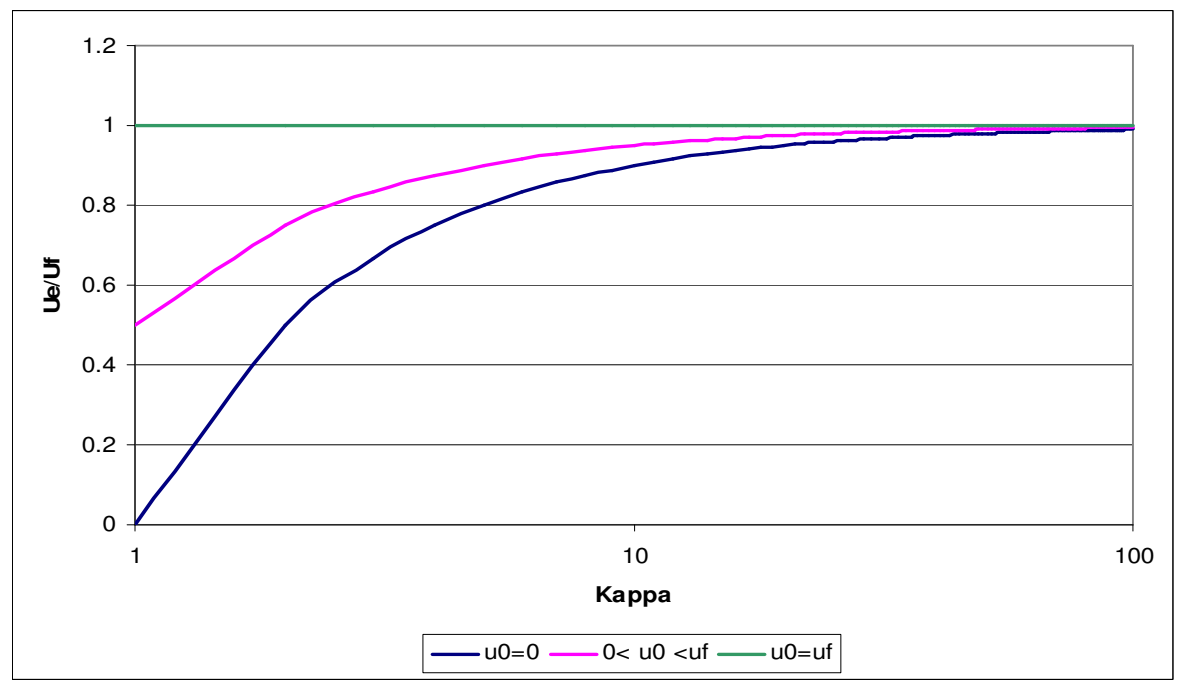

Figura 6-9 - Variação de $\mathrm{u}_{\mathrm{e}} / \mathrm{u}_{\mathrm{f}}$ em relação a Kappa. 
Desta forma, como as curvas características são diretamente dependentes de suas rigidez, analisando separadamente as três curvas apresentadas na Figura 6-9, tem-se:

- Para $\boldsymbol{u}_{0}=0$, quando $\boldsymbol{k}=1$, o valor de $\boldsymbol{u}_{\boldsymbol{e}}=0$, o que significa que o produto " $\boldsymbol{A}_{\boldsymbol{s}} \boldsymbol{G}_{\boldsymbol{s}}$ " é muito grande, relativamente ao valor de " $r G_{M}$ ", ver equação (6.16), o que significa que o suporte é "infinitamente rígido" e que, devido a $\boldsymbol{u}_{0}=0$, foi instalado logo após o maciço ser escavado, como apresentado na Figura 6-10. E, para o outro extremo possível, quando $\boldsymbol{\kappa} \rightarrow \infty$, o valor de $\boldsymbol{u}_{\boldsymbol{e}}=\boldsymbol{u}_{\boldsymbol{f}}$, pois neste caso, o valor " $\boldsymbol{r} \boldsymbol{G}_{\boldsymbol{M}}$ " que tende ao infinito em relação ao produto " $\boldsymbol{A}_{\boldsymbol{s}} \boldsymbol{G}_{\boldsymbol{S}}$ ", portanto, apresentando um suporte "infinitamente flexível";

- Ocorre de forma semelhante para a curva $0<\boldsymbol{u}_{0}<\boldsymbol{u}_{\boldsymbol{f}}$, sendo que, a única diferença reside em quando o $\boldsymbol{\kappa}=1$, o valor de $\boldsymbol{u}_{\boldsymbol{e}}=\boldsymbol{u}_{0}$;

- E para a curva $\boldsymbol{u}_{0}=\boldsymbol{u}_{\boldsymbol{f}}$, que acontece ao se instalar o suporte quando o maciço já se deslocou por completo, portanto, não importando a rigidez do suporte em relação à do maciço, o deslocamento será para este caso $\boldsymbol{u}_{\boldsymbol{e}}=\boldsymbol{u}_{\boldsymbol{f}}$.

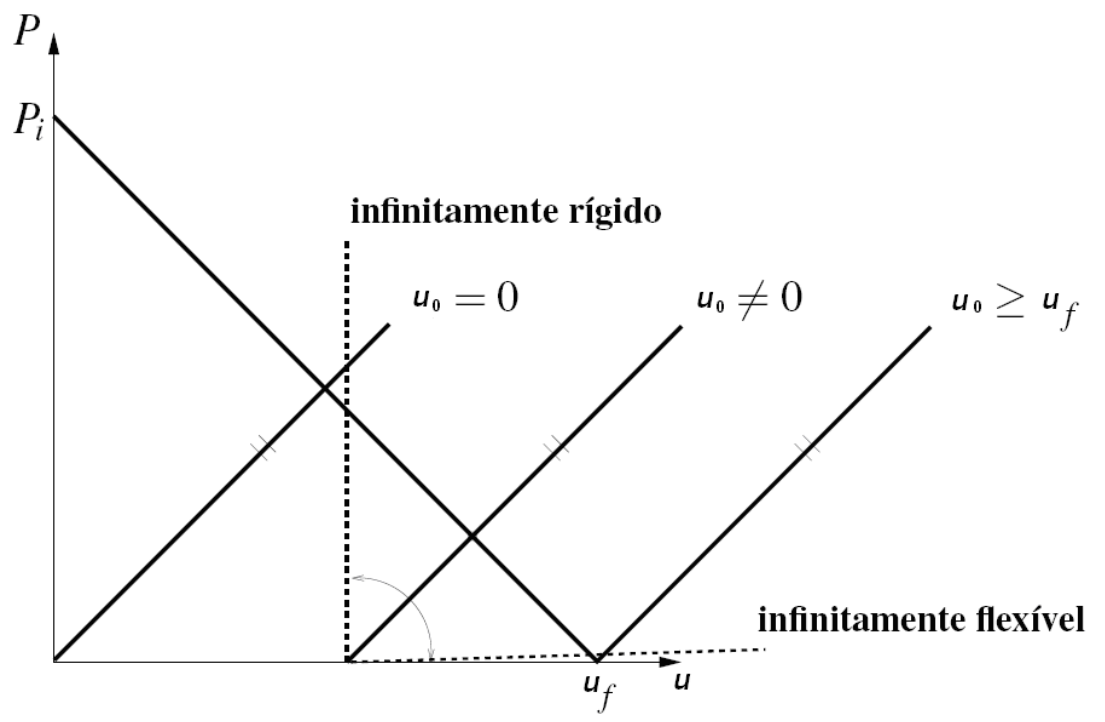

Figura 6-10 - Possíveis valores de $u_{0}$ no gráfico de interação maciço-suporte Freitas (2008). 


\subsubsection{Atraso na instalação do suporte}

Como apresentado em Carranza-Torres \& Fairhurst (2000), Hoek (1999), sugeriu um ajuste, baseado em dados apresentados por Chern et al. (1998), como segue:

$$
\frac{u_{r}}{u_{f}}=\left(1+e^{\frac{-x / D}{0.55}}\right)^{-1.7}
$$

sendo que, tal curva representa uma melhor aproximação para o LDP (Perfil de Deformação Longitudinal, apresentado anteriormente), no gráfico da Figura 6-11 são plotadas uma curva obtida por análises realizadas no item anterior deste trabalho $(D=10)$ e a relação empírica referente à equação (6.19).

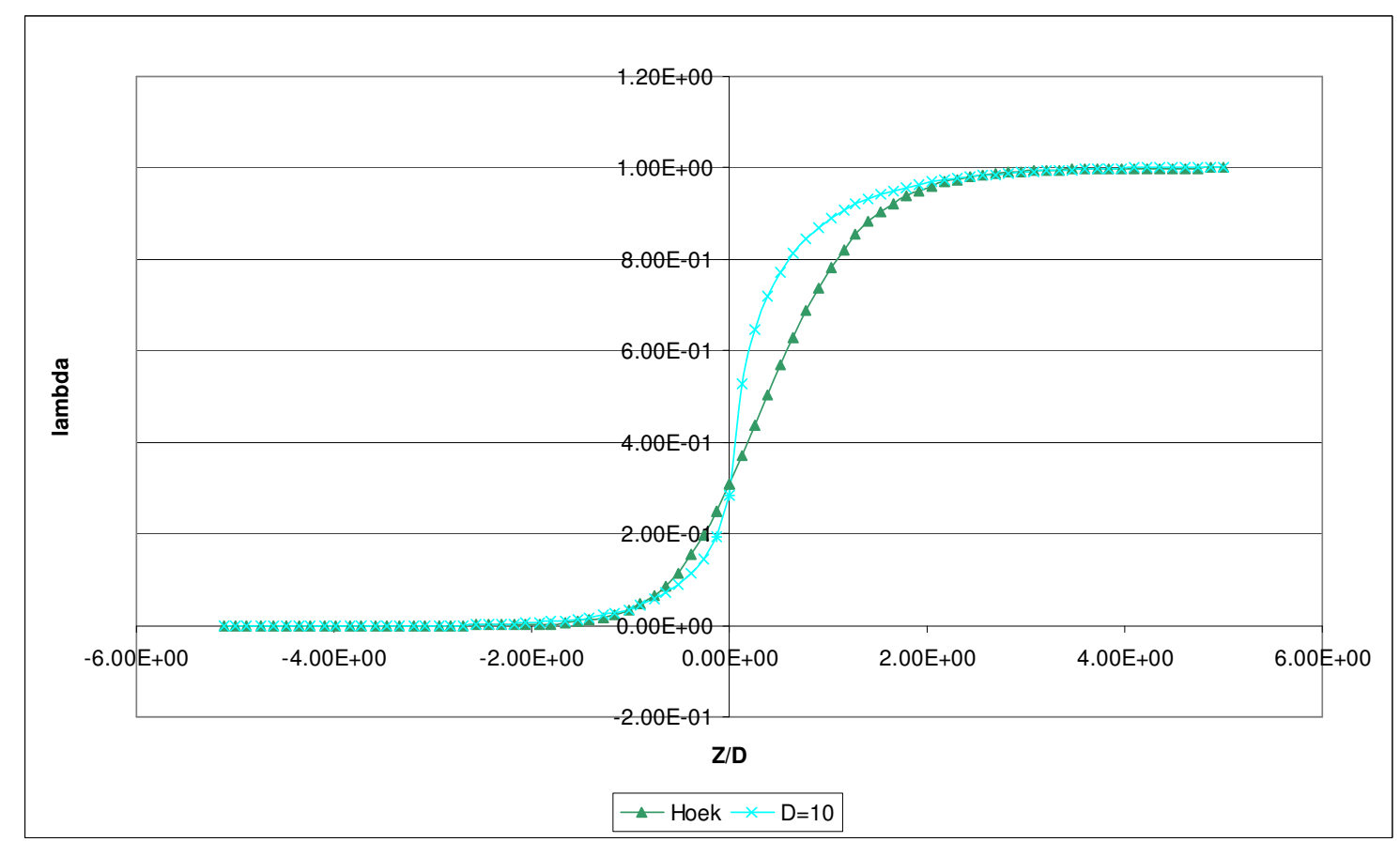

Figura 6-11 - Análise realizada neste trabalho e relação empírica desenvolvida por Hoek (1999).

Como apresentado no item 5.1 deste trabalho, o deslocamento inicial $\boldsymbol{u}_{0}$ do suporte (ou, ponto onde o suporte começa a interagir no sistema) é dado em função do comprimento de atraso, que neste trabalho adotou-se $L_{D}$ como em Hutchinson 
(1982), explicitado no item 5.3. Assim, substituindo este valor na equação (6.19) e esta na equação (6.18), tem-se:

$$
\frac{u_{e}}{u_{f}}=1+\frac{1}{\kappa}\left[\left(1+e^{\frac{-L_{D}^{\prime} / D}{0.55}}\right)^{-1.7}-1\right]
$$

Substituindo-se (6.19) na equação (5.12) que define o fator de atraso na instalação do suporte, tem-se:

$$
\lambda_{d}^{Q}=1-\frac{u_{0}}{u_{f}}=1-\left(1+e^{\frac{-L_{D} / D}{0.55}}\right)^{-1.7} .
$$

Traçado o gráfico na Figura 6-12, dos fatores de atraso de Schwartz \& Einstein (1980), a modificação proposta por Hutchinson (1982) e a proposta neste trabalho, na equação (6.21).

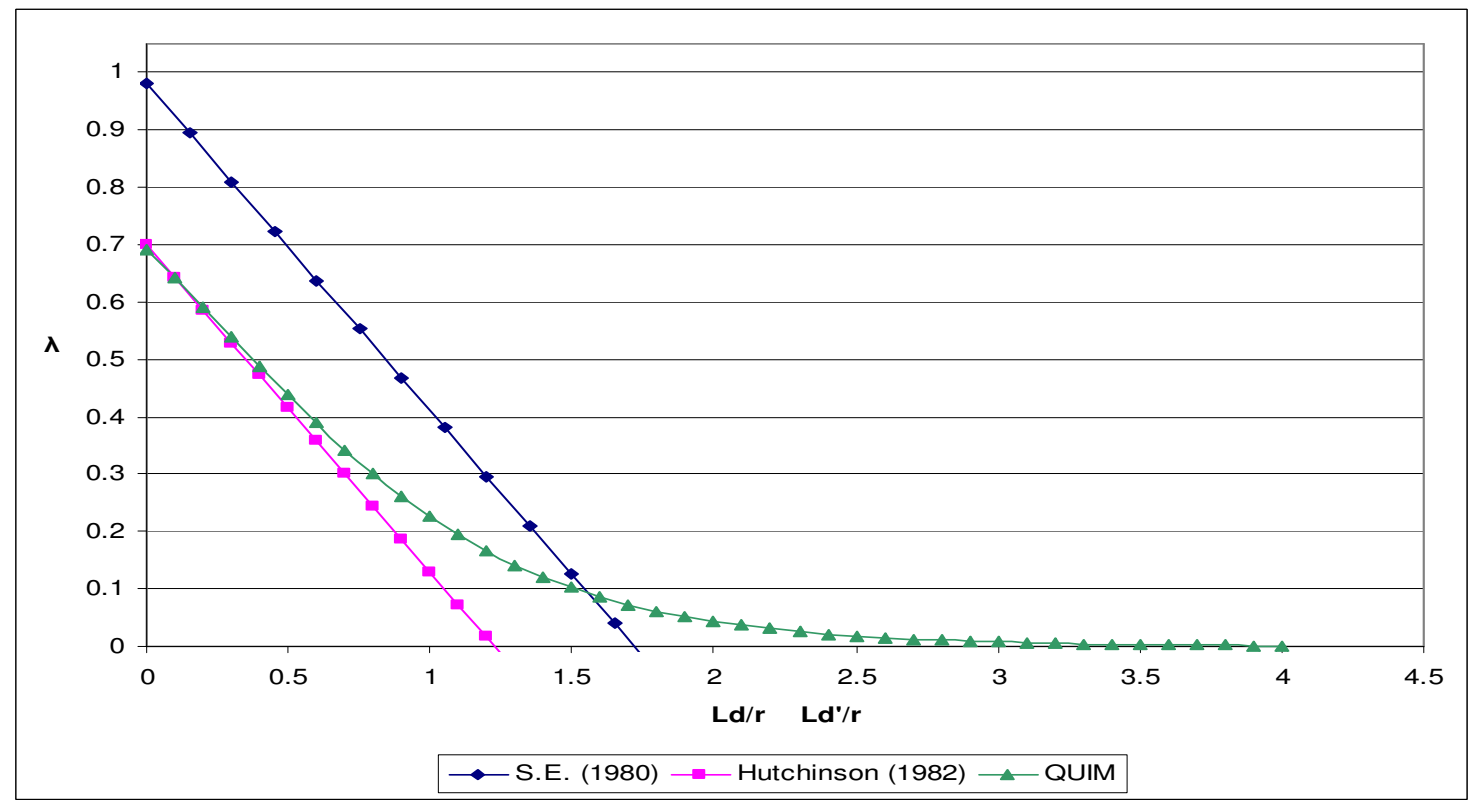

Figura 6-12 - Análise comparativa entre alguns fatores de atraso na instalação do suporte.

$E$, por fim, substituindo-se a equação (6.21) na equação (6.20), tem-se: 


$$
\frac{u_{e}}{u_{f}}=1-\frac{1}{\kappa} \lambda_{d}^{Q} .
$$

Analisando-se a Figura 6-12, conclui-se que, para o método proposto aqui, com $L_{D} \geq 4 r$ o valor de $\boldsymbol{u}_{e}=\boldsymbol{u}_{f}$, o que está de acordo com a realidade, pois mostra (como apresentado na teoria consultada) que a influência do suporte é nula quando o atraso na instalação do mesmo é maior que duas vezes o diâmetro. Para os outros métodos plotados nessa figura, isto ocorre bem antes (Hutchinson (1982) em $\cong 1,25$ e em Schwartz \& Einstein (1980) em $\cong 1,7)$.

É possível constatar também através da Figura 6-12 que o método proposto aqui se equipara ao proposto por Hutchinson (1982) (que é o método apresentado anteriormente que propõe uma melhoria à técnica de Schwartz \& Einstein (1980)) e exclui a imprecisão apresentada por este método.

\subsubsection{Exemplos de Validação}

Para se fazer uma melhor avaliação do potencial da formulação aqui desenvolvida, foram analisados diferentes exemplos de escavações de túneis, variando-se alguns parâmetros, como o comprimento de atraso $L_{D}^{\prime}$ e a rigidez do maciço $E_{M}$.

Foram três análises principais, cada uma com um $L_{D}$ diferente (sendo eles iguais a: 0,$5 ; 1,0$ e 1,5 referentes à $L_{D}$ iguais a: 1,$5 ; 2,0$ e 2,5; respectivamente), e variando o módulo de elasticidade do maciço $E_{M}$ de 50 até 2500. O módulo de elasticidade do suporte foi mantido constante igual a 2500 e o coeficiente de Poisson igual a 0,2 para as duas estruturas.

A seguir, no gráfico da Figura 6-13 é apresentada a comparação entre o método proposto neste trabalho e o desenvolvido em Hutchinson (1982) para o caso 1 , com comprimento de atraso $L_{D}^{\prime}$ igual a meio $(0,5)$. Na Figura 6-14 é efetuada a comparação para o caso 2, comprimento de atraso $L_{D}$ igual a um $(1,0)$ e na Figura 6-15 a comparação para o caso 3 , comprimento de atraso $L_{D}$ igual a um e meio $(1,5)$. 


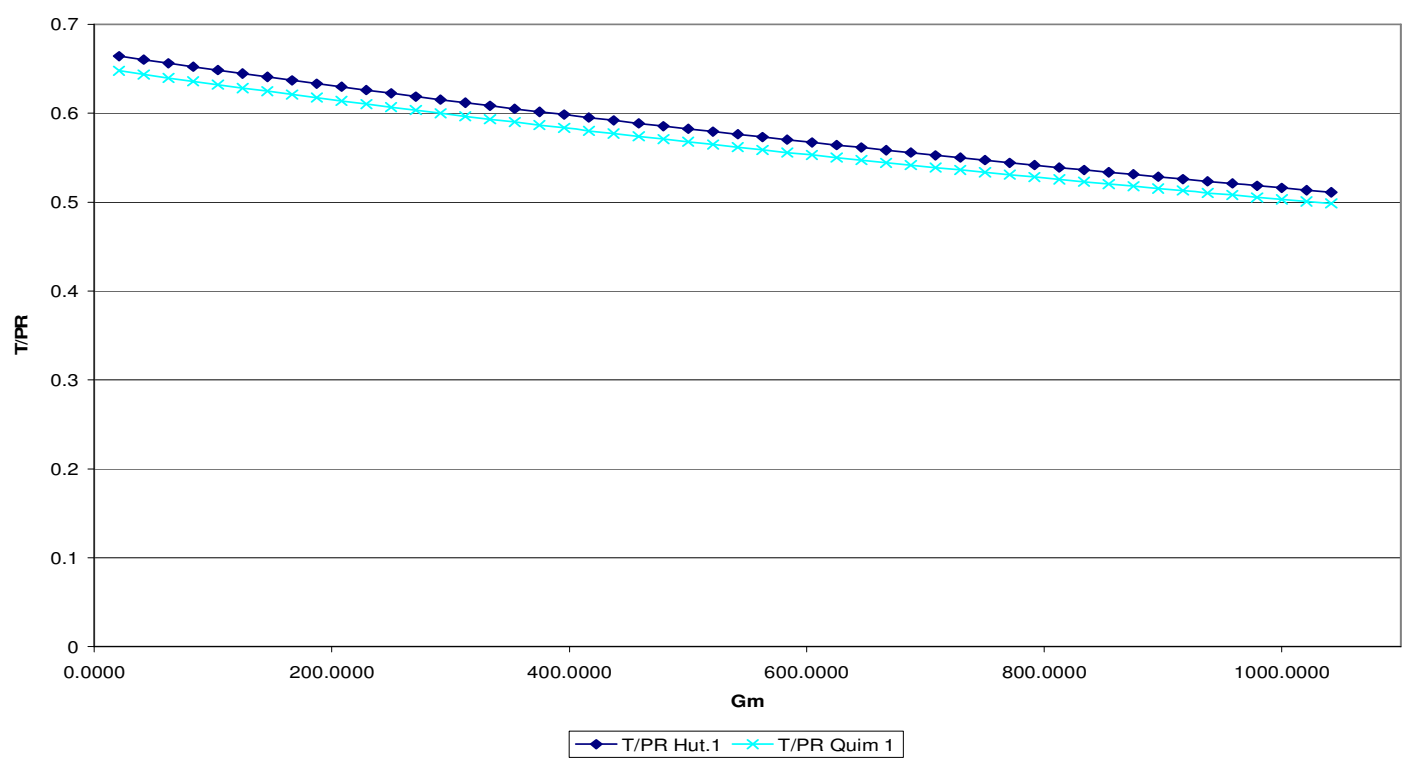

Figura 6-13 - Comparação entre Hutchinson (1982) e este trabalho para um comprimento de atraso na instalação igual a meio $(0,5)$.

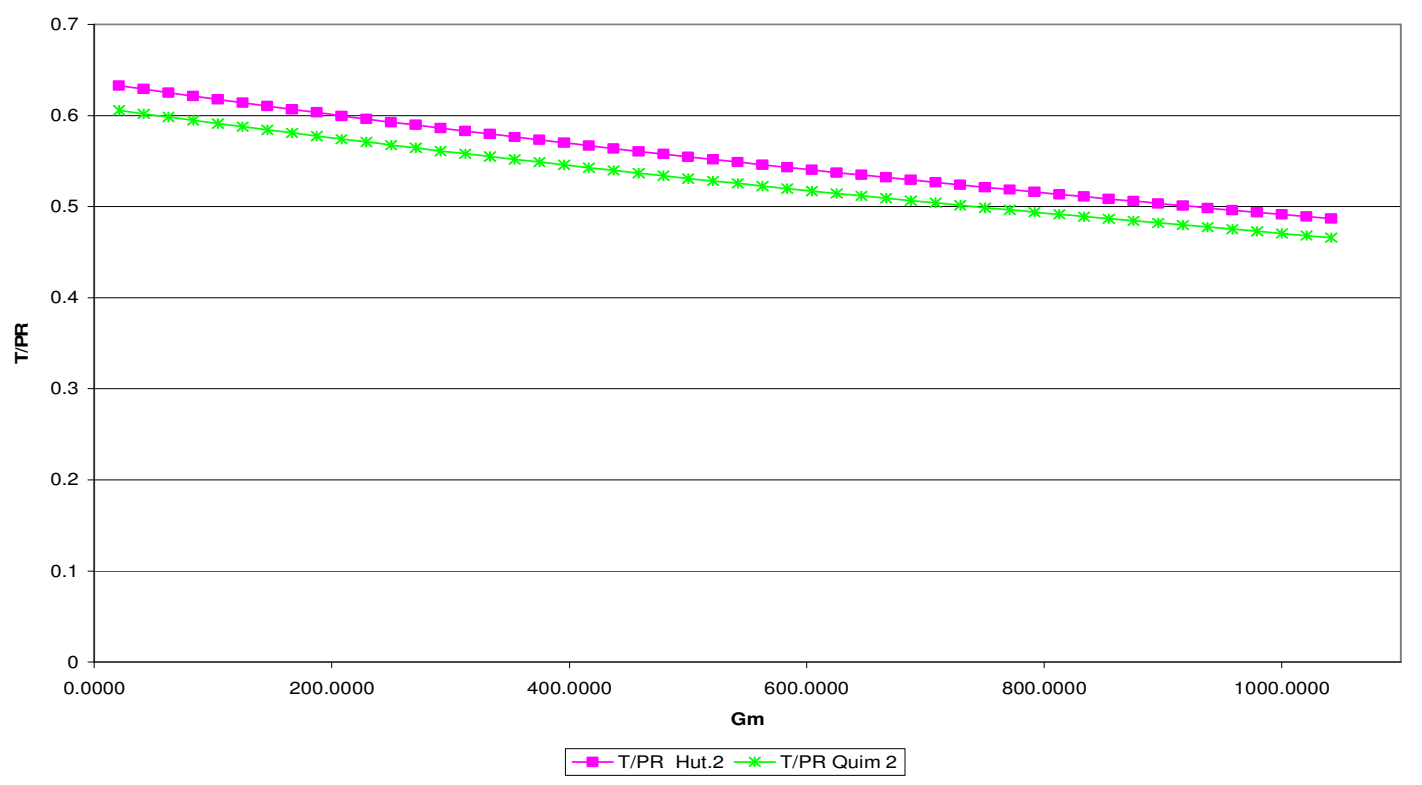

Figura 6-14 - Comparação entre Hutchinson (1982) e este trabalho para um comprimento de atraso na instalação igual a um $(1,0)$. 


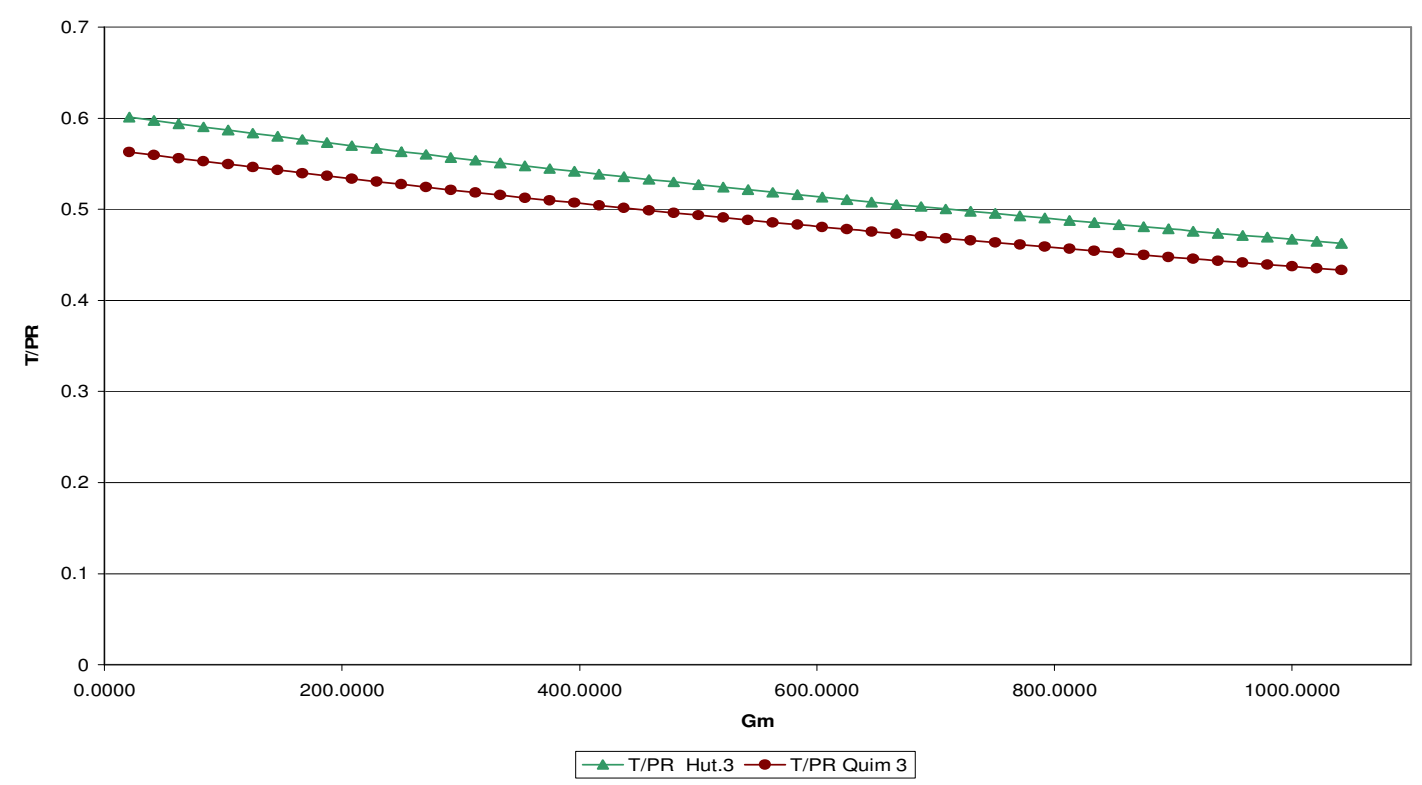

Figura 6-15 - Comparação entre Hutchinson (1982) e este trabalho para um comprimento de atraso na instalação igual a um e meio $(1,5)$. 


\section{CONCLUSÕES}

No presente trabalho, procurou-se analisar o comportamento de escavações enrijecidas, particularmente túneis, através do desenvolvimento de uma formulação do MEC isoparamétrico com aproximação de ordem qualquer, simulando os enrijecedores a partir de correções da rigidez local.

Neste contexto, os exemplos apresentados, foram comparados com as respectivas respostas analíticas (capítulo 2), com resultados de programas comerciais consagrados, baseados no método dos elementos finitos (capítulo 4) e com base em outros trabalhos (capítulo 7), de forma que, obteve a validação das formulações aqui desenvolvidas.

Como proposta para trabalhos futuros, a implementação do acoplamento MEC/MEF tridimensional, bem como o desenvolvimento da formulação a partir de correções de rigidez local agora tridimensional, visando o desenvolvimento de uma formulação mais precisa na consideração do atraso na instalação do suporte. 



\section{REFERÊNCIAS BIBLIOGRÁFICAS}

Azevedo, C. A. C. Formulação alternativa para análise de domínios nãohomogêneos e inclusões anisotrópicas via MEC. São Carlos. 153p. Dissertação (Mestrado) - Escola de Engenharia de São Carlos, Universidade de São Paulo, 2007.

Beer G., Finite element boundary element and coupled analysis of unbounded problems in elastostatics. International journal for numerical methods in engineering, 19, 567-580, 1983.

Beer G., Watson J.; Swoboda G., Three-Dimensional analysis of tunnels using infinite boundary elements. Computers \& Structures, 2, 37-58, 1987.

Beer, G. Programming the boundary element method: An introduction for engineers. John Wiley \& Sons. Ltd, 2001.

Beer, G.; Dünser, C. Boundary element analysis of problems in tunneling. Developments in Theoretical Geomechanics, 103-122, 2000.

Brebbia, C.A.. The boundary element method for engineers. London. Pentech Press, 1978.

Brebbia, C.A. Topics in Boundary Element Research. Springer-Verlag: Berlin and New York. 1984. 
Brebbia, C.A.; Dominguez, J. Boundary elements an introductory course. Computational Mechanics Publications, London, 1992.

Botta, A.S.; Venturini, W.S., Reinforced 2-D Domain Analysis Using BEM and Regularized BEM/FEM Combination. Computer Modeling in Engineering and Sciences - CMES, 8 (1), 15-28, 2005.

Carranza-Torres, C.; Fairhurst C.. The elasto-plastic response of underground excavations in rock masses that satisfy the Hoek-Brown failure criterion. Int. J. Rock Mech. Min. Sci. 36 (6), 777-809, 1999.

Carranza-Torres, C.; Fairhust, C.. Application of the Convergence-Confinement Method of Tunnel Design to Rock Masses That Satisfy the Hoek-Brown Failure Criterion. Tunneling and Underground Space Technology, v. 15, n.2, pp. 187-213, 2000.

Chern J.C.; Shiao F.Y.; Yu C.W. An empirical safety criterion for tunnel construction. In: Proc. Regional Symposium on Sedimentary Rock Engineering. Nov 20-22 1998, Taipei, Taiwan. Balkema, 1998. p. 222-7.

Coda, H. B. Analise tridimensional transiente de estruturas pela combinação entre o método dos elementos de contorno e o método dos elementos finitos. Tese (Doutorado), - Escola de Engenharia de São Carlos, Universidade de São Paulo, São Carlos, 1993.

Coda H.B., Dynamic and static non-linear analysis of reinforced media: a BEM/FEM coupling approach. Computers \& Structures, 79, pp. 2751-2765, 2001.

Coda, H. B. Método dos Elementos de Contorno: notas de aula. São Carlos, Departamento de Engenharia de Estruturas, EESC-USP. Notas de Aula (2008).

Fenner, R.. Untersuchungen zur Erkenntnis des Gebirgsdruckes. Glückauf 74, 681-695 and 705-715, 1938. 
Ferreira, M. D. C., Análise inversa em sólidos bidimensionais utilizando o método dos elementos de contorno. 2007. 190 f. Dissertação (Mestrado em Engenharia de Estruturas) - Escola de Engenharia de São Carlos, Universidade de São Paulo, São Carlos, 2007.

Ferro, N. C. P.. Uma Combinação do método dos elementos de contorno com o método dos elementos finitos para análise de fundações enrijecidas por estacas. 1993. Dissertação (mestrado). Escola de Engenharia de São Carlos, Universidade de São Paulo. Departamento Engenharia de Estruturas, 1993.

Freitas, J.C.A.. Método dos Elementos de Contorno Aplicado à Análise de Escavação em Túneis Utilizando Modelos Aproximados Bidimensionais. 2008. 158 f. Dissertação (Mestrado em Engenharia de Estruturas) - Escola de Engenharia de São Carlos, Universidade de São Paulo, São Carlos, 2008.

Gomes, R. A. M. P. Análise tridimensional de túneis considerando o comportamento dependente do tempo na interação maciço-suporte. Tese (Doutorado) - EESC-USP, Brazil, 2006.

Gomes, R. A. M. P.; Celestino, T. B. Influence of physical and geometrical parameters on three-dimensional load transfer mechanism at tunnel face. Canadian Geotechnical Jornal, 46(7): 855-868. doi: 10.1139/T09-016.

H.J. Kim; Z. Einsenstein. Prediction of tunnel lining loads using correction factors. Engineering Geology, v. 85, p. $302-312$ (2006).

Kane, J.H. Boundary Element Analysis in Engineering Continuum Mechanics. Prentice-Hall, Inc. New Jersey, 1994.

Karakus, M.. Appraising the methods accounting for 3-D tunneling effects in 2-D plane strain FE analysis. Tunnelling and Underground Space Technology 22, 4756, 2007. 
Kupradze, V. D. Potential methods in theory of elasticity: Jerusalem, Israel Program for Scientific Translations, 1965.

Kzam, A. K. L. Formulação Dual em Mecânica da Fratura Utilizando Elementos de Contorno Curvos de Ordem Qualquer. 2009. 186 f. Dissertação de Mestrado Escola de Engenharia de São Carlos, Universidade de São Paulo, 2009.

Leite, L.G.S.; Coda, H.B.; Venturini, W.S. Two-dimensional solids reinforced by thin bars using the boundary element method. In: Congresso Latino Americano $E$ Ibérico Sobre Métodos Computacionais Para Engenharia, 8, 1987, Rio de Janeiro. Anais... Rio de Janeiro: Pontifícia Universidade Católica do Rio de Janeiro, v. B, p. 193-201, 2003.

Leite, L.G.S.; Venturini, W.S., Stiff and soft thin inclusions in two-dimensional solids by the boundary element method. Engineering analysis with boundary elements, 29 (3), 257-267, 2005.

Leite, L.G.S. Desenvolvimento de modelos numéricos para análise de problemas de interação de domínios bidimensionais. 2007. Tese (Doutorado) Escola de Engenharia de São Carlos, Universidade de São Paulo, São Carlos, 2007.

Paccola, R.R.. Análise não linear física de placas e cascas anisotrópicas laminadas acopladas ou não com meio contínuo tridimensional viscoelástico através da combinação entre o MEC e o MEF. 2004. Tese (Doutorado) - Escola de Engenharia de São Carlos, Universidade de São Paulo, São Carlos. 2004.

Paiva, J. B.; Venturini, W.S. Uma formulação alternativa para a resolução de placas via método dos elementos de contorno. In: Congresso Latino Americano $\mathrm{E}$ Ibérico Sobre Métodos Computacionais Para Engenharia, 8, 1987, Rio de Janeiro. Anais... Rio de Janeiro: Pontifícia Universidade Católica do Rio de Janeiro, v. B, p. 307-314, 1987.

Panet, M.; Guenot, A. Analysis of convergence behind the face of a tunnel. In: Tunnelling'82. IMM. [S.I.: s.n.], 1982. p. 197-203. 
París, F.; Cañas, J. Boundary Element Method. Fundamentals and Applications. Oxford University Press, 1997.

Rizzo, F.J. An integral equation approach to boundary value problems of classical elastostatics. Quart. Appl. Math., v.25, p.83-95, 1967.

Sadd, M. H., Elasticity: Theory, Applications and Numerics. Amsterdam; Boston: Elsevier Butterworth-Heinemann, 2005. 461 p.

Schwartz, C. W.; Einstein, H. H. Improved design of tunnel supports:vol 1 simplified analysis for ground-structure interaction in tunneling. In: Report No. UMTA-MA-06-0100-80- 4.US. Department of Transportation. [S.I.: s.n.], 1980. p. 427.

Schwartz, C. W.; Einstein, H. H. Simplified analysis for ground-structure interaction in tunneling. the state of the art in rock mechanics. In: 21 st U.S. Symposium on Rock Mechanics, Rolla. [S.I.: s.n.], 1980. p. 787-796.

Souza, V. J. B. Algoritmos de integração eficientes para o método de elementos de contorno tridimensional. São Carlos, 2001. Dissertação (Mestrado) - Escola de Engenharia de São Carlos, Universidade de São Paulo, 2001.

Timoshenko, S.P.; Goodier, J.N. Teoria da elasticidade. Rio de Janeiro, Ed. Guanabara Dois S.A, 1980.

Valliappan, S. Continuum mechanics - fundamentals. A.A. Balkema, Rotterdam, 1981.

Venturini, W. S. Boundary Element Method in Geomechanics. [S.I.]: SpringerVerlag, Berlin, 1983.

Venturini, W.S. Um estudo sobre o método dos elementos de contorno e suas aplicações em problemas de engenharia. Tese (Livre-Docência) - Escola de Engenharia de São Carlos - USP, 1988. 
Villaça, S.F.; Garcia, L.F.T. Introdução à teoria da elasticidade. Rio de Janeiro: COPPE/UFRJ, 1998.

Waiderman, L.; Venturin,W.S., BEM formulation for reinforced plates. In: Advances in Boundary Element Techniques VIII, Eds. V. Minutolo \& M.H.Aliabadi, EC, Ltd, Eastleigh, UK, 2007.

Wutzow, W.W. Formulação do método dos elementos de contorno para análise de enrijecedores. Dissertação (Mestrado) - Escola de Engenharia de São Carlos, Universidade de São Paulo, São Carlos, 2003.

Wutzow, W.W.; Botta, A.S.; Venturini W.S.; Benallal A., BEM Poroplastic Analysis Applied to Reinforced Solids. In: Advances in Boundary Element Techniques VII, eds: B. Gatmiri, at al, EC Ltd, Eastleigh, UK, 2006. 